\title{
Monitoring Adequate Housing in Ireland
}

Helen Russell, Ivan Privalko,

Frances McGinnity \&

Shannen Enright

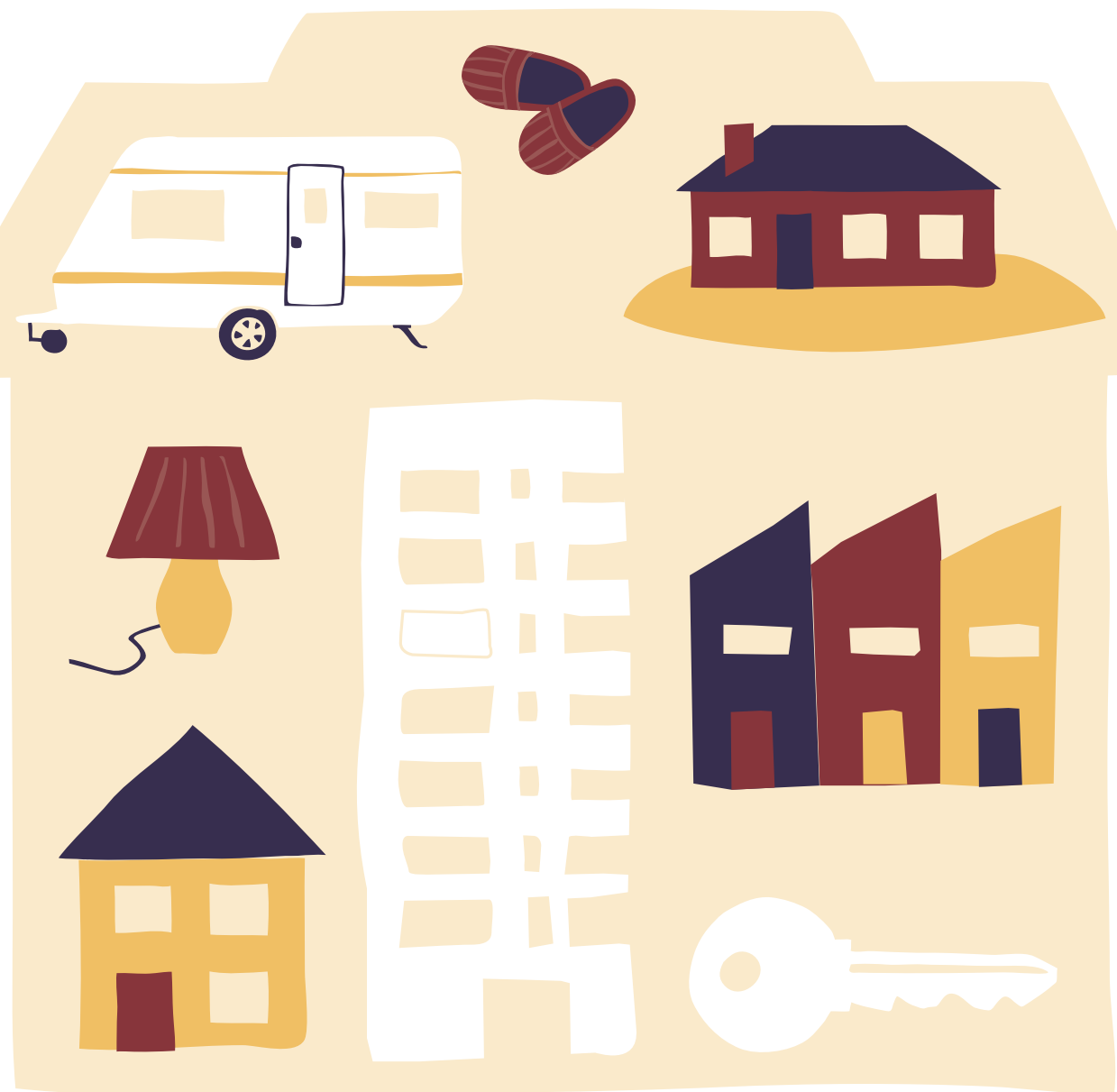



Institute and the Irish Human Rights and Equality Commission.

Irish Human Rights and Equality Commission, 16-22 Green Street, Dublin 7.

The Economic and Social Research Institute, Whitaker Square, Sir John

Rogerson's Quay, Dublin 2

ISBN: 978-1-913492-07-6

https://doi.org/10.26504/bkmnext413

\section{(क) (1)}

This Open Access work is licensed under a Creative Commons Attribution 4.0 International License (https://creativecommons.org/licenses/by/4.0/), which permits unrestricted use, distribution, and reproduction in any medium, provided the original work is properly credited. 


\section{Monitoring Adequate Housing in Ireland}

Helen Russell, Ivan Privalko,

Frances McGinnity \&

Shannen Enright 



\section{CORRIGENDUM}

The results on over-crowding in Sections 7.1 and 7.3 (Chapter 7) were incorrectly described as the percentage of individuals living in over-crowded accommodation. The figures in fact relate to the percentage of households that are over-crowded and it is only the head of household characteristics (e.g. age, gender, nationality) that are reported. The text has now been corrected. 
This report was written by Helen Russell, Ivan Privalko, Frances McGinnity and Shannen Enright. It was prepared for the Irish Human Rights and Equality Commission by the Economic and Social Research Institute as part of the Research Programme on Human Rights and Equality. The report has been peer-reviewed prior to publication. The views expressed in this report are those of the authors and do not necessarily represent those of the Economic and Social Research Institute or the Irish Human Rights and Equality Commission.

The Irish Human Rights and Equality Commission was established under statute on 1 November 2014 to protect and promote human rights and equality in Ireland, to promote a culture of respect for human rights, equality and intercultural understanding, to promote understanding and awareness of the importance of human rights and equality, and to work towards the elimination of human rights abuses and discrimination.

The Economic and Social Research Institute (ESRI) is an independent research institute working towards a vision of 'Informed policy for a better Ireland'. The ESRI seeks to support sustainable economic growth and social progress in Ireland by providing a robust knowledge base capable of providing effective solutions to public policy challenges.

Available to download from www.esri.ie and www.ihrec.ie

(C) 2021. Copyright is held jointly by the Economic and Social Research Institute and the Irish Human Rights and Equality Commission.

Irish Human Rights and Equality Commission, 16-22 Green Street, Dublin 7. The Economic and Social Research Institute, Whitaker Square, Sir John Rogerson's Quay, Dublin 2

https://doi.org/10.26504/bkmnext413

ISBN: 978-1-913492-07-6

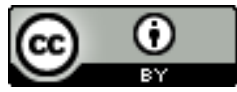

This Open Access work is licensed under a Creative Commons Attribution 4.0 International License (https://creativecommons.org/licenses/by/4.0/), which permits unrestricted use, distribution, and reproduction in any medium, provided the original work is properly credited. 


\section{FOREWORD}

I am delighted to introduce Monitoring adequate housing in Ireland. The right to adequate housing is an area of significant concern for the Commission. Everyone has the right to live somewhere with security, peace and dignity and the State has a responsibility to meet international standards to achieve this. At a minimum, the Commission calls for housing to be of an adequate standard, secure, affordable, and accessible to all. It is our view that housing policy in Ireland must urgently move away from primarily treating housing as a commodity. There must be provisions for low-income or structurally vulnerable groups and action to eliminate discriminatory practices in the public and private sectors, which these groups continuously navigate.

This report seeks to monitor the right to adequate housing in Ireland by providing a baseline measurement framework consisting of six key dimensions: access to housing; housing affordability; security; cultural adequacy; housing quality; and location, access to services and local environment.

Such an approach follows on from the ESRI/IHREC report on Monitoring decent work in Ireland published earlier this year. By monitoring a particular economic, social or cultural right across a set of selected dimensions, reports such as these can provide a baseline on the progression, and regression in this instance, on the right to adequate housing. It can also reveal differential experiences and outcomes for different groups. For example, the Commission is particularly concerned about the profound barriers to adequate housing highlighted in this report among racial and ethnic minorities including Travellers, women, lone parents, younger and older persons, and migrants.

While there is international and national legislation prohibiting discrimination relating to housing it is our view that the right to adequate housing should be enshrined in the Constitution. This is particularly important as we move into a recovery phase following the COVID-19 pandemic and the lifting of the emergency tenancy protection policy measures that were temporarily enacted during this time.

A rights-based approach to housing not only acknowledges that housing is more than bricks and mortar: it combats inequality in housing which is pervasive across the Irish housing 
sector. Adequate housing allows all members of society to not only survive but thrive and achieve their full potential, whilst leading to a more just, inclusive and sustainable society. There is evidence that the public agrees: a survey commissioned by the Commission in 2020 found 82 per cent of people in Ireland consider housing to be a basic human right.

I wish to extend my thanks to Dr Helen Russell and her team for their work on Monitoring adequate housing in Ireland. This report marks the tenth - and final - published report since 2017 under the IHREC / ESRI Irish Human Rights and Equality Research Programme Series. These research reports examine equality and discrimination in Ireland across a wide range of themes and topics including disability, inequality in the labour market, caring and unpaid work, inequality in housing and attitudinal research towards diversity and migration in Ireland. The studies have, both as standalone projects and in a cumulative sense, made a significant contribution to evidence in this country, including methodological innovation.

On behalf of the Commission, I would like to acknowledge the ESRI and all of the researchers who worked on these studies and to thank you for your significant contribution to knowledge on equality and discrimination in Ireland.

Sinéad Gibney Chief Commissioner, Irish Human Rights and Equality Commission 


\section{THE AUTHORS}

Helen Russell is a Research Professor at the Economic and Social Research Institute (ESRI) and an Adjunct Professor at Trinity College Dublin (TCD). Ivan Privalko is a Postdoctoral Researcher at the ESRI and an adjunct at TCD. Frances McGinnity is an Associate Research Professor at the ESRI and Adjunct Professor at TCD. Shannen Enright was a Research Assistant at the ESRI at time of writing.

\section{ACKNOWLEDGEMENTS}

This report is the tenth report in a research programme on human rights and equality and we gratefully acknowledge the funding received from the Irish Human Rights and Equality Commission (IHREC) to support this research programme. From IHREC's research team we would like to thank Iris Elliott (IHREC), Sarah Sheridan (IHREC), Cliona Doherty (formerly IHREC) and Cian Finn (formerly IHREC) for their input into the report, also Karen McLaughlin for responding to legal queries. With thanks too to Tania Burchardt (LSE) for her input and constructive comments as a research programme steering group member. Thanks also to Doireann O'Brien for her input as part of a research internship at the ESRI. The report also benefited from the detailed comments of two ESRI reviewers, as well as a careful reading from Anne Nolan, who acted as editor of the report. Special thanks to Eva O'Regan from the CSO who helped with our analysis of SILC data, and Justin Anderson and Kieran Culhane from CSO who provided information on HAP and housing waiting list recipients. We also wish to thank Brian Gallwey from RTB for supporting us with RTB data and insight. A large number of people from a wide range of organisations attended a stakeholder engagement event on indicators of adequate housing, we thank them for giving their time. Finally, we thank Anna de Courcy for copyediting the report and Sarah Burns for managing its publication.

This report has been peer reviewed prior to publication. The authors are solely responsible for the content and the views expressed. 



\section{TABLE OF CONTENTS}

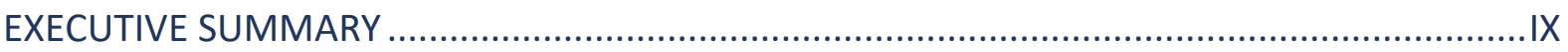

CHAPTER 1 DEFINING AND MEASURING ADEQUATE HOUSING .......................................

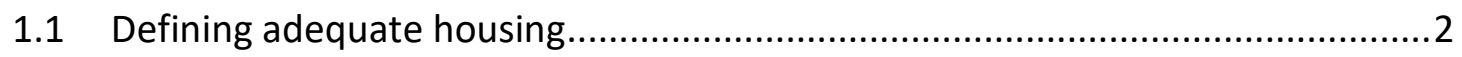

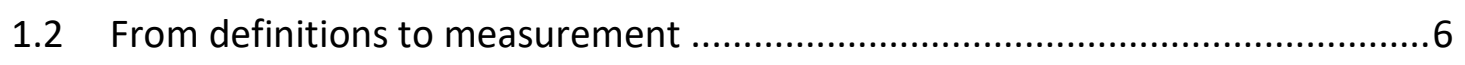

1.3 Equality and non-discrimination in Irish law .................................................13

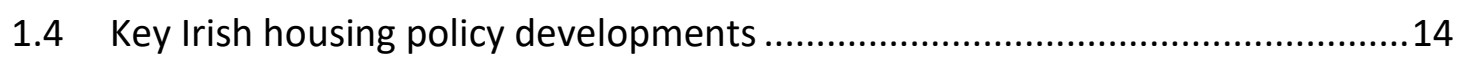

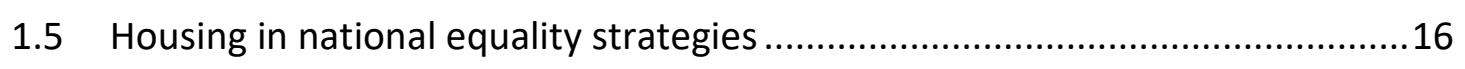

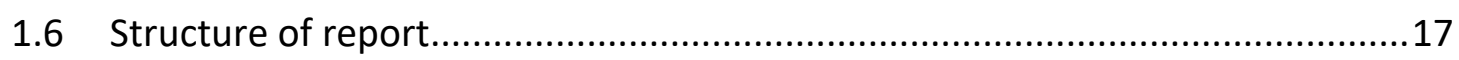

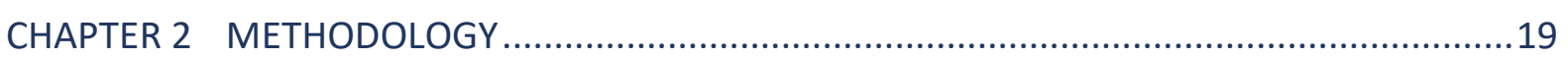

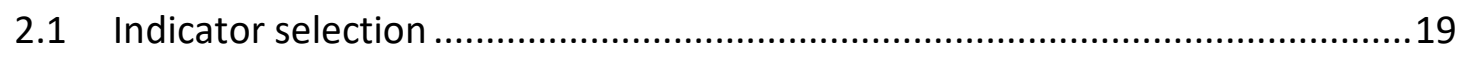

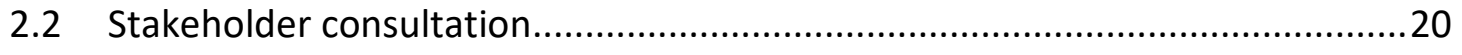

2.3 Individual-level outcome indicator selection ................................................22

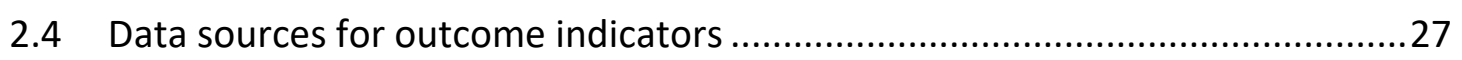

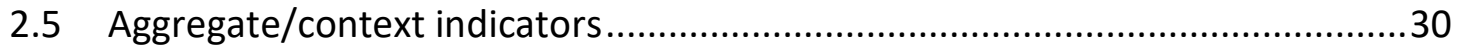

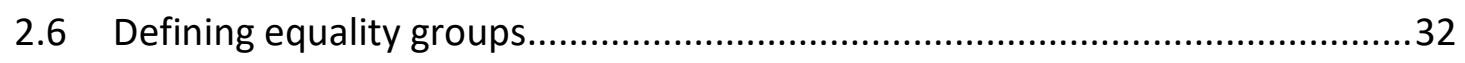

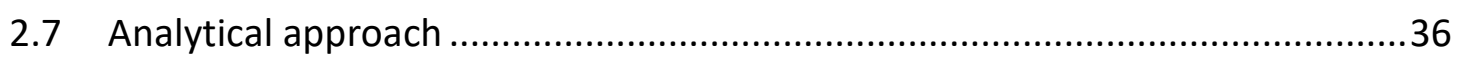

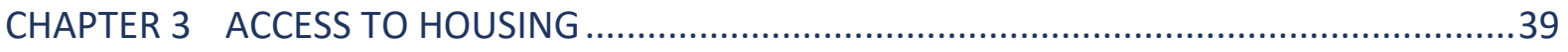

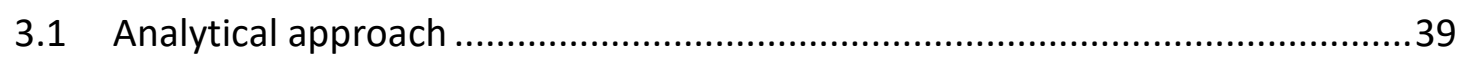

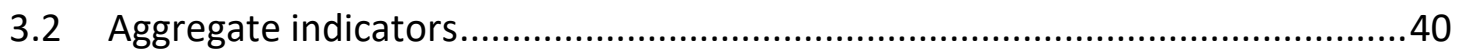

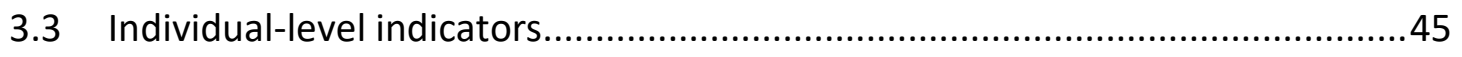

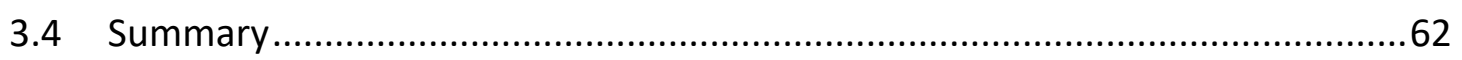

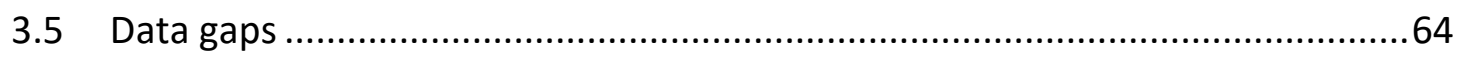

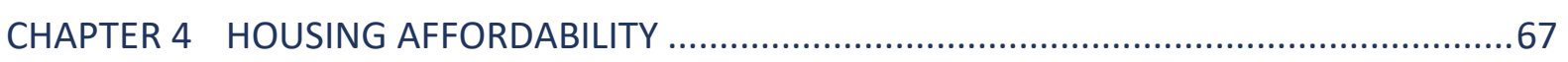

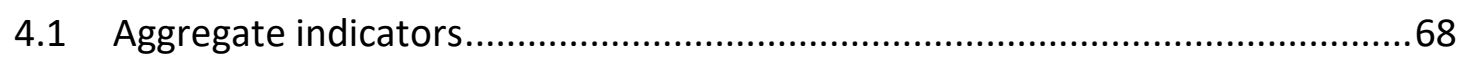

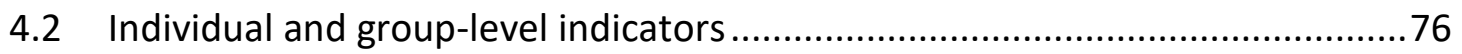

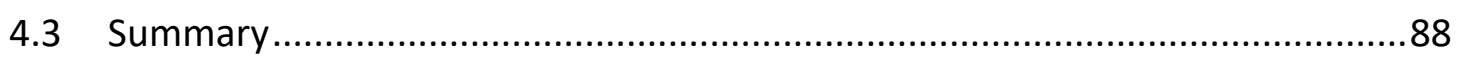

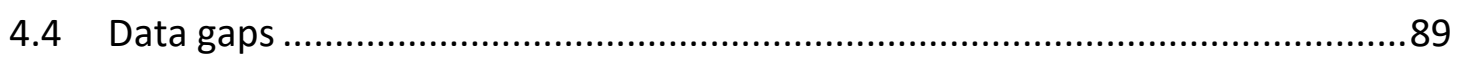

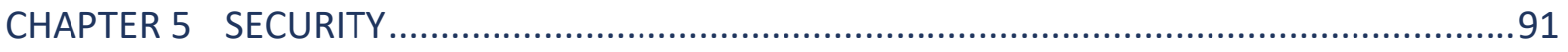

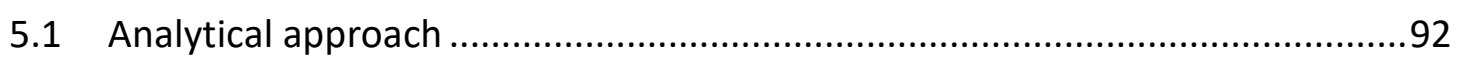

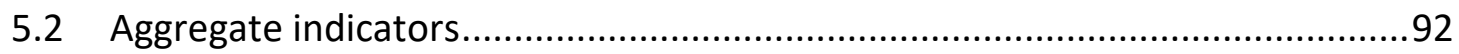

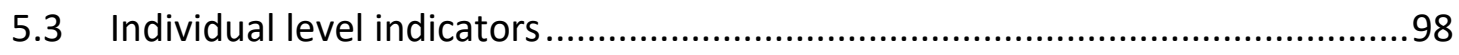

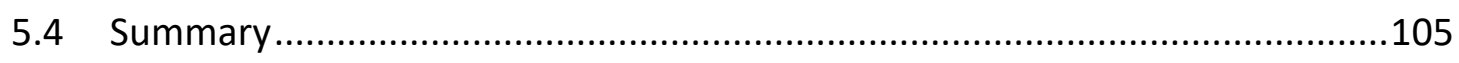

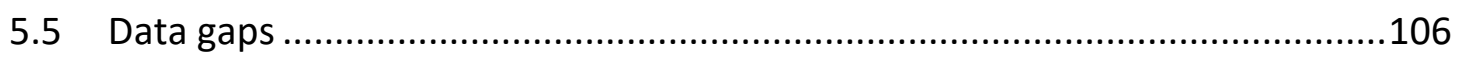




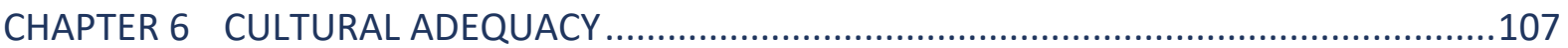

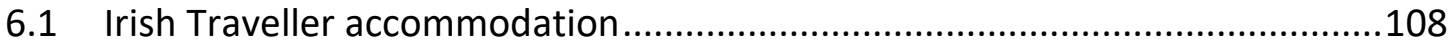

6.2 Direct Provision accommodation for protection applicants ..........................115

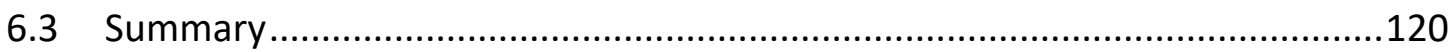

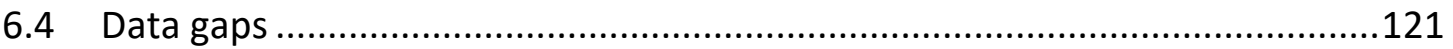

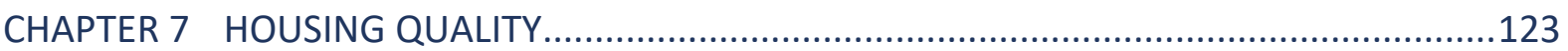

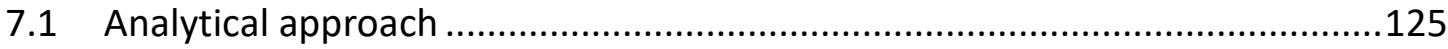

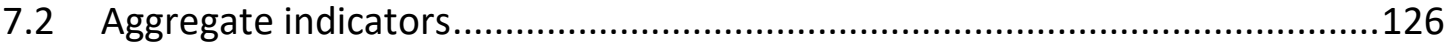

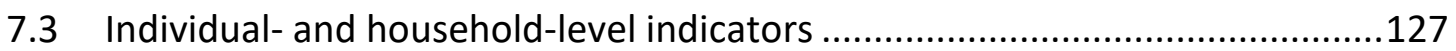

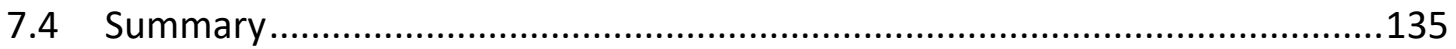

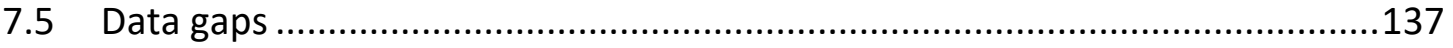

CHAPTER 8 LOCATION, ACCESS TO SERVICES AND LOCAL ENVIRONMENT .......................139

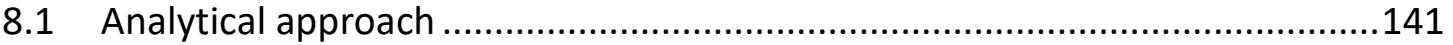

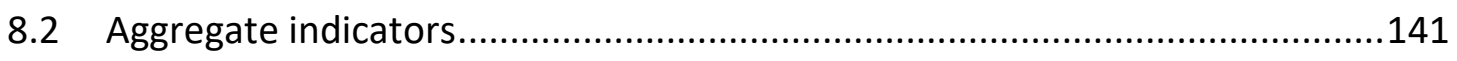

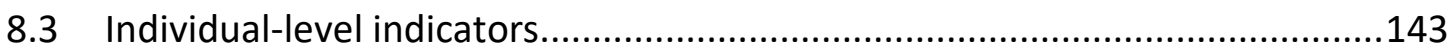

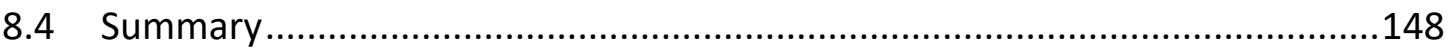

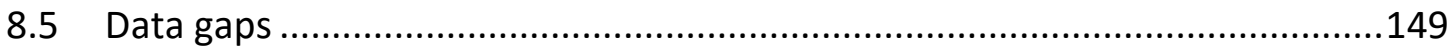

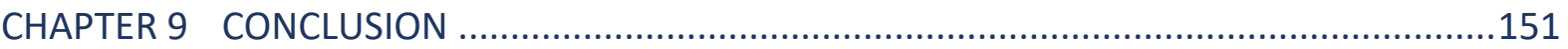

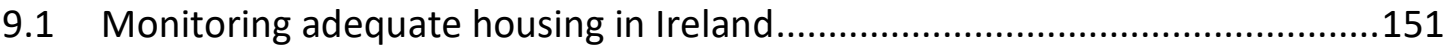

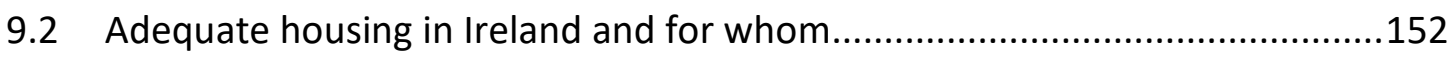

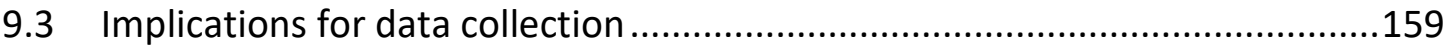

9.4 Strengths and weaknesses of a monitoring approach ...................................162

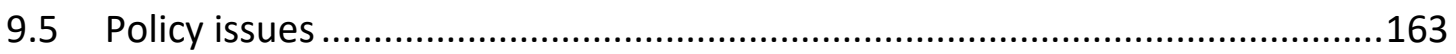

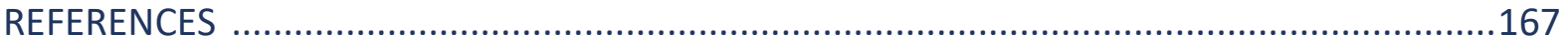

APPENDIX 1 ADEQUATE HOUSING INTERNATIONAL INSTRUMENTS ................................183

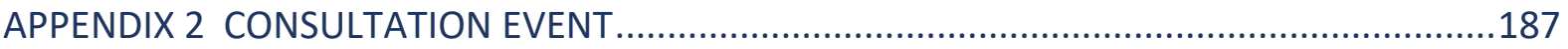

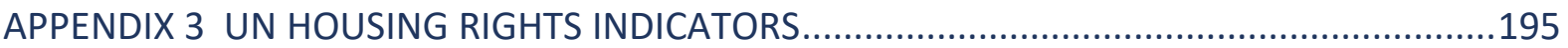




\section{LIST OF TABLES}

Table 2.1 Outline of dimensions, outcome indicators and data sources .....................29

Table 2.2 Breakdown of groups measured across data sources .....................................33

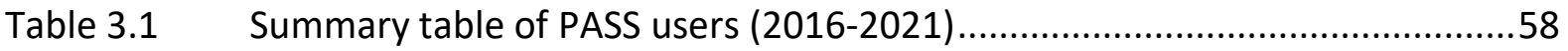

Table 4.1 Average monthly rent, average monthly earnings, and their ratio

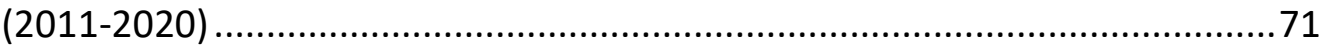

Table 4.2 Rent Supplement recipients (characteristics of main tenant) ........................72

Table 4.3 Housing Assistance Payments (characteristics of main tenant) .....................75

Table 5.1 Total RTB disputes and termination disputes over time (2017-2019)............95

Table 6.1 Estimate (count) of Traveller families by accommodation type 2019..........110

Table 6.2 Drawdown of funds for Traveller accommodation by Local Authority (2019 and 2020) ...............................................................................114

Table 6.3 Length of time in Direct Provision (end July 2020) .....................................118

Table A1.1 Dimensions of adequate housing international reporting table ..................183

Table A2.1 Task Two with results from consultation ..................................................188

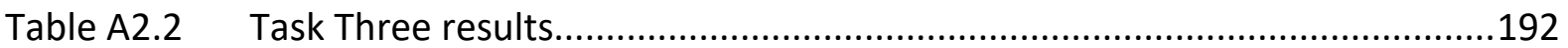

Table A2.3 List of consultation organisations ...........................................................193

Table A3.1 Housing rights indicators developed by UN Housing Rights Programme......195 


\section{LIST OF FIGURES}

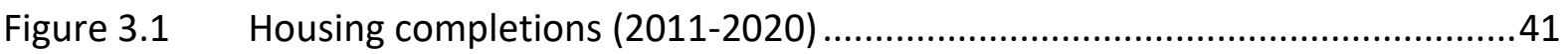

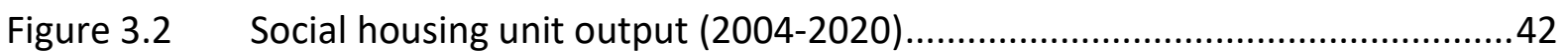

Figure 3.3 Capital spending on housing V34.A (1994-2020) .......................................43

Figure 3.4 Housing supplement spending (HAP, RS and RAS only) (2004-2019).............44

Figure 3.5 Group differences in owner occupation rates, with and without mortgage

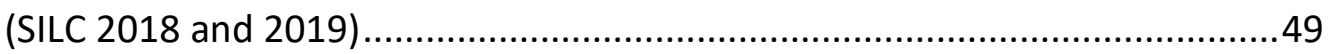

Figure 3.6 Group differences in private rental rates (SILC 2018 and 2019)....................52

Figure 3.7 Group differences in Local Authority rental (SILC 2018 and 2019) ................54

Figure 3.8 Gender differences in homeless services use (PASS system) (January 2016-March 2021) ....................................................................5

Figure 3.9 Age composition of homeless services users March 2021 (PASS system) and general adult population....................................................................58

Figure 3.10 Composition of housing waiting list........................................................61

Figure 4.1 Trend in rental cost (2007-2020) indexed to 2007 .......................................70

Figure 4.2 Group differences in affordability 30/40 rule (SILC 2018 and 2019) ..............80

Figure 4.3 Group differences in poverty after housing costs (SILC 2018 and 2019)........83

Figure 4.4 Group differences in arrears on housing costs (SILC 2018 and 2019) ............87

Figure 5.1 RTB/ESRI Rent Index - tenancy length by quarter (\%) ................................93

Figure 5.2 Total mortgage accounts in arrears by principal dwelling houses (PDH)

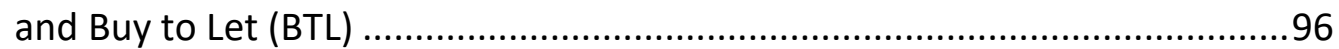

Figure 5.3 Residential properties in repossession at beginning of quarter by principal dwelling houses (PDH) and Buy to Let (BTL) .............................................97

Figure 5.4 Length of time (mean years) in current dwelling (SILC 2018 and 2019).........99

Figure 5.5 Group differences in subjective insecurity of housing (EQLS, 2016) ............104

Figure 6.1 Annual estimate (count) of Traveller families by accommodation type, (2009-2019)

Figure 6.2 Numbers in Direct Provision accommodation (2009-2020) ........................117

Figure $7.1 \quad$ Age of housing stock in Ireland (Census 2016) .........................................127

Figure 7.2 Group differences in over-crowding Head of Household (Census, 2016) .....128

Figure 7.3 Group differences in housing quality index (SILC 2018 and 2019) ...............132 
Figure 7.4 Group differences in difficulty keeping the home adequately warm (SILC 2018 and 2019).

Figure 8.1 Proportion of private households with access to basic facilities (Census 2016)

Figure 8.2 Proportion of private households with no access to internet by location (Census 2016)

Figure 8.3 Proportion of respondents who had difficulty accessing two or more services (EQLS, 2016)

Figure 8.4 Proportion of respondents who feel safe when they walk alone in their area after dark (EQLS, 2016) 



\section{GLOSSARY}

BTL Buy to Let

CEDAW Committee on the Elimination of Discrimination Against Women

CERD Committee on the Elimination of Racial Discrimination

CESCR Committee on Economic, Social and Cultural Rights

CRC Committee on the Rights of the Child

CRPD Convention on the Rights of Persons with Disabilities

CSO Central Statistics Office

EHRC UK Equality and Human Rights Commission

EQLS European Quality of Life Survey

ERRC European Roma Rights Centre

ESA Equal Status Acts

ESC European Social Charter

ICCPR International Covenant on Civil and Political Rights

ICESCR International Covenant on Economic Social and Cultural Rights

OECD Organisation for Economic Co-operation and Development

RPZ Rent Pressure Zone

UNECE United Nations Economic Commission for Europe

UNHRP UN Housing Rights Programme 



\section{EXECUTIVE SUMMARY}

\section{INTRODUCTION}

Adequate housing is essential to the quality of life of individuals and families. Housing provides safety and shelter and underpins people's ability to hold employment, participate in education, and otherwise engage with civil society. Housing precarity and housing deprivation are associated with poor mental health, poor physical health, precarity, and homelessness, which have consequences not just for individuals but also for wider society. This report considers the right to adequate housing in Ireland, with reference to Ireland's international commitments to housing rights. The analysis is framed within the definition of adequate housing set out in the International Convention on Economic and Social Rights and applies social science methods to monitoring the dimensions of adequacy set out there.

This report presents a set of indicators for monitoring the right to adequate housing in Ireland and provides baseline figures across a range of dimensions and across different social groups in Ireland. We focus on six dimensions of adequate housing, which are identified in the International Convention on Economic Social and Cultural Rights; accessibility, affordability, security of tenure, cultural adequacy, quality, and location. Following consultation with key stakeholders and civil society groups we selected a set of indicators to reflect each dimension. In each case, we first consider aggregate, societal level indicators which provide the broad context, before exploring group differences in the outcome indicators measured at the individual level, using survey data or the Census. Where this is not possible, we outline the data gaps.

The groups considered cover a number of the grounds protected in Irish equality legislation - gender, age, nationality/ethnicity, family status, as well as an indicator of social class (education level). The report argues that a single metric to measure adequate housing would not reflect the complexity and multi-dimensionality of the housing situation. Whilst similar monitoring exercises compare housing and living standards across countries, the aim of this report is to devise a monitor specifically for Ireland.

The purpose of this monitor is to develop indicators to describe progress and regression in achieving adequate housing and to highlight inequalities in housing outcomes. The monitor 
is primarily descriptive, and we do not analyse the processes behind differences in outcomes, though we refer to the broader literature on mechanisms.

At the time of writing, Ireland was still experiencing the COVID-19 pandemic. Both the pandemic and the national response will likely impact on the housing market and wider society for quite some time. This monitor provides a snapshot of adequate housing before or in the early part of the pandemic, yet this can inform debates about the appropriate policy responses to the pandemic and provides a baseline for monitoring progress in achieving adequate housing.

\section{ADEQUATE HOUSING: KEY FINDINGS}

Regarding access to housing, we consider three aggregate indicators, before addressing group differences in outcomes. We find that housing completions have increased, but from a low base and have been stalled by Covid shutdowns. We also find that social housing output has increased, as has capital spending on housing, and housing supplement spending. In terms of individual indicators, we consider group differences in housing tenure, homelessness rates, and the characteristics of the housing waiting list.

In March 2021, 5,894 adults were availing of homeless services, including 913 families who had 2,166 dependants. In 2020, there were 61,880 households on the waiting list for social housing and in 2019 , there were over 91,600 people in receipt of government benefits to cover housing costs (HAP, Rent Supplement or RAS). We also find inequalities between age groups, country of birth groups, and household composition groups in these measures.

Differences between age groups are evident on all indicators of access. Young respondents (25-44) are less likely to live in owner-occupied housing; they are also overrepresented in homeless services when compared to older groups. Differences between country of birth categories also emerged, with migrants overrepresented on the housing waiting list and in private rental accommodation. Lone parents reported some of the lowest rates of homeownership and some of the highest rates of private rented accommodation and Local Authority housing. Lone parent families were also overrepresented amongst homeless families, and in the housing waiting list. 
For housing affordability, we consider two main context indicators; the average cost of rent, and the demographics of housing transfer recipients. We find that average rent has increased substantially, and that this increase has risen faster than average earnings.

In terms of individual indicators, we adopt three measures, the $30 / 40$ rule, ${ }^{1}$ post-housing cost poverty rates, and the prevalence of arrears in rent or mortgage costs. Lone parents routinely recorded higher rates of affordability issues when compared to other household types. Children and young adults also experienced higher rates of affordability issues, regardless of the measure used. Given that children are disproportionately more likely to experience poverty than other age groups (CSO, 2019; Maître et al., 2020) this could stem from lower income and higher household expenses of households with children, relative to households without children. Finally, migrant groups were more likely to experience affordability issues than the Irish-born population on each measure, which may be related to their reliance on the private rental sector.

In terms of security, we consider length of occupancy in current home and subjective housing security. Group differences in length of occupancy are strongly associated with housing tenure type, with much shorter spells among those in private rental housing. Migrants and lone parents had lived in their accommodation for a shorter time compared to others, though this is chiefly explained by the fact that they are more likely to live in private rented accommodation. On its own this does not necessarily indicate disadvantage, as length of occupancy will be influenced by age and preferences. For measures of subjective security, we used data from the European Quality of Life Survey, which asked 'How likely or unlikely do you think it is that you will need to leave your accommodation within the next six months because you can no longer afford it?'. We found a low level of insecurity in Ireland using this measure and no statistically significant differences between groups, though this may be linked to the small sample size in this survey. Less than 5 per cent stated they are 'likely' to have to move for affordability reasons, suggesting that even those with affordability issues feel somewhat secure in their home. However, this measure does not capture insecurity arising from limited tenancy length or landlord's decision to sell or 
renovate. Overall, we suggest that there is a need for new data collection to accurately capture the individual differences in this dimension of housing adequacy.

Looking at repossessions we find that there has been a decrease in owner-occupied repossessions in the years following the financial crisis. For private rental accommodation we find that although the total number of disputes between landlords and tenants reported to the Residential Tenancies Board increased between 2017 and 2019, the proportion of these tied to validity of notice and unlawful termination fell.

For measures of cultural adequacy, we focus on two groups: members of the Traveller community, and those living in Direct Provision centres. For Travellers, Local Authorities are responsible for providing Traveller-specific accommodation. Data from 2019 show that only two-thirds of the allocated funding for Traveller accommodation was drawn down by Local Authorities, and there is substantial variation between Local Authorities in the extent of this drawdown. There is also considerable mismatch between Travellers' preferred accommodation and their actual accommodation. Combined with evidence of Travellers being overrepresented in homelessness figures and over-crowded accommodation, this highlights significant disadvantage in terms of adequate housing for this group. On Direct Provision, despite improvements to the system, such as reducing the length of stay and increasing the proportion of own-door accommodation, evidence suggests the system of accommodation in its current form is not meeting the needs of asylum seekers, and several deficiencies have been recognised (Government of Ireland, 2020). The current government is committed to ending Direct Provision, but it is unclear how a new system will be implemented.

On housing quality or habitability, the indicators used were over-crowding (defined as more than one person per room), an index of housing deprivation which consists of four items: leaking roof/damp/rot, lack of central heating, lack of double glazing, and issues with light or darkness; and an inability to keep the home adequately warm. We find that households headed by migrants, specifically those from Eastern Europe and non-EU countries, are more likely to live in over-crowded conditions. The largest differences in over-crowding rates are between ethnic groups, with households headed by Irish Travellers, Black, and Asian minorities reporting worse conditions than other groups. In terms of housing deprivation, 
people with a disability have a higher chance of experiencing housing deprivation when compared to those without a disability. Once again, lone parents are also particularly vulnerable to experiencing some measures of housing deprivation. Regarding inability to keep the home warm, we find that young people, migrants, lone parents, and people with a disability are especially likely to report this problem.

In several measures, we note that a number of equality groups like lone parents, people with a disability, and migrants consistently report a disadvantage in terms of housing outcomes. While some of these differences can be attributed to personal preference, such as a preference for rental accommodation, group differences in housing quality, overcrowding, or affordability should be of concern to researchers and policymakers. Future research should consider these groups explicitly when modelling differences in housing outcomes, and future monitoring exercises should strive to include these groups in their analysis.

\section{FUTURE DATA COLLECTION}

Despite Ireland's commitments to improve housing outcomes for key groups, we find a number of groups for which no housing data are collected by any ongoing national survey; these include ethnic background, religion, gender identity, and sexual orientation. The Survey on Income and Living Conditions is a key resource for housing adequacy in Ireland. Given its in-depth consideration of housing, it is the best resource for group differences in housing outcomes. Where data are collected on minority groups, we find that the small sample sizes for surveys such as the European Quality of Life Survey (EQLS) restrict their usefulness as we cannot determine significance between groups. Surveys such as EQLS are designed as general population surveys and as such they do not usually contain large samples of minority groups.

Ethnicity remains rarely measured in Ireland, in either surveys or administrative data. We use data from the Census to show the housing disadvantage experienced by Irish Travellers and other ethnic and religious minorities. These groups are not identified in either the Survey on Income and Living Conditions, nor the Irish Labour Force Survey and this is a significant data gap. 
Further, research has shown that migrants are diverse in terms of their education and employment outcomes (McGinnity et al., 2020b). Despite this diversity, there are few migrant categories available in the data and second-generation migrants and refugee status are not captured. As a result, researchers must make conclusions about migrant groups using broad categories, which are often a poor fit for the different countries of birth in that category and do not capture generational differences. Further, many surveys have small sample sizes which prevent further breakdown of migrant groups where data are available.

Finally, certain important measures of housing adequacy, such as security, are not well measured in the data. Future research into group differences in security should consider additional measures which capture precarity or instability in housing. In addition, although access to services is captured in the data, small sample sizes restrict the usefulness of these data. Future iterations of EQLS or surveys with similar questions on local services should consider boost samples for minority respondents to ensure all equality groups are adequately captured in the data. 


\section{CHAPTER 1}

\section{Defining and measuring adequate housing}

This report sets out to develop a framework and baseline for monitoring the right to adequate housing in Ireland. Lack of adequate housing impacts on individuals' physical health and psychological well-being, and is detrimental to child development, is disruptive to family life and is a barrier to accessing or maintaining employment, education, and other services (Desmond and Gershenson, 2016; Kim, 2010; O'Campo et al., 2009; Wood et al., 2017; Grotti et al., 2018). Adequate housing is also crucial from a societal perspective to build sustainable communities and civic society. Adequate housing has been addressed through a wide variety of perspectives. Here we examine how an equality and human rightsbased approach to adequate housing might be operationalised based on the obligations and principles that Ireland has committed to in international agreements. This report is designed to inform the work of the Irish Human Rights and Equality Commission which, as Ireland's national human rights institute and equality body, monitors progress and regression in meeting international commitments. A key element of an equality monitoring perspective on housing is the consideration of the distribution of opportunities and outcomes across the groups protected by equality legislation. Non-discrimination is also a core feature of a human rights-based approach to monitoring. Therefore, the report sets out to provide evidence not just at a societal level but also, where possible, disaggregated across social groups.

Monitoring can also serve a number of other functions. It can provide evidence for policymaking on deficits in meeting housing needs across society or among particular groups. It can also help to highlight data gaps, measurement limitations, and can contribute to building the infrastructure for capturing the disaggregated data necessary for reviewing progress. The report builds on a monitor of decent work in Ireland (McGinnity et al., 2021). The aim is to identify the key dimensions of housing adequacy as outlined in the rights frameworks that Ireland is committed to, and to develop a set of indicators that are valid, robust, and have meaning and legitimacy for stakeholders. The views of stakeholders were obtained through a consultation process (see Chapter 2 for details). In their guidelines for the implementation for the right to adequate housing, Farha (2019) note that analysis 
should also include the participation of those affected and access to justice for those affected by human rights violations of the right to housing.

The purpose of monitors such as this is to track changes across the key dimensions of a social phenomenon over time. As such the emphasis is on devising a set of indicators that can accurately and validly capture a broad range of dimensions of the issues under consideration and the experiences of those affected. This monitor, like others outside Ireland (e.g. Eurofound, 2017; Joseph Rowntree Foundation et al., 2015; EHRC, 2018) and at a national level (Department of Employment Affairs and Social Protection, 2019), is primarily descriptive. It does not attempt to disentangle the mechanisms that lead to the observed outcomes, as such an approach would require a different research design and a much smaller range of outcomes; but rather points to deficits or challenges in realising the right to adequate housing in Ireland.

This chapter discusses the definition and measurement of adequate housing. We start from the definition of adequate housing specified in international rights frameworks and how this has been operationalised and monitored internationally. We also consider the lessons and evidence from the social, economic, and quality of life literature on the key dimensions of adequate housing and its measurement. From these two bodies of research, we draw insights on how to monitor housing adequacy in Ireland.

\subsection{DEFINING ADEQUATE HOUSING}

Given the aims of the report we begin with the definitions of adequate housing from the international rights agreements. However, in developing appropriate indicators we also draw on research and monitoring exercises in the quality of life and equality traditions for insights into the selection of appropriate indicators. Note that there is a good deal of consensus between the approaches mentioned above in the dimensions identified.

Ireland is a signatory to a number of international conventions and agreements that include the right to adequate housing. One of the first references to the right to housing is in Article 25 (1) of the Universal Declaration of Human Rights. This states that: 
Everyone has the right to a standard of living adequate for the health and well-being of himself and of his family, including food, clothing, housing and medical care and necessary social services, and the right to security in the event of unemployment, sickness, disability, widowhood, old age or other lack of livelihood in circumstances beyond his control.

The protection of the right to adequate housing is a subset of the right to an adequate standard of living. However, it is in the International Covenant on Economic Social and Cultural Rights (ICESCR), where the right to housing is spelled in out more detail. In Article 11 it states:

The States parties to the present Covenant recognize the right of everyone to an adequate standard of living for himself and his family, including adequate food, clothing and housing, and to the continuous improvement of living conditions.

The meaning of this provision is elaborated in the Committee's General Comment No. 4 (1991) and in General Comment No. 7 (1997) on Forced Evictions. General Comment No. 4 sets out the characteristics of the right to adequate housing as follows:

- Legal security of tenure: All persons should possess a degree of security of tenure which guarantees legal protection against forced eviction, harassment, and other threats;

- Affordability: Financial costs associated with housing should not threaten or compromise the attainment and satisfaction of other basic needs (for example, food, education, access to healthcare);

- Habitability: Adequate housing should provide for elements such as adequate space, protection from cold, damp, heat, rain, wind or other threats to health, structural hazards, and disease vectors;

- Availability of services, materials, facilities, and infrastructure: Housing is not adequate if its occupants do not have safe drinking water, adequate sanitation, energy for cooking, heating, and lighting, sanitation and washing facilities, means of food storage, refuse disposal, etc.; 
- Accessibility: Housing is not adequate if the specific needs of disadvantaged and marginalised groups are not taken into account (such as the poor, people facing discrimination; persons with disabilities, victims of natural disasters);

- Location: Adequate housing must allow access to employment options, healthcare services, schools, childcare centres, and other social facilities and should not be built on polluted sites nor in immediate proximity to pollution sources;

- Cultural adequacy: Adequate housing should respect and take into account the expression of cultural identity and ways of life.

The UN comments that:

These elements are just as fundamental as the basic supply and availability of housing. For housing to be adequate, it must, at a minimum, meet [the above] criteria. (UN Habitat, 2009)

Additionally, General Comment No. 7 (CESCR) further elaborates on protection from forced evictions. Forced evictions are defined as the:

permanent or temporary removal against their will of individuals, families and/or communities from the homes and/or land which they occupy, without the provision of, and access to, appropriate forms of legal or other protection.

These aspects of adequacy have been further elaborated and tested through case law, as have their limitations. Hohmann (2013) argues that the focus of the security dimension on evictions results in an emphasis on the symptom rather than the cause of insecurity. The affordability dimension goes further than the others in that the means to achieve affordability are also set out in Comment No. 4:

Steps should be taken by States parties to ensure that the percentage of housing-related costs is, in general, commensurate with income levels. States parties should establish housing subsidies for those unable to obtain affordable housing, as well as forms and levels of housing finance which adequately reflect housing needs. In accordance with the principle of 
affordability, tenants should be protected by appropriate means against unreasonable rent levels or rent increases.

Hohmann (2013) argues that this direction is overly prescriptive, and it is likely beyond the competency of the Committee to determine which measures might be effective in such a complex policy area, which will vary depending on the national context. Similarly, the basic standards, facilities and services set out in the ICESCR comment might be seen as the minimal requirements in a global context; their usefulness in establishing an acceptable minimum in a wealthy country like Ireland is more questionable. Definitions of poverty and social inclusion that are built into Ireland's national anti-poverty strategies, suggest that rather than applying an absolute threshold, an adequate standard of living is measured against the prevailing norms, that is being excluded from participating in the 'normal way of life of society'. The goods and services that are necessary to meet this standard, including those relating to housing will necessarily change over time and space. ${ }^{2}$ Nevertheless, the ICESCR provides a clear outline of the domains that should be included in the monitoring of adequate housing, and we explore how these might be operationalised in a meaningful way in the Irish context. In our discussion, we combine the habitability and availability of services etc. into one 'housing quality' dimension.

Within the ICESCR framework, the right to housing must also respect the principles of progressive realisation and non-discrimination. The principle of progressive realisation requires that States must 'take steps... to the maximum of their available resources' to achieve progressively the full realisation of economic, social, and cultural rights (Article 2.1 ICESCR; UN factsheet 33). This means that Ireland's compliance with these obligations is assessed in the light of available resources. The UN has emphasised that the right to adequate housing does not require the State to build housing for the entire population. Instead, the right to adequate housing covers measures required to prevent homelessness, ensure security of tenure to all, guarantee that housing is adequate and protect the most majority. 
vulnerable. This can be achieved through legislation, regulation, policy, or public spending (UN Habitat Fact Sheet 21/Rev 1).

The Covenant also requires states to guarantee the enjoyment of economic, social, and cultural rights without discrimination and to ensure the equal right of men and women to the enjoyment of these rights (UN Factsheet 33). The principle of non-discrimination requires immediate implementation rather than progressive realisation. This means that any state action on housing must be non-discriminatory. ICESCR identifies that the grounds of discrimination include, but are not limited to race, sex, language, religion, political opinion, nationality, social origin, property, birth, and 'other status' which encompasses disability, health status or sexual orientation, poverty, and economic marginalisation (UN Habitat 2017 , p.10). The committee also mentions the possibility of multiple discrimination when individuals occupy a number of disadvantaged statuses, which is also termed intersectionality.

There is a great deal of discussion and legal argument as to the effectiveness and limitations of the right to adequate housing in international law as a means to achieve concrete outcomes for members of society and effecting social change. It is beyond the scope of this report to address these issues; rather the aim is to take these principles and definitions and explore how progress towards their achievement might be measured. The reader is referred to Hohmann $(2013)$ and Kenna $(2005 ; 2011)$ for further discussion, and to Hearne and Kenna (2014) for an application of the rights-based approach to housing in Ireland.

\subsection{FROM DEFINITIONS TO MEASUREMENT}

The ICESCR definition of adequate housing provides the starting point for developing a set of dimensions and indicators for monitoring the right to adequate housing in Ireland. Monitoring progress and holding states to account is a core element of the human rights process. The current exercise is intended to provide information that is useful for IHREC and civil society actors to inform their submissions to the monitoring process, especially on outcomes. ${ }^{3}$ There is also a strong tradition of equality monitoring and of social indicator 
research within the social sciences; of particular relevance is research that has endeavoured to monitor the standard of living and quality of life of individuals over time and across countries. Equality monitoring such as the EIGE Gender Equality Index (2020) is based on concepts of social justice and equality of opportunity and tracks inequality of outcomes [as signifiers of unequal opportunities]. It typically uses large, representative data to allow the results to be generalisable to the population and examines difference in experiences across social groups, particularly minorities and those vulnerable to exclusion.

Social indicator frameworks are influential in terms of research and public policy-making and provide important evidence for developing a robust and valid monitor of adequate housing in Ireland and selecting appropriate indicators. These frameworks tend to focus on outcome indicators, in particular inequality of outcomes across social groups. Ireland is currently in the process of developing a social indicator framework focused on well-being (Department of the Taoiseach, 2021). In the research literature, legislation and legal rights may be included as context or possible explanatory mechanisms to explain differences but are not the core focus. In this section we consider a number of prominent measurement frameworks for measuring decent housing. We also draw on the UK Equality and Human Rights Commission (EHRC) measurement framework, which combines both human rights and equality approaches.

It is important to note that many of the monitoring exercises discussed below are designed for comparing housing and living standards across countries whereas our aim is to devise a monitor for Ireland. An international monitor would bring a different set of constraints, for example the need to locate measures and data that were harmonised and meaningful across countries. A comparative analysis of housing adequacy is beyond the scope and design of the current project.

The frameworks also have different emphases, which reflect their different perspectives. Some are 'standalone' frameworks, in others housing is one important element of a broader assessment of well-being. Some frameworks combine indicators to an index or indices of adequate housing, and some frameworks have been more influential in terms of research and public policy-making, at either national or international level. This monitor aims to combine elements of each to develop a set of indicators appropriate and useful for Ireland. 


\subsubsection{UN Housing Rights Programme indicator set}

The UN Housing Rights Programme (UNHRP) was established in 2002. In 2003 it developed a set of indicators to monitor the progressive realisation of the right to adequate housing. ${ }^{4}$ The report noted that while there were well-established indicator frameworks for monitoring other human rights (e.g. the UN Human Development Report), no such scheme existed for housing rights. The HRP identified six elements of housing rights to be monitored (see Appendix Table A3.1) and selected 17 quantifiable indicators to capture these elements.

To identify the core elements the UNHRP drew on the ICESCR General Comments 2 and 4 discussed above, the principles of human rights international law (such as the progressive realisation of rights using maximum available resources, minimum core standards, non-discrimination), and issues that housing rights experts have identified as important. The indicators included a measure of the extent of homelessness in the last 12 months and six indicators of housing adequacy. Three of these refer to very minimal standards: access to potable water, sanitation, and living in temporary structures, while another three refer to the cost of housing relative to median income, over-crowding, and accessibility for people with a disability. Four indicators of security were also included, while the remaining indicators referred to legislative protections and acceptance of international standards and so relate to policies, structures, and institutions rather than outcomes. Although the framework draws on ICESCR definition of housing adequacy, the UN Housing Rights Programme notes that 'Cultural adequacy may be the most difficult component of housing adequacy to measure using quantitative methodologies' (2003, p.32), and does not identify any indicator of cultural adequacy. Furthermore, no measure of location (e.g. proximity to environmental hazards or average distance to nearest school/hospital etc) made it to the final shortlist (ibid p.32). 
In selecting the indicators, the UNHRP emphasises the statistical reliability and validity of the measures along with the ability to disaggregate the measures across different groups. The committee notes that:

...it is critical that data be disaggregated so as to capture inequalities with regard to gender, age, income level, race, and ethnicity.... In particular, disaggregation should occur with respect to measurements of all of the components of adequate housing, security of tenure, ... forced eviction and... homelessness (UNHRP 2003 p.57).

This is an important principle of the selection of indicators for our own monitor.

\subsubsection{UN Habitat}

Another international framework considered is the UN Habitat (2017) domains for adequate housing. These were developed to measure progress towards Sustainable Development Goal 11.1 which is to 'ensure access for all to adequate, safe and affordable housing and basic services and upgrade slums' by 2030. UN Habitat set out six basic dimensions of adequate housing which include: access to water, access to sanitation, living area, housing durability, security of tenure, and affordability. Indicators within these domains include household expenditure on housing, and tenure agreements. As these domains and indicators were developed for international use, some of these indicators are not as relevant for the Irish population. For example, within the access to water domain UNECE states that individuals should have 20 litres of water per person within collection distance. In Ireland, the vast majority of the population have access to running water in their homes, with the notable exception of members of the Traveller community who reside in unserviced halting sites and members of the Roma population who experience extreme housing deprivation.

\subsubsection{Housing indicators in poverty monitoring in Ireland and the EU}

Ireland was one of the forerunners in establishing a system of poverty monitoring. The first National Anti-Poverty Strategy was launched in 1997. Poverty monitoring was informed by a rigorous body of research (see reviews in Whelan et al., 2019; Watson et al., 2017a) based on a theoretical perspective that recognised the multi-dimensional nature of poverty, 
placed it in the wider context of social inequalities, and drew on Sen's $(1993 ; 2004)$ concept of capability deprivation.

The core measure of poverty adopted in Irish policy termed 'consistent poverty' combines both income poverty and material deprivation. The measure of deprivation used in poverty monitoring in Ireland consists of a set of items that cover a range of goods and social participation items that are deemed necessary to participate in the normal life of society. These items have changed over time to reflect changing social norms on basic necessities and what is minimally adequate (see Watson et al., 2017a). Two of the 11 current deprivation measures relate to housing adequacy; inability to keep home adequately warm and unable to afford to replace worn-out furniture. Measures of access to very basic dimensions of housing adequacy such as access to sanitation were considered in the development of deprivation indicators, but were found to be lacking by too few households to build a meaningful measure of deprivation in Ireland in the 1990s and 2000s. The annual Social Inclusion Monitor published by the Department of Social Protection (DEASP, 2019) also includes two measures relating to housing affordability in their measure of economic stress; arrears (which includes but is not limited to rent and mortgage arrears) and subjective reports that housing costs are a heavy burden.

While material deprivation and consistent poverty have been core indicators for Irish social policy, there have also been attempts to capture broader quality of life measures. These included a wider set of dimensions and indicators including housing and neighbourhood environment alongside health, well-being and income (Watson et al., 2016). The indicators included crowded accommodation and housing quality problems (dampness and insufficient light), problems with noise, crime or pollution in the local area and feeling unsafe in the area at night. The latest Irish anti-poverty strategy the Roadmap for social inclusion 2020-2025 includes two targets that focus on access to adequate housing: the housing cost overburden rate ${ }^{5}$ and the over-crowding rate. ${ }^{6}$ No target is set for homelessness, though the Rebuilding

5 The housing cost overburden rate is defined by those households which allocate 40 per cent or more of their disposable income to housing. This benchmark is taken from the Living Conditions in Europe Report, 2018 Edition. The report is available here https://ec.europa.eu/eurostat/web/products-statistical-books/-/KS-DZ-18001.

6 The over-crowding rate is defined on the basis of the number of rooms available to a household, the household's size, family situation and the ages of its members. 
Ireland Action plan for housing and homelessness aims to provide 50,000 new social housing units over five years.

Lack of access to adequate housing is also recognised in the EU conceptions of social exclusion and poverty. The 'European Platform Against Poverty' initiative describes poverty in the following way:

Poverty in its multiple dimensions includes a lack of income and sufficient material resources to live in dignity; inadequate access to basic services, such as healthcare, housing and education; labour market exclusion and poor-quality work. (EU 2010, p.6).

\subsubsection{OECD measure of quality of life}

Another international attempt to measure and monitor housing quality is the OECD's 'Better Life Initiative'. Using the 'Framework for measuring well-being and progress' across OECD countries (OECD, 2011; 2013). The OECD Better Life Index identifies several dimensions on which country performance is evaluated which are combined into an aggregate score; housing, income, jobs, community, education, environment, civic engagement, health, life satisfaction, safety, and work-life balance. All dimensions are given equal weighting. The indicators of housing included in the index include housing expenditure, rooms per person and households without basic facilities. The OECD How's Life 2020 report includes housing measures like over-crowding and affordability. In the OECD report, Ireland recorded an average score (close to the overall OECD average) in affordability, and a low score for overcrowding compared to other countries (OECD, 2020).

\subsubsection{Eurofound - European Quality of Life Survey}

Similar to the OECD Better Life Index and reports, the Eurofound European Quality of Life Survey focuses on the well-being of individuals. The framework (Eurofound, 2017) stresses the importance of including housing indicators due to the profound effect housing has on quality of life. The quality-of-life framework focuses on eight broad dimensions; material living conditions, health, education, leisure and social interaction, economic security, physical activity, governance and basic rights, and natural and living environment. These dimensions are then broken down into topics and indicators. The framework combines both 
objective and subjective measures of housing such as housing structure issues, overcrowding and subjective satisfaction with the accommodation. Eurostat highlights the need for both types of measures as 'objective situations and subjective perceptions combine to determine an individual's well-being' (Eurostat, 2020).

\subsubsection{EHRC UK}

The EHRC Measurement Framework for Equality and Human Rights, developed in 2017, is a framework to monitor social and economic rights in the UK. Although housing is not listed as a separate domain within this framework, it is considered a core indicator within the living standards domain. The framework lists several sub-indicators/topics of housing which include homelessness, over-crowding and suitable accommodation, housing tenure and housing benefits. As this framework concentrates on human rights and equality, there is a focus on disaggregation of the data on the protected grounds of discrimination; this disaggregation is not present in many of the other frameworks considered. Capability is a core concept in the UK EHRC framework (EHRC, 2017; Burchardt and Vizard, 2011).

Consequently, there is an emphasis on individuals' opportunity to exercise their own choices and the inclusion of subjective as well as objective indicators, which will also be incorporated into the set of indicators for Ireland.

\subsubsection{Lessons from existing frameworks}

In the following chapter we draw on these frameworks to devise a set of indicators for monitoring the right to adequate housing in Ireland. While the ICESCR provides us with a set of dimensions to be covered from a human rights perspective, equality monitoring and social indicator monitoring frameworks highlight dimensions that statistical analysis has found to be strongly related to an underlying concept of social inclusion or standard of living and to the well-being of members of society. The importance of disaggregating across social groups is central to both approaches. Some frameworks for measuring adequate housing,

such as the OECD's framework for measuring well-being and progress, combine indicators to a single index, while most retain individual items. One disadvantage of composite indicators is that they are less transparent about what exactly is being measured. A second is that they can conceal or misrepresent important trends within the individual measures. We argue that a single metric for Ireland would be unhelpful in terms of reflecting different aspects of adequate housing, as it is a complex and multi-dimensional concept. 
These existing frameworks also provide insight into the criteria needed to evaluate potential indicators for monitoring purposes. We spell out these methodological lessons in Chapter 2.

\subsection{EQUALITY AND NON-DISCRIMINATION IN IRISH LAW}

As this analysis is framed in terms of equality monitoring and human rights-based approaches that emphasise the principle of non-discrimination, it is important to describe the legal context in Ireland and the protected groups that the study should seek to monitor. In addition, while Ireland has committed to international treaties, given the dualist legal system by virtue of Article 29.6 of the Constitution of Ireland, international agreements such as ICESCR are not part of domestic law unless made so by the Houses of the Oireachtas.

In Ireland, protection against discrimination in access to housing and services is provided for by the Equal Status Acts (2000-2018). Discrimination is prohibited under these Acts across ten grounds: gender, age, sexual orientation, race/ethnicity/nationality, disability, religion, family status, civil status, membership of the Traveller community and it is now prohibited to discriminate against those in receipt of housing assistance, rent supplements or social welfare payments. Receipt of housing assistance, rent supplements or social welfare payments was introduced as a protected ground on 1 January 2016 under the Equality (Miscellaneous Provisions) Act 2015. This was introduced to prevent landlords from refusing to rent to individuals solely because they were low-income households and were receiving social housing support.

Discrimination is broadly defined as being treated unfavourably due to a person's membership of one of the ten grounds mentioned above. The Acts address direct discrimination, indirect discrimination, discrimination by association and discrimination by imputation. Direct discrimination is where an individual is treated worse than another in the same situation due to any of the ten grounds mentioned above. Indirect discrimination refers to practices or conditions which do not overtly seem discriminatory but have discriminatory impacts. Discrimination by association can be described as being unfavourably treated due to a person's association with another person. Discrimination by imputation is when an individual is treated less favourably because they are believed to belong to one of the categories covered under the ten grounds. Under these Acts discrimination is prohibited across the aforementioned grounds in relation to: 
selling a property, making or ending a tenancy agreement, providing accommodation or any related service or amenity or ending the provision of accommodation (IHREC, 2015, p.20).

Available research indicates, however, that despite introduction of this ground under the Equal Status Acts, discrimination due to housing assistance may be difficult to prove and therefore continues to occur in the context of a highly competitive housing market (Hearne and Walsh, forthcoming).

\subsection{KEY IRISH HOUSING POLICY DEVELOPMENTS?}

The most recent housing policy in Ireland is set out in Rebuilding Ireland Action plan for housing and homelessness published in 2016. The plan consisted of five pillars to tackle the housing shortage in the country comprising:

- addressing homelessness by increasing rent supplements and housing assistance payment, providing new housing supply, and enhancing supports for the homeless;

- accelerating social housing with 47,000 social housing units to be delivered by 2021 ;

- building more homes with 25,000 units to be delivered every year from 2017-2021;

- improving the rental sector by introducing an affordable rent scheme and encouraging 'build to rent';

- utilising existing housing by purchasing vacant housing held by financial institutions and regeneration initiatives.

Tackling the housing crisis by utilising vacant properties is also covered under the Vacant Housing Reuse Strategy 2018-2021 which includes a vacant site levy of 7 per cent (from 2019) to incentivise the development of land. Ensuring the delivery of social housing is addressed under the Urban Regeneration and Housing Act 2015. Under Part V of this Act, 
10 per cent of housing units in new developments are required to be set aside for social housing. ${ }^{8}$

There are other policy measures which have been introduced in recent years which seek to address affordability in housing. For example, to address the rising costs of rent, the government introduced Rent Pressure Zone legislation through the Planning and Development (Housing) and Residential Tenancies Act 2016. Rent Pressure Zones (RPZs) are designated areas where the cost of rent cannot increase by more than 4 per cent a year. RPZs are implemented in the parts of the country where rents are highest and where affordable accommodation is the most lacking, such as cities and large towns. In December 2016 Cork City Council, Dublin City Council, Dún Laoghaire-Rathdown County Council, Fingal County Council, and South Dublin County Council were designated as RPZs. By September 2020, an additional 50 LEAs and County Councils were designated as Rent Pressure Zones. ${ }^{9}$

The Residential Tenancies (Amendment) Act of 2019 further provided the RTB with powers to 'investigate and sanction landlords who engage in certain breaches of rental law'. Investigations happen through formal complaints to the RTB or proactive decisions by the board. Breaches of the Act can result in formal cautions or fines of up to $€ 15,000$.

Further, the affordability of housing is central to the recently published Affordable Housing Bill $2021^{10}$ which includes several measures, including the roll-out of cost rental housing, with 400 such homes expected in 2021. Cost rental housing relies on a model where 'rents cover only the incurred costs of a stock of dwellings, rather than the current market value of the property' (NESC, 2020). In the chapters that follow, key elements of housing policy are discussed, and outputs measured (e.g. spending on social housing, housing assistance payments).

Further information on the Part V scheme is available here https://www.gov.ie/en/publication/3279c-socialhousing-strategy-2020/.

9 A full list of rent pressure zones, and their year of designation is available here https://www.rtb.ie/during-atenancy/rent-review-in-a-rent-pressure-zone-rpz/where-are-rent-pressure-zones. For an area to be designated an RPZ the average rent in the previous quarter must be above the average national rent in the relevant reference area and the annual rate of rent inflation in the area must have been 7 per cent or more in four of the last six quarters.

10 More information about the bill is available here: $\mathrm{https} / /$ www.gov.ie/en/press-release/a8178-minister-obrienwelcomes-cabinet-approval-for-the-publication-of-affordable-housing-bill-2021/. 


\subsection{HOUSING IN NATIONAL EQUALITY STRATEGIES}

Ireland also has a number of national equality strategies that aim to address the needs of specific protected groups and to tackle structural inequalities. Those with disabilities are the only protected equality group that has a specific housing strategy published by the government. The National Housing Strategy for People with a Disability 2011-2016 vision is to:

facilitate access, for people with disabilities, to the appropriate range of housing and related support services, delivered in an integrated and sustainable manner, which promotes equality of opportunity, individual choice and independent living.

Although initially intended to expire in 2017, the strategy was extended to 2020 to deliver on its aims.

Housing is relatively unaddressed in national equality strategies, with the exception of the National Traveller and Roma Inclusion Strategy 2017-2021 which covers multiple dimensions of adequate housing such as access, cultural adequacy, and affordability. The strategy's objectives include the provision of 'accessible, suitable and culturally appropriate accommodation' for Travellers; access to 'targeted financial services' for accommodation such as the caravan loan scheme as well as expenditure of all funds allotted for Travellerspecific accommodation.

Other strategies such as the Migrant Integration Strategy 2017-2020, National Strategy for Women and Girls 2017-2020 and National Youth Strategy 2015-2020 do not specifically mention housing. However, they do discuss equal access to services. The LGBTI+ National Youth Strategy 2018-2020 also discusses this facet of adequate housing, specifically mentioning the urban/rural divide in the provision of and access to services. The strategy notes that young LGBTI+ people outside of Dublin have significantly reduced access to services compared to those inside Dublin. 


\section{COVID-19 Housing Policy Responses}

A number of housing-related policies were introduced during the COVID-19 crisis in Ireland in order to mitigate the economic and social impact of the pandemic. The Government introduced two main emergency measures to protect tenants at the beginning of the pandemic: rent freezes and eviction bans. Both measures were introduced for an initial period of three months beginning 27 March but have since been extended and apply to all forms of rental accommodation. Under the Residential Tenancies Act 2020 an eviction ban is automatically introduced anytime movement has been restricted to 5 kilometres under COVID-19 guidelines (Citizens Information, 2021b). If an eviction notice has been served, it is temporarily paused while said restrictions are in place and for a further ten days after they have been lifted. Under the rent freeze policy, valid rent increase notices did not take effect; however, as of 2 August 2020, rent increases were allowed to be implemented for those not financially impacted by the crisis. At the time of writing, rent increases were not permitted before 13 July 2021 for those who have been financially impacted by the pandemic (ibid).

In addition, Irish banks and non-bank mortgage owners agreed 'an industry-wide payment break framework in early March 2020' due to COVID. These payment breaks lasted for up to six months (Gaffney and Greaney, 2020). Mortgage breaks for Local Authority mortgages were also introduced for those unable to pay their mortgage due to COVID. This break was initially introduced for three months but has been extended three times to allow individuals who continued to struggle meeting payments to take four breaks up to a total of 12 months (Rebuilding Ireland Home Loan, 2021).

COVID-19 health measures that have temporarily closed down building sites have led to a significant shortfall in house building. The latest ESRI estimates suggest that only 15,000 houses will be completed in 2021 and 16,000 in 2022, well below the projected demand which is likely to put increased pressure on house prices (McQuinn et al., 2021).

\subsection{STRUCTURE OF REPORT}

The rest of the report takes the following form. In Chapter 2 we describe the methodology and principles used to select and measure the indicators of adequate housing for the monitor. This includes a discussion of the consultation process carried out. Chapters 3 to 8 address each of the dimensions of adequate housing. Each chapter sets out the indicators selected, the data sources used and the analytical approach. Aggregate level (or macrolevel) indicators set the scene for the population as a whole and then individual-level indicators are disaggregated across as many of the protected groups as is possible using the most recent data available. Chapter 3 begins with the dimension of housing access. Chapter 4 addresses affordability, Chapter 5 security, Chapter 6 cultural adequacy, Chapter 7 housing quality and Chapter 8 location and neighbourhood quality. In Chapter 9 
we summarise the findings on access to adequate housing in Ireland across these six dimensions identified in international rights frameworks and in social indicators research. We examine which groups are least likely to have access to adequate housing. We also evaluate the strengths and limitations of this monitoring exercise and the efforts needed to improve monitoring. Finally, we appraise the progress Ireland has made towards realising the housing rights envisaged in the international standards. 


\section{CHAPTER 2}

\section{Methodology}

This chapter presents our methodology, the dimensions and indicators selected and the rationale behind their selection based on a review of existing monitoring frameworks and consultation with relevant stakeholders (Section 2.2). We describe the dimensions and indicators in detail (Section 2.3), their data sources (Section 2.4), and the context measures which frame these indicators (Section 2.5). We also discuss the equality groups which we use throughout the analysis (Section 2.6), and how these groups are defined and measured in the relevant datasets. Finally, we outline the analytic strategy of the report (Section 2.7), commenting on the strengths and limitations of the monitoring approach.

\section{$2.1 \quad$ INDICATOR SELECTION}

The first step in the selection of indicators for monitoring adequate housing was to compile a 'longlist'. These were informed primarily by the ICESCR and the UN's report on the Right to Adequate Housing. ${ }^{11}$ We grouped these indicators under six dimensions of adequate housing, which were similar to the dimensions outlined by the UN. The dimensions are; access, affordability, cultural adequacy, security of tenure, housing quality and location. As noted in the previous chapter the 'housing quality' dimension combines two of the ICESCR dimensions of habitability and availability of services, as the services mentioned refer to household utilities such as access to sanitation, heating, etc.

Several important principles and considerations were used to compile the longlist (see McGinnity et al., 2021 for further discussion). Firstly, the indicators must be robust and valid, in other words they measure what they set out to measure, are unbiased and can be used over time. Secondly, as a key element of the monitor is the comparison of outcomes for groups protected from discrimination in Irish legislation, the monitor must include indicators that are measured at the individual level and can be disaggregated by key characteristics. Thirdly, to effectively monitor the realisation of the right to adequate housing in Ireland, the indicators should be chosen to allow change over time to be tracked. 
This not only allows the measurement of progression or regression in housing adequacy but also overcomes some of the shortcomings of indicator measurement. Even if a given indicator is imperfect, if it is measured consistently it will detect important changes. ${ }^{12}$ The indicators should also be as up-do-date as possible to reflect the current situation, though we recognise the inevitable time-lag in data collection and production. Finally, the indicators need to be meaningful for rights holders and a general audience. For a monitor to be useful, its findings must be communicable and salient for researchers, policymakers, the general public, civil society organisations including NGOs and those involved in data collection (Burchardt, 2017).

In total we compiled a longlist of 27 individual-level indicators (Table A2.1) based on existing data sources in Ireland. They derive from national surveys that are collected at repeated intervals, using validated questions and robust random sampling methods (or complete Census). While some indicators might be relevant across multiple dimensions, each indicator was included only once under their main dimension of interest. For example, high housing costs could be an indicator for affordability or security or access. However, we only list this measure under affordability to avoid listing indicators multiple times. We then used the longlist of indicators in the consultation process to gain insight and feedback from key stakeholders.

\subsection{STAKEHOLDER CONSULTATION}

In order to ascertain the views of stakeholders a consultation process was set up. The consultation took place in person at the ESRI on 3 March 2020. We invited 37 individuals and organisations, and participants were selected as representatives of key groups including NGOs, academics, researchers, legal experts, and policymakers involved in key housing issues. We included participants representing the following social risk groups; those experiencing homelessness, people with a disability, Travellers and Roma communities, migrants, refugees, young people and students, Local Authority and social housing tenants, private rental tenants, women, lone parents, those in long-term care, older people, rural dwellers, and those living in poverty. Table A2.3 in the Appendix lists the organisations that 
attended this consultation. We encouraged those who could not attend the meeting to participate via email or telephone. Follow-up one-to-one consultations were undertaken with the Department of Housing, Local Government and Heritage and The Housing Agency.

We began the consultation with a presentation on the project's objectives and its conceptual background, including an outline of the ICESCR framework and the human rights and equality approach to monitoring. We also described the participants' tasks.

Thirty participants attended the consultation, they were split into six groups and given three tasks to complete within groups. A note-taker was assigned to each table and each group selected one member to act as the facilitator. The first task asked respondents to discuss what the right to adequate housing meant to them or to the organisation that they represented, and whether the ICESCR principles cover the relevant dimensions of adequate housing. We also provided participants with a hard copy of the ICESCR definition of housing adequacy (as described in Chapter 1) as well as a list of the protected groups in Irish equality legislation.

The second task asked respondents to choose their top ten indicators of adequate housing from a list of 27 choices across six domains. The information sheet also listed the data source for each indicator, the date of the most recent data, frequency of data collection (e.g. annual, every five years) and the range of equality groups that each indicator could cover (see Appendix Table A2.1). For the final task, we asked groups to choose their top five context indicators or national indicators for adequate housing (Table A2.2). We also gave each group the option to add indicators that they believed were important but missing from our summary. The consultation ran for three hours.

\section{Key lessons:}

1. Participants emphasised that it is important to add a right to housing into the Constitution of Ireland. The rationale for this view was that it would increase people's ability to take legal cases in the courts, and would increase the obligations 
that public and private bodies have to vulnerable groups. Currently there is no right to housing in Irish law.

2. Participants noted that certain groups were missing from the data and therefore could not be included in the monitoring exercise. These groups include Roma, Travellers, people leaving care, those in institutions, those in domestic violence refuges, students, and 'couch surfers'.

3. Participants felt that the available indicators for 'security of tenure' and 'cultural adequacy' did not adequately capture these domains.

4. Participants emphasised the importance of building sustainable communities and neighbourhoods and not just houses. For this to happen, there would need to be a bigger emphasis on housing security. Such security would prevent excessive housing transience.

\subsection{INDIVIDUAL-LEVEL OUTCOME INDICATOR SELECTION}

This section briefly introduces each outcome considered in the report. Participants debated the indicators extensively, and while we cannot include all the feedback received during the consultation, it is important to note that the indicators used throughout were chosen with a broad consensus. The participants were presented with the indicators across the six dimensions of housing quality and each group was asked to select their top ten indicators. Their rankings and the broader discussion recorded by the note-takers were taken into account in the final indicator selection.

In the next section we discuss each dimension and the indicators chosen by participants. Details on the precise measurement of the indicators are outlined in the relevant chapters. Importantly, we analyse these indicators at the individual level. While some indicators are collected at the household level, and while some reports discuss group differences in the characteristics of the head of the household, we are broadly interested in group differences at the individual level, and so we focus on these throughout. 


\subsubsection{Access to housing}

There was a clear consensus that access to housing is a key dimension of adequate housing and an important starting point in the discussion of housing rights. Three individual-level indicators were selected; homelessness, housing tenure (homeownership, private rental, and Local Authority housing), and housing waiting lists.

Previous research on housing inequality analysed homelessness using statistics from the Irish Census (Grotti et al., 2018). There was a clear preference among consultation participants to use more up-to-date information than available in the Census, we therefore use monthly homelessness figures collected by the Department of Housing, Local Government and Heritage ${ }^{13}$ as the source. These data are produced by Local Authorities through the Pathway Accommodation and Support System (PASS). The people and families counted in the reports are in State-funded emergency accommodation. The information in the reports is limited but allows us to isolate gender and age differences in the homeless population. We are also able to look at the number of homeless families in the data. Importantly, this data source does not consider rough sleepers and does not include hidden homelessness, the homeless population which is staying with family or friends. It also does not include those who are residing in domestic violence refuge accommodation, which comes under the remit of Tusla - the Child and Family Agency.

The second indicator selected was housing tenure. This information is available annually in the Survey on Income and Living Conditions (SILC) which distinguishes between those who own their own home (outright or with a mortgage), those renting in the private sector (those with a reduced rent or a market rent, but not Local Authority rent), and those renting from Local Authorities. ${ }^{14}$ Importantly, this measure of tenure is self-defined, and there may be errors in reporting (see Chapter 3). However, these are the most up-to-date data on individual housing tenure available. Later we will show that our estimates of the private rental market using SILC, LFS, and Census data are very similar.

Monthly reports on homelessness can be found here https://www.gov.ie/en/collection/80ea8-homelessnessdata/.

Homeownership is one of the agreed Zaragoza indicators of migrant integration and as such is included in the Integration Monitor that is published bi-annually by the ESRI (McGinnity et al., 2020). 
The third indicator examines the characteristics of those are on the housing waiting lists. Here we draw on summary statistics from the Summary of Social Housing Assessments (SSHA) annual report. This report is produced by the Housing Agency using data collected by the CSO. Importantly those who are in receipt of Housing Assistance Payment (HAP) are not included, since this group is removed from the social housing waiting list, regardless of their housing preference.

Participants also noted that previously there was a clearer understanding of what 'being housed' meant but this definition has been 'breaking down' for some time because of the shift from social housing to subsidies for renting in the private rental sector. There was a sense that the housing system was providing temporary accommodation, instead of housing security, for a significant portion of the population.

\subsubsection{Affordability}

When discussing the affordability domain, we rely on three indicators: the proportion of individuals living in households that spend more than 30 per cent of income on housing costs and who are in the bottom 40 per cent of the income distribution (the '30/40 rule'); the proportion of households who are below the poverty line when housing costs are deducted from income; and the proportion of individuals with rent and mortgage arrears over the last 12 months. Each of these is available in the SILC dataset. Details on how these measures are constructed are in Chapter 4.

\subsubsection{Sufficiency and cultural adequacy}

Regarding sufficiency and cultural adequacy, participants agreed that this domain was important, but noted that the proposed indicators were insufficient, especially for differences between the Traveller population and the wider population. They said that the subjective indicator regarding satisfaction with the home had potential, as did measures of housing types used to accommodate Traveller communities. Other questions about the need for renovations in a home and housing suitability more broadly were not favoured by stakeholders.

Participants discussed the challenges of measuring this domain more broadly, focusing on three indicators; tenure types in the Traveller community, drawdown of Traveller 
accommodation funds, and numbers in Direct Provision. Data availability was noted as a key issue. We rely on several sources for these indicators. For Traveller community accommodation, we rely on the Census, as well as annual reports from the Department of Housing, Local Government and Heritage. ${ }^{15}$ For drawdown of funds, we rely on relevant reports from the Department of Housing, Local Government and Heritage. For statistics on Direct Provision, we use statistics from multiple sources. For 2009-2018, we use data provided by the Department of Justice and Equality. For 2019 we use data available at the Oireachtas website. For end of July 2020, we use data from the Day Report (Government of Ireland, 2020, Annex 3).

\subsubsection{Security}

Each group agreed that security of tenure was an important domain but felt that the available individual-level indicators did not capture it sufficiently. Some groups felt that the indicator capturing a subjective sense of security was adequate, but others pointed out that it only focused on insecurity caused by affordability problems, rather than a wider sense of insecurity in the home. Two groups suggested using data from the RTB to look at forced evictions or the average length of tenancies. This provides information at the national level but cannot be disaggregated to compare the experiences of different equality groups, it is therefore included as an aggregate indicator (see below).

We include people's length of tenure in years and the respondent's subjective sense of housing security. The first measure is taken from the SILC dataset. Although this measure is 'right-censored' (that is the person's tenure is ongoing when they answer the question, and we do not know how long current tenure will last) and correlated with age (older respondents will build up more tenure than younger respondents), group differences in this measure can still inform us about potential disadvantages in the housing market.

The second measure is from the European Quality of Life Survey (EQLS), where Ireland regularly features. It considers a respondent's subjective sense of security, asking, 'How likely or unlikely do you think it is that you will need to leave your accommodation within 
the next six months because you can no longer afford it?'. Those who strongly agreed or agreed with the statement were given a value of 1 ; those who disagreed or neither agreed nor disagreed were given a value of 0 . One issue with the measure is the that the sample size for Ireland $(\mathrm{N}=1,000)$ is considerably smaller than in the other data sources. As we will show, only a small group of respondents agree with this statement, making it particularly difficult to find group differences.

When discussing security of tenure, the consultation participants noted that eviction was just one phase in a cycle of insecurity; repossession and the legal process tied to repossession were also important in contributing to insecurity. Given that eviction is a trigger to homelessness, differences in security could lead to clues about groups which are potentially vulnerable in the housing market.

\subsubsection{Housing quality}

The SILC dataset contains seven indicators related to housing quality. These covered structural issues (damp/leaks, dwelling too dark), and facilities such as double glazing, sanitation, central heating, inability to keep the house warm, and households who had to go without heating and furniture. Some participants suggested splitting this domain into two separate sections, with habitability and quality as one domain and facilities as a separate domain. They also believed that certain indicators, such as access to flushing toilets, were outdated.

Given the lack of agreement on these measures, the research team adopt an index of housing quality that has been used in previous research (Grotti et al., 2018). This index consists of four items of housing deprivation; leaking roof/damp/rot, lack of central heating, lack of double glazing, and issues with light or darkness. Previous analysis found that these items loaded onto one factor, indicating they capture the same underlying concept, and were related to measures of income and housing type.

Further, we include a measure of fuel poverty, that is households who cannot keep their home 'adequately warm'. Finally, we include a measure of over-crowding. Households with greater than one person per room are counted as over-crowded (see Chapter 7 for details). 
This measure also featured in previous housing reports (Grotti et al., 2018), however here we use Census 2016 data and not SILC.

\subsubsection{Location and access to services}

While fewer groups rated the location and access to services domain as important, almost all groups agreed that the safety indicator was crucial, as individuals should feel safe in their neighbourhood and at home. The indicators which looked at the availability of clean water and sanitation were not considered useful by participants given the universality of these services. Instead, the participants focused on two measures; whether people have easy access to a range of services and whether people feel safe walking alone after dark. These consisted of an index of access to local services and a subjective question of whether respondents feel safe walking home at night. Both measures are from the EQLS 2016.

Access to local services is an index of multiple measures. Respondents are asked the following question 'Thinking of physical access, distance, opening hours and the like, how easy or difficult is your access to the following services?' They are presented with six different services: banking; public transport; cinema, culture, or theatre; recreational areas; grocery stores; and recycling services. We consider the rate of respondents who have difficulty accessing recreational areas, supermarkets, banking, or public transport, but not the cinema/culture/theatre or recycling as stakeholders felt these were not essential. The second measure is also from the European Quality of Life Survey. It asks respondents whether they agree with the following statement 'I feel safe when I walk alone in this area after dark', this is also converted into a rate, focusing on those who agree with the statement.

\subsection{DATA SOURCES FOR OUTCOME INDICATORS}

The indicators above come from two main sources, the CSO's Survey on Income and Living Conditions (SILC), and Eurofound's European Quality of Life Survey (EQLS). Additional indicators are taken from sources like the Census and Department of Housing, Local Government and Heritage Homeless Statistics. Table 2.1 outlines the selected dimensions discussed above, the related indicators, and the data sources used to measure these. Most of the outcome indicators in this report come from survey data. Survey data have an important advantage in that they are representative of the population in Ireland. This 
means differences can be generalised to the wider population. However, one issue with such datasets is that they rarely measure the LGBT community, racial minorities, or other equality groups relevant to our report.

SILC is an annual survey of private households administered by the CSO under EU legislation for the purpose of providing information on income and living conditions. To increase the number of observations, we consider both 2018 and 2019 rounds of data collection together. Participation in the survey is voluntary, it has a sample of over 10,800 respondents in 2018 , and over 10,300 respondents in 2019 . The final number of participants depends on missing values found in each dependent variable; as a result the sample differs slightly depending on the outcome considered. We use survey weights throughout to adjust the sample to population estimates based on age by sex, region, and household composition.

The European Quality of Life Survey is a pan-European study of objective and subjective measures of life quality. It looks at a range of issues such as employment, income, education, housing, family, health, and work-life balance. It also looks at subjective topics, such as happiness, life satisfaction and perceived quality of society. Ireland is a regular participant in the survey. We consider Irish data for 2016 throughout, which is the most recent round available at the time of writing. The survey differs from SILC in that it only considers respondents aged 18 and over. As with SILC, responses are weighted to better reflect the population under study. 
TABLE 2.1 OUTLINE OF DIMENSIONS, OUTCOME INDICATORS AND DATA SOURCES

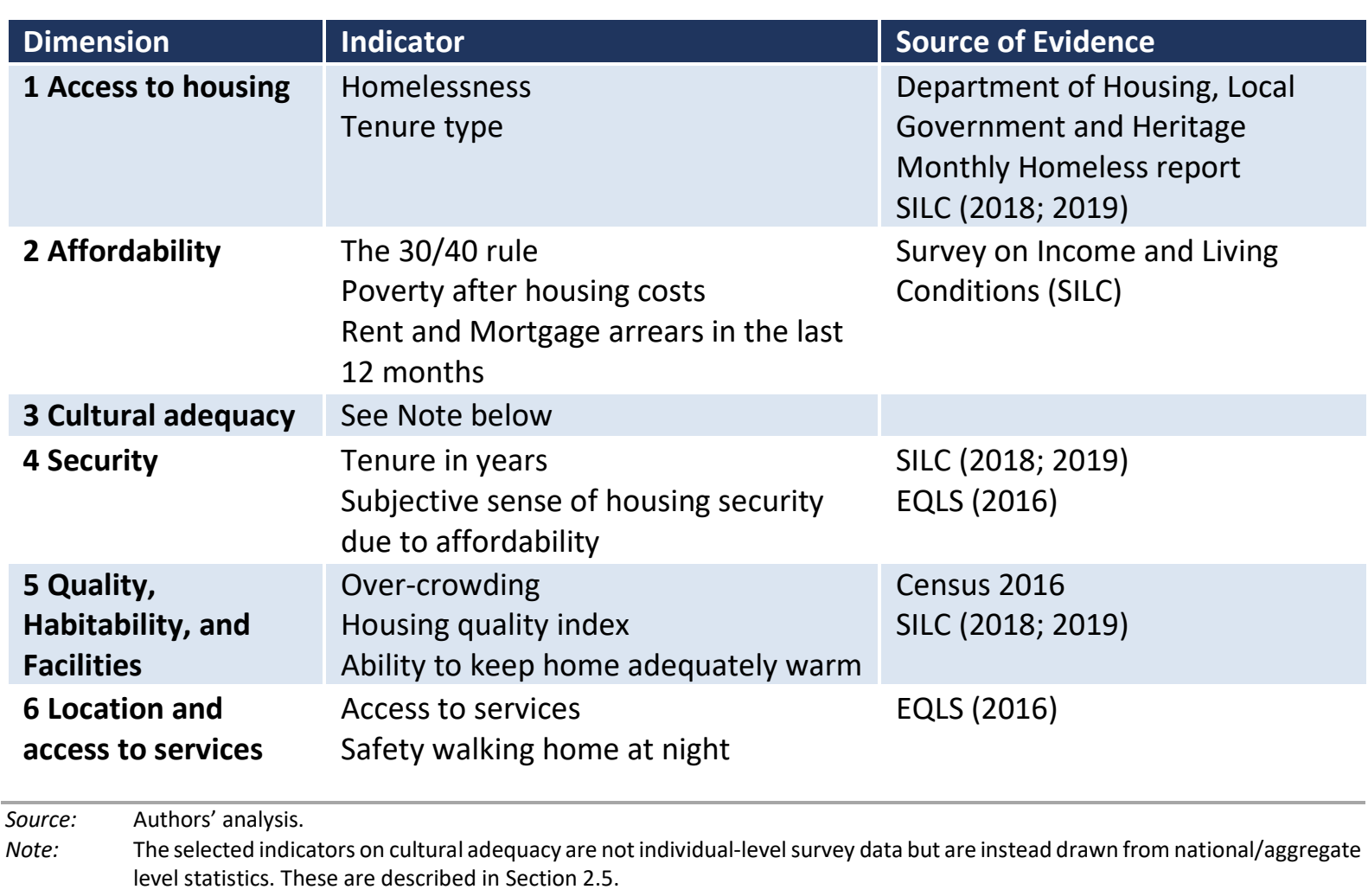

It is important to note that all surveys used (apart from Census data) draw on samples of people living in private housing. Therefore, they exclude those who are homeless, living in Direct Provision centres, or other residential settings. These groups may be particularly vulnerable to disadvantage and discrimination. In order to better include such groups in our analysis, we turn to sources that are different from regular household surveys. For the homeless population, we turn to the Department of Housing, Local Government and Heritage's monthly homeless statistics. ${ }^{16}$ For housing statistics in the Traveller community, we rely on the Census, annual reports from the Department of Housing, Local Government and Heritage, ${ }^{17}$ as well as statistics on the drawdown of funds. For statistics on Direct Provision, we draw from multiple sources, including reports from the Department of Justice and Equality and the Oireachtas website.

In their guidelines on improving the collection and use of equality data, the European Commission (2018) highlights the imbalance in the collection of data across different 
equality grounds. The European Commission specifically recommends including individuals residing in 'institutional settings such as care homes, prisons, asylum reception centres, nomadic people, homeless people and people living in temporary accommodation' in order to obtain more inclusive data. As stated, these populations do not appear in our main sources of data, which are national surveys of private households; we present figures based on administrative data where available.

\subsection{AGGREGATE/CONTEXT INDICATORS}

In addition to outcome indicators which look at micro-level differences between groups, we also present a number of aggregate indicators of housing in Ireland. These indicators are generally measured at the population level and cover issues such as the number of housing completions or spending on housing benefits. ${ }^{18}$ The full list of aggregate indicators we consulted on and how they were ranked by participants in the consultation is presented in Appendix Table A2.2.

In terms of access to housing the report presents two measures; the number of housing completions and the amount of spending on social housing over time. The statistics on housing completions are available from the $\mathrm{CSO}^{19}$ the series is quarterly and available for years 2011 to 2020 .

The data on social housing unit outputs are published by the Department of Housing, Local Government and Heritage. Given the shift in housing policy from direct build social housing to subsidies for renting for low-income households in the private rental sector, we also discuss patterns of spending on housing supports. Figures on housing supports are taken from four sources; data on Rent Supplement are taken from the Annual Social Welfare Services Statistical Information Report 2019; data on Housing Assistance Payments from 2014 to 2018 come from Kilkenny (2019); data for 'Non-Pay related' capital spending for the HAP scheme 2019-2020 come from the Department of Public Expenditure and Reform Databank (Series V34.A.6 Housing Assistance Payment Scheme); and Local Authority spending statistics for RAS come from the Department of Housing, Local Government and 
Heritage statistics report which is titled RAS Current Expenditure Housing Programmes 2011 to 2020 .

Regarding affordability, we include three indicators; average cost of rent over time, ratio of average rental costs to average earnings, and the number of people receiving housing transfers tied to private rented accommodation. For rental costs we use data from the RTB and ESRI Quarterly Rental Index. We relate these costs to average earnings taken from the CSO's LFSEAADS dataset (more information in Chapter 4).

For housing security, we use two indicators. First, RTB statistics on end of lease disputes and the average length of tenancies commenced. We draw from RTB mediation data, which list the number of mediations tied to 'validity of notice of termination' and 'unlawful termination'. We will also consider statistics on the number of terminations issued by landlords to tenants. These data run from Q2 2019 to Q3 2020. Prior to this, landlords were not required to notify the RTB if a notice of termination was issued. Second, figures on mortgage default numbers, including evictions or repossessions are considered. For this we focus on mortgage arrears and repossessions among principal dwelling houses and Buy to Let agreements, as recorded by the Central Bank.

On cultural adequacy, participants stressed the importance of the two suggested indicators on Travellers' housing: drawdown funds for Traveller accommodation by Local Authorities, and the proportion of Travellers living in different types of accommodation. Both sets of statistics are sourced from the Department of Housing, Local Government and Heritage. The number of people in Direct Provision was selected by one of the groups in the consultation and has been included in the monitor because of concerns about the system from a human rights perspective by the UN Committee on the Rights of the Child (2016) and IHREC (2019). The data on Direct Provision have multiple sources. For 2009-2018, we use data provided by the Department of Justice and Equality. For 2019 we use data available at the Oireachtas website. For end of July 2020, we use data from the Day Report (Government of Ireland, 2020, Annex 3).

Finally, though no aggregate-level indicators for housing quality or location/access to services were selected by stakeholders in the consultation, we select one indicator for each that can be tracked over time. Firstly, we select the age of housing stock in Ireland using 
Census data, as previous research has shown this to be correlated with housing quality at the aggregate level. Secondly, we report the proportion of private households with access to three basic services; piped water, sewerage facilities and internet access (broadband access). Again, this is drawn from Census data.

\subsection{DEFINING EQUALITY GROUPS}

Access to housing is a fundamental human right, one that is protected under international instruments such as the United Nations Universal Declaration of Human Rights and the Council of Europe European Social Charter. Currently, the Irish Constitution does not recognise the right to housing. Adequate housing is also necessary for the achievement of other basic rights such as health and family life. It is central to the well-being of adults and children alike. In Ireland, discrimination in the provision of housing is prohibited under the Equal Status Acts (2000-2015). These acts prohibit discrimination in the provision of accommodation on ten grounds. These grounds are the basis of the equality groups that this study measures; gender, age, sexual orientation, race/ethnicity/nationality, disability, religion, family status, civil status, membership of the Traveller community and receipt of housing assistance, rent supplements or social welfare payments. It is currently not possible to bring a case to court on discrimination on the grounds of social class or social origin, although amending the legislation to introduce socio-economic status is under consideration at present (Government of Ireland, 2020), so it is also considered here. We do not consider those in receipt of housing supports as a separate group in the analysis, as receipt of such supports is closely tied to the issues of affordability and access, which we include as outcomes. Our goal is to explore housing outcomes for a range of equality groups, where possible and appropriate to measure.

There are two main limitations to this goal. First, due to small numbers in certain categories, some groups have been simplified. For example, nationality groups are often collapsed into Irish, EU, and non-EU respondents. This is an issue given that non-Irish nationals are a diverse group in terms of resources, labour market outcomes, and occupational attainment (McGinnity et al., 2020b), as are ethnic groups (McGinnity et al., 2018). Second, for certain key groups data are unavailable and group comparisons cannot be made. Sexual orientation, religion, and membership of the Traveller or Roma community are not measured in any of our sources and therefore we can say little about these groups. Despite 
these two limitations, the remaining groups are available in most datasets; we summarise their availability in Table 2.2.

\section{TABLE 2.2 BREAKDOWN OF GROUPS MEASURED ACROSS DATA SOURCES}

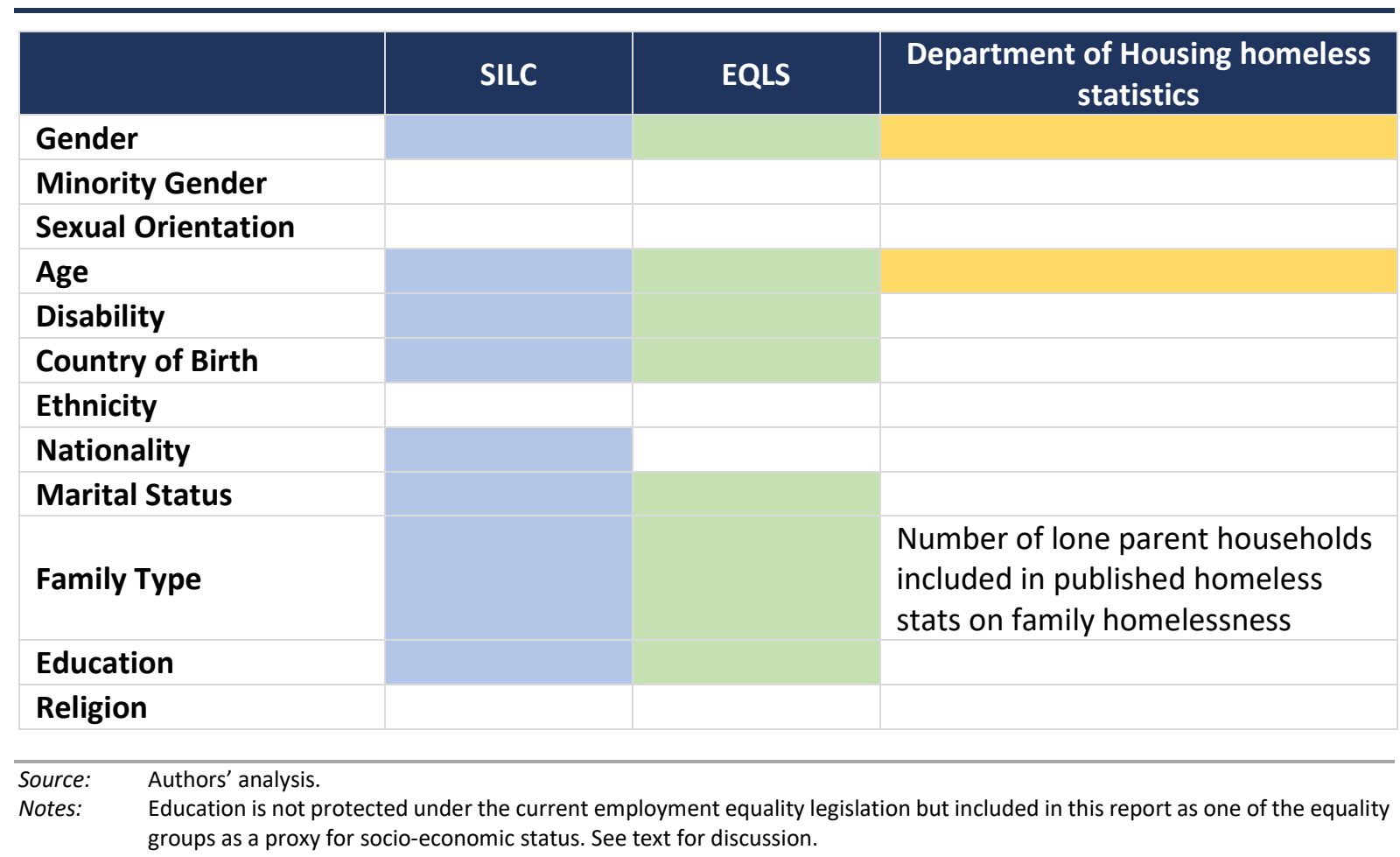

Gender was measured in the same way across all surveys considered, but minority gender status ${ }^{20}$ was not recorded in any of the surveys above. Age was measured in all surveys in the form of date of birth or provision of respondent's exact age. For our purposes we recorded these values into categories, those aged 0-17, those aged 18-24, those aged 25-44, those aged 45-64, and those aged 65+. As mentioned, the EQLS only considers those who are over the age of 18 .

In the SILC dataset disability was measured using a question on general activity limitations. The questionnaire reads 'For at least the last six months have you been limited in activities people usually do, because of a health problem? (If limited, specify whether strongly limited or limited)'. Respondents were asked if they were strongly limited, limited, or not limited. Those with strongly limited or limited ability were considered as having a disability. This measure of disability has been used in previous studies based on SILC (McGinnity et al., 
2021; Watson et al 2017b: Grotti et al., 2017); however it is not ideal due to the alignment of disability with a health problem. In the European Quality of Life Survey disability was measured in a similar way, asking 'Do you have any chronic (long-standing) physical or mental health problem, illness or disability? By chronic (long-standing) I mean illnesses or health problems which have lasted, or are expected to last, for six months or more.' We consider all those who answered yes to the question as having a disability. Subsequent questions in the survey try to capture the severity of this disability, but we do not consider these in our report. Neither survey provides information on the type of disability, ${ }^{21}$ and therefore differences in housing needs within this broad group cannot be identified.

In equality legislation 'race' is a wide category, covering not only race but also colour, nationality or ethnic or national origin. These concepts are rather different. The concept of 'race or ethnicity' is different to the concept of 'nationality' or 'national origins in Ireland', however we will focus mostly on nationality throughout the report, except where limited data on race are available.

For national origin, we use country of birth. Although nationality appears in SILC, this is a binary measure for Irish and non-Irish nationals. Country of birth is measured in both the LFS and EQLS data. In the LFS, country of birth appears as an open-ended question, which is recoded into individual country categories. Due to small cell sizes in certain groups, we re-categorise these into a comparison of people from Ireland, UK, EU-West, EU-East, and Other countries. In EQLS country of birth is measured in a similar way. For comparability, we recode this measure to reflect the same categories captured in SILC, comparing people from Ireland, the UK, EU-East, EU-West, and Other countries.

Marital Status was measured similarly across surveys. In SILC and the EQLS respondents were asked their marital status and given five options. The categories were identical in both surveys. ${ }^{22}$ These were re-categorised into three groups: single, married, and formerly

21 SILC contains a measure of disability and difficulty with limited activity (PH030) and a measure of chronic illness (PH020). We do not consider the measure of chronic illness because it does not consider the extent to which the condition 'limits activity'. SILC's measure of chronic illness does consider specific illnesses such as visual and hearing impairment; however these measures are not mutually exclusive, and the extent of the illness is not known. Previous research has focused on the limited activity measure in SILC (PH030) as noted above. 
married (separated/divorced/widowed). Household composition is measured using six categories; one-adult households, two-adult households, three or more adults, one adult with children aged under 18 (lone parents), two adults with 1-3 children aged under 18 (couple with children), and other households with children. In the EQLS household composition is split into five categories: single, couple, single with children, couple with children, other composition. These groups are broadly comparable for our purposes.

IHREC (2017) recommends including socio-economic status as a separate equality ground, protected under equality law. As noted above, socio-economic status is not yet protected under equality law in Ireland, but introduction of this ground is under consideration in the 2020 Programme for Government. ${ }^{23}$ Article 2(2) of CESCR also recognises the need to protect against discrimination based on social origin. This commitment is also consistent with a long tradition of social research which identifies inequalities based on social origin (Erikson and Goldthorpe, 2002; Bottero, 2005). In common with the monitor on decent work (McGinnity et al., 2021) we use education as a proxy for socio-economic status. ${ }^{24}$

Education was defined in different ways in SILC when compared to the EQLS. In SILC, education was split using the International Standard Classification for Education (ISCED). These were then recoded into a binary measure for those with and without a third-level qualification. In the EQLS, a measure exists capturing those with and without a third-level education.

In both the EQLS and SILC, respondents define themselves as members of equality groups. They may choose not to disclose their gender, age, or other characteristics about themselves, although this is rare. It is also important to note that the equality groups often intersect, and that focusing on the experience of each group separately underplays how these characteristics interact to influence housing outcomes. For example, respondents with

Page 77 of the 2021 Programme for Government reads 'We will examine the introduction of a new ground of discrimination, based on socio-economic disadvantaged status to the Employment Equality and Equal Status Acts.' The programme is available here https://www.gov.ie/en/publication/7e05d-programme-for-governmentour-shared-future/. 
a disability may experience a disadvantage in the housing market, but individuals with a disability and without a third-level education are likely to experience confounding penalties in society which would not be captured in this analysis.

\subsection{ANALYTICAL APPROACH}

We explore group differences in each indicator through secondary data analysis. Given the large number of indicators and outcomes, we will take a descriptive approach throughout the report, in that we will present basic and unadjusted group differences in housing outcomes as they appear the respective datasets.

Given our approach it is important to state that we cannot identify the causes of the relationship between housing outcomes and equality groups. The differences observed are descriptive and may result from multiple mechanisms. For example, nationality differences in homeownership may stem from discrimination, but they may also stem from taste, preference, or differences in income that arise from language or qualification differences. The relationship may be due to a third confounding factor, such as variation in the age profile of nationality groups. In short, non-Irish nationals may be younger, they may have fewer resources, or they may prefer rented accommodation because their stay in Ireland is temporary. We do not try to unpack these differences here, as that is beyond the scope of the project.

We use survey weights throughout the project to adjust responses to the population. Weighted results are presented as bar charts displaying the mean response per group and error bars surrounding these values. These error bars capture 'confidence intervals', i.e. the upper and lower bound range within which we can be 95 per cent confident that the true population value falls.

Confidence intervals indicate whether there are statistically significant differences between various categories within the same group. If there is no overlap between the confidence intervals, the differences between groups are statistically significant. This means that the differences found between groups are not due to chance, and reflect differences found between groups in the population. However, where confidence intervals do overlap, it does not necessarily mean that the differences are not statistically significant, especially where 
the degree of overlap is small. It is important to note that confidence intervals are larger for groups where the sample sizes are small; some differences may not be significant due to the small sample sizes of a given group. In the next chapter we turn to our results which are split one dimension of housing adequacy per chapter. 



\section{CHAPTER 3}

\section{Access to housing}

The most basic indicator of adequate housing is access. Issues of access also influence other dimensions of adequacy such as housing quality, services, cultural adequacy, and security. Problems accessing housing can lead to inadequate or poor-quality housing for some, and homelessness for others. Access to housing is therefore closely linked to other domains, which are examined in later chapters. Similarly, issues of access are often closely linked to issues of affordability; therefore while these concepts are considered separately in the ICESCR and human rights discussions, as well as our report, housing access is indivisible from other domains of adequate housing.

Access to adequate housing is a fundamental human right protected by international conventions such as the Universal Declaration of Human Rights and the European Social Charter. In Ireland, discrimination in the provision of housing is prohibited under the Equal Status Acts (2000-2015). Despite this, there are group differences in overall access to housing and housing type. We explore these differences throughout this chapter. We also present a set of context indicators which show Ireland's pattern of housing provision in the last few years.

\subsection{ANALYTICAL APPROACH}

Across the findings chapters we consider both aggregate level indicators of housing provision and individual-level indicators disaggregated across equality groups. The aggregate indicators can monitor progress toward access to housing at a societal level, while group differences can highlight which groups are experiencing difficulties and deficits in housing. The monitoring approach does not however allow us to identify the underlying mechanisms behind the patterns that we describe, as the focus is on presenting a range of suitable indicators that can be tracked over time rather than an in-depth analysis of one dimension using statistical modelling.

We lack sufficient recent data to analyse housing discrimination across equality groups. These measures are available in certain equality modules of the LFS and QNHS datasets. 
The survey carried out in 2019 has insufficient cases for most groups (CSO, 2019; McGinnity et al., 2021). Previous research drawing on earlier QNHS modules found that younger people $(18-34 ; 35-44)$, those of Black or other ethnic minority background, lone parents and those with a disability were all significantly more likely to report that they had been discriminated against while looking for housing in the preceding two years. These differences persisted even when education and employment status were held constant (Grotti et al., 2018). Travellers were 22 times more likely to report discrimination accessing housing than the settled community (Grotti et al., 2018). Similarly, there is a relatively large body of experimental research (mostly field experiments) which find that certain migrant groups and ethnic minority groups are discriminated against in accessing housing in the US (Ewens et al., 2014; Hanson and Hawley, 2011), and Europe (Andersson et al., 2012; Bosch et al., 2010; Ahmed and Hammarstedt, 2008, Drydakis, 2011; Baldini and Federici, 2011). The first housing discrimination field experiment in Ireland by Gusciute et al. (2020) found that Polish and Nigerian house-hunters were significantly less likely to be called for a viewing than Irish applicants, with Nigerians experiencing greater discrimination than Polish applicants. The authors also found evidence of gender discrimination as men were significantly less likely to be called for viewings than women.

\subsection{AGGREGATE INDICATORS}

This section considers two context indicators which capture trends in housing supply; housing completions and spending on social housing projects.

\subsubsection{Housing and social housing completions}

Housing supply in Ireland has been characterised by extreme volatility since the early 2000 s. Based on CSO statistics of ESB connections, housing completions rose to 80,000 per year at the peak of the credit-fuelled housing boom in 2006-2008 and fell to less than 10,000 completions in 2012 (Grotti et al., 2018). Figure 3.1 presents more recent data on new build housing units from 2011 (Series NDA01, 2011-2019). These figures show that housing output continued to decline during 2012 and 2013. In the period 2011 to 2014 less than 
$7,000^{25}$ units were built in the State each year. This is far below the structural demand for new housing which is estimated to be in the region of 25,000 to 35,000 per year (Conefrey and Staunton, 2019; Bergin and Garcia-Rodriguez, 2020). Housing projections by Duffy et al. (2016) suggest that housing demand will reach just above 30,000 units per year by 2024.

Overall housing completions began to increase from 2015, with apartment completions rising only from 2016. However even this growth in overall supply was well below predicted demand (McQuinn et al., 2017). Further, the onset of the COVID-19 pandemic in Q2 2020 led to a steep decline in housing completions as building sites were closed. The second shutdown of the construction sector in Q1 of 2021 suggests that housing output for 2021 will continue to fall short of demand. This undersupply has significant implications for access and affordability of housing (McQuinn, 2021) and the effect will likely differ for vulnerable groups.

\section{FIGURE 3.1 HOUSING COMPLETIONS (2011-2020)}

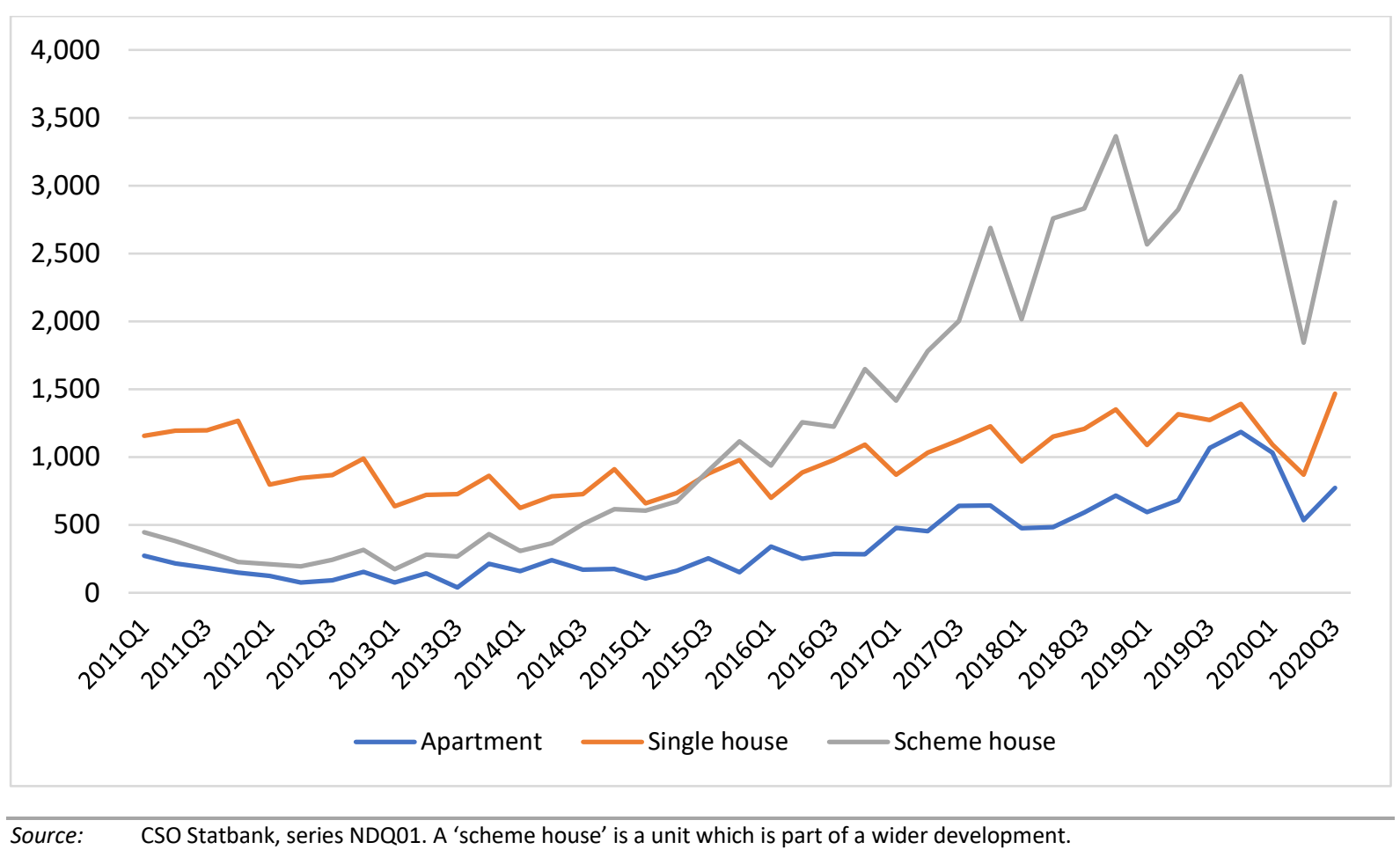
that ESB connection data refer not only to new dwellings but also include 'new connections and reconnections to the electricity network. Thus, it should not be interpreted as the number of new housing completions but rather as the number of ESB connections.' 
There has also been significant change in the supply of social housing in recent years.

Figure 3.2 shows the number of housing units built, bought, leased, or restored since 2004 . Building and acquisition schemes declined dramatically from 2009. Less than 500 new social housing units were built each year between 2011 and 2015. Building resumed in 2016 and increased to 6,000 new builds in 2019. Acquisitions also picked up during this period. This upward trend for all housing units ended abruptly in 2020 with the onset of the COVID-19 pandemic. Leasing has remained steady in terms of producing housing units with little change in output between 2009 and 2019; overall this scheme provides a small but steady number of units to the stock of social housing. Voids and regenerations spiked in 2016 and 2017 in the absence of new builds, these units are the re-use of existing social housing units after periods of non-use or after a previous tenant leaves the unit. Since 2018 their contribution to the social housing stock has become negligible again.

This trend in low social housing provision should also be put in the context of the longerterm shift in housing provision in Ireland. In 1961, 18 per cent of the housing stock was made up of social housing, but by 2016, this figure had fallen to 10 per cent; part of this trend stems from the selling of social housing stock (Grotti et al., 2018).

\section{FIGURE 3.2 SOCIAL HOUSING UNIT OUTPUT (2004-2020)}

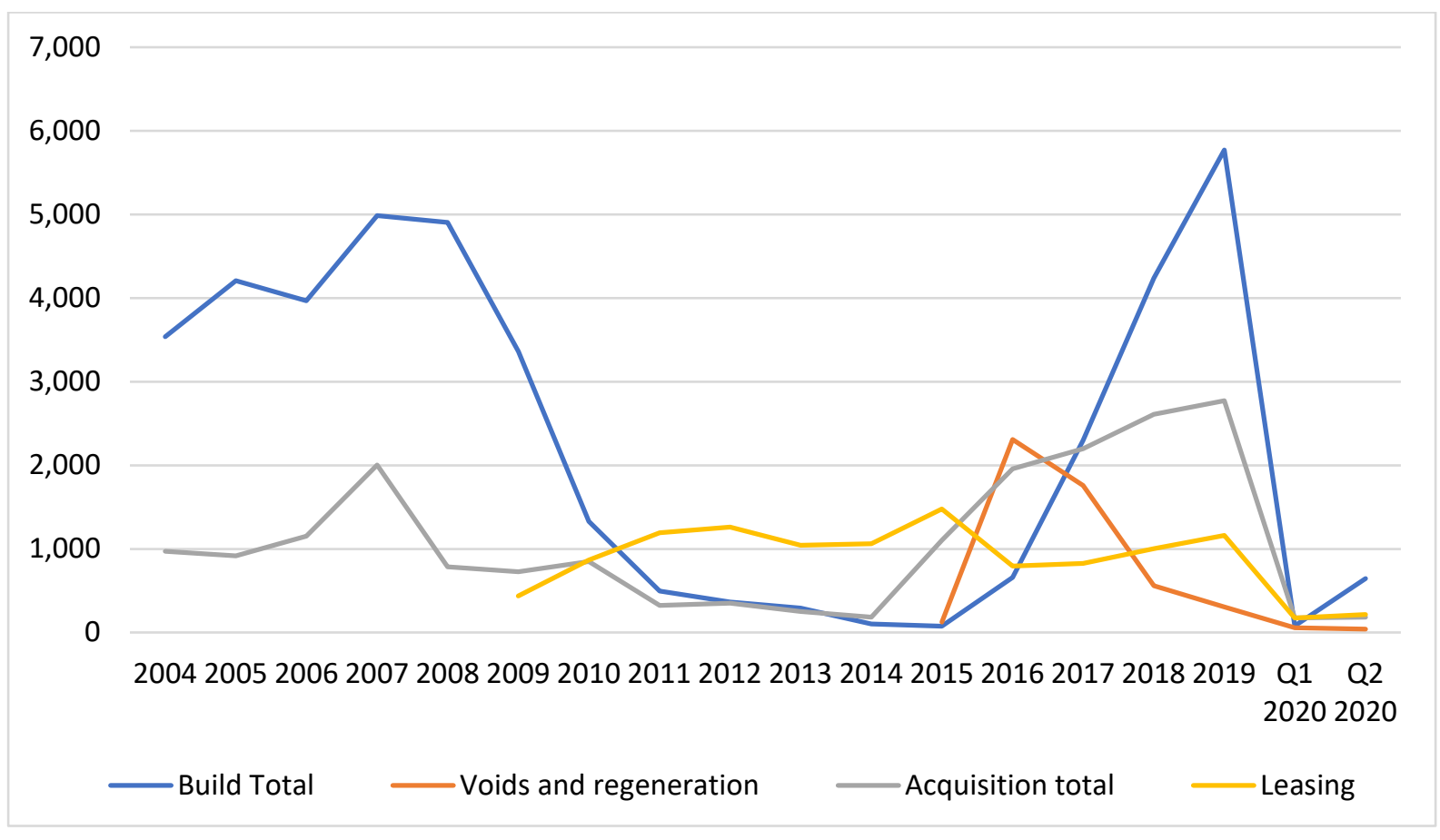




\subsubsection{Spending on housing and social housing provision}

Government investment in housing consists of both capital spending (to build or acquire housing) and expenditure on subsidising housing costs. A similar trend to that in Figure 3.2 emerges when we consider the level of government capital spending on housing provision based on data from the Department of Public Expenditure and Reform Databank. Government capital expenditure on housing was strongly pro-cyclical. Figure 3.3 shows that capital spending on housing increased sharply between 1999 and 2008, before experiencing a precipitous drop. Spending rose again in 2016 and reached previous levels in 2019. ${ }^{26}$ Within this budget there is an allotted amount designated to Local Authority housing. This figure increased from 2012 before falling between 2019 and 2020.

\section{FIGURE 3.3 CAPITAL SPENDING ON HOUSING V34.A (1994-2020)}

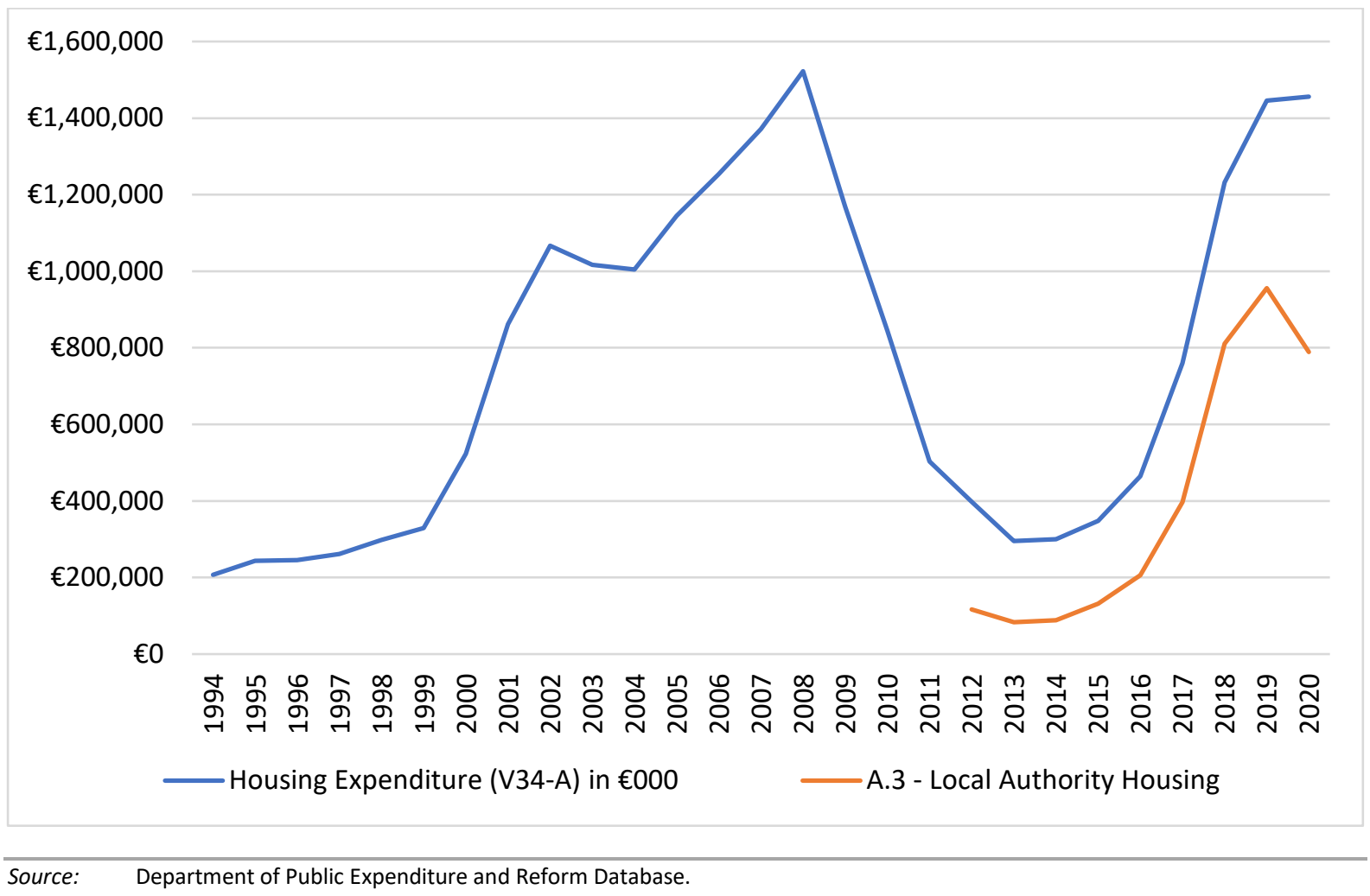

There has been a significant shift in housing policy from provision of social housing to the use of income supports and housing transfers that subsidise rent in the private sector. Figures on government spending on the three main housing benefits, namely Housing 
Assistance Payments (HAP) Rent Supplement (RS), and Rental Accommodation Scheme (RAS) are presented in Figure 3.4. ${ }^{27}$

Starting with Rent Supplement there has been a steady fall in RS funding since 2012. Some of this decline can be attributed to economic recovery which meant fewer people fell below the means test to qualify for the payment (Maître et al., 2020). Some of the decline can also be attributed to the introduction of the HAP scheme, which was designed to replace the RS scheme for those with a long-term housing need who qualify for social housing support. ${ }^{28}$ This scheme has grown in importance since its introduction in 2013, and funding for the scheme surpassed RS funding in 2018. During this time, funding for the Rental Accommodation Scheme (RAS), a scheme designed to help RS recipients with a long-term need for housing support, remained steady.

\section{FIGURE 3.4 HOUSING SUPPLEMENT SPENDING (HAP, RS AND RAS ONLY) (2004-2019)}

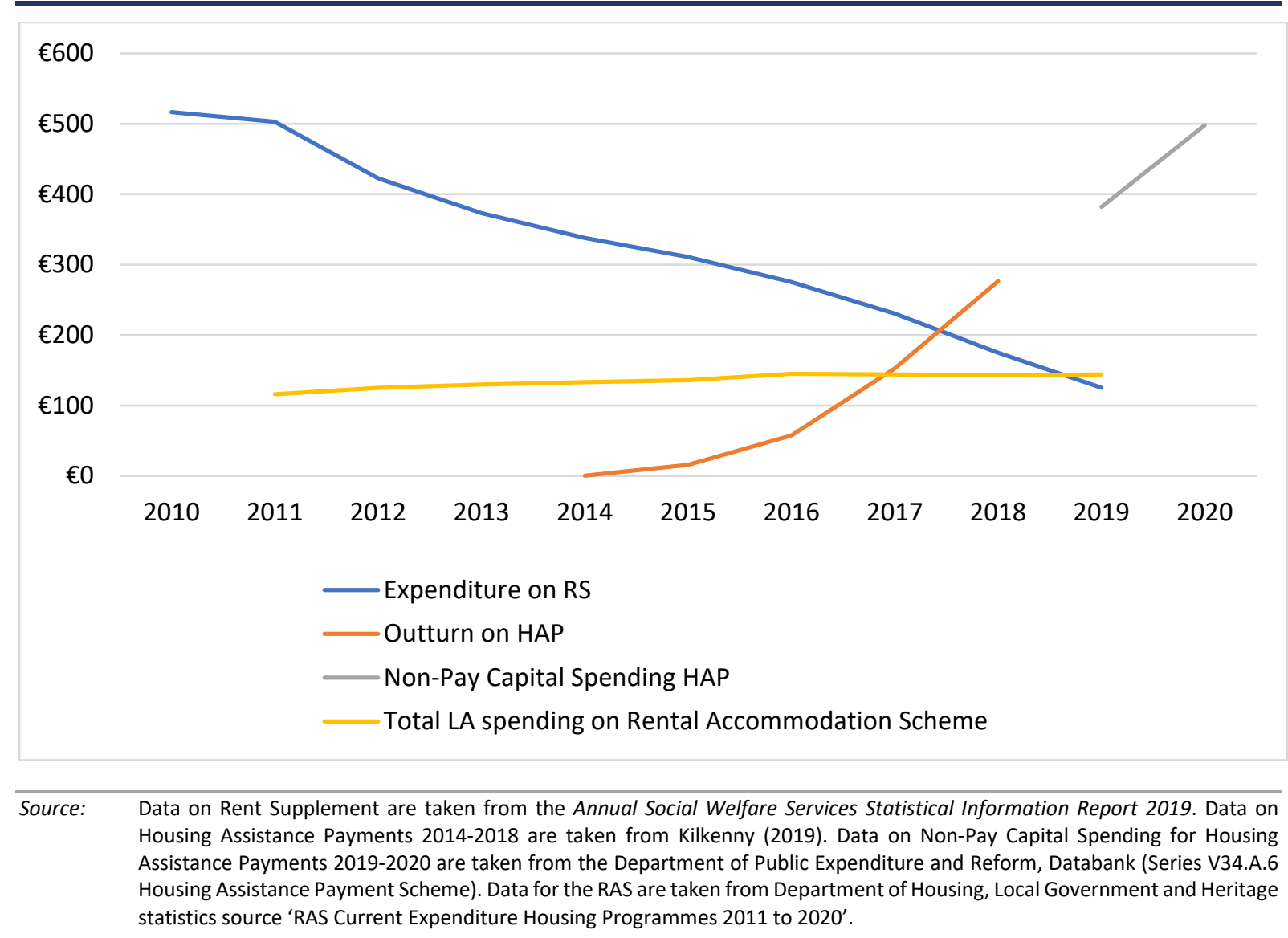

The figures do not include expenditure on Mortgage Income Supplement which was discontinued in 2018.

A crucial difference between HAP and RS is that HAP applicants are removed from the housing list numbers. We discuss this point when presenting data on the housing waiting list. More information on the scheme is available here https://www.citizensinformation.ie/en/housing/renting_a_home/housing_assistance_payment.html. 
The three schemes (HAP, RS, and RAS) differ in their administration and in the eligibility requirements. Rent supplement is a means-tested payment provided by the Department of Social Protection, it is paid directly to the household to cover short-term needs. HAP is paid by Local Authorities and is paid directly to the landlord. In most cases the tenant must source the accommodation themselves, a feature of the scheme that has caused difficulties for homeless families and other vulnerable tenants and has been criticised by several authors (e.g. Hearne and Murphy, 2018; Hearne and Walsh, forthcoming; Byrne and McArdle, 2020). Private rented accommodation that is subsidised through income support also differs from social housing support in terms of tenant security. We return to this issue in later chapters on affordability and security.

Broadly, we find that access to housing as measured by housing supply and government spending was severely impacted by the Great Recession. Although Ireland has recovered from this downturn, spending levels have only recently returned to previous rates and housing output remains below the peak of the housing boom and below estimates of housing demand.

\subsection{INDIVIDUAL-LEVEL INDICATORS}

In this section we move from macro-level indicators of housing supply to consider access to housing at an individual level. The aim is to highlight current inequalities in access across social groups and to provide a basis for future monitoring of these differences.

We first consider access to different types of housing tenure; owner-occupied, private rented and Local Authority housing. Secondly, we investigate those who are excluded from housing and are homeless. Thirdly we consider the characteristics of those are on the housing waiting lists. We draw on a range of sources including summary statistics from the PASS system, data from the Survey on Income and Living Conditions, and Housing Waiting list data from the Department of Housing, Local Government and Heritage.

\subsubsection{Tenure types}

We first consider group differences in tenure types between our key groups. Difference in housing tenure is influenced by preferences, by stage in the life course and socio-economic 
position (Grotti et al., 2018). Housing tenure is also strongly influenced by housing policy and supply, and societal norms around living arrangements.

We previously showed that the supply of newly constructed homes was low for a prolonged period and that social housing output began to rise only recently, suggesting there will be considerable competition for housing during our period of study. Previous research has shown that net migration was positive during this period (McGinnity et al., 2020a). Constraints in supply push a greater number of people into housing tenures that are not of their choice. Lack of choice is likely to be particularly acute for low-income and other vulnerable groups (Corrigan and Watson, 2018). Tenure type in and of itself is not a measure of housing adequacy, as there is wide variation in the size, habitability, location and quality within tenure types (RTB, 2020). However, there are fundamental differences in security between different tenure types in Ireland; there are also tenure differences in affordability (Corrigan et al., 2019b) and quality of housing (Corrigan and Watson, 2018).

While some group differences in housing tenures may reflect preferences, they also highlight potential issues in terms of the sustainability of tenure for different groups. For example, some of those born outside of Ireland may rely on the private rental sector because they do not plan to remain in Ireland, while others may desire to own a home but are excluded due to lack of resources. This issue of choice and constraint is especially true in the private rental sector, where 86 per cent of tenants express the wish to become homeowners (Corrigan et al., 2019a). Regarding migrant groups, the Zaragoza indicators of migrant integration also include relative levels of homeownership as one dimension of integration, suggesting group differences in access to homeownership may be a challenge to Ireland's integration commitments (McGinnity et al., 2020a).

We use the same categories for tenure used previously by Grotti et al. (2018); homeowners (owned outright or with a mortgage), private renters, and those renting from the Local 
Authority. ${ }^{29}$ The figures reported in the section below refer to individuals rather than households, and the tenure type applies to all those living in the household; this means for example, that dependants are classified according to the status of their parents.

Most people in Ireland (70 per cent) live in owner-occupied accommodation (with or without a mortgage), and the small difference between men and women is not statistically significant (Figure 3.5). There are substantial differences between age groups in this measure, with those aged $25-44$ being the least likely to live in owner-occupied housing (53 per cent) and those aged over 65 the most likely (93 per cent). The majority of the younger groups reported here (0-17 years of age and 18-24 years of age) are likely living with parents. According to figures from SILC, 54 per cent of young adults aged between 18 and 34 were living with their parents in $2019 .{ }^{30}$

Those born in Ireland have a higher rate of owner occupation (80 per cent) when compared to those born outside of Ireland (under 42 per cent). However, within the born abroad group, those born in the UK (77 per cent) and those born in Western Europe (47 per cent) have a substantially higher rate of homeownership, compared to those from EU-East countries (14 per cent). This finding reflects previous trends in migrant tenure types in Ireland (Maître and Fahey, 2018; Maître and Russell, 2017; Grotti et al., 2018). These differences in tenure may arise from a preference to rent in the private rental market especially for those who do not intend to remain in Ireland long term. However, they may also stem from a disadvantage in terms of income or access to homeownership (Grotti et al., 2018).

There are differences in homeownership between marital status groups. Respondents who were never married are least likely to live in owner-occupied housing (under 62 per cent),

We exclude respondents who live in their accommodation rent free (1 per cent). SILC includes two categories of renters - those renting at market rent or below market rent. These categories are better suited to housing systems in other jurisdictions. Comparing the SILC results the Census and the LFS we judge that those 'renting below market rent' are likely to be private tenants in receipt of housing benefits but may also include people living in RPZs. This category may also include a small proportion of people who rent from Approved Housing Bodies. These would be better grouped with Local Authority tenants, but it is not possible to separate them. Comparing tenure types in the Census 2016, LFS 2019, and SILC 2018 and 2019, we find a similar rate for private rented accommodation in each dataset (18.5 per cent, 18.7 per cent, and 18.7 per cent, respectively). Therefore, our measure for private rented accommodation appears consistent with other sources. 
while respondents who are married are most likely (over 80 per cent). This difference could be related to income differences between groups. Corrigan et al. (2019b) show that married couples have lower chances of affordability issues because of the household's pooled incomes. Elsewhere Baker et al. (2015) find that affordability issues are usually short-term for coupled households.

Non-graduates and graduates report similar rates of homeownership, though there are significant differences in the two other types of tenure (see below). Age is likely to be a confounding factor here as older age groups have lower educational qualifications.

Confining the analysis to those under 65 years, graduates are somewhat more likely to be in owner-occupied housing (72 versus 67 per cent). 
FIGURE 3.5 GROUP DIFFERENCES IN OWNER OCCUPATION RATES, WITH AND WITHOUT MORTGAGE (SILC 2018 AND 2019)

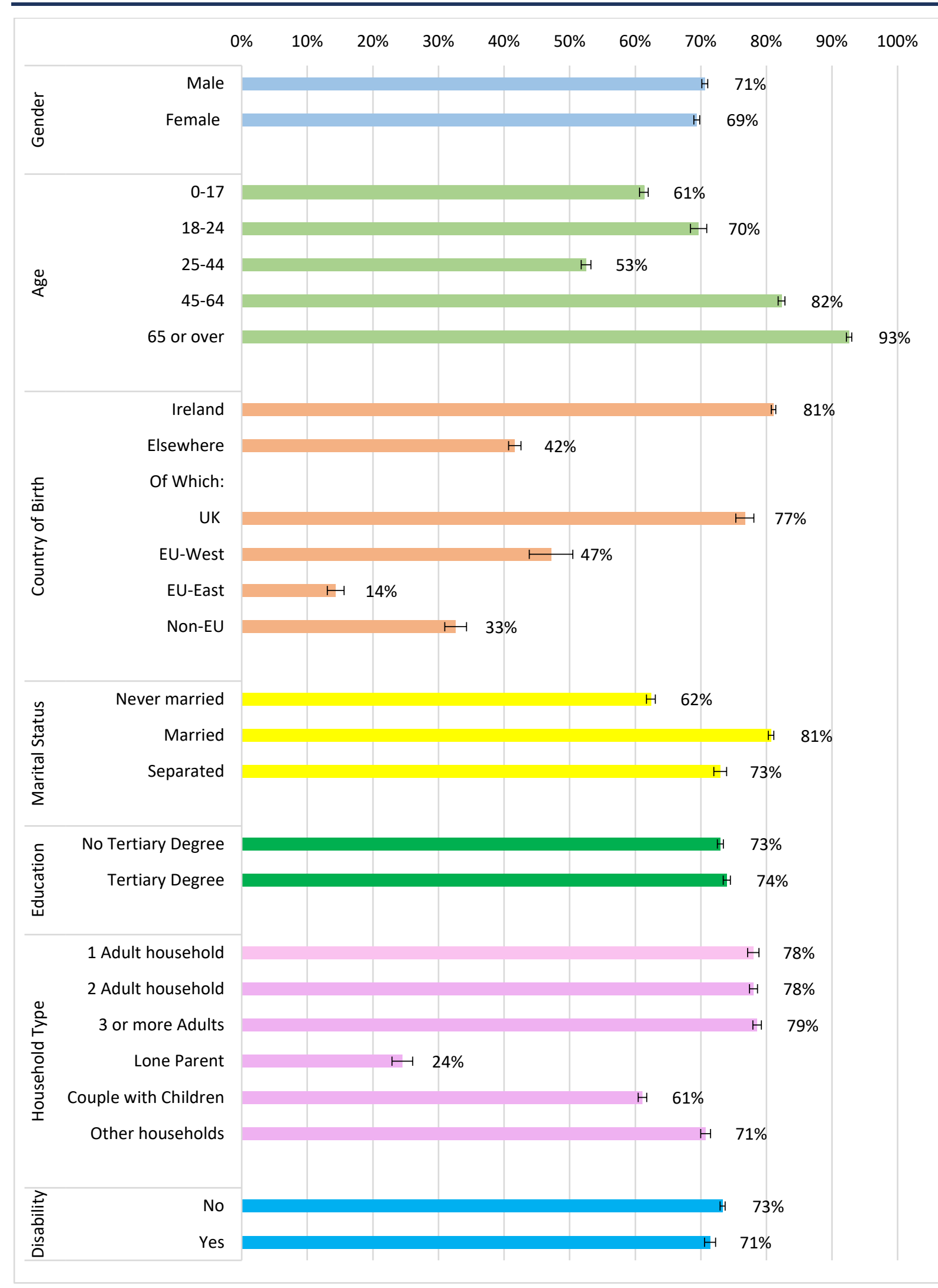

Source: $\quad$ SILC 2018 and 2019 combined.

Notes: $\quad$ Figure lists proportions and 95 per cent confidence intervals by group. 
There are also wide differences in homeownership rates between household composition types. Single adult, two adult, and multi-adult households have the highest rates of homeownership (almost 80 per cent for each group). While adults with children have the lowest rates of homeownership, this is especially true for lone parent households (under 25 per cent). Once again, age is likely a factor here given the large share of older people who live alone (CSO Census 2016). ${ }^{31}$ Finally, there is no difference in ownership rates between those with and without a disability.

One-in-five people in Ireland now live in private rental housing; we again find no significant gender difference (Figure 3.6). We find a significant age difference, in that older respondents are particularly unlikely to be in private sector rented accommodation ( 2 per cent). Respondents aged 45-64 are also particularly underrepresented in this group (8 per cent). Respondents aged 25-44 report the highest rate of private rental (36 per cent). This rate is also statistically different from those aged $0-17 .^{32}$ The sharp difference between those aged 0-17 and those aged 18-24 likely reflects younger respondents who live with their parents. Thus, for these two groups, they are reflecting the tenure of their parents who may have slightly higher chances of renting when children are younger (0-17) but higher chances of homeownership when children are older (18-24).

Migrants are significantly more likely to be in the private rental sector ( 48 per cent) when compared to those born in Ireland (9 per cent). There are wide differences within this group, with EU-West migrants reporting a lower rate (49 per cent) when compared to EU-East migrants (80 per cent). Those born in the UK were also less likely to live in the private rental sector (10 per cent), when compared to other migrant groups. Despite the wide range of differences between migrants, each migrant group reports higher chances of private rental when compared to respondents born in Ireland. High levels of private rental among nonIrish nationals are routinely found in Irish research, and EU-East nationals often have the highest rates of private rental (Maître and Fahey, 2018; Maître and Russell, 2017). These findings may be related to age or the length of residency in Ireland. UK migrants are less 
likely to be recent migrants, whereas EU migrants have shorter durations in Ireland on average (McGinnity et al., 2020b). These findings may also reflect occupational differences, with Eastern European migrants being more heavily concentrated in non-managerial jobs, where there is lower pay and less security (McGinnity et al., 2020b).

Regarding marital status, we note that those who were never married ( 22 per cent) are the most likely to live in the private rental sector, when compared to those who are married (14 per cent) and those who are separated/divorced/widowed (13 per cent). This difference is also statistically significant but would likely be explained by age differences and household composition differences between groups. 
FIGURE 3.6 GROUP DIFFERENCES IN PRIVATE RENTAL RATES (SILC 2018 AND 2019)

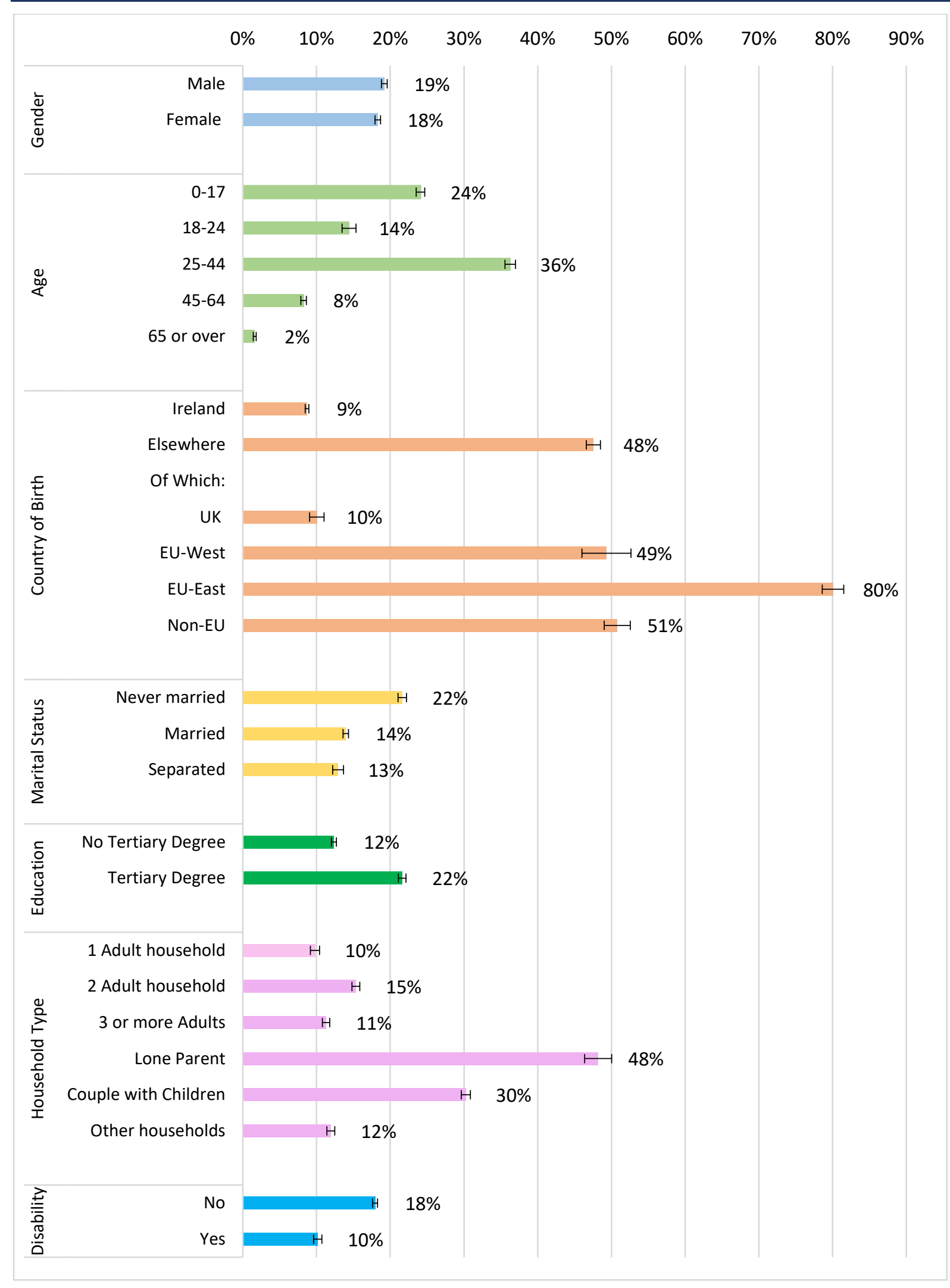

Source: $\quad$ SILC 2018 and 2019 combined.

Notes: $\quad$ Figure lists proportions and 95 per cent confidence intervals by group.

There is a significant difference between those with and without a third-level education.

Graduates are significantly more likely to live in private rental accommodation (22 per cent) 
than non-graduates (12 per cent), while the reverse is true for Local Authority tenancy (see Figure 3.7). These patterns are likely driven by differences in age and income.

There are also broad differences in household composition and the chances of living in private rented tenure. Lone parents (one adult with children) are the most likely to live in private rented accommodation (48 per cent), while one-adult and two-adult households are less likely live in private rented accommodation (10 per cent and 15 per cent respectively). Households with two adults with children also report a high rate of private rental tenure (30 per cent), which could reflect the fact that these households belong to young families.

There are also differences in private rented accommodation in terms of those with and without disability. Those with a disability (10 per cent) are significantly less likely to rent in the private market, when compared to those without a disability (18 per cent) and are more likely to live in Local Authority accommodation. This is likely to reflect lower income levels among people with a disability (Watson et al., 2015). However, it could also reflect discrimination faced by applicants with disabilities in accessing rented accommodation. This discrimination is described using field experiments in the US (Rich, 2014; Turner et al., 2005).

Finally, we consider Local Authority housing, which is the tenure for 11 per cent of the population (Figure 3.7). ${ }^{33}$ In our results, there is a minor but significant gender difference in the likelihood of LA housing between men and women (10 per cent and 12 per cent respectively). However, this difference is not significant.

Children under 18 years (14 per cent) and young people aged 18-24 (16 per cent) are significantly more likely to live in LA accommodation when compared to all other age groups. This may reflect the priority given to families in access to Local Authority housing and the greater availability of larger housing units in the LA housing stock (see Grotti et al., 2018). 
FIGURE 3.7 GROUP DIFFERENCES IN LOCAL AUTHORITY RENTAL (SILC 2018 AND 2019)

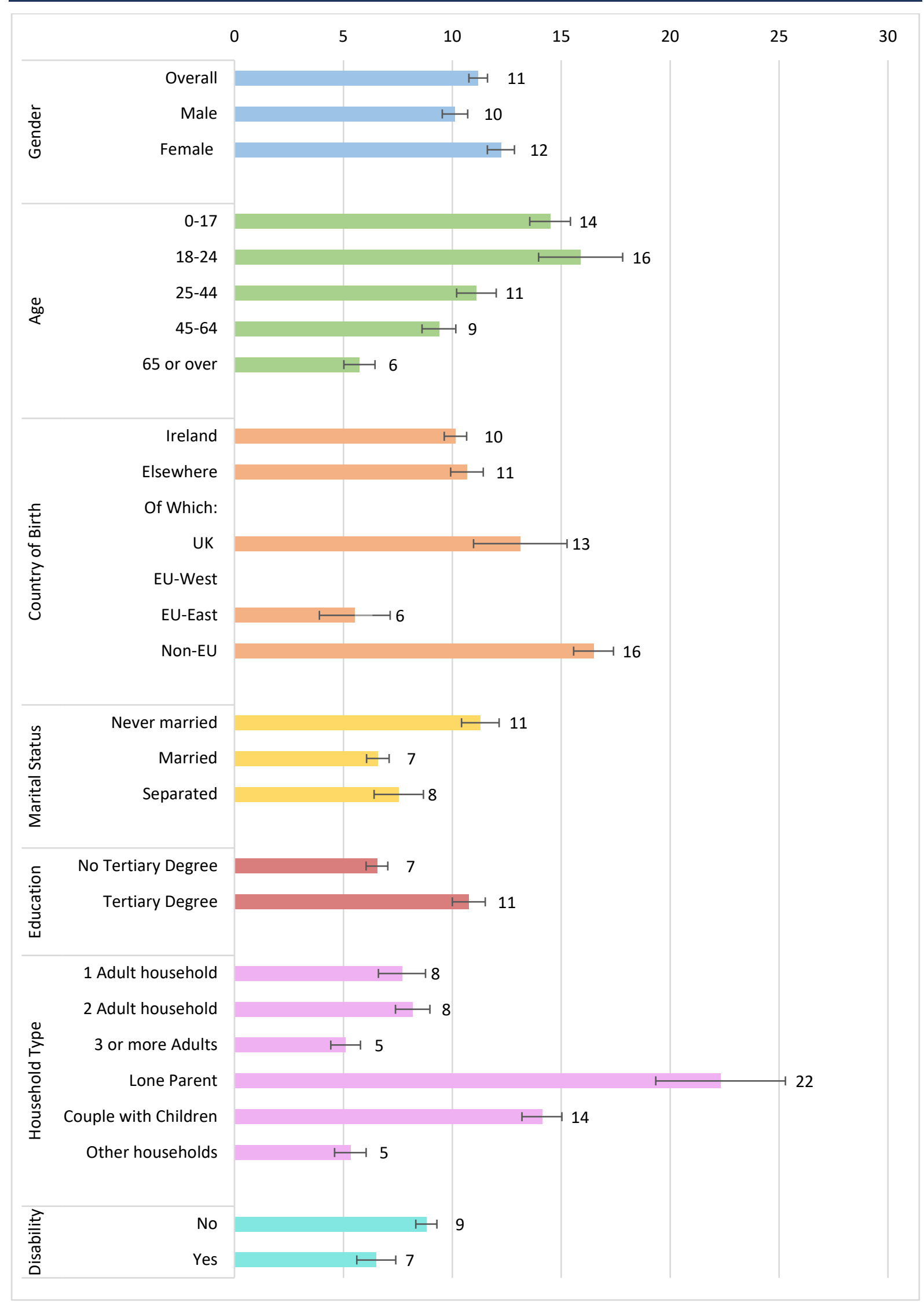

Source: Source: SILC 2018 and 2019 combined.

Notes: $\quad$ Figure lists proportions and 95 per cent confidence intervals by group. 
Those born in Ireland had a lower rate of occupancy in LA housing (10 per cent) when compared to respondents born elsewhere (13 per cent) although, again, the migrant category contains wide differences by country of birth, with those from the UK (13 per cent) and those from outside the EU (16 per cent) being the most likely to rely on this tenure type. Those born in the UK and those born outside the EU were more likely to live in LA housing when compared to those born in Ireland. This finding is similar to that of previous Irish research (Maître and Fahey, 2018; Maître and Russell, 2017) where UK nationals and non-EU Nationals recorded significantly higher chances of holding such tenancies.

Regarding marital status, married respondents (5 per cent) were the least likely to live in LA housing, most likely due to higher incomes on average for these households. The proportion is significantly higher for those who are never married (11 per cent).

There are also differences between education groups in terms of LA housing. Those without a third-level education (14 per cent) are significantly more likely to hold an LA tenancy when compared to graduates (4 per cent), which again could reflect age or income differences.

Lone parents ( 27 per cent) have significantly higher chances of holding such tenancies, and two-adult homes have significantly lower chances of holding such tenancies (10 per cent) when compared to single adult homes (8 per cent). This difference is also likely the result of income differences between these groups.

Lastly, we consider disability differences in holding these tenancies. Those with a disability have significantly higher rates of residing in LA housing (18 per cent), when compared to those without such a disability (8 per cent). This may arise because disability increases the respondent's chances of receiving such tenancies, or because of lower levels of income.

\subsubsection{Homelessness and homeless services}

Homelessness is the most extreme example of problems in access to housing. Previous research from IHREC and the ESRI (Grotti et al., 2018) using the 2016 Census highlighted that a number of equality groups are overrepresented in the homeless population, including men, young adults, families with very young children, those who are single, separated or divorced, those from minority religions, people with a disability, non-Irish nationals, those of 
Black ethnicity and Travellers. The authors note that although families are underrepresented amongst the homeless overall, lone parents and their children (overwhelmingly female headed) accounted for 60 per cent of all homeless families despite making up only 16 per cent of all families in the State (Grotti et al., 2018).

We turn to official homelessness data, as reported by Local Authorities using the Pathway Accommodation and Support System (PASS). These figures capture the number and details of individuals in State-funded emergency accommodation. ${ }^{34}$ These data omit rough sleepers, those who are forced to stay with family and friends due to homelessness (so called hidden homelessness), as well as families in domestic violence accommodations and those in 'long-term' homeless accommodation. However, it is a strong sample of the adult homeless population and an improvement on previous approaches to measuring the homeless population (Daly et al., 2018; Gambi and Sheridan, 2020). Further, the monthly PASS figures are more up-to-date than the Census, which was last carried out in 2016. Finally, the dataset is particularly useful in identifying distinct patterns of service use, and some characteristics of those who use homeless services.

The number of service recipients in the PASS system has increased since 2016, before levelling off in 2018, and declining in 2020. In March 2021, 5,984 adults were recorded as homeless. Generally, there is a significantly higher number of men in the system when compared to women. The figures for women have also declined since September 2019, while the figures for men have remained around 4,000. This suggests the gender gap in homelessness has widened in the last year. However, previous research has shown that women are more likely to experience hidden homelessness, in that they move in with friends or family instead of relying on formal services like those recorded in the PASS system (Mayock and Sheridan, 2012). Further, it should be noted that some of the decline in homeless service use may be attributed to emergency policy measures brought on by the COVID-19 economic lockdown. Such policies involve increased protection for tenants and a stop to all evictions. 
FIGURE 3.8 GENDER DIFFERENCES IN HOMELESS SERVICES USE (PASS SYSTEM) (JANUARY 2016-MARCH 2021)

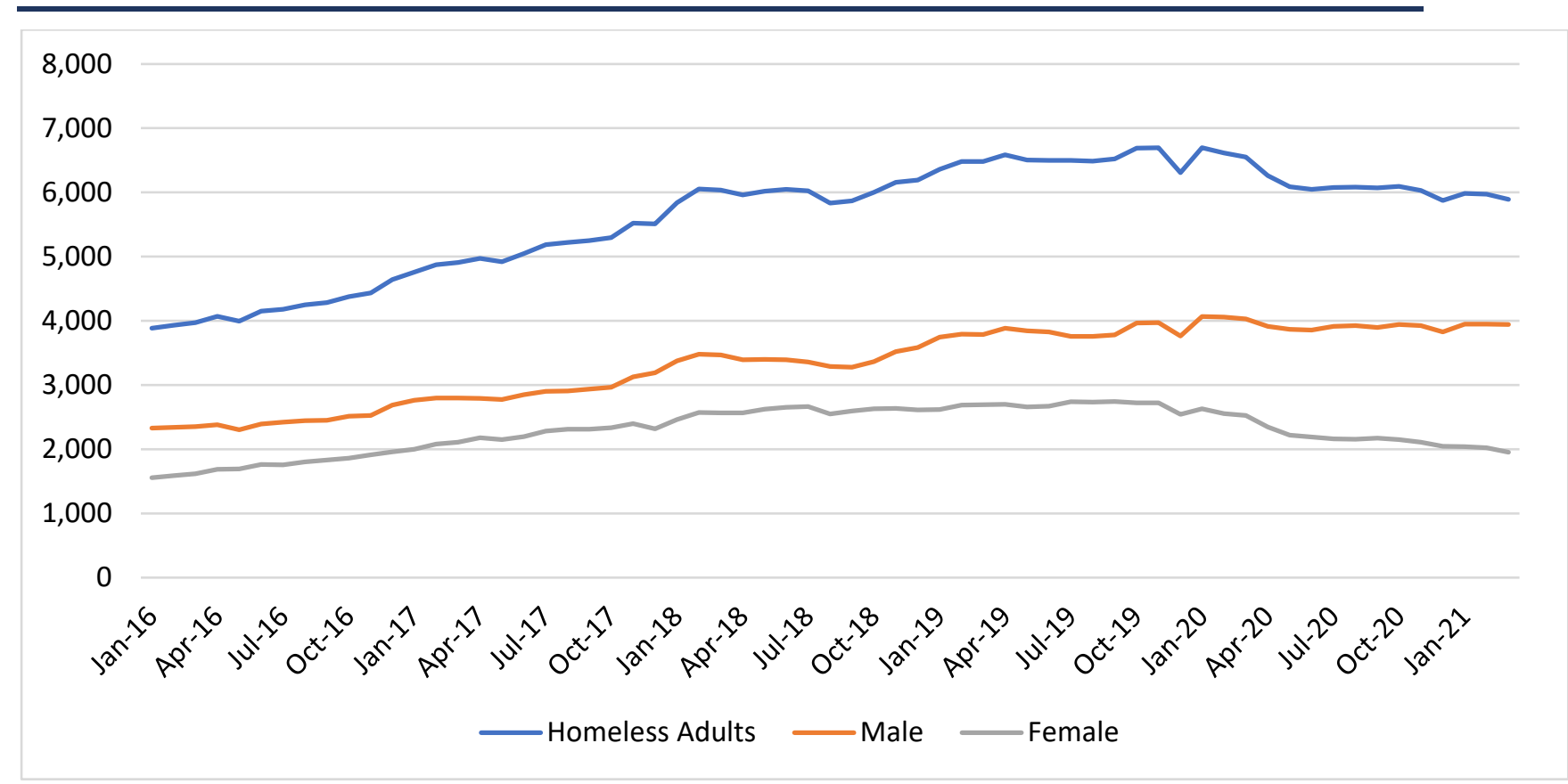

Source: Department of Housing, Local Government and Heritage Monthly Homeless Reports (January 2016-March 2021).

Note: $\quad$ The figures refer to the service users (all aged 18 and over) and not to their dependants.

We can also consider the age composition of those on the PASS system. These results indicate that most people recorded in the PASS system are aged 25-44, and that only a minority are aged over 65. The share of people aged $45-64$ has grown since September 2016, from 21 to 28 per cent, suggesting this age group has grown in terms of the wider homeless adult population. Those aged 18 to 24 accounted for 12.5 per cent of homeless service users, and so are somewhat overrepresented when compared to their share of the adult population (11 per cent in Census 2016). Those aged 25 to 44 are strongly overrepresented compared to their share of the general population (57 per cent versus 39 per cent). 

FIGURE 3.9 AGE COMPOSITION OF HOMELESS SERVICES USERS MARCH 2021 (PASS
SYSTEM) AND GENERAL ADULT POPULATION

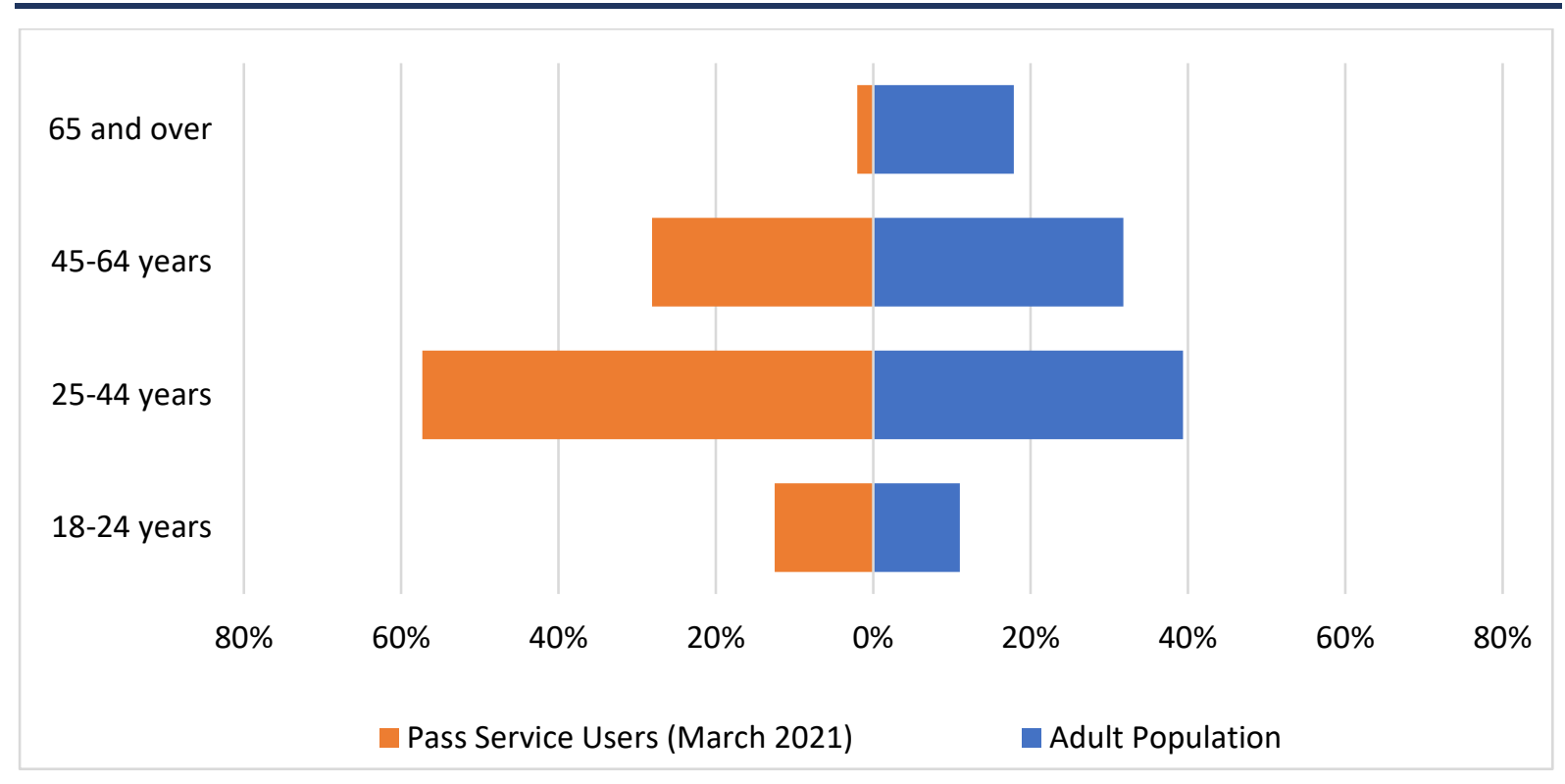

Source: Department of Housing, Local Government and Heritage Monthly Homeless Reports September 2020 and Census 2016

Finally, we briefly summarise the number of adults, families, single parent families and children as they appear in the official homelessness reports.

According to the PASS data there were 913 families in homelessness in March 2021, a decrease of 575 families from March 2020. Over half of these families (53 per cent) were lone parent families, which echoes the Census finding noted above. There were 2,166 dependants in these homeless families in March 2021, 1,189 fewer than in March 2020. It is important to note that during this time there was an eviction moratorium and rents were frozen.

TABLE 3.1 SUMMARY TABLE OF PASS USERS (2016-2021)

\begin{tabular}{|l|l|c|c|c|c|}
\hline Date & Total & Single & Families & $\begin{array}{c}\text { Single parent } \\
\text { families }\end{array}$ & Dependants \\
\hline $\mathbf{0 1 / 0 3 / 2 0 1 6}$ & 3,969 & 3,014 & 955 & 625 & 1,994 \\
\hline $\mathbf{0 1 / 0 3 / 2 0 1 7}$ & 4,909 & 3,653 & 1,256 & 830 & 2,643 \\
\hline $\mathbf{0 1 / 0 3 / 2 0 1 8}$ & 6,035 & 4,315 & 1,720 & 1,038 & 3,646 \\
\hline $\mathbf{0 1 / 0 3 / 2 0 1 9}$ & 6,484 & 4,751 & 1,733 & 1,021 & 3,821 \\
\hline $\mathbf{0 1 / 0 3 / 2 0 2 0}$ & 6,552 & 5,064 & 1,488 & 838 & 3,355 \\
\hline $\mathbf{0 1 / 0 3 / 2 0 2 1}$ & 5,894 & 4,981 & 913 & 492 & 2,166 \\
\hline
\end{tabular}

Source: Department of Housing, Local Government and Heritage Monthly Homeless Reports. 


\subsubsection{Housing waiting list}

The number and characteristics of those on the housing waiting list provides a broader definition of those who are experiencing problems accessing housing. Here we draw on summary statistics from the Summary of Social Housing Assessments (SSHA) annual report. This report is produced by the Housing Agency using data collected by the CSO. There were 61,880 households on the housing waiting list in 2020 , down from 85,800 in 2017 . The report defines the housing waiting list as the set of people who qualify for social housing support and those 'whose social housing need is not being met'. These respondents are not renting from the Local Authority, and they are not in receipt of HAP or RAS, but they may receive Rent Supplement. It is important to note that those in receipt of HAP are not included, ${ }^{35}$ even if some or many of this group would prefer social housing. In addition, HAP tenants do not have security of tenure, and therefore should be retained on the assessment of housing need.

Starting with differences between age groups, we see that most people on the waiting list are in their thirties (30 per cent in 2020) and forties (23 per cent in 2020). There are few older and younger respondents in the data, with respondents in their seventies ( 3 per cent in 2020) being the least likely to appear on the housing waiting list.

Regarding employment status, we find that most people on the social housing waiting list in 2020 are unemployed (54 per cent), while roughly 27 per cent are in employment, up from 22 per cent in 2017. A small portion of this population is limited in their ability to seek work. They are either reliant on one parent family support ( 5 per cent), home-makers ( 2 per cent) or they are retired (3 per cent).

On the main source of household income, most people rely fully on social welfare (59 per cent in 2020). A significant number of people rely on employment income (19 per cent in 2020) and the combination of both employment and welfare transfers (8 per cent in 2020). Most people on the waiting list are also single (52 per cent in 2020), although lone parent accommodation, voluntary/co-operative accommodation, accommodation provided under the Housing Assistance Payment (HAP) scheme, accommodation provided under the Rental Accommodation Scheme (RAS), accommodation provided under the Social Housing Capital Expenditure Programme (SHCEP) schemes or any household on a transfer list are not included in the total number on the housing waiting list. 
families are also common ( 25 per cent in 2020 ) as are couples with and without children (24 per cent in 2020).

Most people on the social housing waiting list (79 per cent) do not have 'specific requirements'. Ten per cent are classified as homeless in 2020, and 6 per cent have a disability. This is surprisingly low given the prevalence of disability in the population (circa 14 per cent) and in the homeless population (27 per cent) as noted by Grotti et al. (2018). This difference may come from a priority given to applicants with a disability over applicants without a disability. We previously showed that respondents with a disability had higher chances of living in LA housing, which could mean that people with a disability spend less time on the waiting list, although we do not measure this explicitly. The low figure may also be an artefact of how the statistics are recorded, for example some of those with disabilities may not be recorded as having a special requirement.

Similarly, less than 2 per cent have a special requirement as Travellers, though according to the Census, 9 per cent of the homeless population were members of the Traveller community (Grotti et al., 2018). It is possible that some of this group is classified in the general homeless category. Again, issues of under-reporting of Traveller status may also affect these statistics.

Regarding their tenure, most people on the waiting list in 2020 are in private rented accommodation (with or without Rent Supplement), while a significant portion are living with parents (24 per cent); this proportion has increased from 17 per cent in 2017. Some of those who live with parents may be experiencing a type of hidden homelessness, although it is difficult to split this group in terms of preference. There is also a risk of over-crowding in households where there are multi-generational households. 


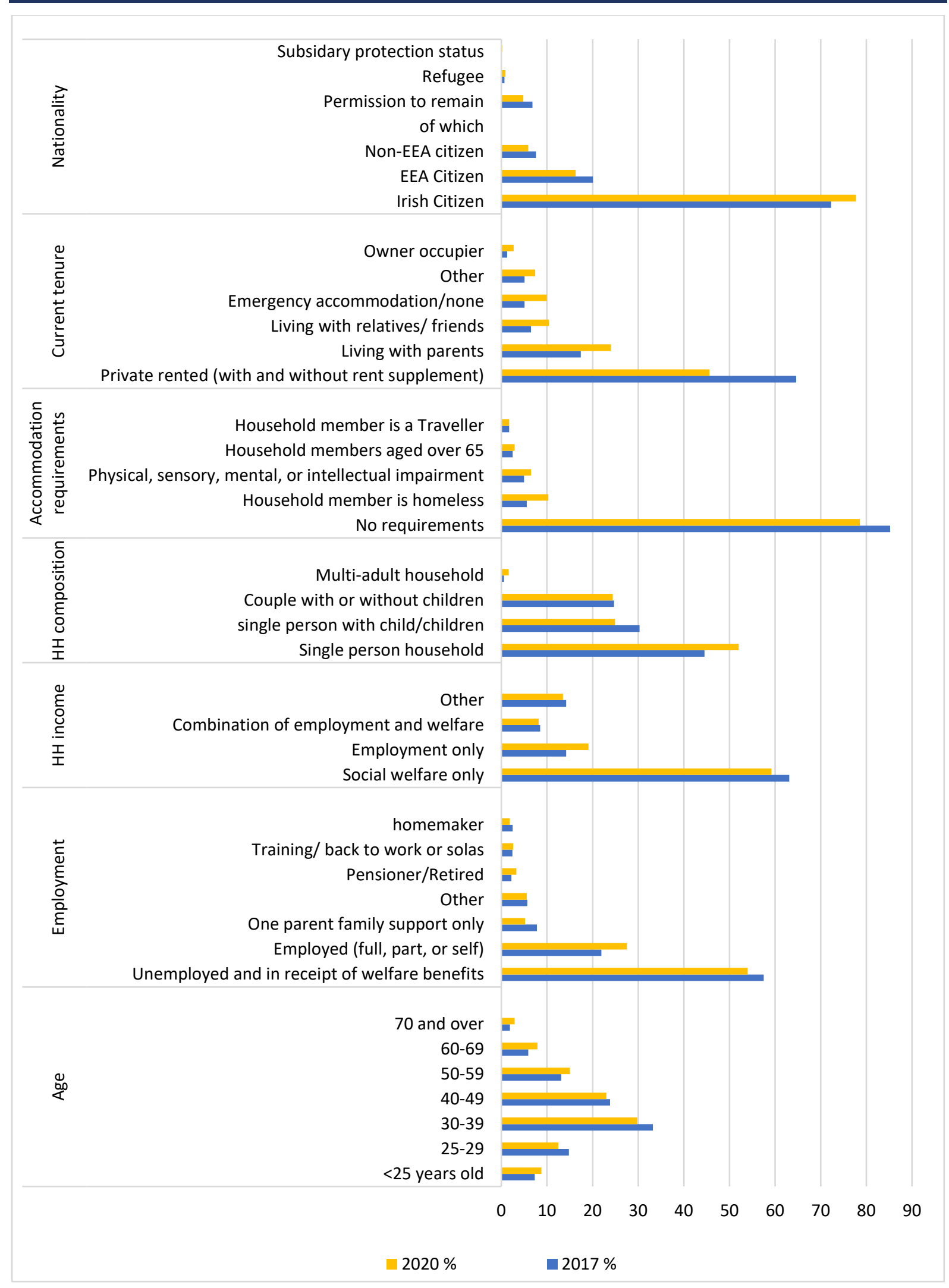

Source: Housing Agency. Summary of Social Housing Assessments Report 2017 and 2020.

A quarter (22 per cent) of those on the housing waiting list are non-Irish nationals, which is considerably higher than the proportion of migrants in the population (16 per cent in the 
2016 Census). Migrants are likely overrepresented for two reasons, first their younger age profile, and second their reliance on the private rented sector for housing. EEA nationals are the next most common group (16 per cent in 2020), with non-EEA nationals being the least common (6 per cent in 2020).

\subsection{SUMMARY}

The data examined in this chapter suggest that there are persistent problems in relation to housing access in Ireland. Focusing on a point in time for which we have complete data, in September 2019, 6,524 adults were recorded as homeless, including 1,756 families who had 3,873 dependants. There were over 68,600 households on waiting lists for social housing and over 91,600 in receipt of government benefits to cover housing costs (HAP, Rent Supplement or RAS). ${ }^{36}$ Daly (2019) highlights that there are significant weaknesses in how homelessness is measured in Ireland and recommends that the State adopts the ETHOS Light approach. This approach is applied in almost all European countries and the 'conceptual foundation is explained more thoroughly than any other definition' (Amore et al., 2011).

There has been a fall in the number of homeless service users since 2017 and there were increases in housing completions, including social housing completions, between 2016 and 2019 , reflecting a significant increase in capital spend. However, even with this growth, supply does not match the level of structural demand. Further, the COVID-19 crisis and the consequent shut down of building activity brought the increase in supply to a sharp stop. Emergency measures to prevent house evictions and the imposition of a freeze on rents during lockdown prevented any rise in homelessness in the first half of 2020 (Figure 3.8). These measures were in operation until April 2021. It is likely that the fall in housing supply will have a significant negative effect on future housing access.

In general, we find significant barriers for certain equality groups in access to different housing tenures and in the risk of being homeless and being on the housing waiting list. Though we note that we cannot distinguish between the role of choice and constraint in group differences in tenure-type, age is significantly related to housing access. New 
household formation occurs mainly in early adulthood and therefore difficulties in access are likely to be most acute at this stage of the life course. Young adults are much less likely than other age groups to be homeowners. This difference is likely to reduce as the group ages and accumulates capital. However, there may also be a cohort effect to these differences. Roantree et al. (2021) show that the rate of homeownership by age 30 has declined substantially for today's generation of young adults, when compared to previous generations at the same age. Less than 20 per cent of those born in the 1980 s were homeowners at age 30 but almost 60 per cent of those born in the 1960s were homeowners by age 30 . Young adults are also overrepresented among the homeless service users, though it is the $25-44$ age group that is particularly affected relative to the population. In the next chapter we will show group differences in the 30/40 rule of affordability, which highlights that young respondents (25-44) and children (0-17) are more likely to live in homes with affordability issues compared to respondents aged 65 and over, which is especially true for those who rent in the private sector.

There are also differences between migrant groups in terms of housing access. Migrants (excluding those born in the UK) are less likely to own their homes, and more likely to rent. Those from EU-East countries are highly concentrated in the private rented sector, while those born in non-EU countries are overrepresented in Local Authority housing, according to SILC data. Migrants are also significantly overrepresented in Census homeless figures and are overrepresented on the social housing waiting list. We know from previous experimental research that migrant groups are at risk of housing discrimination (Drydakis, 2011; Auspurg, 2017; Gusciute, 2020), which may be driving some of these differences. Previous ESRI research has also shown that certain migrant groups are less likely to hold professional and managerial jobs (McGinnity et al., 2020a), which could also affect their chances of ownership.

Lone parents emerged as a disadvantaged group on several indicators. They are overrepresented on the housing waiting list, amongst homeless families, and are much less likely to own their own home than couples with children.

While those with a disability do not emerge as a distinctive group in our set of indicators, international experimental research has shown that they are more likely to be discriminated 
against in the housing market (Rich, 2014; Turner et al., 2005). Grotti et al. (2018) find that those with a disability are twice as likely to report discrimination in the housing market compared to those without a disability even when employment status and education are held constant.

\subsection{DATA GAPS}

We find several data gaps in our analysis of housing access. First, SILC does not consider respondents' religion, ethnicity, sexual orientation, or minority gender status. As a result, we cannot comment on differences between these groups. Further, the data available on migrants do not consider second generation migrants, who are instead considered as Irish respondents. Splitting these respondents would lead to a better understanding of migrant status and the impact of duration in Ireland on housing outcomes (McGinnity et al., 2020a).

Second, beyond SILC, the groups described in the first point are not represented in other survey statistics. Broadly speaking, we cannot comment on their housing situation overall, although some statistics from the Irish Census for 2016 are captured by Grotti et al. (2018). Previous research has shown the importance of race and religion in terms of access to housing, and we would expect vulnerable groups to vary in terms of access, as shown in previous field experiments (Baldini and Federici, 2011; Turner and Ross, 2003a; 2003b).

Third, data for migrants capture some regions of birth, but cannot be disaggregated into more detailed country groupings. Previous research has shown that migrants vary extensively in employment status and occupational attainment by country of birth; broad continent categories (like those used throughout the chapter) hide differences between countries of birth (McGinnity et al., 2020b). This is an obstacle in SILC, but data from the Department of Housing, Local Government and Heritage do not consider this measure at all and so mark a significant gap.

Fourth, the indicators considered here cannot tell us about housing preferences or individual matches to housing tenure. For example, respondents who are in Ireland temporarily may prefer private rented accommodation, hence the sharp difference between respondents born in Ireland and respondents born elsewhere. In a similar vein, older respondents who are mortgaged homeowners may prefer social housing with a differential 
rent, especially if they experienced a sudden change to their source of income. In this way, we do not know respondent's preferences for tenure type.

There are also gaps in evaluating the housing waiting list. While certain data exist from the Housing Agency, these data do not consider many of the eligibility requirements that shape the population on the housing waiting list. For example, income levels do not appear in the data, although the sources of income do appear. Further, ethnicity is not included in the data, while nationality does appear. In addition, while PASS data on those in homeless services are welcome, these sources lack certain characteristics of service users which would be insightful, mainly the person's country of birth and ethnicity. One important measure for PASS reports to consider is whether people in the system are leaving other care services. This measure is not provided. 



\section{CHAPTER 4}

\section{Housing affordability}

This chapter considers aggregate and micro-level indicators of housing affordability. Group differences in affordability are important as they can lead to social exclusion, poverty and deprivation. While some affordability issues are temporary and to some degree 'normal', persistent affordability issues are often an issue for vulnerable groups (Wood and Ong, 2011). Temporary issues of affordability may be stepping-stones for young and educated workers who anticipate their earnings to rise over the long term. ${ }^{37}$ Persistent affordability issues are a common disadvantage among unemployed households and households with children (Baker et al., 2015; Wood and Ong, 2011). Affordability issues are also linked to another key dimension of housing adequacy: security. Those who face persistent problems with meeting housing costs and who fall into long-term arrears can face the threat of eviction.

Affordability of housing is covered under the right to housing in several international human rights monitoring committees. The State has an obligation under Article 11(1) of ICESCR not only to ensure the right to housing is fulfilled but also that the costs associated with housing should not threaten or compromise 'the attainment and satisfaction of other basic needs'. Tenants should also be protected from 'unreasonable rent levels or rent increases.' ${ }^{38}$ This affordability dimension is also addressed under the Article 31(3) of the European Social Charter which specifies that states should ensure that the cost of housing is affordable for those without adequate resources. Other international committees specify the need for affordable housing in relation to specific groups such as families, ${ }^{39}$ migrant workers and their families, ${ }^{40}$ those at risk of poverty or social exclusion ${ }^{41}$ and children. ${ }^{42}$ Several international committees also require the State to realise the right to non-discrimination in

Despite this, recent research from the ESRI (Roantree et al., 2021) has shown that younger cohorts in Ireland are particularly vulnerable to high housing costs when compared to older cohorts of the same age.

ISESCR 11(1) General Comment No.4, para 8(c).

ESC Article 16.

ESC Article 19(4).

ESC Article 30.

CRC Article 27 (3). 
access to housing by stipulating equal access to mortgages for women, ${ }^{43}$ access to housing and property ownership for racial, national, or ethnic minorities ${ }^{44}$ and those with disabilities. ${ }^{45}$

In this chapter we first present aggregate indicators of the housing market for context; these relate to trends in the cost of housing on one hand and trends in the receipt of housing support (Housing Assistance Payments and Rent Supplement) on the other hand. These indicators provide a broad sense of two key drivers of affordability. Housing supply, which is a central determinant of housing costs, was considered in the previous chapter.

We then outline descriptive differences in three affordability measures across equality groups.

\subsection{AGGREGATE INDICATORS}

We consider three context indicators; trends in rental costs, ratio of average rent to average earnings, and receipt of housing supplements. These indicators provide baseline information on housing affordability in Ireland that can then be monitored over time. The first two indicators draw on data from the RTB and ESRI's Quarterly Rent Index. ${ }^{46}$ The first considers trends in rental costs over time (indexed to 2007). The second indicator relates the same data on rental cost to trends in mean gross monthly wage. ${ }^{47}$ This provides a broad sense of whether rental costs have become less affordable for workers overall. The macro indicators of housing costs focus on the private rental sector since affordability problems have arisen quickly here (Corrigan et al., 2019b). Problems of arrears are also significant for those in social housing (Russell et al., 2011). However, for this group, the issue of affordability is more closely tied to low income than to high housing costs, as social housing rents are related to income. The private rental sector has also become a much more significant part of the Irish housing market in the last 20 years. McQuinn (2021) discusses

CEDAW Article 13(b).

CERD Article 5 (d)(v) and (e)(iii).

CRPD Article 28 (1).

Further details are available here:

https://www.rtb.ie/images/uploads/Comms\%20and\%20Research/RTB_Rent_Index_2020_Q3_\%28WEB\%29_Fi nal.pdf.

47 We rely on the CSO's EAADS for the earnings data. Further information can be found here: https://data.cso.ie/table/NEA05. 
house price and mortgage loan trends from 1995 to 2020 and shows that the gap between house prices and income was widest in 2006/2007 just before the crash. Affordability problems across all tenancy types are captured using three indicators at the individual level in Section 4.2 .

The third indicator is receipt of Housing Supports namely Rent Supplement and Housing Assistance Payments (HAP), which we discussed briefly in the previous chapter. Households in receipt of these benefits are in need of State support to meet housing needs, though coverage of benefits will depend on eligibility criteria. The availability of HAP data by household characteristics (provided to us by the CSO) allows us to explore the groups most likely to need this support.

\subsubsection{Trends in rental costs}

This RTB/ESRI Rent Index reports rent as recorded in the national register of tenancies, with reference to Q3 2007 (set at 100). It controls for the size of the dwelling and the location. Results in Figure 4.1 show that between 2007 and late 2012 rents fell for all areas considered (Dublin, non-Dublin, the Greater Dublin Area, and Outside the Greater Dublin Area). After that date, rents began to rise as the economy recovered from recession, with rents in Dublin growing at a particularly fast rate. Rent Pressure Zone legislation was introduced by the government in late $2016 .{ }^{48}$ This legislation limited rent price growth to 4 per cent or less in designated areas. It also specified that rent cannot be set above the market rate for a new tenancy. ${ }^{49}$ Cork City Council, Dublin City Council, Dún LaoghaireRathdown County Council, Fingal County Council, and South Dublin County Council were designated as Rent Pressure Zones in 2016. By September 2020, an additional 50 LEAs and County Councils were designated as Rent Pressure Zones. ${ }^{50}$ Despite this, by 2020 , the cost of rent had surpassed its pre-crisis levels by almost 40 per cent in Dublin, and 20 per cent elsewhere, as shown in Figure 4.1. rpz. 
FIGURE 4.1 TREND IN RENTAL COST (2007-2020) INDEXED TO 2007

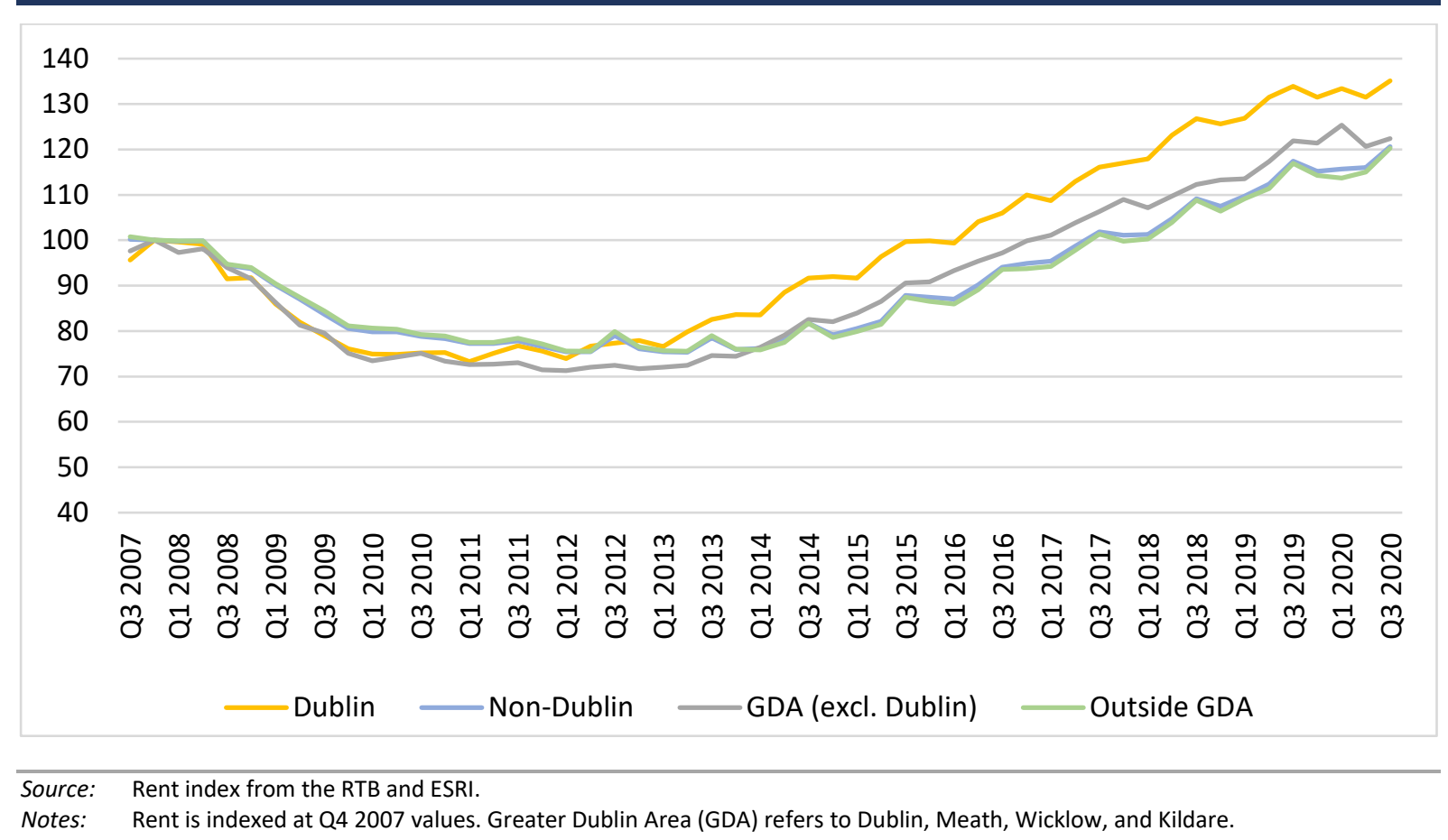

\subsubsection{Average rent and average earnings}

Rising rental costs may not be an issue if the changes are matched by increased incomes. The second indictor calculates the ratio of average monthly rent to the average monthly wage for Dublin and the State overall (Table 4.1, right hand side). There are two things to note in the table. First, the ratio is consistently higher in Dublin compared to the State overall for each year considered. Second, both ratios have risen since 2011, with a particularly strong rise in Dublin. This is due to rents rising at a significantly faster rate than average earnings.

The series for average earnings runs only to 2018 , but using another source to estimate changes in earnings at the national level, we estimate that the national ratio fell slightly in 2019 and remained stable in $2020 .{ }^{51}$ The widening gap between rental prices and average earnings will likely feed into affordability problems for vulnerable groups at the household level, which we show later. 
One issue with Table 4.1 is that it considers Dublin and State averages, without considering group differences behind these averages. For example, the incomes of those not in employment are considerably lower than the employed, so these figures are a conservative indicator of the gap between rents and income. Despite this, even for the average worker this gap has risen in recent years. The figure suggests that even those on average earnings are likely experiencing affordability issues as they are defined in the literature.

TABLE 4.1 AVERAGE MONTHLY RENT, AVERAGE MONTHLY EARNINGS, AND THEIR RATIO (2011-2020)

\begin{tabular}{|l|l|c|c|c|c|c|}
\hline Year & $\begin{array}{c}\text { Mean } \\
\text { Monthly } \\
\text { Earnings } \\
\text { (State) } €\end{array}$ & $\begin{array}{c}\text { Mean } \\
\text { Monthly } \\
\text { Earnings } \\
\text { (Dublin) } €\end{array}$ & $\begin{array}{c}\text { Mean } \\
\text { Monthly Rent } \\
\text { (State) } €\end{array}$ & $\begin{array}{c}\text { Mean } \\
\text { Monthly } \\
\text { Rent } \\
\text { (Dublin) } €\end{array}$ & $\begin{array}{c}\text { National } \\
\text { Ratio }\end{array}$ & $\begin{array}{c}\text { Dublin } \\
\text { Ratio }\end{array}$ \\
\hline $\mathbf{2 0 1 1}$ & $3,310.08$ & $3,693.83$ & 751.18 & 953.04 & 0.23 & 0.26 \\
\hline $\mathbf{2 0 1 2}$ & $3,316.00$ & $3,701.17$ & 745.94 & 961.66 & 0.22 & 0.26 \\
\hline $\mathbf{2 0 1 3}$ & $3,334.58$ & $3,730.33$ & 761.01 & 995.91 & 0.23 & 0.27 \\
\hline $\mathbf{2 0 1 4}$ & $3,369.75$ & $3,774.92$ & 795.24 & $1,086.44$ & 0.24 & 0.29 \\
\hline $\mathbf{2 0 1 5}$ & $3,427.50$ & $3,855.67$ & 856.32 & $1,192.32$ & 0.25 & 0.31 \\
\hline $\mathbf{2 0 1 6}$ & $3,468.92$ & $3,934.67$ & 930.52 & $1,292.92$ & 0.27 & 0.33 \\
\hline $\mathbf{2 0 1 7}$ & $3,555.50$ & $4,064.25$ & $1,009.83$ & $1,414.68$ & 0.28 & 0.35 \\
\hline $\mathbf{2 0 1 8}$ & $3,681.67$ & $4,233.42$ & $1,184.25$ & $1,534.04$ & 0.32 & 0.36 \\
\hline $\mathbf{2 0 1 9}$ & $3,814.21 *$ & $1,167.52$ & $1,650.21$ & $0.31 *$ & \\
\hline $\mathbf{2 0 2 0}$ & $3,985.85 *$ & $1,231.07$ & $1,734.82$ & $0.31 *$ & \\
\hline \multicolumn{7}{|l|}{} \\
\hline Source: \\
Note:
\end{tabular}

\subsubsection{Housing supplement recipients}

Beyond trends in rental costs, it is worth considering the characteristics of those who receive HAP and RS housing supplements. For RS recipients we use the data published in the Department of Social Protection's annual report. These are presented in Table 4.2. 
TABLE 4.2 RENT SUPPLEMENT RECIPIENTS (CHARACTERISTICS OF MAIN TENANT)

\begin{tabular}{|c|c|c|c|c|}
\hline & 2018 & & 2019 & \\
\hline & $\mathbf{N}$ & $\%$ & $\mathbf{N}$ & $\%$ \\
\hline \multicolumn{5}{|l|}{ Gender } \\
\hline Male & 11,254 & 49.1 & 7,954 & 50.0 \\
\hline Female & 11,676 & 50.9 & 7,959 & 50.0 \\
\hline All & 22,930 & & 15,913 & \\
\hline \multicolumn{5}{|l|}{ Age } \\
\hline $0-19$ & 26 & 0.1 & 7 & 0.1 \\
\hline $20-24$ & 574 & 2.5 & 196 & 1.2 \\
\hline $25-44$ & 12,055 & 52.6 & 7,281 & 45.8 \\
\hline $45-64$ & 8,390 & 36.6 & 6,599 & 41.5 \\
\hline 65 and over & 1,885 & 8.2 & 1,830 & 11.5 \\
\hline \multicolumn{5}{|l|}{ Nationality } \\
\hline Ireland & 15,081 & 66.5 & 10,597 & 66.6 \\
\hline UK & 956 & 4.2 & 689 & 4.3 \\
\hline EU13 & 407 & 1.8 & 289 & 1.8 \\
\hline EU15 to EU28 & 4,535 & 20.0 & 3,077 & 19.3 \\
\hline Non-EU & 1,890 & 8.3 & 1,261 & 7.9 \\
\hline All & 22,930 & 100.0 & 15,913 & 100.0 \\
\hline
\end{tabular}

Table 4.3 shows a sharp fall in Rent Supplement recipients in recent years, which we discussed previously, along with the fall in funding for Rent Supplement (Figure 3.4). The number of recipients fell from over 22,900 in 2018 to over 15,900 in 2019 as claimants were moved off housing supports completely or towards HAP.

For both years, we see no gender difference in Rent Supplement recipients, with men and women equally represented in both years. We also see that most Rent Supplement recipients were aged 25-44 in both years. A substantial portion of recipients are also aged 45-64, suggesting that early career recipients are not the only group represented in the data.

Finally, we see that although most recipients are Irish nationals, other nationality groups are overrepresented among recipients. Taking 2019 data from McGinnity et al. (2020a) (Table A1.1) we note that Irish nationals make up 87 per cent of the population but only 66 per cent of RS recipients. UK nationals make up 2.3 per cent of the population but 4 per cent of RS recipients. EU-West nationals are 1.7 per cent of the population and 1.8 per cent of RS recipients. Eastern European nationals make up 5 per cent of the population, and 
19 per cent of RS recipients. Lastly, non-EU nationals make up 3.3 per cent of the population but 8 per cent of RS recipients. As argued in the previous chapter, migrants are more likely to live in private rented accommodation when compared to those born in Ireland, and so they may be more likely to qualify for Rent Supplement, when compared to Irish nationals, who have a higher chance of living in owner-occupied housing.

Table 4.4 shows the characteristics of those receiving Housing Assistance Payments (HAP). This scheme is a housing supplement paid directly to the landlord to cover part of the cost of rent. Although the scheme places the responsibility of finding accommodation on the individual, which may leave them open to discrimination (Byrne and McArdle, 2020), it has become an important part of housing provision in Ireland and warrants attention. We previously discussed the rise in funding for HAP, which has increased substantially in recent years (Figure 3.3). Table 4.3 contains data from the CSO, which splits HAP recipients by several groups.

Most HAP respondents are aged 25-44 (64 per cent), and a minority are aged over 65 (4 per cent). Despite low earnings among younger respondents, few HAP main tenants are aged under 25 (6 per cent). Regarding gender, women are overrepresented as HAP recipients (61 per cent), while men are underrepresented (38 per cent); part of this could stem from the high rate of lone parent households, which is disproportionately made up of women.

Regarding nationality types we again find an over-representation of migrants in the results. Focusing on 2019 results and considering 2019 data from McGinnity et al., 2020a (Table A1.1) we note that Irish nationals make up 87 per cent of the general population but only 63 per cent of HAP recipients. UK nationals make up 2.3 per cent of the population but 4 per cent of HAP recipients. EU-West nationals are 1.7 per cent of the population and 1.8 per cent of HAP recipients. Eastern European nationals make up 5 per cent of the population and 21 per cent of HAP recipients. Lastly, non-EU nationals make up 3.3 per cent of the population but 10 per cent of HAP recipients.

In terms of household composition, single parent tenants are the most common (42 per cent), followed by couples with children ( 26 per cent), and single adult households (22 per cent). Couples without children are underrepresented (4 per cent). These differences are most likely the result of income differences between these groups. 
On ethnicity, White Irish tenants are the largest group (60 per cent) followed by other White tenants (25 per cent) and Black or Black Irish tenants (7 per cent). White Irish Traveller tenants make up 1.4 per cent of HAP recipients. Compared to the proportion of the population, White Irish tenants are underrepresented among HAP recipients (60 per cent compared to 82 per cent of the population), whereas Black or Black Irish tenants (7 per cent compared to 1.4 per cent of the population), other White tenants ( 25 per cent compared to 9.5 per cent of the population) and White Irish Traveller tenants (1.4 per cent compared to 0.7 per cent of the population) are overrepresented among HAP recipients. ${ }^{53}$ Regarding religious affiliation, we note that Catholic tenants are the most common (67 per cent), as are other Christian tenants (14 per cent).

Finally, most tenants in receipt of HAP are single (47 per cent) with a significant portion being either married, in a civil partnership or in a common law partnership (36 per cent). Separated or divorced (14 per cent) people are overrepresented to their share of the adult population. 


\begin{tabular}{|c|c|c|}
\hline \multirow[t]{2}{*}{ Year } & \multicolumn{2}{|c|}{2019} \\
\hline & $\mathbf{N}$ & $\%$ \\
\hline \multicolumn{3}{|l|}{ Age Group } \\
\hline Under 25 & 3,840 & 6.7 \\
\hline $25-44$ & 36,370 & 63.1 \\
\hline $45-64$ & 15,170 & 26.3 \\
\hline $65+$ & 2,250 & 3.9 \\
\hline \multicolumn{3}{|l|}{ Gender } \\
\hline Female & 35,530 & 61.7 \\
\hline Male & 22,090 & 38.3 \\
\hline \multicolumn{3}{|l|}{ Nationality } \\
\hline Ireland & 36,040 & 62.6 \\
\hline EU-East & 12,200 & 21.2 \\
\hline Rest of World & 5,860 & 10.2 \\
\hline United Kingdom & 2,450 & 4.3 \\
\hline EU-West & 1,010 & 1.8 \\
\hline Unknown & 70 & . \\
\hline \multicolumn{3}{|l|}{ Education } \\
\hline Lower than Third Level & 36,360 & 84.7 \\
\hline Third Level or Higher & 6,570 & 15.3 \\
\hline Missing & 3,880 & . \\
\hline Unlinked & 10,990 & \\
\hline \multicolumn{3}{|l|}{ Disability status } \\
\hline Without Disability & 37,320 & 79.9 \\
\hline With Disability & 9,370 & 20.1 \\
\hline Unlinked & 10,990 & \\
\hline \multicolumn{3}{|l|}{ HH composition } \\
\hline 1 Adult with children & 24,250 & 42.1 \\
\hline Couple with children & 15,040 & 26.1 \\
\hline 1 Adult & 13,200 & 22.9 \\
\hline Other & 2,850 & 5.0 \\
\hline Couple & 2,280 & 4.0 \\
\hline \multicolumn{3}{|l|}{ Ethnicity } \\
\hline White Irish & 26,520 & 59.1 \\
\hline Any other White background & 11,350 & 25.3 \\
\hline Black or Black Irish & 3,190 & 7.1 \\
\hline Other including mixed background & 1,680 & 3.8 \\
\hline Asian or Asian Irish & 1,470 & 3.3 \\
\hline White Irish Traveller & 640 & 1.4 \\
\hline Not Stated & 1,960 & \\
\hline Unlinked & 10,990 & \\
\hline
\end{tabular}


TABLE 4.3 CONTD.

\begin{tabular}{|l|r|r|}
\hline Year & \multicolumn{2}{|c|}{2019} \\
\hline Religion & N & $\%$ \\
\hline Roman Catholic & 30,200 & 67.1 \\
\hline No religion & 5,190 & 11.5 \\
\hline Other Christian & 6,270 & 13.9 \\
\hline Muslim & 2,530 & 5.6 \\
\hline Other Stated religions & 810 & 1.8 \\
\hline Not Stated & 1,820 & \\
\hline Unlinked & 10,990 & \\
\hline HH composition & & 47.4 \\
\hline Single & 27,210 & 36.4 \\
\hline Married/Civil Partner/Common law/Cohabiting & 20,880 & 14.3 \\
\hline Separated/Divorced/Former civil partner/Deserted & 8,220 & 1.9 \\
\hline Widowed/Surviving Civil Partner & 1,060 & \\
\hline Unknown & 250 & \\
\hline
\end{tabular}

Source: Data provided by the Central Statistics Office.

In total, the tables show that women and young respondents are especially likely to be HAP and RS recipients, and therefore these groups may be especially likely to experience affordability issues in the analysis below. Further, non-Irish nationals or migrants are also likely to receive housing supplements, suggesting they may also be more likely to experience affordability issues, though the over-representation of migrants is also likely to be influenced by their younger age and their concentration in the rental sector.

\subsection{INDIVIDUAL AND GROUP-LEVEL INDICATORS}

This section presents group differences in affordability using data from the CSO's SILC. We focus on three individual-level indicators:

- the proportion of households spending more than 30 per cent of their income on housing costs and in the bottom 40 per cent of the income distribution;

- the poverty rate after housing costs;

- the rate of arrears on mortgage and rental costs.

A functioning housing market ensures affordable homes for those who need them (Nepal et al., 2010). If housing costs take up a disproportionate portion of a household's income the 
expense can lead to deprivation, exclusion, and poverty at the household level (Maître et al., 2020; Nepal et al., 2010), and to lower levels of consumption and economic growth at a wider level (Quigley and Raphael, 2004; Corrigan et al., 2019b).

Issues of affordability are typically correlated with age and stage in the life course. In the early stages of one's life, households may choose to spend more on housing with the expectation that their earnings will rise over time. However, group differences in affordability can point to more long-term problems for vulnerable groups (like migrants or people with a disability). As a result, group differences in affordability are useful in that they point to key communities who would benefit from further analysis.

Further, within each measure different approaches have been taken by researchers, whether to focus on gross or net income (Nepal, 2010), or to use equivalised or non-equivalised income (Corrigan et al., 2019b; Heylen, 2020). As a result, there may be small differences in estimates, but group disadvantages should emerge in each of these approaches.

\subsubsection{The $30 / 40$ rule}

The proportion of household income spent on housing, rent or mortgage costs (the ratio approach) is the most widely used measure of housing affordability. This approach considers several thresholds from 30 per cent to 50 per cent of gross income (Gabriel et al., 2005). Here we adopt the $30 / 40$ rule, which has been applied in a range of contexts including Ireland (Corrigan et al., 2019b; Nepal, 2010; Wood and Ong, 2011). This measure is made up of two parts. First, it considers equivalised ${ }^{54}$ housing costs defined as the cost of monthly rent or the cost of monthly mortgage and interest payment. Utility costs such as electricity or gas payments are not included in the calculation of housing costs. This cost is expressed as a rate of the household's equivalised monthly net income, which includes any social transfers tied to the cost of housing (Housing Assistance Payments and Rent Supplement

54 We equalise income to take account of different household needs and economies of scale. Equivalisation will affect the type of households who are in the bottom quintiles of the income distribution, and therefore the differences across the equality groups in affordability. We use the national equivalisation scale (natscl) as provided by the CSO. Alternative measures exist, such as the OECD equivalisation scale (Heylen, 2020; Nepal et al., 2010). However, we use the national scale in order to make our findings comparable with any future statistics released by the Central Statistics Office. 
etc). If this rate is above 30 per cent the first criterion is satisfied, in that the household has affordability issues.

Second, it only considers households in the bottom 40 per cent of the equivalised disposable income distribution. This second criterion aims to exclude wealthier households who may choose to spend a larger proportion of their income on more expensive housing. Landt and Bray (1997) show that the $30 / 40$ rule is better able to capture groups experiencing housing stress such as lone parents, young and single people, as well as elderly couples. Testing the appropriateness of the 30/40 rule in Ireland, Corrigan et al. (2019b) find that a non-equivalised version of the measure identifies a group with very low residual incomes after paying their housing payment costs, although they also note that a higher income cut-off may be more suitable. Nepal et al. (2010) suggest using the $30 / 40$ rule, as the rule is less:

sensitive to the choice of income type because of larger differences between disposable and gross income at the higher rather than lower end of the income distribution.

While affordability is measured at the household level, we apply the outcome to each household member and report the characteristics of all individuals, not just that of the head of the household or the primary tenant.

We find that 7.7 per cent of respondents spend more than 30 per cent of their income on housing. Restricting the definition to those who are also in the bottom 40 per cent of the income distribution we find that 5 per cent of individuals have affordability issues, although the figures vary strongly by tenure status. ${ }^{55}$ We do not find a gender difference in affordability using this measure, with both men and women reporting unaffordable housing costs at a similar rate (5 per cent).

We also find few differences between age groups in their chances of facing issues of affordability. However, respondents aged 0-17 (7 per cent) and 25-44 (6 per cent) report the 
highest rates of unaffordability, while respondents aged 65 and over report the lowest rates of unaffordability (less than 1 per cent). This difference is also statistically significant, with both young age groups reporting significantly higher rates than the remaining groups. We previously noted that people over 65 are the most likely own their home outright, while respondents aged 0-17 were the most likely group to be children in a young family who hold a mortgage. We also know from previous research that homeownership rates correlate with age, even within income quintiles (Quigley and Raphael, 2004). This difference may play a part in age differences in affordability. For this reason, these groups may differ in the size and type of home that they need, which could impact housing costs and affordability. The finding is consistent with research that shows children are more likely to experience deprivation and income poverty (Maître, 2020; Watson et al., 2012).

We find a statistically significant difference between respondents born in Ireland (3 per cent) and respondents born abroad facing issues of affordability ( 9 per cent). Those born abroad are more likely to live in urban areas where housing is more expensive, when compared to respondents born in Ireland. They are also more likely to rent in the private market (see Chapter 3; and Fahey et al., 2019) compared to those born in Ireland, who are more likely to own their home outright. Further, there are substantial differences within the migrant group. Non-EU migrants (13 per cent) and EU-East migrants (10 per cent) have high rates of affordability issues. Affordability problems among EU-West respondents are uncommon, and we cannot show the results due to CSO rules on small sample size. Migrants from the UK (4 per cent) have the lowest rate of affordability issues among migrant groups. Previous research has shown substantial differences between migrant groups in terms of access to work, and access to high-skilled work (McGinnity et al., 2020b). These differences are also likely to influence the ability to cover the cost of housing. 
FIGURE 4.2 GROUP DIFFERENCES IN AFFORDABILITY 30/40 RULE (SILC 2018 AND 2019)

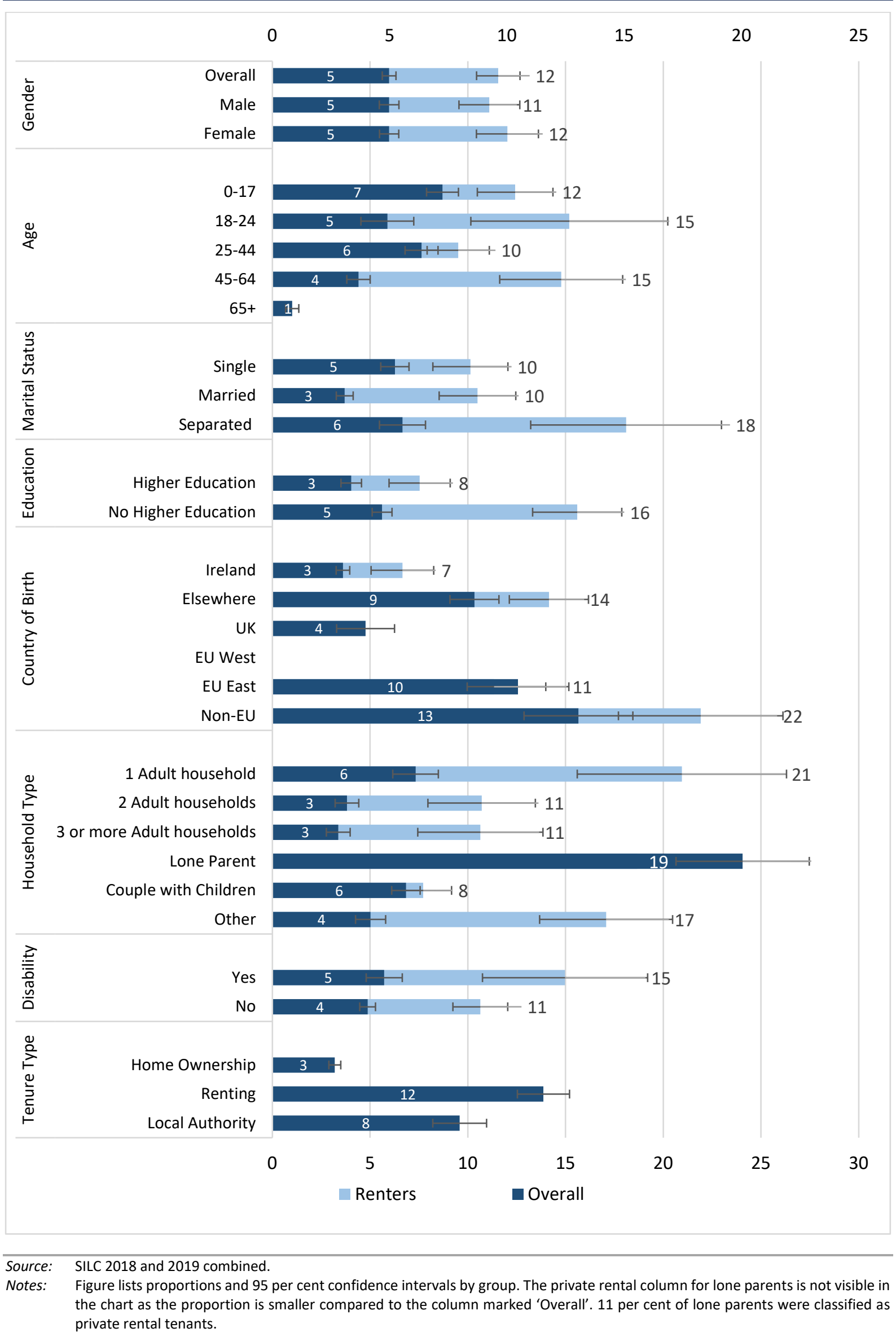


There is a significant difference in affordability between different marital status groups. Respondents who were never married and those who are separated, divorced, or widowed both have significantly higher rates of affordability problems ( 5 per cent and 6 per cent respectively), when compared to married respondents ( 3 per cent). This difference may stem from the number of working individuals in the household, and this could be reflected in the advantage that married respondents have in terms of affordability.

We also find a significant difference in affordability issues between those with ( 3 per cent) and without ( 5 per cent) a third-level education. Although the difference is minor, those with a third-level education have a lower chance of experiencing affordability issues. Given the difference in age composition between the two groups, and the fact that older respondents likely own their own home, these gaps may become more extreme when focusing only on those in the private rental sector, as previous research has shown (Corrigan et al., 2019b).

Regarding household composition, lone parent families have the highest chance of experiencing affordability issues (19 per cent), which is by far the highest rate of the categories considered. Single adults ( 6 per cent) and two adults with children (6 per cent) report a similar rate. Adult couple households without children have significantly lower rates of affordability issues ( 3 per cent), even when compared to single adult households. Previous research has shown that lone parent families are especially likely to experience deprivation and non-employment (Privalko 2019; Maître et al., 2020, Watson et al., 2016).

Finally, we consider the difference between individuals with and without a disability. Those with a disability report higher rates of affordability issues, when compared to those without a disability. This difference could stem from the lower employment rates among individuals with a disability or the frequent underemployment of people with a disability (McGlinchey et al., 2013; Watson et al., 2015; 2016; Berthoud, 2008).

For reference purposes, we also note that there are tenure differences in this rule, as noted by Corrigan et al. (2019b). Affordability issues are least common among owner-occupiers (3 per cent), rise to 8 per cent for Local Authority tenants, and are highest among those who rent in the private sector (12 per cent). 
We also present group differences in unaffordable housing for those in the private rented sector (Table 4.1). The divergence in affordability between groups is even wider among those living in a privately rented home. Among private tenants, one-in-five non-EU tenants in this sector experiences affordability problems. This suggests that private renting encompasses both advantaged and disadvantaged groups.

\subsubsection{Poverty after housing costs}

This measure is similar to the $30 / 40$ rule but is designed specifically with those at risk of poverty in mind. Corrigan et al. (2019b) propose that high income groups are able to sustain paying a higher proportion of their income on housing costs because their residual income is sufficient to cover other living expenses. Despite this, the authors later find that residual income can often be low even in the $60^{\text {th }}$ percentile after housing costs are accounted for. For this measure, we identify those who fall below an income poverty threshold when housing costs are deducted from income (60 per cent of the median ${ }^{56}$ equivalised posthousing costs income). This approach is similar to Byrne and Treanor (2020) and Fahey et al. (2004). Saunders et al. (2016) use a similar measure but set the poverty line at 50 per cent of median income after housing costs.

Because we have two years of data, we consider two separate benchmarks, which depend on the year of interview. We use equivalised measures for both disposable income and housing costs (the monthly rent, or mortgage and interest payments).

Under this definition 15 per cent of the population are experiencing difficulties with housing costs. An important feature of this measure is that it includes households who have a low income before housing costs are included. For this group affordability issues arise because of low income and poverty, regardless of housing costs. For example, households living in Local Authority housing may be below this income threshold even though their subsidised rents are low, similarly older people on a low pension income but who own their home outright would be included in this measure despite having no housing costs. 
FIGURE 4.3 GROUP DIFFERENCES IN POVERTY AFTER HOUSING COSTS (SILC 2018 AND 2019)

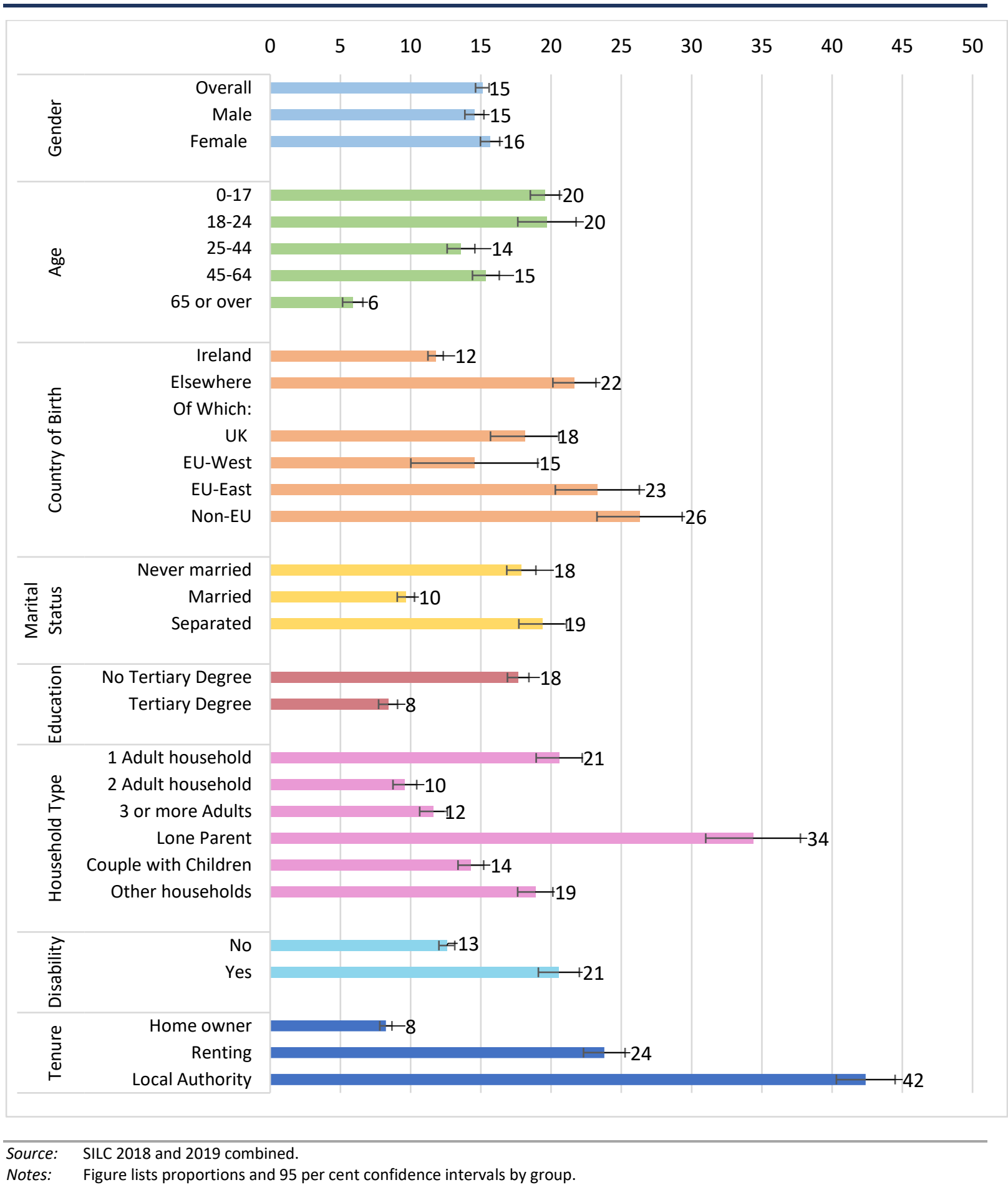

We find no gender difference in post-housing cost poverty, with women having a similar rate of poverty (16 per cent) to men (15 per cent). We find significant age differences; children aged 0-17 and those aged 18-24 experience the highest poverty rates (20 per cent). Respondents aged 65 and older report the lowest poverty rate (10 per cent). Previous research shows that income poverty is more prevalent among households with young 
children which will influence this measure (Maître et al., 2020; CSO, 2019; ${ }^{57}$ Byrne and Treanor, 2020; Watson et al., 2016).

We find a statistically significant difference in poverty between respondents born in Ireland (11 per cent) and respondents born elsewhere (22 per cent), which could stem from a difference in incomes and/or a difference in housing costs between the two groups. As before, there are wide group differences between migrant groups, with EU-East migrants reporting significantly higher rates of poverty (24 per cent) when compared to Irish-born respondents. Migrants from EU-West have the lowest rate of poverty (18 per cent) among the migrant groups and this rate is not significantly different from respondents born in Ireland. The highest rate was recorded among non-EU migrants (26 per cent) which was significantly different from respondents born in Ireland.

There are substantial differences in poverty after housing costs between marital status groups. Married respondents are significantly less likely to experience poverty (10 per cent) compared to respondents who were never married (18 per cent). Respondents who were separated/divorced/widowed also report a high poverty rate (19 per cent), however this rate is not significantly different from the never married group, as in the $30 / 40$ rule indicator. Age and household composition are likely confounding factors here.

We also find a difference between those with ( 8 per cent) and those without (18 per cent) a third-level education. This finding is to be expected given the lower labour market participation and average earnings among those without a third-level education, when compared to graduates. Those living alone, i.e. single adult households (34 per cent) have significantly higher chance of poverty when compared to almost every other household category. The only exception is lone parent households, where the poverty rate after housing costs is, again, 20 per cent.

Finally, we find a significant difference between respondents without a disability (12 per cent) and respondents with a disability (20 per cent). Given the fact that respondents with a disability report higher chances of living in owner-occupied housing (as shown in Chapter 3), 
this result could stem from the lower incomes and lower chances of employment among people with a disability (McGlinchey et al., 2013; Watson et al., 2015; 2016).

As a reference point, we also consider the tenure differences in this measure. As before those who own their own home are less likely to experience poverty (8 per cent), when compared to respondents who rent privately (24 per cent) and those who rent from their Local Authority (42 per cent). Here too, those renting from Local Authorities have especially low incomes, and as a result are closer to the poverty benchmark despite being in social housing. Meanwhile older respondents are more likely to own their own home, and this group has seen especially low levels of poverty and deprivation in recent years (Roantree et al., 2021; Maître et al., 2020; Privalko et al., 2019).

\subsubsection{Arrears on housing costs (rent and mortgage payments)}

Our final indicator considers the percentage of people who have experienced arrears on mortgage or rental payments in the last 12 months. Lapsed payments in housing costs increase the chance of homelessness, especially among those in the private rental sector affected by poor supply (Corrigan and Watson, 2018) and therefore are linked to another source of housing adequacy - security. Housing arrears are an important predictor of financial stress. One limitation of this measure is that people who cut back on essential costs (such as food, heating, or health) to avoid arrears are considered as not having affordability issues. However, these respondents are captured by the previous two indicators as having an affordability issue.

Overall, 9 per cent of the population experienced such arrears in 2018/2019, with women (9 per cent) reporting a similar rate to men (8 per cent). Children aged 0-17 and young adults aged 18-24 are most likely to live in households experiencing arrears (10 per cent). Arrears are the least common among those aged 65 and over, this very low percentage has a cell size that prohibits us from reporting the score.

We find no significant difference between Irish-born (8 per cent) and non-Irish born respondents (9 per cent). However, there are group differences in the migrant category that are worth noting, with non-EU migrants reporting significantly higher rates of arrears 
(12 per cent) compared to Irish-born respondents. We again cannot comment on migrants from EU-West countries because arrears are simply too uncommon among this group.

Regarding marital status, we note that married respondents are the group least likely to experience arrears ( 6 per cent), as with the previous two affordability measures. Those who are separated have the highest rate of arrears (15 per cent) most likely because separated and divorced individuals live in single income households, highlighting a significant problem for this group. People who were never married also have higher chances of arrears (10 per cent) which is likely related to age and greater use of private rented accommodation (see Chapter 3).

On education, we find that respondents with a third-level degree ( 5 per cent) have lower chances of arrears when compared to those without a degree (11 per cent). This difference also likely stems from the lower earnings of those without a degree, as well as their less stable work contracts.

There are significant household composition differences in arrears, with lone parents reporting more arrears (13 per cent) than two-adult households without children ( 7 per cent). Single person households also have a relatively high level of arrears (10 per cent). 


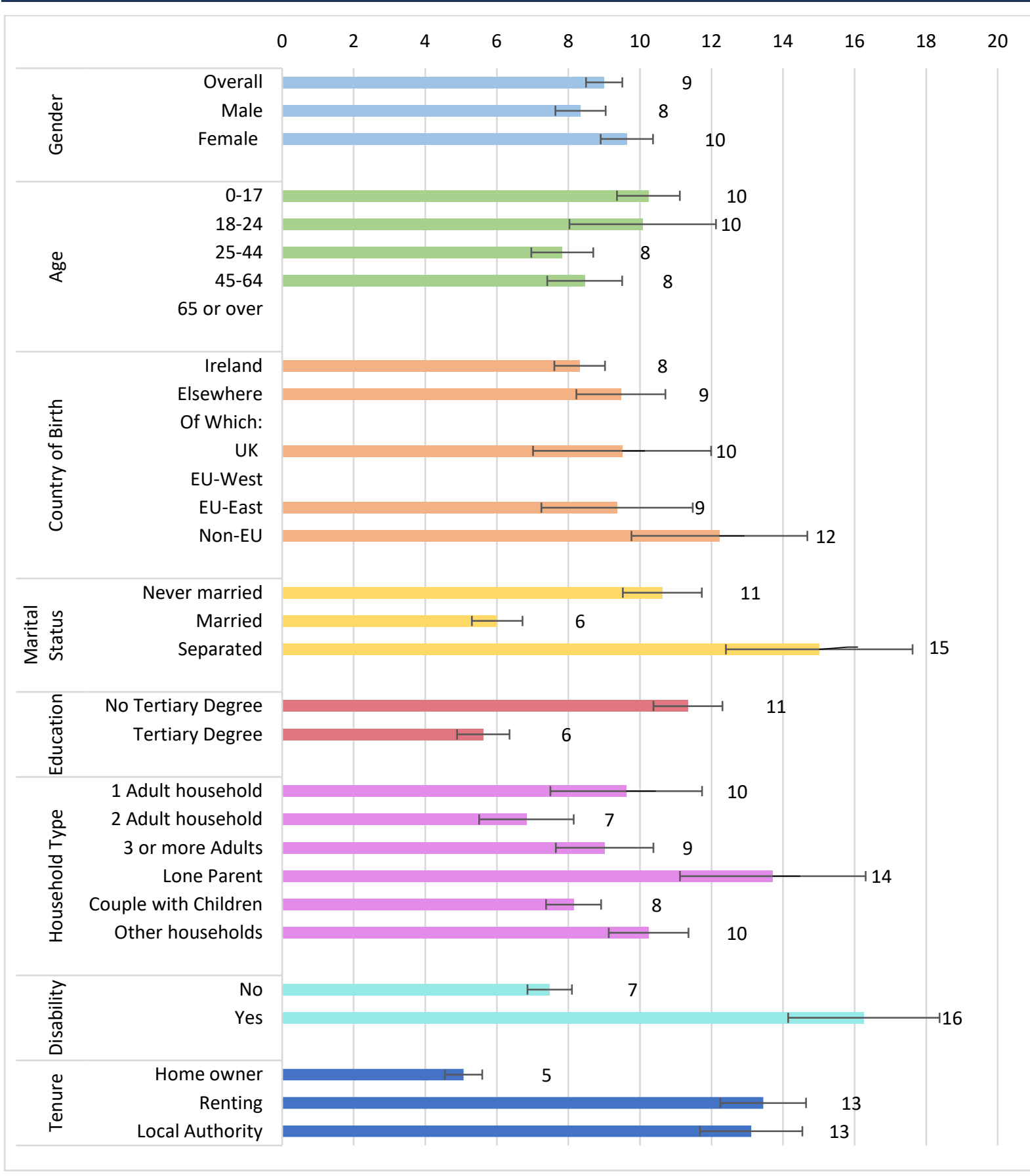

Source: $\quad$ SILC 2018 and 2019 combined.

Notes: $\quad$ Figure lists proportions and 95 per cent confidence intervals by group.

Finally, respondents with a disability report significantly higher chances of arrears (16 per cent) when compared to respondents without a disability (7 per cent). Again, this difference likely stems from the lower rates of employment among respondents with a disability, and the unstable nature of that employment (Watson et al., 2015). 
Once again, we include differences in tenure for reference. Homeowners are less likely to experience arrears (5 per cent), while those who rent privately (13 per cent) and those who rent from their Local Authority (13 per cent) have higher chances of arrears.

\subsection{SUMMARY}

Issues with housing affordability can lead to over indebtedness (Russell et al., 2011), homelessness (Corrigan and Watson, 2018), or poverty (Watson et al., 2020). Group differences in affordability can signal a given group's disadvantage in the housing market. While some issues with affordability can be transitory, for example among young professionals at the start of their career, wider differences between groups can point to structural vulnerabilities.

Using a range of indicators, we find that similar groups tend to record affordability issues regardless of measure. Lone parent households routinely record higher rates of affordability issues when compared to other household types. We know from previous research that this group also relies on housing transfers to alleviate the pressures of deprivation and low income (Maître et al., 2020). Children and young adults are also exposed to higher rate of affordability issues on all three measures. Given that children are disproportionately more likely to experience poverty than other age groups (CSO, 2019; Watson et al., 2016; Maître et al., 2020) this makes sense, and likely stems from the income of early career, young parents, and the expenses of households with children relative to households without children.

Previous research has shown that the living conditions of children in Ireland were significantly affected after the recession (Whelan et al., 2016; Watson et al., 2016). Thus, part of the affordability issues that we see among those aged 0-17 may reflect deeper rooted poverty issues.

We also see that migrant groups experience greater affordability issues than non-migrants on all three measures. Part of this result is explained by the fact that migrant groups are more likely to rent from the private market, whether due to preference or to lack of access to a mortgage. 


\subsection{DATA GAPS}

We note several important gaps in the discussion of affordability. First, SILC does not collect information on respondent's religion, ethnicity, sexual orientation, or minority gender status. As a result, we cannot comment on differences between these groups. Further, the data available on migrants do not consider second generation migrants, who are a key group in studies of integration outcomes. Given the way that the data are collected, these respondents are recorded as non-migrants, and although it is true that such respondents are Irish-born respondents, they also form a part of a group that is relevant to integration studies and therefore are worth monitoring explicitly. Distinguishing these respondents would lead to a better understanding of migrant status and the impact of duration in Ireland on housing outcomes (McGinnity et al., 2020b).

Information on ethnicity, sexual orientation and religion are not collected in administrative data, such as PASS data on homeless services for example; however data matching by the CSO has expanded the scope of these data considerably and allowed us to explore these characteristics amongst HAP recipients, for example.

Data for migrant groups are available in SILC, however limitations in the number of observations means that the data cannot be split into more meaningful groups of migrants. Previous research has shown that migrants vary extensively by country of birth, and that broad continent categories (like those used throughout the chapter) hide differences between countries of birth (McGinnity et al., 2020b). 



\section{CHAPTER 5}

\section{Security}

Housing security is a core aspect of the right to housing under Article 11(1) of ICESCR which specifies that all individuals, regardless of their housing tenure should have some degree of security surrounding their housing which 'guarantees legal protection against forced eviction, harassment, and other threats'. ${ }^{58}$ Regarding forced eviction, ICESCR requires states to ensure that all possible options are explored to avoid or minimise forced evictions and that those affected have access to all 'legal recourses and remedies' ${ }^{59}$ Security is also broadly covered under Article 31 of the European Social Charter which states that the State should prevent and reduce homelessness. Under Article 17 of the International Covenant on Civil and Political rights, individuals should be protected from 'unlawful interference' with their home. This protection is also covered for children under the Convention of the Rights of a Child. ${ }^{60}$

Many international treaty monitoring committees also require the State to realise the right to non-discrimination in relation to this aspect of the right to housing for certain groups such as families, ${ }^{61}$ migrant workers and their families, ${ }^{62}$ racial, national, or ethnic minorities, ${ }^{63}$ those with disabilities, ${ }^{64}$ and those at risk of poverty of social exclusion. ${ }^{65}$ As mentioned in Chapter 3, Ireland was previously in violation of Article 16 of the European Social Charter (right of the family to social, legal, and economic protection). In the case of the European Roma Rights Centre (ERRC) v. Ireland, ${ }^{66}$ the security aspect of the right to housing was violated as there were 'inadequate safeguards for Travellers threatened with eviction' and evictions were carried without the necessary safeguards. In reference to this violation. IHREC (2021a) notes that although Ireland has made progress towards provision of

ISESCR 11(1) General Comment No.4, para 8(a).

ISECSR 11(1) General Comment No.7, para 11, 13.

CRC Article 16(1).

ESC Article 16.

ESC Article 19 (4).

CERD Article 5 (e)(iii).

CRPD Article 28 (1).

ESC Article 30.

No. 100/2013 European Roma Rights Centre (ERRC) v. Ireland. 
accommodation for Travellers, the long-term lack of such accommodation pushes many Travellers into the private rental sector or homelessness.

\subsection{ANALYTICAL APPROACH}

In terms of contextual indicators, this chapter considers three measures, two from the Residential Tenancies Board (RTB) - length of tenancy contract agreed, and number of disputes tied to termination of the lease, and one from the Central Bank of Ireland mortgage arrears and repossessions.

In terms of individual-level indicators, this chapter considers two outcomes from two data sources, the CSO's SILC dataset (2018 and 2019), and Eurofound's EQLS dataset (2016). From the SILC dataset we take a measure of the years living in current dwelling. The EQLS asks respondents 'How likely or unlikely do you think it is that you will need to leave your accommodation within the next six months because you can no longer afford it?'. Respondents who claim this is likely are given a value of 1 , all other answers are given a value of 0 (neither, unlikely, very unlikely).

\subsection{AGGREGATE INDICATORS}

\subsubsection{Length of tenancy}

We turn to data in the RTB/ESRI Rent Index report to consider the trend in the tenancy length i.e. the length of time covered by the rental agreement as agreed at the beginning of private sector rental tenancies. The actual duration of the tenancy may be longer, if the tenant renews their lease, or shorter, if they leave the property (or are forced to leave the property) before the existing lease expires. It is important to note that the RTB data do not represent the entirety of the Irish private rental market, however this is the best available data source on tenancy length in the private rental market.

Figure 5.1 shows that longer tenancies are becoming more common in the Irish rental market, with growth in the number of tenancies lasting 12 months or more. The RTB does not consider the duration of the tenancy overall in this measure. These data would be useful in future reports, as they would indicate turbulence of the private rented sector. Combined 
with some measure of tenant characteristics, it would be easier to track groups that are structurally vulnerable to precarious tenancies.

\section{FIGURE 5.1 RTB/ESRI RENT INDEX - TENANCY LENGTH BY QUARTER (\%)}

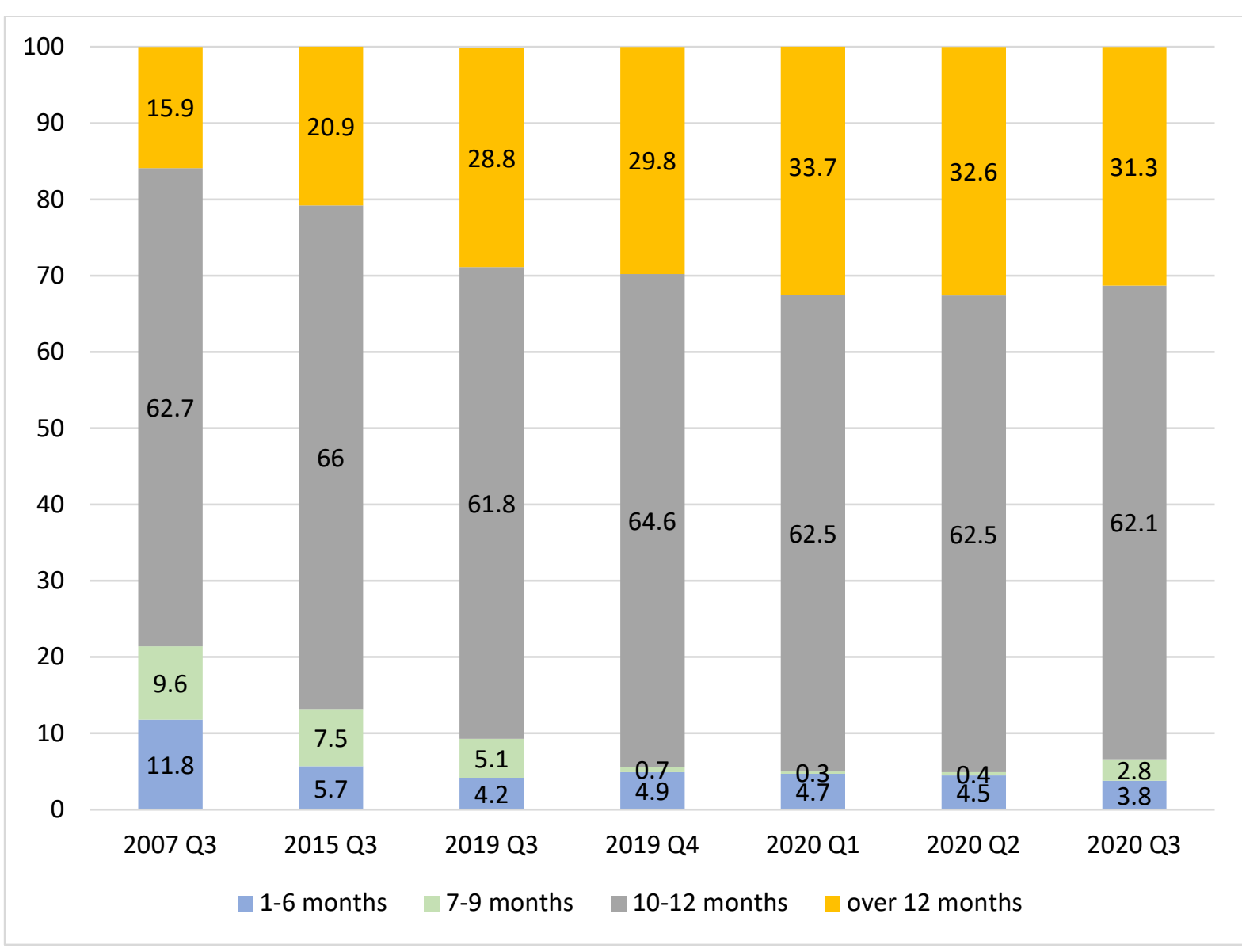

Source: $\quad$ Residential Tenancies Board Rent Index Report Q3 2020.

\subsubsection{Termination disputes in the private rental market}

Our second indicator uses dispute resolution statistics as reported by the Residential Tenancies Board. These are summarised in Table 5.1. While the total number of disputes has risen between 2017 and 2019 (we include incomplete data for 2020 as reference), the number of disputes tied to the validity of the notice of termination has fallen, as has its percentage relative to all disputes. Importantly, 2020 brought a moratorium on evictions from March to August. ${ }^{67}$ This was then reintroduced from December 2020 to April $2021 .{ }^{68}$ to-be-extended-until-august-1st. 
Part of the fall in unlawful evictions would be as a result of these rules, which ended all terminations and evictions.

The number of disputes tied to unlawful terminations has remained stable between 2017 and 2019, but its percentage of overall disputes has fallen. This suggests such disputes are less common between those years. It may also suggest that tenants are less willing to report such disputes, since tenancies are becoming more competitive, and households are uncertain about securing new, affordable tenancies (Byrne and McArdle, 2020).

Further, the RTB provided researchers with a breakdown of all notices of termination received between Q2 2019 and Q3 2020. Prior to this, landlords were not required to notify the RTB if issuing a Notice of Termination. These statistics should be read with caution for two reasons. First, a notice of termination does not mean that a tenancy has ended. Second, the RTB may not receive all notices issued to tenants. For example, Table 5.1 shows that the number of disputes tied to the validity of termination notices is greater than the number of termination notices received by the RTB in 2019. Despite these limitations, there has been an increase in the number of termination notices issued in 2020 , with most notices coming from Q1 of 2020 (774). This sharp difference may come from the second point noted above, that the RTB are only receiving a portion of notices issued to tenants. Since the rules were only introduced in 2019, the RTB may be picking up a greater portion of notices in 2020.

While RTB figures are not representative of illegal terminations or broader evictions, the figures suggest these disputes are recorded less often, which could point to a fall. These figures could also stem from a fall in the reporting of disputes by tenants and landlords. Byrne and McArdle (2020) show through qualitative interviews that some tenants are becoming increasingly reluctant to challenge landlords due to a lack of available and affordable tenancies in Ireland. This factor could also be impacting the trends in Table 5.1. 


\begin{tabular}{|c|c|c|c|c|}
\hline Dispute type & 2017 & 2018 & 2019 & 2020 (Q1-Q3) \\
\hline Tenant disputes & 3,696 & 3,775 & 3,515 & 2,240 \\
\hline Landlord disputes & 2,015 & 2,495 & 2,539 & 1,529 \\
\hline Third party disputes & 112 & 128 & 131 & 102 \\
\hline Total & 5,823 & 6,398 & 6,185 & 3,871 \\
\hline Validity of notice of termination & 1,505 & 1,396 & 1,345 & 524 \\
\hline $\begin{array}{l}\text { Validity of notice of termination } \\
\text { as a per cent of all disputes }\end{array}$ & $25.85 \%$ & $21.82 \%$ & $21.75 \%$ & $13.54 \%$ \\
\hline Unlawful termination & 491 & 503 & 459 & 294 \\
\hline $\begin{array}{l}\text { Unlawful termination as a per } \\
\text { cent of all disputes }\end{array}$ & $8.43 \%$ & $7.86 \%$ & $7.42 \%$ & $7.59 \%$ \\
\hline $\begin{array}{l}\text { Notices of termination received } \\
\text { by the RTB (Q2 2019-Q3 2020) }\end{array}$ & NA & NA & 677 & 1,377 \\
\hline
\end{tabular}

\subsubsection{Mortgage arrears and repossessions}

Our third indicator considers the Central Banks of Ireland's Residential Mortgage Arrears and Repossession Statistics. We also split these figures by Principal Domestic House (PDH) and Buy to Let (BTL) properties. ${ }^{69}$

After the onset of the crisis, Ireland saw an increase in the number of principal dwellings in payment arrears. These arrears decreased from 2013 as the economy began to recover. Arrears returned to 2009 rates by 2020 . This fall represents greater security among those who own their own home.

From 2013 onwards there was also a small decline in the mortgage arrears of BTL properties. While these mortgages are between landlords and lending bodies (which exclude tenants), their decline will also bring some security to those in the private rental sector. However, given that unstable private rented accommodation is closely associated with homelessness (Corrigan and Watson, 2018), the trend of mortgage arrears, especially of those in the BTL category, should be monitored closely. 


\section{FIGURE 5.2 TOTAL MORTGAGE ACCOUNTS IN ARREARS BY PRINCIPAL DWELLING HOUSES (PDH) AND BUY TO LET (BTL)}

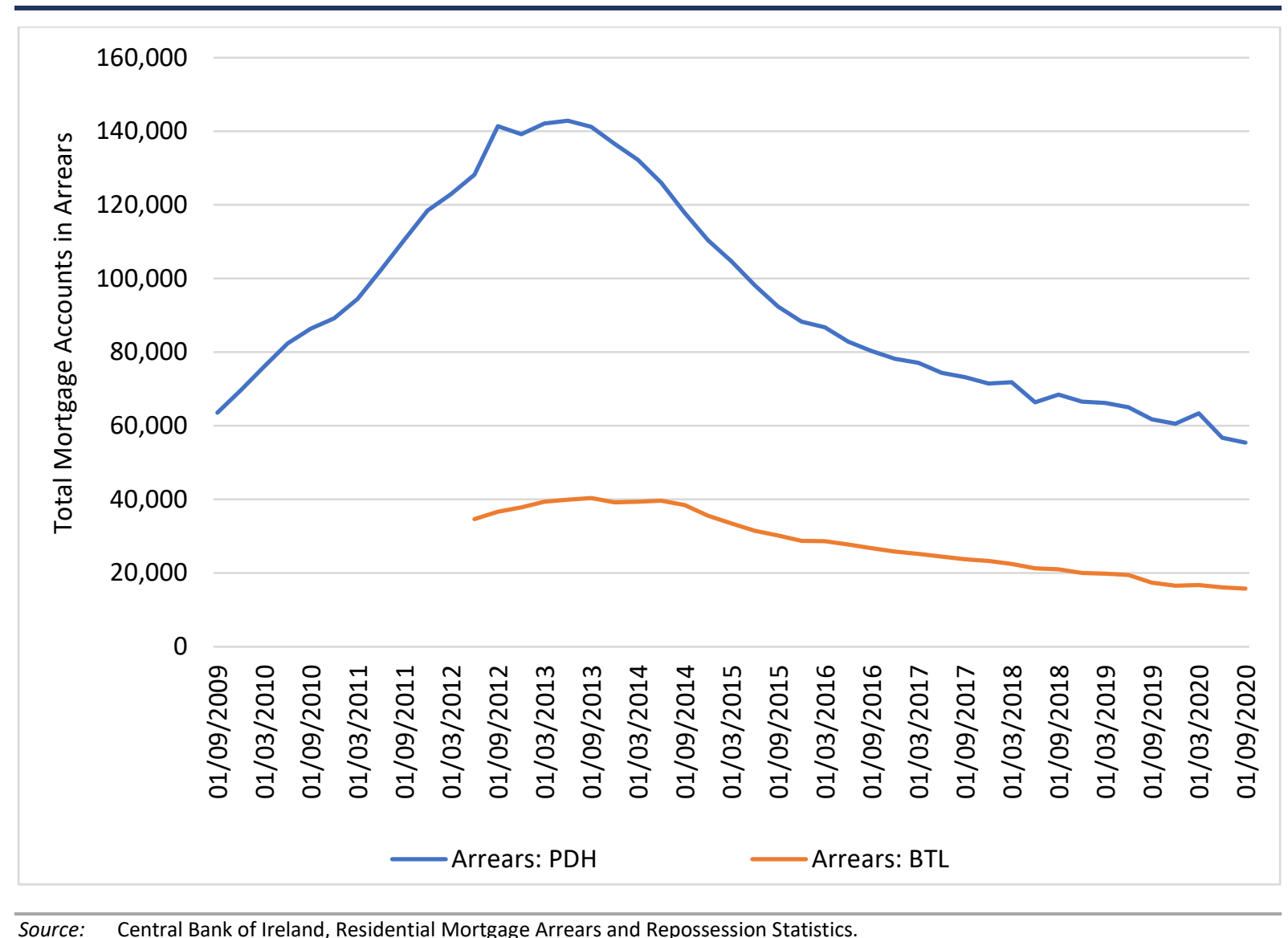

Source: Central Bank of Ireland, Residential Mortgage Arrears and Repossession Statistics.

A portion of properties that have mortgage arrears are repossessed. This figure rose steadily from 2009 to 2016 among Principal Dwelling Households before declining slowly. The change in Buy to Let properties was sudden, after a period of relative stability. The jump in repossessions in 2018 comes from a high number of cases where properties were voluntarily surrendered or abandoned in the previous quarter. This jump in repossessions may affect the security of those living in private rented accommodation, although such repossessions are highly uncommon, relative to the number of properties which are in arrears. 


\section{FIGURE 5.3 RESIDENTIAL PROPERTIES IN REPOSSESSION AT BEGINNING OF QUARTER BY PRINCIPAL DWELLING HOUSES (PDH) AND BUY TO LET (BTL)}

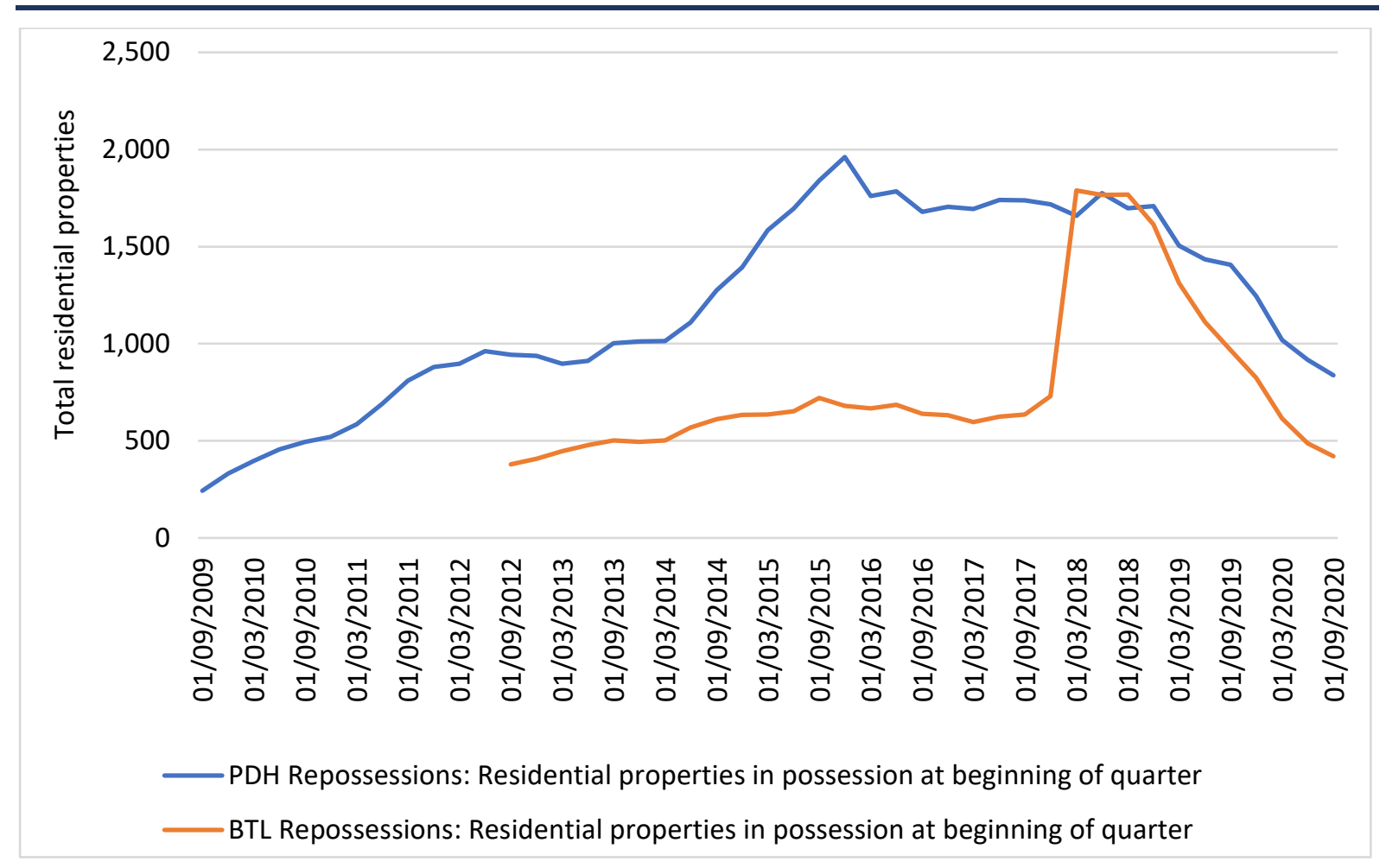

Source: Central Bank of Ireland, Residential Mortgage Arrears and Repossession Statistics.

Note: $\quad$ The sudden increase in the possession of Buy to Let properties in 2018 stems from a sudden rise in properties voluntarily surrendered or abandoned. This figure increased suddenly from 243 in September 2017 to 1,191 in December 2017, before falling again to 129 in March 2018.

Overall, we find that from 2013 onwards the tenancy length of private rented accommodation has increased, and the number of complaints tied to lease terminations has declined, at least among the total set of complaints recorded by the RTB. We also find a fall in the number of mortgage arrears, both tied to principal dwellings and Buy to Let properties. Lastly, we note a decline in repossessions of principal dwellings but a sudden increase in the repossessions tied to Buy to Let properties. Although they may affect the security of those in the private rented sector, they make up a minor portion of all properties that are in arrears.

In general, we find that measures of security are improving at the aggregate level. However, these aggregate level figures may hide group differences in this security. We now turn to these group differences, using micro-level data. 


\subsection{INDIVIDUAL LEVEL INDICATORS}

\subsubsection{Length of time in current dwelling by equality groups}

Figure 5.4 considers the average tenure lengths for our social risk groups overall, and for those who live in the private rental market only. On average, we find that respondents have been living in their current dwelling for an average of 16 years. We also note that those who rent have been in their dwelling for far shorter (four years on average). This measure is limited in that any address-based survey is more likely to pick up longer housing tenures. Also, the duration of residency is ongoing, and we do not know what the outcome will be i.e. whether occupants will continue their current residence or move either by choice or by necessity. However, the purpose of this indicator is to highlight whether certain groups have shorter tenancies on average, which could capture a tendency to move between dwellings more often than other groups. In the discussion below, we first note group differences in the sample overall, before considering only those in the private rental market.

We first consider the average duration of residency for all respondents, before considering the duration for rental sector respondents alone. Both men and women report having roughly 16 years tenure on average. There is no significant gender difference in duration of gender. This reflects similar findings in an earlier report produced under this research programme by Grotti et al. (2018) who find few differences between men and women in terms of housing outcomes but note that lone parents, the majority of whom are women, may be disadvantaged in terms of tenure duration. We will report similar results later. 
FIGURE 5.4 LENGTH OF TIME (MEAN YEARS) IN CURRENT DWELLING (SILC 2018 AND 2019)

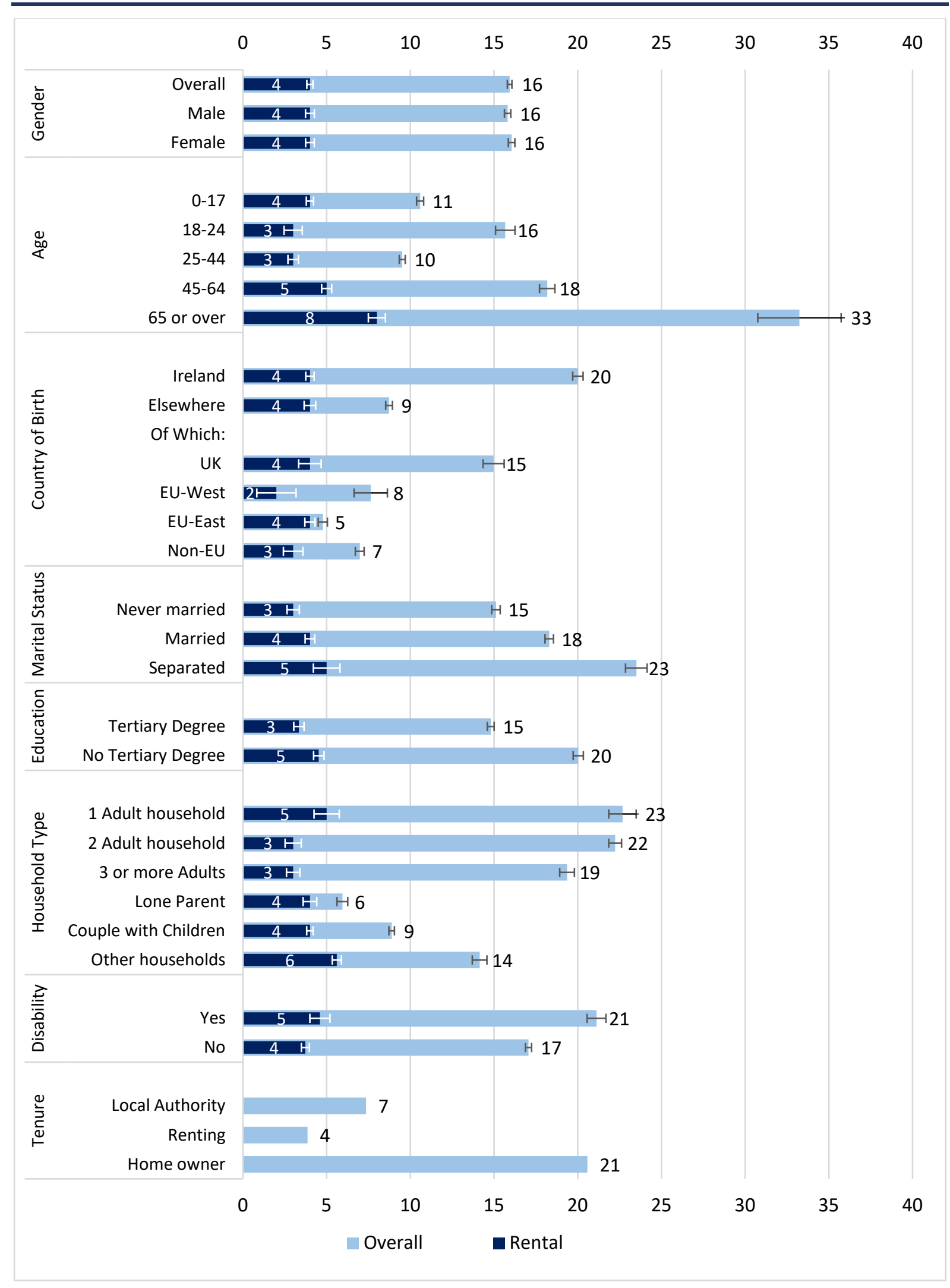

Source: $\quad$ SILC 2018 and 2019 combined.

Notes: $\quad$ Figure lists proportions and 95 per cent confidence intervals by group. 
Those aged 25-44 report significantly lower tenure on average (nine years), when compared to the youngest group (0-17 years of age). This may be because the 25-44 age group has had to leave the family home for work or college. Those aged 18-24 report longer tenures on average (16 years) most likely because a greater portion of these people still live in the family home with parents. Those aged 45-64 have significantly longer tenure on average (18 years) which is roughly double that of the previous group. The highest average tenure is that of those aged aver 65 (33 years), most likely because this is the oldest age group and because this age group has the highest chance of owning their own home. Previous research shows that groups under 30 are especially vulnerable to disadvantage and discrimination in the Irish housing market (Grotti et al., 2018).

As expected, migrants have significantly lower duration of residency in current dwelling, on average (nine years), when compared to people born in Ireland (20 years). Within this group there are also wider differences, with those born in the UK having longer tenure (15 years), but at a level that is significantly lower than those born in Ireland. These differences are likely to reflect duration of time in Ireland, alongside other factors. Those from EU-East countries have the lowest duration of tenure (five years) on average, which is again significantly different from respondents born in Ireland. The EU-West group (15 years) also has lower tenure when compared to respondents born in Ireland, as do respondents born in countries outside the EU (six years). In general, migrants from EU-East, EU-West, and nonEU countries may be more susceptible to mobility in the housing market when compared to respondents born in Ireland and the UK. Among those who are renting, differences between groups are smaller and it is Western European migrants who report the shortest tenancies.

The overall findings fit with previous work on migrant differences in housing outcomes. Migrant status and non-citizenship have a negative effect on homeownership in the US (Coulson, 2002) which in turn affects tenure durations. However, other research points to age, duration in the country, and other important factors which could explain this difference (OECD, 2015; Hilber, 2007; McGinnity et al., 2020b). Research from Ireland suggests that migrants have a higher chance of renting in the private housing market and significantly lower chances of homeownership, although differences in duration in Ireland are again important (Maître and Fahey, 2018; Maître and Russell, 2017). 
Regarding marital status, people who have never married record lower tenure length (15 years) when compared to married (18 years) and separated, widowed, or divorced respondents ( 23 years). Here there is also a possible age effect; we also know that married respondents are more likely to own their own home with a mortgage, which means they are more established in their home than those in the private rental market. Again, these differences are much narrower when we consider only those in the private rental sector.

There is a significant difference by education, with those who have a third-level education recording a shorter tenure on average (14 years) when compared to those without a degree (20 years). This is likely to be an age effect as older groups are less likely to hold a tertiary qualification. The pattern may also be influenced by greater occupational and consequent geographical mobility among those with higher educational qualifications (Reichelt and Abraham, 2017). These differences remain for those in the rental sector, but they are greatly reduced.

Further, there is a difference in household composition and average tenure in years. Tenure is especially short for lone parent households (six years) which suggests this group is more mobile in the housing market, when compared to other groups. This difference could stem from housing mobility connected to family formation; however it is also possible that lone parents are susceptible to precarious positions in the housing market, meaning they must move often. We saw in Chapter 3 that lone parents are much more likely to live in private rented housing than other groups. This appears to be a significant factor in length of occupancy: when we confine the analysis to this sector, lone parent households are not distinctive. Households where two adults live with children also have significantly lower tenures on average (nine years) when compared to households where one adult lives alone (22 years tenure). Two-adult households without children also have higher durations of tenure (22 years). 
Finally, we can consider group differences between those with and those without a disability. Those with a disability report longer tenures (21 years) when compared to those without a disability (17 years). This reflects the older age profile of those with a disability. ${ }^{70}$

For reference, we also include the differences in tenancy type in tenure duration. As expected, homeowners have higher tenure durations on average (21 years) when compared to those renting from the private market (four years), or the Local Authority (seven years). Group differences are narrower among private renters suggesting that the variations found for the overall sample are connected to tenure type.

\subsubsection{Subjective security of housing}

We now turn to group differences in subjective security. The results come from responses to the question 'How likely or unlikely do you think it is that you will need to leave your accommodation within the next six months because you can no longer afford it?'. Overall, we find a low level of insecurity on this measure. Among 1,008 respondents, just 40 (4 per cent) say they are 'likely' to have to move for affordability reasons. Thus, it may be that even those with affordability issues feel somewhat secure in their home. The measure only captures those who may have to move for affordability reasons and not those who are insecure because of short-term leases or landlord decisions.

There is no significant difference in security between men and women. Younger respondents are more likely to report insecurity. Among those aged 18-24, 5 per cent report insecurity, but among those aged 65 and over just 1 per cent noted insecurity. However, due to the small sample size, this difference is not statistically significant.

Those born outside of Ireland (7 per cent) report higher insecurity than those born in Ireland (3 per cent). However, this difference is only significant at the 0.1 level. Part of this effect may come from tenure differences where migrants have reduced access to homeownership and Local Authority renting (Maître and Russell, 2017; Maître and Fahey, 2018). Some of 
this effect may also stem from affordability, as migrants from non-English speaking countries find it harder to maintain spells of affordable housing (Wood and Ong, 2011).

Never married respondents ( 5 per cent) have a higher rate of subjective insecurity when compared to married ( 3 per cent) and separated respondents ( 3 per cent), however these differences are not statistically significant. Further, respondents with a tertiary degree report higher insecurity ( 5 per cent) when compared to those without a college degree (3 per cent) but again, this difference is insignificant due to sample size.

Regarding household composition we see higher levels of insecurity among vulnerable groups, with lone parents (10 per cent) having higher insecurity when compared to households without children (4 per cent for both single and coupled households). This difference does not emerge for households with ( 3 per cent) and without (4 per cent) a disability but, as before, none of the estimates are statistically significant. 
FIGURE 5.5 GROUP DIFFERENCES IN SUBJECTIVE INSECURITY OF HOUSING (EQLS, 2016)

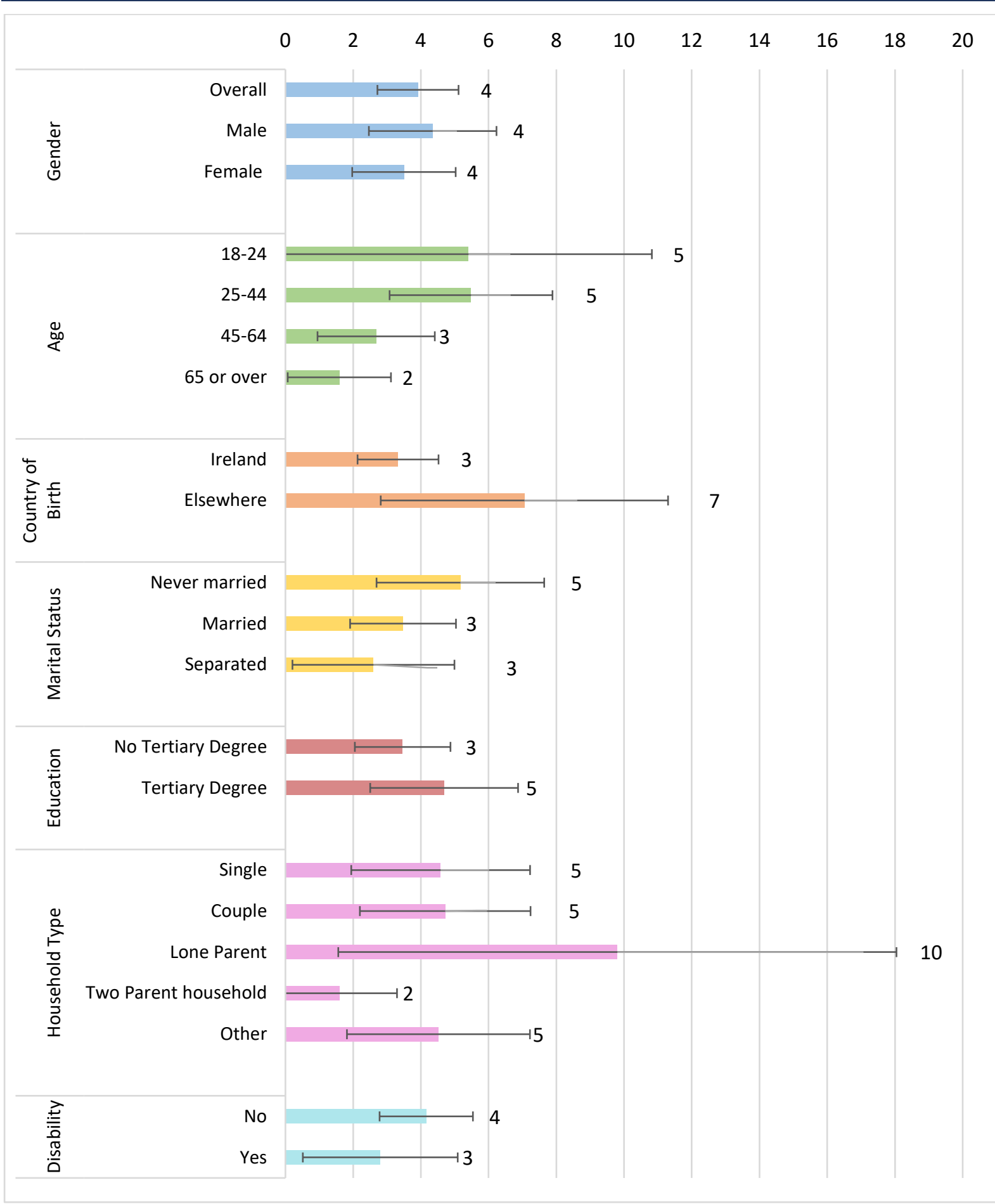

Source: EQLS 2016.

Notes: $\quad$ Figure lists proportions and 95 per cent confidence intervals by group.

In general, only a small minority of respondents feels insecure to the extent that they may have to change their home in the coming year due to affordability issues. It is likely that this question is too narrow to capture wider insecurity felt by tenants who worry about losing their home for other reasons unrelated to affordability. Byrne and McArdle (2020) argue that insecurity in the Irish rental sector is a function of the relationship between landlords 
and tenants. In short, the power asymmetry between landlords and tenants allows the former to create insecure housing environments despite existing policies and legislation, or sometimes circumventing these. For example, landlords can terminate tenancies with the intention of selling or refurbishing a property, which impacts tenants even when they comply with their obligations (Byrne and McArdle, 2020). Further, they find that landlords can discriminate against certain tenants (by refusing HAP payments for example) and the tenants' fear of homelessness prevents them from reporting this, despite strong rules on this type of discrimination. Byrne and McArdle (2020) propose that secure housing is essential not only to the rights of the tenant but also within the overall housing model and the enforcement of existing rules.

\subsection{SUMMARY}

We note some positive trends in the data tied to security. There has been a fall in mortgage arrears on people's primary homes. This has had a positive effect in that repossessions have declined. There has also been a fall in the number of RTB disputes tied to terminations of the lease, however this figure is dependent on tenants taking action. Legitimate disputes are also shaped by existing law and policy, so weaknesses in tenant protection limit the number of cases that can be taken. For example, cases cannot be taken for terminations of tenancies where a landlord decides to sell the property, one of the key drivers of family homelessness (Focus Ireland, 2019). ${ }^{71}$

On the micro-level, we find several group differences in people's length of tenure, with lone parents and migrants noting significantly lower tenure than their respective reference groups. However, this difference does not emerge when observing tenure lengths for those only in the rental sector. Further, we find that data on insecurity in the EQLS are insufficient to consider subjective feelings about security of tenure, because of the relatively small sample size. We also considered additional data from the Housing Agency survey which also included a subjective security measure. Here too the numbers were too small to 
disaggregate responses, as just 30 respondents out of 605 reported their tenure as insecure or very insecure.

\subsection{DATA GAPS}

One of the main data gaps for housing security is the lack of data available on subjective experiences of security in housing. Although the EQLS does contain a measure on this, the sample size is too small to allow us to determine whether differences between groups are statistically significant. In addition, the EQLS does not contain questions on sexual orientation, religion, or gender identity beyond male and female, and we are unable to disaggregate migrant groups further than distinguishing between born in Ireland and born abroad. To allow for meaningful analysis of housing security, adequate data with large sample sizes are needed and a measure that captures the multifaceted nature of insecurity. One potential way to resolve this data gap is to add a question on subjective sense of housing security to an existing survey with a large sample size such as SILC. 


\section{CHAPTER 6}

\section{Cultural adequacy}

Cultural adequacy of housing as outlined in ICESCR refers to

the way housing is constructed, the building materials used and the policies supporting these [which] must appropriately enable the expression of cultural identity and diversity of housing. (see Appendix A1.1). ${ }^{72}$

Additionally, the availability of culturally appropriate housing for particular ethnic groups is addressed in the International Convention on the Elimination of All Forms of Racial Discrimination (CERD). General Recommendation 23 requires states to 'take the necessary measures, as appropriate, for offering Roma nomadic groups or Travellers camping places for their caravans, with all necessary facilities' (see online Appendix). Other general recommendations of CERD concern the avoidance of segregation in housing provision and the involvement of minority ethnic groups in housing policy and planning.

Cultural adequacy is also closely related to the dimension of access and adequacy. Ability to participate in the normal way of life in any society is a core element of relative measures of poverty. Measures of over-crowding also refer to norms for society that could be considered 'culturally adequate', for example norms about sharing rooms etc. These norms of basic adequacy are addressed in Chapter 7 under the housing quality dimension. ${ }^{73}$ In this chapter we focus on specific groups that have been identified as having particular needs around cultural adequacy, and those who have been accommodated in congregated settings ${ }^{74}$ such as Direct Provision accommodation for international protection applicants.

As different issues pertain to different groups, the structure of this chapter is different to others. Rather than distinguishing aggregate indicators from group-level indicators, this chapter focuses on the situation of specific groups, namely Irish Travellers and those living

Article 11 (1). General Comment No. 4 - The right to adequate housing, para.8(g) - Cultural adequacy. Culture is understood here to refer to opinions, norms and corresponding behaviour in a given society, or groups within a society.

These groups were selected based on previous research (Watson et al., 2017). The inclusion of these groups on measured of cultural adequacy was also viewed as important by consultation participants. 
in Direct Provision accommodation. These are protected groups under the Equal Status Acts (see Chapter 1). ${ }^{75}$ Available data relevant to the particular groups are presented in each section with a view to assessing cultural adequacy, where possible with comparisons to the whole Irish population. There are no specific comparisons of individual-level outcomes for multiple groups, as in other chapters.

\subsection{IRISH TRAVELLER ACCOMMODATION}

The term Travellers refers to

the community of people who are commonly called Travellers and who are identified (both by themselves and others) as people with a shared history, culture and traditions including, historically, a nomadic way of life on the island of Ireland. (Ireland, Equal Status Act, 2000, Sec 2 (1)).

According to the 2016 Census, there were 8,717 Traveller households (that is where at least one resident was a Traveller). A total of 30,987 individuals identified as 'White Irish Traveller' in the Census 2016, accounting for 0.7 per cent of the total population. ${ }^{76}$ Census 2016 reveals that Irish Travellers tend to live in larger family units, are younger and more likely to live in urban settings than the general Irish population. Sixty per cent of Travellers were aged under 25 years, compared to one-third of the general population. ${ }^{77}$

Current arrangements for providing accommodation for members of the Traveller community were established by the Housing (Traveller Accommodation) Act, 1998. Under this act, housing authorities have statutory responsibility for the assessment of the accommodation needs of Travellers and the preparation, adoption, and implementation of multi-annual Traveller Accommodation Programmes (TAPs) in their areas. The Traveller and Roma Strategy 2017-2021 is the main policy instrument regarding Irish Travellers in place at congregated settings such as prisons are beyond the scope of this report. 
present, including accommodation. ${ }^{78}$ One objective of this strategy is that 'there should be adequate provision of accessible, suitable and culturally appropriate accommodation available for Travellers'.

Each year, an Annual Estimate (count) of the number of Traveller families and the type and tenure of their accommodation in each Local Authority operational area is undertaken by Local Authorities. ${ }^{79}$ The Annual Estimate is undertaken by Local Authority staff (often social workers for Travellers), and as each Local Authority conducts its count independently, interpretations of the categories of accommodation may vary. The most recent results from 2019 show that there were 10,809 Traveller families counted by Local Authorities. ${ }^{80}$ Table 6.1 presents different accommodation types and tenures occupied by Traveller households. These data reveal that, in 2019, 4,934 households (45.6 per cent) of all Traveller households lived in social housing. In total, 6.4 per cent of Traveller families were accommodated using their 'own resources' and a further 8.6 per cent lived in shared accommodation (i.e. of which they were not the registered tenant or owner). There are differences between Local Authority areas regarding the extent to which Traveller housing is provided directly by the Local Authority, as well as the extent to which Traveller-specific accommodation (such as group housing or halting sites) is provided. Looking at accommodation that is Traveller-specific, in 2019 we find that 7.9 per cent of Traveller families lived in Local Authority group housing and 8.8 per cent lived on Local Authority sites. 2021.pdf/Files/National\%20Traveller\%20and\%20Roma\%20Inclusion\%20Strategy,\%202017-2021.pdf. Similar to Census Figures, groups which represent Travellers have highlighted that these counts under-renumerate the Traveller population (Irish Travellers Movement, 2021). 
TABLE 6.1 ESTIMATE (COUNT) OF TRAVELLER FAMILIES BY ACCOMMODATION TYPE 2019

\begin{tabular}{l|c|c}
\hline \multicolumn{1}{c}{ Type of Accommodation } & Total N & $\%$ \\
\hline Local Authority Group Housing & 852 & 7.9 \\
Local Authority Halting Sites & 952 & 8.8 \\
Social Housing & 4,934 & 45.6 \\
On Unauthorised Sites & 529 & 4.9 \\
\hline Own Resources (Estimate) & 690 & 6.4 \\
\hline Private Rented Accommodation (Estimate) & 1,919 & 17.8 \\
Sharing Housing & 933 & 8.6 \\
\hline Total & 10,809 & 100.0 \\
\hline Source: https://www.gov.ie/en/collection/29c76-Traveller-accommodation-statistics for each year separately.
\end{tabular}

Figure 6.1 shows different accommodation types occupied by Travellers over time from 2009 to 2019. Overall, we see that Traveller families are increasingly likely to live in Local Authority housing compared to private rental accommodation. The number of families accommodated by or with assistance of the Local Authority has risen steadily since 2015 from 5,575 to 6,738 in 2019 . This includes those in social housing, Local Authority halting sites and group housing. In contrast, the numbers living in private rental housing have decreased from a high of 2,818 in 2014 to 1,919 in 2019 . There have also been gradual increases in the number of Traveller families living on unauthorised sites, using their 'own resources' and in shared housing since 2015. Shared housing is typically an informal arrangement, that is where a family is staying in a friend or family member's house and, along with unauthorised halting sites, has been described by some Traveller representative organisations as 'hidden homelessness' (Houses of the Oireachtas, 2018). 
FIGURE 6.1 ANNUAL ESTIMATE (COUNT) OF TRAVELLER FAMILIES BY ACCOMMODATION TYPE (2009-2019)

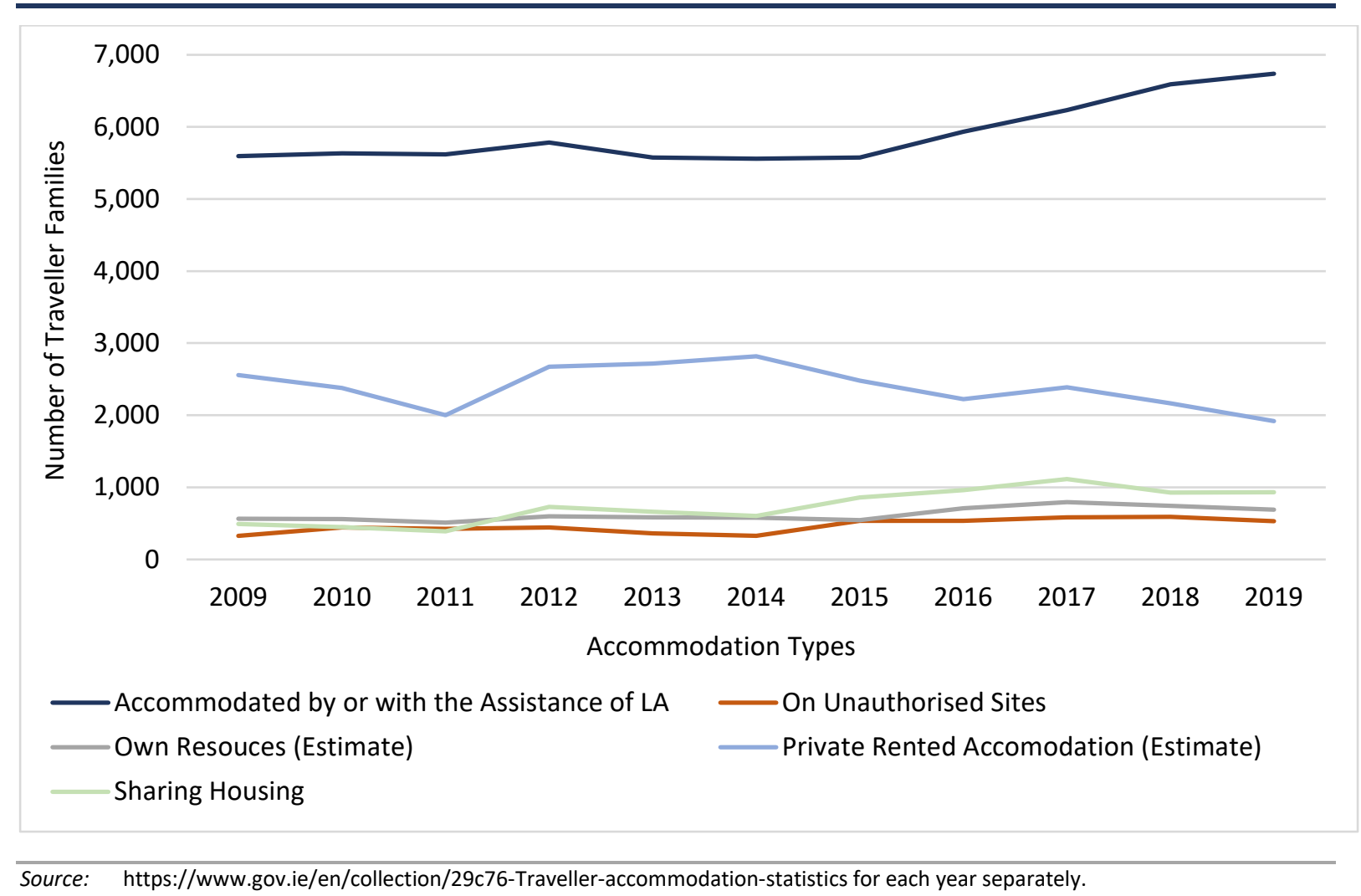

To what extent are these living arrangements meeting the requirements of the Traveller community? A recently conducted survey of Travellers and Roma in six countries carried out by the European Fundamental Rights Agency (FRA, 2020) found that 92 per cent of Travellers in Ireland felt that there was insufficient Traveller-specific accommodation in Ireland. ${ }^{81}$ This was also true for over 90 per cent of Travellers in Belgium and the Netherlands. A survey of Travellers undertaken in 2017 by the National Traveller Data Steering Group and the Community Foundation for Ireland (2017) found that a group housing scheme or permanent halting site was the preferred accommodation type for 26 per cent of respondents; 67 per cent wished to live in owner-occupied or Local Authority rented housing and only 5 per cent preferred to live in private rented accommodation. ${ }^{82}$ Comparing these figures to those found in Table 6.1 we can see that many Traveller families are not residing in their preferred accommodation type with 17.8 per cent living in private rental accommodation in 2019 compared to only 5 per cent reporting this preference in The interviews took place between December 2018 and July 2019. 07.pdf. 
2017. Similarly, fewer Travellers lived in Local Authority group housing and halting sites (16.7 per cent) than had stated preference for these types of accommodation in 2017 (26 per cent). This lack of culturally appropriate Traveller accommodation has been highlighted by IHREC (2021a) with concerns that this may have negative impacts on their mental health, especially where the type of housing provided results in separation from social networks.

The expert group on Traveller housing (DHPLG, 2019) highlights that the increasing use of rental subsidies for private renting (HAP) presents a problem for Travellers because they face very strong barriers in accessing and maintaining private rented tenancies. In 2019, Irish Travellers reported a high level of discrimination when trying to rent or buy houses in the preceding five years: 73 per cent of those who had sought accommodation had experienced discrimination (FRA, 2020). This is consistent with previous research in Ireland which suggests that the odds of experiencing discrimination in access to housing were almost ten times higher for Travellers compared to the settled community (Grotti et al., 2018). This research also showed that Travellers were the ethnic group most at risk of homelessness. Travellers made up less than 1 per cent of the population in Ireland, but they made up 9 per cent of the homeless population in 2016 (ibid).

One recurring issue in housing policy for Travellers in Ireland is unevenness across the Local Authorities (city or county councils) in the extent to which they spend the national allocation of funds for Traveller accommodation. While the government has delegated responsibility for providing Traveller-specific accommodation to Local Authorities, Table 6.2 shows that in total only two-thirds of the allocated funding for Traveller accommodation was drawn down by Local Authorities in 2019. Table 6.2 also shows substantial variation between Local Authorities in terms of whether the allocated money for 2019 was spent at the end of the year. In some Local Authority areas, none of the allocation was spent. For example, Donegal ( $€ 161,816)$, Leitrim ( $€ 178,390)$, Longford $(€ 2,922)$, Monaghan $(€ 100,000)$, Tipperary $(€ 25,655)$, Westmeath $(€ 100,000)$ and Wicklow $(€ 104,533)$ spent none of their allocated funds in 2019. Other county councils drew down a much higher proportion of allocated funds: some councils' drawdown figures even exceeded their allocation for 2019. Five Local Authorities had a budget of $€ 0$ for 2019; this is due to the fact that these groups had no approved projects at the time of allocation. However, this did not mean that these 
groups could not receive funding during the year; councils without an allocated budget are free to submit new proposals and drawdown funds from the reserve.

Data on allocations are unavailable for 2020 as the department has ceased allocating budgets to individual Local Authorities; instead all Authorities could apply for funds and draw down funds at any point during the year which was encouraged by the Department of Housing, Local Government and Heritage. The Department set a budget of $€ 14.5$ million for 2020 and as can be seen in Table 6.2 this was drawn down in full. Funds drawn down by Local Authorities can be used to build new housing units and cover maintenance and repairs etc. Therefore, drawdown of funds by Local Authorities should not be interpreted as funds solely to address shortages in housing units.

In their review of Traveller accommodation, the expert review group report (DHPLG, 2019) ${ }^{83}$ identifies a clear gap between accommodation units planned and numbers delivered. This report argues that opposition from residents' associations and councillors is one part of the problem, but also the land use planning system is a significant factor in blocking and delaying the delivery of accommodation. For example, Local Authority social housing requires the approval of councillors which they regularly fail to provide (ibid.). This expert review group report (DHPLG, 2019) concludes that policies on foot of the Housing (Traveller Accommodation) Act, 1998 have important strengths, and have enabled the delivery of significant amounts of accommodation. However, the policies have failed to provide enough accommodation to meet the needs of the community, as evidenced by homelessness, and the uneven record of delivery among Local Authorities (ibid). 
TABLE 6.2 DRAWDOWN OF FUNDS FOR TRAVELLER ACCOMMODATION BY LOCAL AUTHORITY (2019 AND 2020)

\begin{tabular}{|c|c|c|c|c|}
\hline Local Authority & $\begin{array}{c}\text { Allocation } \\
2019 \\
€\end{array}$ & $\begin{array}{c}\text { Drawdown } \\
2019 \\
€\end{array}$ & $\begin{array}{l}\text { Drawdown } 2019 \\
\text { (\% of allocation) }\end{array}$ & $\begin{array}{c}\text { Drawdown } \\
2020 \\
€\end{array}$ \\
\hline Carlow & 70,000 & 381,898 & 546 & 206,986 \\
\hline Cavan & 95,458 & 94,500 & 99 & 13,114 \\
\hline Clare & 635,000 & 669,389 & 105 & 174,032 \\
\hline Cork City & 275,799 & 42,319 & 15 & $1,504,850$ \\
\hline Cork County & 258,390 & 184,745 & 71 & 133,684 \\
\hline Donegal & 161,816 & 0 & 0 & 245,499 \\
\hline Dublin City & $1,628,695$ & 895,197 & 55 & $2,066,977$ \\
\hline Dun Laoghaire / Rathdown & 0 & 32,834 & & 747,750 \\
\hline Fingal & 0 & 848,957 & & 486,858 \\
\hline Galway City & 0 & 0 & & 861,334 \\
\hline Galway County & $1,412,596$ & 670,440 & 47 & $1,107,714$ \\
\hline Kerry & 77,200 & 75,131 & 97 & 15,773 \\
\hline Kildare & $1,000,000$ & 360,231 & 36 & 261,110 \\
\hline Kilkenny & 21,682 & 408,856 & 1,886 & 125,638 \\
\hline Laois & 0 & 0 & 0 & 192,520 \\
\hline Leitrim & 178,390 & 0 & 0 & 375,635 \\
\hline Limerick City and County & $1,015,179$ & $1,424,782$ & 140 & $2,370,922$ \\
\hline Longford & 2,922 & 0 & 0 & 0 \\
\hline Louth & 132,531 & 341,863 & 258 & 287,087 \\
\hline Mayo & 0 & 0 & 0 & 215,951 \\
\hline Meath & 75,000 & 91,790 & 122 & 58,845 \\
\hline Monaghan & 100,000 & 0 & 0 & 423,201 \\
\hline Offaly & 815,117 & 692,329 & 85 & 499,833 \\
\hline Roscommon & 253,084 & 73,843 & 29 & 148,168 \\
\hline Sligo & $1,435,913$ & $1,131,397$ & 79 & $1,193,489$ \\
\hline South Dublin & 130,557 & 106,719 & 82 & 284,390 \\
\hline Tipperary & 25,655 & 0 & 0 & 156,731 \\
\hline Waterford City and County & 170,000 & 77,562 & 46 & 14,550 \\
\hline Westmeath & 100,000 & 0 & 0 & 114,326 \\
\hline Wexford & 335,000 & 52,870 & 16 & 30,382 \\
\hline Wicklow & 104,533 & 0 & 0 & 180,305 \\
\hline Total & $10,510,516$ & $8,657,652$ & 82 & $14,497,654$ \\
\hline Reserve & $2,489,484$ & - & - & - \\
\hline Budget & $13,000,000$ & $8,657,652$ & 67 & $14,497,654$ \\
\hline
\end{tabular}

Source: Allocation 2019 figures retrieved from https://www.oireachtas.ie/en/debates/question/2020-05-13/1247/. Drawdown 2019 and 2020 received from Department of Housing, Local Government and Heritage. Written answer to PQ.

At international level, European Commission Against Racism and Intolerance (2019) in its report on Ireland strongly recommends that Irish authorities step up efforts to meet the accommodation needs of Travellers, including by improving existing halting sites to meet decent and safe living standards, and by providing adequate accessible, suitable, and 
culturally appropriate accommodation. The Committee on the Elimination of Racial Discrimination in its 2019 review (CERD, 2019) expresses concern at reports that ethnic minority groups such as Travellers:

who have limited access to social housing, face serious discrimination and inequality in the competitive private rental sector and are disproportionately at risk of being homeless (ibid).

In its recent comment on the 18th National Report on the Implementation of the European Social Charter, IHREC reiterated its concern that the current accommodation provisions for Travellers do not fulfil the State's obligation to provide culturally appropriate accommodation for this group. IHREC also recommended that there was a need for the State to give greater consideration of the housing preferences of Travellers, 'their culture and identity, including nomadism, living in extended family groups, keeping horses, and other social and economic activities' (IHREC, 2021a, pp.11-12).

A fundamental problem identified by the expert group (DHPLG, 2019) relates to the lack of a strong evidence base for policy-making. The current system for assessing the scale and nature of need is not working effectively, so it is very difficult to ascertain whether accommodation needs are being met.

\subsection{DIRECT PROVISION ACCOMMODATION FOR PROTECTION APPLICANTS}

The system of Direct Provision for those awaiting decisions on asylum applications has been widely criticised as breaching standards of adequate housing (IHREC, 2020; Ombudsman for Children, 2020; CERD 2019;84 Irish Refugee Council (Arnold, 2012). The system was introduced in Ireland in 2000 and was intended to provide short-term support for asylum seekers. As of August 2020, there were around 7,400 asylum seekers in Direct Provision and emergency accommodation in Ireland (Government of Ireland, 2020). Direct Provision is provided through 44 accommodation centres, 37 of which are privately owned and managed (Day Report, Government of Ireland, 2020). The accommodation is mostly in congregated settings such as former hotels, hostels, or guest houses, though there are some 
self-contained units in mobile homes, holiday homes etc. In many cases residents do not have access to private living spaces and just under half (48 per cent) do not have access to private cooking facilities (Day Report, Government of Ireland 2020, p.20). In some settings single residents are allocated to shared bedrooms with other unrelated residents. The Irish Refugee Council reports that children may live in a room with their families; teenagers and young adults share rooms with parents; and that children share communal bathrooms with unrelated adults. These conditions are neither culturally adequate, nor adequate in terms of basic housing needs.

Figure 6.2 presents the numbers living in Direct Provision accommodation from 2009-2020, as well as the proportion of all applicants this represents. All international protection applicants are offered accommodation following the making of their application but there is no legal requirement to accept it, and not all protection applicants live in the Direct Provision system, as shown. In 2018-2019, a rise in applicants combined with an increasing number of applicants taking up the offer of accommodation led to capacity problems in the system and the use of emergency accommodation, such as hotels and guesthouses (Department of Justice and Equality, 2019; Sheridan, 2020). Commentators, including the Ombudsman, the Irish Refugee Council (IRC) (Sheridan, 2020) and IHREC (2020) have expressed serious reservations about the use of emergency accommodation (Sheridan, 2020). ${ }^{85}$ IHREC (2020) highlights the need for vulnerability assessments both on arrival in reception centres and on an ongoing basis to deliver appropriate accommodation to vulnerable persons including those with disabilities. These assessments could inform the identification of housing needs for those residing in Direct Provision centres. 


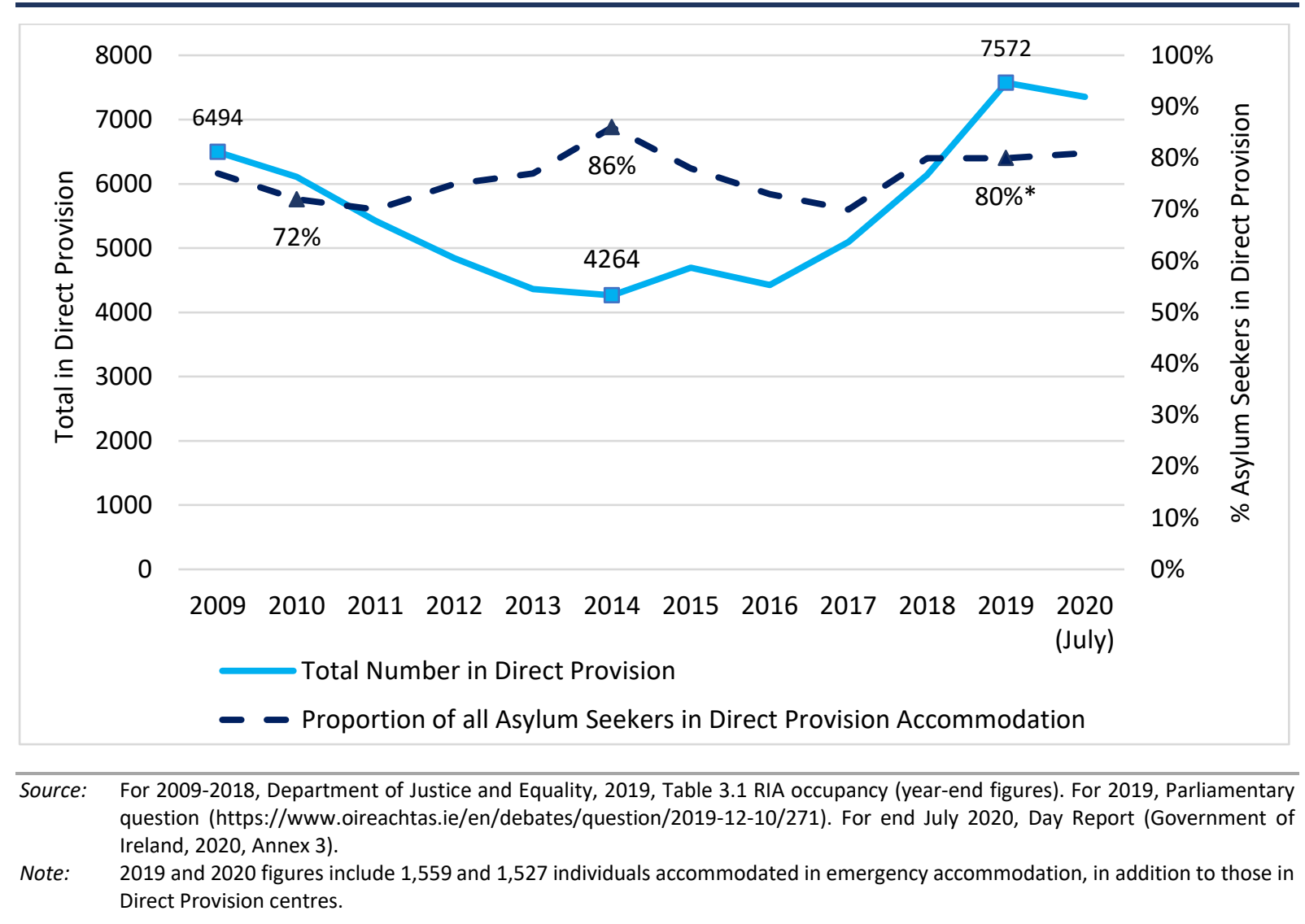

The numbers in Direct Provision and emergency accommodation will fluctuate with the number of applicants for protection, therefore it is also relevant to record the length of time asylum seekers remain in such provision. Table 6.3 presents the number of asylum seekers by length of time in Direct Provision in Summer 2020. The majority of residents - over 70 per cent - had been living in Direct Provision accommodation for one year or more, with one-quarter of all residents living there for three years or more. By 2020, just over 6 per cent of residents had been living in Direct Provision for five years or more. This represents a decrease in recent years; in 2014, 38 per cent of residents had been living in Direct Provision for five years or more (McMahon, 2015). ${ }^{86}$ However it is clear that this is not a short-term form of accommodation for many. 
TABLE 6.3 LENGTH OF TIME IN DIRECT PROVISION (END JULY 2020)

\begin{tabular}{|l|r|r|}
\hline & $\mathbf{N}$ & \% \\
\hline $\mathbf{1}$ year & 2,004 & 28.0 \\
\hline $\mathbf{1}$ year & 2,186 & 30.6 \\
\hline $\mathbf{2}$ years & 1,296 & 18.1 \\
\hline $\mathbf{3}$ years & 666 & 9.3 \\
\hline $\mathbf{4}$ years & 538 & 7.5 \\
\hline $\mathbf{5}$ years & 260 & 3.6 \\
\hline Over $\mathbf{5}$ years & 201 & 2.8 \\
\hline
\end{tabular}

Source: $\quad$ Adapted from Table 2.3.1 Day Report (Government of Ireland, 2020).

As of the end of July 2020, there were 1,957 children (aged under 18) living in Direct Provision (27.4 per cent of resident applicant population at that time). ${ }^{87}$ Most of these children (82 per cent) were aged 12 or under. Article 27 of the CRC states that:

States Parties recognize the right of every child to a standard of living adequate for the child's physical, mental, spiritual, moral and social development (see Online Appendix).

Prolonged stays in Direct Provision create many problems for children, ranging from the lack of privacy to the lack of space including a quiet place to study and do homework, and the lack of a normal family life. Most go to local schools, but many have reported feeling stigmatised because of living in Direct Provision centres and being subjected to racism (OCO, 2020).

In July 2020, the Ombudsman for Children published a report giving children's views and experiences of living in Direct Provision. The suggestions of children living in Direct Provision regarding how their situation could be improved included:

a faster process for determining their immigration status and action to counteract and stamp out racism.... more living space, more privacy and greater access to transport that would allow them greater freedom. (OCO, 2020, p.4) 
Many children interviewed for this project wanted an end to centre-based, communal accommodation and a move to own-door housing in the wider community.

The deficiencies of the Direct Provision system have been widely recognised, and both national and international human rights bodies have called for the abolition of the system (UNCRC, 2016; IHREC, 2019). In 2016, the UN Committee on the Rights of the Child stated that:

$$
\begin{aligned}
& \text { asylum and refugee accommodation centres do not offer adequate child } \\
& \text { protection services, sufficient access to education for children or sufficient } \\
& \text { access to appropriate clothing and food in general, including culturally } \\
& \text { appropriate food for minority faith children accommodated in such centres. }
\end{aligned}
$$

One of the key recommendations of the 2019 report of the UN Committee on the Convention on the Elimination of all Forms of Racial Discrimination (CERD) report on Ireland was the reform of the Direct Provision system and the development of an alternative reception model.

The current Programme for Government commits to ending the Direct Provision system, but McGinnity et al. (2020a) note that it is important that its replacement 'is durable and meets the needs of applicants and is not just Direct Provision by another name' (Government of Ireland, 2020, p.17). The recently published Day Report on supports for asylum seekers (Government of Ireland, 2020) recommends that by 2023 international protection applicants should be provided with own-door accommodation within three months of application. ${ }^{88}$ The report also recommends that asylum applicants should be provided with housing payment supports similar to HAP and other income supports in order to access housing in the community. In its submission to the Human Rights Committee prior to the

'After 3 months in the reception centre, applicants should move to own-door accommodation under the responsibility of the Local Authorities. To enable applicants to live in the community, the weekly allowances currently paid should be replaced by a housing allowance modelled on the Homeless Housing Assistance Payment (HHAP) and access to social assistance payments equivalent to the range of income supports (e.g. Supplementary Welfare Allowance, Child Benefit) available to Irish citizens. These should be reviewed in line with reviews of all social welfare payments.' 
fifth periodic examination of Ireland, IHREC (2021b) recommends that the Committee asks for an update and timeline for ending the Direct Provision system.

However, asylum seekers as well as other vulnerable groups are likely to face significant difficulties in accessing accommodation in the private sector by themselves even with the aid of income supports. These challenges include lack of knowledge about local housing markets, language difficulties and discrimination. IHREC (2019) note that even those who have been granted leave to remain report great difficulty in securing accommodation, even with access to HAP, and may also be at risk of discrimination in accessing emergency homeless accommodation. ${ }^{89}$ Arnold et al. (2019) point out that programme refugees are already offered substantially more integration supports - including assistance to finding housing - than spontaneous refugees, who have come through the Direct Provision system and been granted protection status. ${ }^{90}$ An indication of such difficulties and the need to support transitions out of Direct Provision is illustrated by the fact that 11 per cent of residents have already been granted protection status (Houses of the Oireachtas, 2019).

\subsection{SUMMARY}

This chapter has considered cultural adequacy for two specific groups: Irish Travellers, who have particular needs around cultural adequacy, and those living in Direct Provision.

These are challenging policy areas, and the chapter highlighted some key areas where policy is not meeting the needs of the community. For Travellers, the evidence suggests that Local Authorities do not provide enough accommodation to meet the needs of the community, as evidenced by homelessness, the uneven record of delivery among Local Authorities and the mismatch between Travellers' preferred accommodation, which is central to their cultural identity and way of life, and their actual accommodation.

While there have been improvements to the system of Direct Provision accommodation in recent years, such as reducing the length of stay and increasing the proportion of own-door

The supports needed to exit Direct Provision are not confined to housing supports but also extend to access to education, employment, language supports and welfare etc. 
accommodation, as it stands the system is not meeting the needs of asylum seekers in Ireland, and its deficiencies have been widely recognised (Government of Ireland, 2020). The current government is committed to ending the Direct Provision system, but it remains to be seen what it will be replaced with and when this will happen.

\subsection{DATA GAPS}

The measurement of ethnicity, including Irish Travellers, in survey and administrative data in Ireland is a recurring issue. If ethnicity is so rarely measured, it is very difficult to know if the needs of minority groups are being met. An additional problem with social surveys is that, as Irish Travellers are a small population group, too few may be measured for meaningful analysis.

As noted by McGinnity et al. (2020a), refugees and asylum seekers are not identified in national surveys or general administrative data in Ireland, and there are no dedicated surveys of refugees. Thus, it is not possible to monitor their needs or integration outcomes. This is problematic given a range of research has shown that they struggle both in the labour market and in the housing market in Ireland (Ní Raghallaigh et al., 2016; McGinnity et al., 2020a; McGinnity et al., 2020b). 



\section{CHAPTER 7}

\section{Housing quality}

This chapter considers aggregate and group level indicators of housing quality. It is important to consider not only access to housing but also the quality of housing in which people reside. Whether a home is of good quality impacts people's quality of life and housing which is of poor quality, e.g. damp or cold, can negatively impact the inhabitants' physical and mental health (Fisk et al., 2007; Orr et al., 2016; Shortt and Rugkasa, 2007; WHO, 2018). ICESCR also note how inadequate housing is 'invariably associated with higher mortality and morbidity rates' ${ }^{91}$

As noted in Chapter 1, ICESCR outlines a number of aspects of adequate housing. Here we consider two dimensions that refer directly to housing quality issues: habitability and availability of services/facilities/infrastructure. Regarding habitability, ICESCR outlines that housing must protect inhabitants 'from cold, damp, heat, rain, wind or other threats to health, structural hazards, and disease vectors' and provide adequate space to inhabitants. Under availability of services etc., ICESCR refers to fairly basic facilities such as: the availability of safe drinking water; adequate sanitation; energy for heating, cooking, and light; means of food storage; and refuse disposal. We have kept location which covers the quality of the neighbourhood and local environment as a separate domain, which is discussed in Chapter 8.

Chapter 1 noted that adequate housing is also addressed in rights instruments designed for specific groups such as women, ${ }^{92}$ racial, nationality or ethnic minorities, ${ }^{93}$ children, ${ }^{94}$ the elderly, ${ }^{95}$ families ${ }^{96}$ and those with disabilities. ${ }^{97}$

ISESCR General Comment No.4 (d). CEDAW Article 14 2(h).

CERD 5 e (iii).

CRC Article 27(1).

ESC Article 23(a).

ESC Article 16.

CRPD Article 9 (1)(a). 
A number of public policies cover different facets of housing quality in Ireland. Minimum standards for rental accommodation are set out in the Housing (Standards for Rented Houses) Regulations 2019. ${ }^{98}$ Under these regulations, rental properties are required to be in 'an appropriate standard of repair' and should not be defective 'due to dampness of otherwise'. Every room should also provide effective heating. Local Authority housing has different standards from private rental accommodation and requirements for quality generally only cover laundry, food preparation and storage facilities. ${ }^{99}$ IHREC (2021a) highlights that the State is not in conformity with Article 16 of ESC and that:

in the absence of a national timetable for the refurbishment of local authority housing stock, the State has not fulfilled its obligation to ensure community safety for local authority tenants (p.24).

When evaluating housing quality, it is also necessary not only to look at structural issues but also the size or space people have within their accommodation. The government has committed to increasing the delivery of housing, however the quality of this housing must also be considered. Restrictions on the minimum size of new apartments were relaxed in 2018, with studio apartments now allowed in all developments and the minimum size reduced from 40sqm to 37sqm (Department of Housing, Planning and Local Government, 2018). In recent years there has also been a move towards creating co-living accommodation in the private rental market which consists of individual bedrooms and bathrooms but shared communal spaces such as kitchens and living rooms. These living arrangements result in less private space for inhabitants and are envisaged for shorter lease periods than standard forms of rental properties such as houses or apartments, 'up to a year in duration' (Department of Housing, Local Government and Heritage, 2020a). These types of living arrangements are generally targeted at younger people and were initially intended to exist only in city centres such as Dublin, however a number of planning applications have been submitted in areas of Dublin outside the city centre (ibid). In November 2020, the

\section{S.I. No. $137 / 2019$.}

Quality requirements for Local Authority housing include: 'facilities for the installation of cooking equipment, sink, with a piped supply of potable cold water taken directly from the service pipe supplying water from the public main or other source to the building containing the house and a facility for the piped supply of hot water, and an adequate draining area, suitable facilities for the effective and safe removal of fumes to the external air by means of a cooker hood or extractor fan and suitable and adequate number of kitchen presses for food storage purposes' (Minimum standards in rented accommodation, 2021). 
Minister for Housing, Local Government and Heritage decided to amend the 2018 Planning guidelines to 'restrict all future commercial co-living development in Ireland' however, legislation on this has yet to be introduced (Department of Housing, Local Government and Heritage, 2020b). This decision was due to the increased planning permissions submitted outside of city centres and the belief that the concept of co-living had moved from playing a more niche role in the housing sector to a larger role (ibid).

\subsection{ANALYTICAL APPROACH}

We consider one aggregate measure of housing quality at national level - age of housing stock. We then consider several aspects of housing quality measured at an individual level which allow us to compare housing quality across seven equality grounds; gender, age, country of birth, marital status, household type, disability status, and educational achievement. Although we are unable to make causal inferences about the nature of differences seen, the monitor can highlight housing quality problems for particular groups protected under equality legislation. These categories include key groups which may be at risk of disadvantage or social exclusion such as lone parents. Whilst we try to include as many group differences as possible, small cell sizes prevent us from reporting results on certain indicators.

Most of the individual-level indicators analysed in this chapter use data from the 2018 Survey on Income and Living Conditions with the exception of the over-crowding indicator which uses data from the 2016 Census. We use the Census because it provides better coverage of at-risk groups, including Travellers and other ethnic minorities. We measure over-crowding based on the ratio of persons to rooms in a household. Households with greater than one person per room are counted as over-crowded. The number of rooms includes kitchens, living rooms, bedrooms, and studies, but excludes bathrooms, toilets, kitchenettes, utility rooms, halls, and landings. This measure is simpler than that applied by Eurostat which also takes into account the age and sex of the residents. The $>1$ person per room definition has been applied in previous research in Ireland (Grotti et al., 2018). The over-crowding data provided by the CSO is measured at the head of household level, and therefore differs from the other indicators. The household may include someone who has a disability or who is born abroad but unless they are the head of household this is not captured. 
The second individual-level indicator we examine is an index of housing deprivation which includes four items:

1. Leaking roof/damp walls, floor or foundation/rot in windows frames or floor;

2. Dwelling too dark;

3. No central heating;

4. No double glazing.

Previous analysis found that these four items are strong indicators of housing deprivation (Grotti et al., 2018). ${ }^{100}$ The rates presented in the chapter for this measure focus on individuals who had one or more of the issues listed above. The final group indicator presented in this chapter looks at individuals who are unable to keep their home adequately warm. The rates presented in this chapter focus on individuals who answered no to the question 'does the household keep the home adequately warm'.

\subsection{AGGREGATE INDICATORS}

Figure 7.1 shows the age of housing stock in Ireland at the time of the last Census (2016). It is important to note that the housing stock presented here includes only private households in permanent housing units as these were the only readily available data at the time of writing. When looking at housing quality it is important to look at the age of the housing in which people reside as older houses are usually less energy efficient, and will therefore be more difficult and expensive to keep warm. In addition, older houses are more likely to have quality issues due to their age. Using the SILC data Corrigan and Watson (2018) found that 23 per cent of houses built before 1940 had two or more quality problems compared to 5-6 per cent for those built in 1991 or later. 


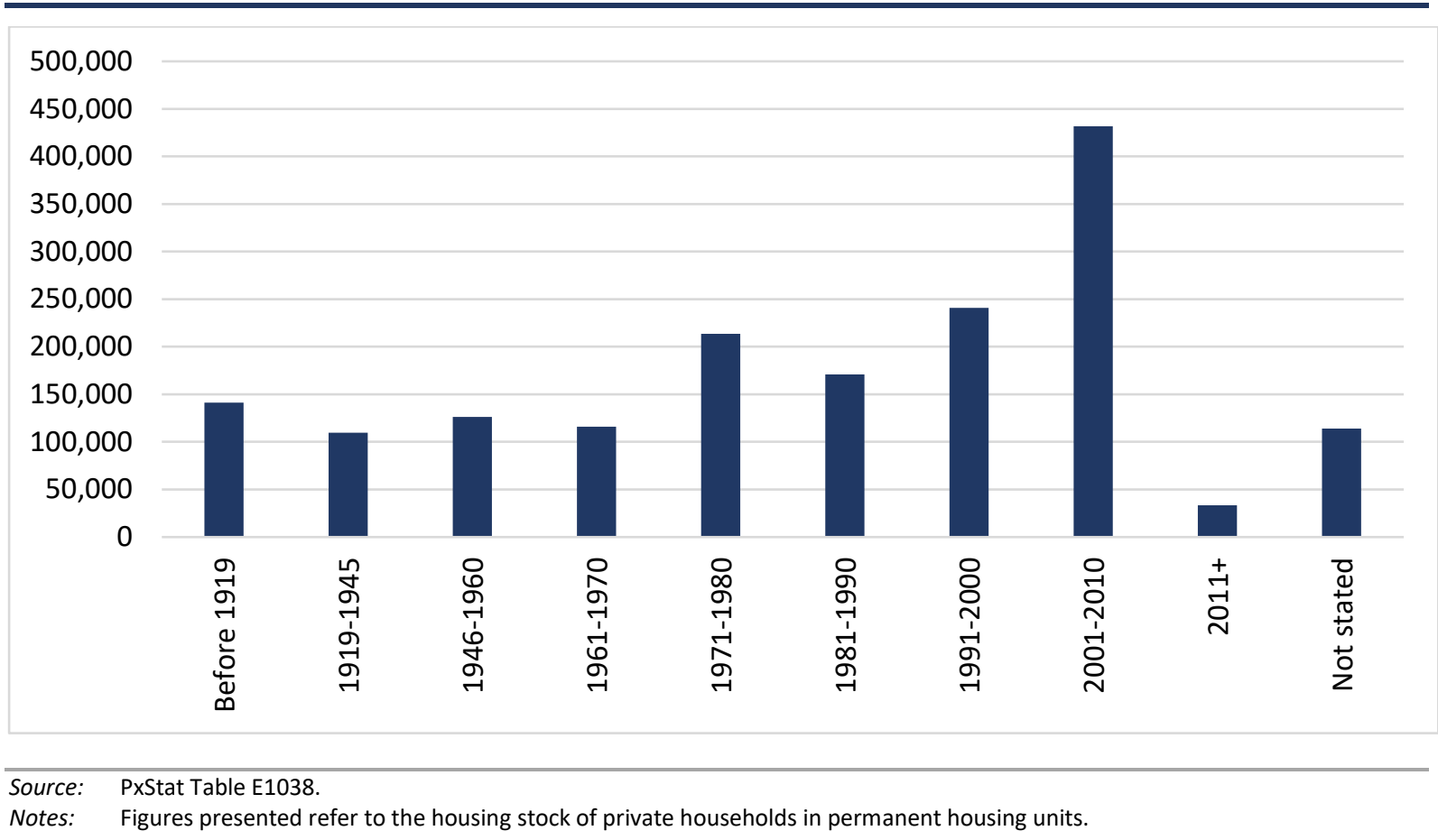

As seen in Figure 7.1, a significant proportion of the housing stock was built between 2001 and 2010. Roughly 40 per cent of private permanent housing units were built before 1980 . Individuals living in these houses may incur additional expenses to ensure an adequate standard of living in their homes, for example replacing windows, and it may also cost more to heat their houses. One potential solution to high heating costs and colder homes is upgrading the quality of older dwellings. The Sustainable Energy Authority of Ireland administers home energy grants to allow individuals to upgrade their homes with energy efficient measures such as insulation. The scheme is open to all homes built before 2006 (Department of the Environment, Climate and Communications, 2020). According to figures from the Sustainable Energy Authority of Ireland (SEAI, 2021), 219,988 grants were issued under the Better Energy Homes Scheme between its launch in March 2009 to June 2018.

\subsection{INDIVIDUAL- AND HOUSEHOLD-LEVEL INDICATORS}

This section considers one household-level and two individual-level indicators of housing quality; over-crowding, a housing quality index, and a measure of ability to keep the home adequately warm. The following analysis looks at basic group differences across these indicators and uses data from SILC and the Census. The results for over-crowding refer to the head of household. The other two indicators include all individuals and housing characteristics are assigned to every person in the household including children. 
FIGURE 7.2 GROUP DIFFERENCES IN OVER-CROWDING: HEAD OF HOUSEHOLD

CHARACTERISTICS (CENSUS, 2016)

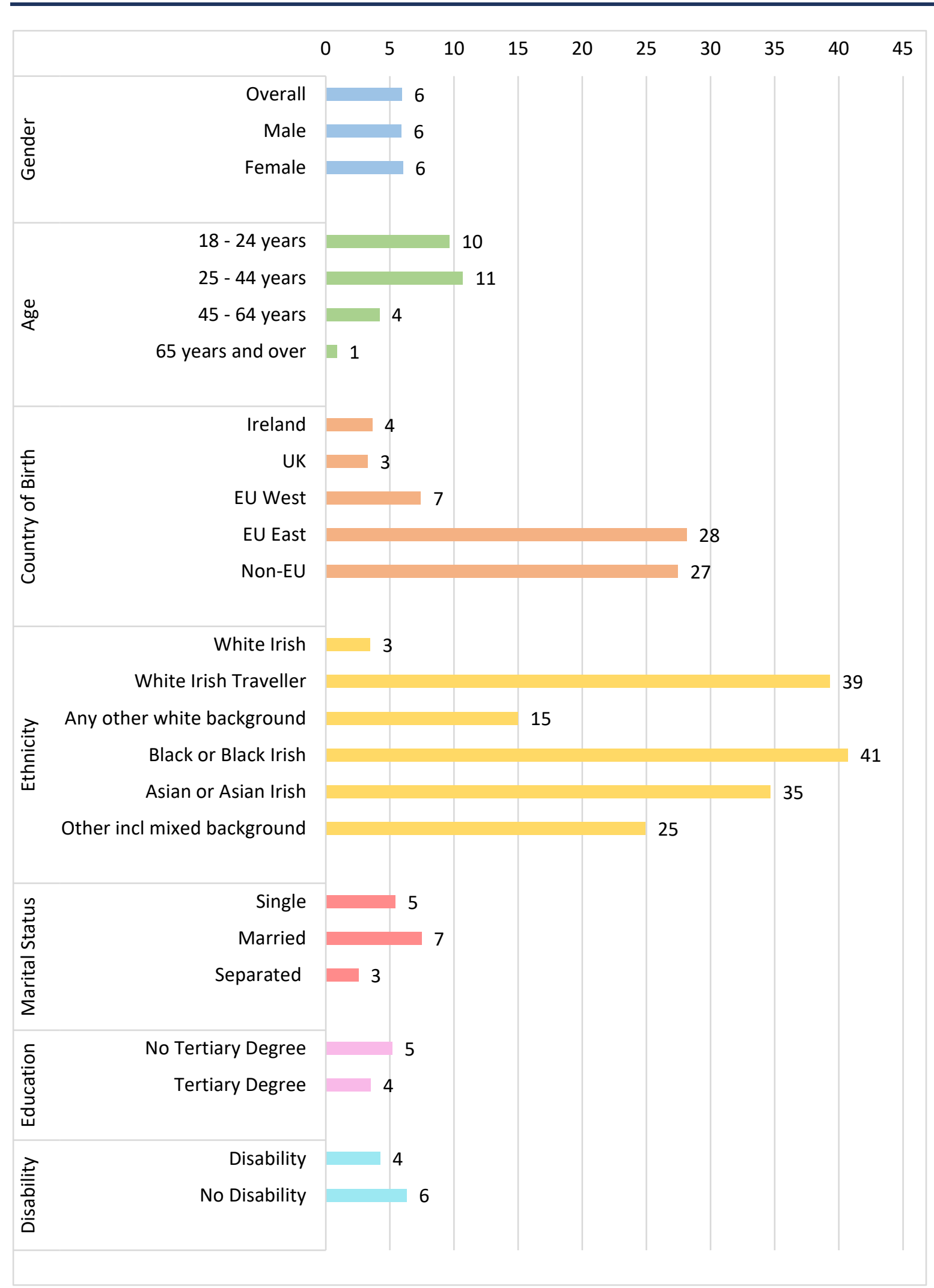

Source: Census 2016. Data provided by the Central Statistics Office.

Notes: Figure lists proportions of households. As this is not a sample no confidence intervals are required. Over-crowding is defined as accommodation where there is more than one person per room (rooms include bedrooms living rooms, kitchens and studies; and exclude bathrooms, toilets, kitchenettes, and utility rooms). 


\subsubsection{Over-crowding}

Overall, we find that 6 per cent of households live in over-crowded accommodation, defined as accommodation where there is more than one person per room. The likelihood of living in over-crowded accommodation did not differ between households headed by men (6 per cent) and women (6 per cent).

We find that the likelihood of living in over-crowded accommodation decreases with the age of the head of household. Households headed by someone aged 18 to 24 (10 per cent) and 25 to 44 (11 per cent) are most likely to live in such conditions. This rate decreases to 4 per cent for those aged 45 to 64 . Only 1 per cent of households headed by someone aged over 65 live in over-crowded housing. Over-crowding may be related to life cycle stage as suggested by Grotti et al., (2018), with students and young people who are not in relationships more likely to live in over-crowded conditions. Respondents who are older are also more likely to have entered the empty nest period in their lives and therefore have fewer individuals residing in their household.

We also find significant differences in over-crowding rates by country of birth of the household head, with those born outside Ireland having higher rates of over-crowding than those born in Ireland with the exception of UK migrants. Heads of household from Eastern Europe (28 per cent) and non-EU countries (27 per cent per cent) report significantly higher rates of over-crowding compared to those born in Ireland and all other migrant groups. Previous research by Grotti et al. (2018) has similarly found high rates of over-crowding (top decile measure) among Eastern European and non-EU migrants which persist even after controlling for age, family status, household composition, disability, and income. However, once housing tenure was controlled for i.e., whether an individual rents or owns their home, the difference between Eastern European and Irish respondents became insignificant (ibid).

There is significant variation in over-crowding rates by ethnicity of the head of household, with all groups experiencing significantly higher levels than the White Irish group. Households headed by a person from other White backgrounds (15 per cent) had the second lowest rates of over-crowding. Over 35 per cent of households headed by an Asian or Asian Irish person, 39 per cent of households headed by a Traveller and over 40 per cent of households with a Black or Black Irish head live in over-crowded accommodation. Over- 
crowding and lack of adequate housing for Travellers has been found repeatedly in previous research; Using the same definition of over-crowding using 2011 Census data, Watson et al. (2017a), find that in 2011 over half - 56 per cent - of individual Travellers were living in overcrowded accommodation compared to 8 per cent of non-Travellers. The FRA survey from 2020 also found that 24 per cent of Travellers surveyed face severe housing deprivation, ${ }^{101}$ 30 times higher than the general population in Ireland, and 22 per cent of Travellers point to crime, violence, and vandalism in their neighbourhood (FRA, 2020). Very little research on differences in housing quality among ethnic groups has been conducted in Ireland, however the findings do reflect research from the UK which found that ethnic minorities are more likely to live in over-crowded households than White British individuals (Equality and Human Rights Commission, 2017).

Looking at the marital status of groups, we find that households headed by a separated person ( 3 per cent) are the least likely to live in over-crowded conditions whereas those headed by a married person are the most likely to live in such conditions (7 per cent).

Households headed by a person with a tertiary degree (4 per cent) are less likely to live in over-crowded conditions compared to those without a tertiary degree ( 5 per cent) though this difference is small. As over-crowding is linked to income (Grotti et al. 2018) we would expect there to be a wider difference by education; therefore it is likely that other confounding factors are operating here (e.g. family status and age).

Finally, households headed by a person with a disability (4 per cent) are less likely to live in over-crowded accommodation compared to those without ( 6 per cent) though again this difference is small.

\subsubsection{Housing quality index}

Figure 7.3 examines group differences in the housing quality index. Respondents are included if they have one or more of the following issues: leaking roof/damp walls; dark and exhibit at least one of the housing deprivation measures, namely a leaking roof, no bath/shower and no indoor toilet, or a dwelling considered too dark. (see https://ec.europa.eu/eurostat/statisticsexplained/index.php?title=Glossary:Severe_housing_deprivation_rate). 
rooms; no central heating; or no double glazing. Overall, we find that 22 per cent of respondents reported having at least one of these issues. No significant differences were found between men ( 21 per cent) and women ( 22 per cent). Regarding age, we find that those aged 18-24 (23 per cent) and 25-44 (22 per cent) are more likely to experience quality issues in their home, although those aged over 65 also had high rates of quality issues (22 per cent).

Looking at country of birth, we find a significant difference between respondents born in Ireland (22 per cent) and those born abroad ( 24 per cent), with migrants more likely to experience deprivation. We find that migrants from the UK ( 25 per cent) and non-EU countries (27 per cent) have higher housing deprivation rates than those from Eastern (22 per cent) and Western Europe (19 per cent), though these differences were not significant. These results are also similar to Grotti et al. (2018) who find that non-Irish nationals and non-EEU nationals especially were more likely to report poor quality housing, even when controlling for a range of measures.

Rates of housing deprivation are significantly higher for those who have never been married (27 per cent) or who are separated (26 per cent) compared to respondents who are married (18 per cent).

Educational background was also found to play a role in housing deprivation with those without a third-level degree (24 per cent) significantly more likely to report one or more issues on the housing index compared to those with a third-level education (19 per cent).

Lone parents (32 per cent) report the highest levels of housing deprivation among all groups whereas two-parent households report the lowest levels (18 per cent). Those living alone (28 per cent) were also found to report significantly higher levels of housing deprivation compared to all other groups, with the exception of lone parents. 
FIGURE 7.3 GROUP DIFFERENCES IN HOUSING QUALITY INDEX (SILC 2018 AND 2019)

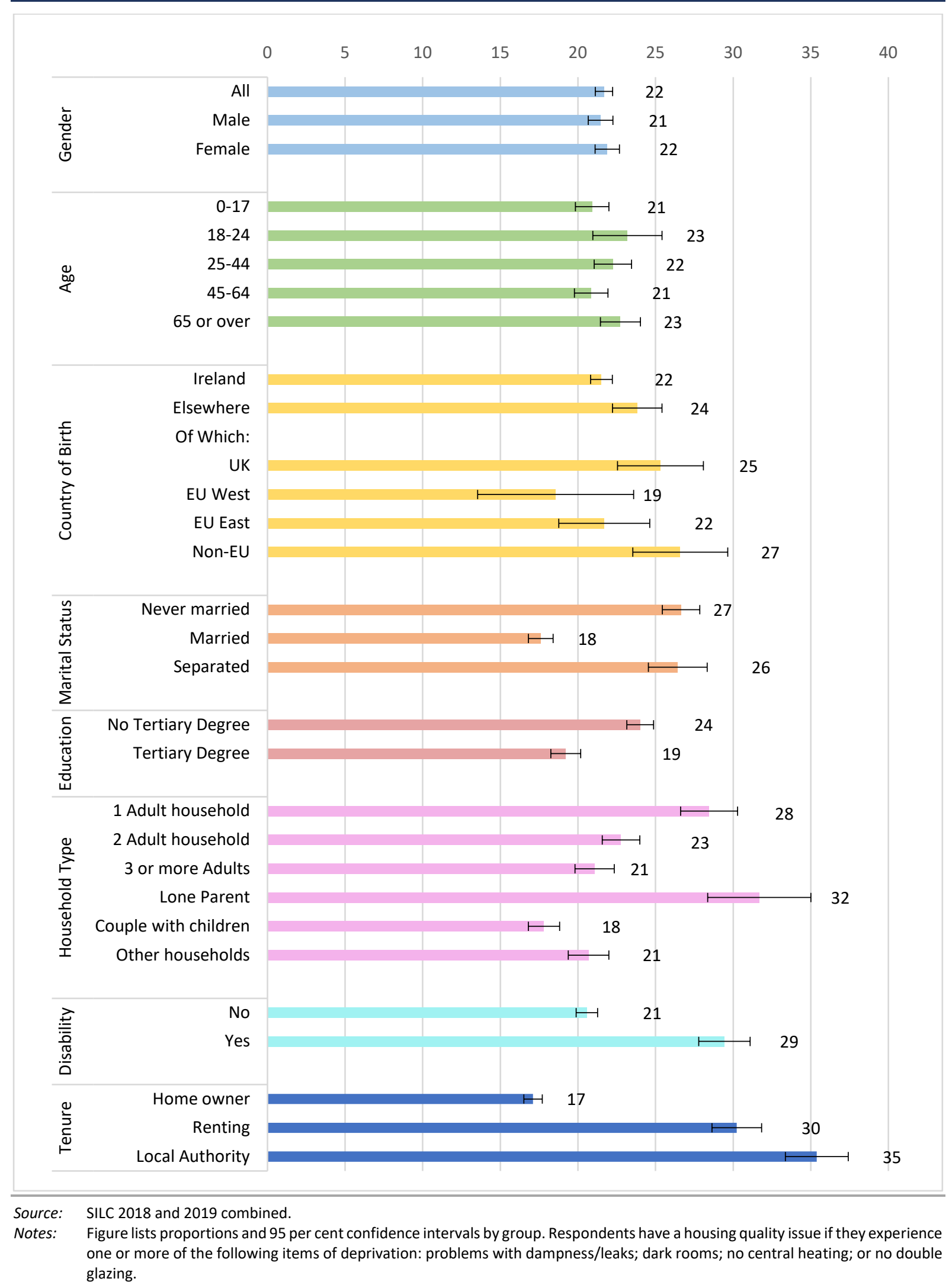

Finally, we find that respondents with a disability are also significantly more likely to experience housing deprivation compared to those without. This may be tied to lower levels of employment found among those with a disability, which is closely associated with 
different types of deprivation (Watson et al., 2015; Maître et al., 2020). There is also an issue with a lack of accessible housing for those with disabilities in Ireland. The Department of Housing, Local Government and Heritage carries out social housing needs assessments annually; in 2019, 5,319 housing units were needed for those with disabilities (The Housing Agency, 2021).

As before, we include differences by tenure type for reference. In general homeowners are less likely to experience housing quality problems (17 per cent) when compared to those who rent privately (30 per cent), and those living in Local Authority housing ( 35 per cent).

\subsubsection{Households who cannot keep the home adequately warm}

The final indicator we examine is whether individuals have the ability to keep their homes adequately warm. Whether an individual can keep their home adequately warm has been used as a subjective measure of fuel poverty in previous research (Scott et al., 2008). Energy poverty is the result of a combination of different factors such as low income, lack of disposable income and poor energy efficiency in the home. Living in a cold home is associated with adverse health effects; it has been found to increase the risk of respiratory infections and negatively impact the circulatory system (WHO, 2018; Orr et al., 2016).

Overall, we find that only 5 per cent of respondents were unable to keep their home adequately warm. Again, this did not differ significantly between men ( 5 per cent) and women (5 per cent).

Similar to other measures of housing quality we find that younger respondents are the most likely to live in households with heating issues; 8 per cent of those aged 18 to 24 reported this issue. Inability to keep the home warm is more uncommon among older respondents, just 3 per cent for respondents aged 65 or over report this issue. This is in line with the analysis of Irish data from 2006 by Scott et al. (2008), although these authors compare only respondents aged under 65 to those aged over 65 , finding that older respondents have lower odds of experiencing subjective fuel deprivation. The lower proportion of heating issues among those over 65 is likely due to the availability of means tested fuel allowances for those of pension age. 
Migrants are significantly more likely to be unable to keep their homes warm with 6 per cent of respondents born abroad reporting this issue compared to 4 per cent of respondents born in Ireland. Respondents born in non-EU countries, Eastern Europe and the UK report similar levels of difficulty. We are unable to report findings for respondents born in Western European countries due to small cell sizes in the data.

FIGURE 7.4 GROUP DIFFERENCES IN DIFFICULTY KEEPING THE HOME ADEQUATELY WARM (SILC 2018 AND 2019)

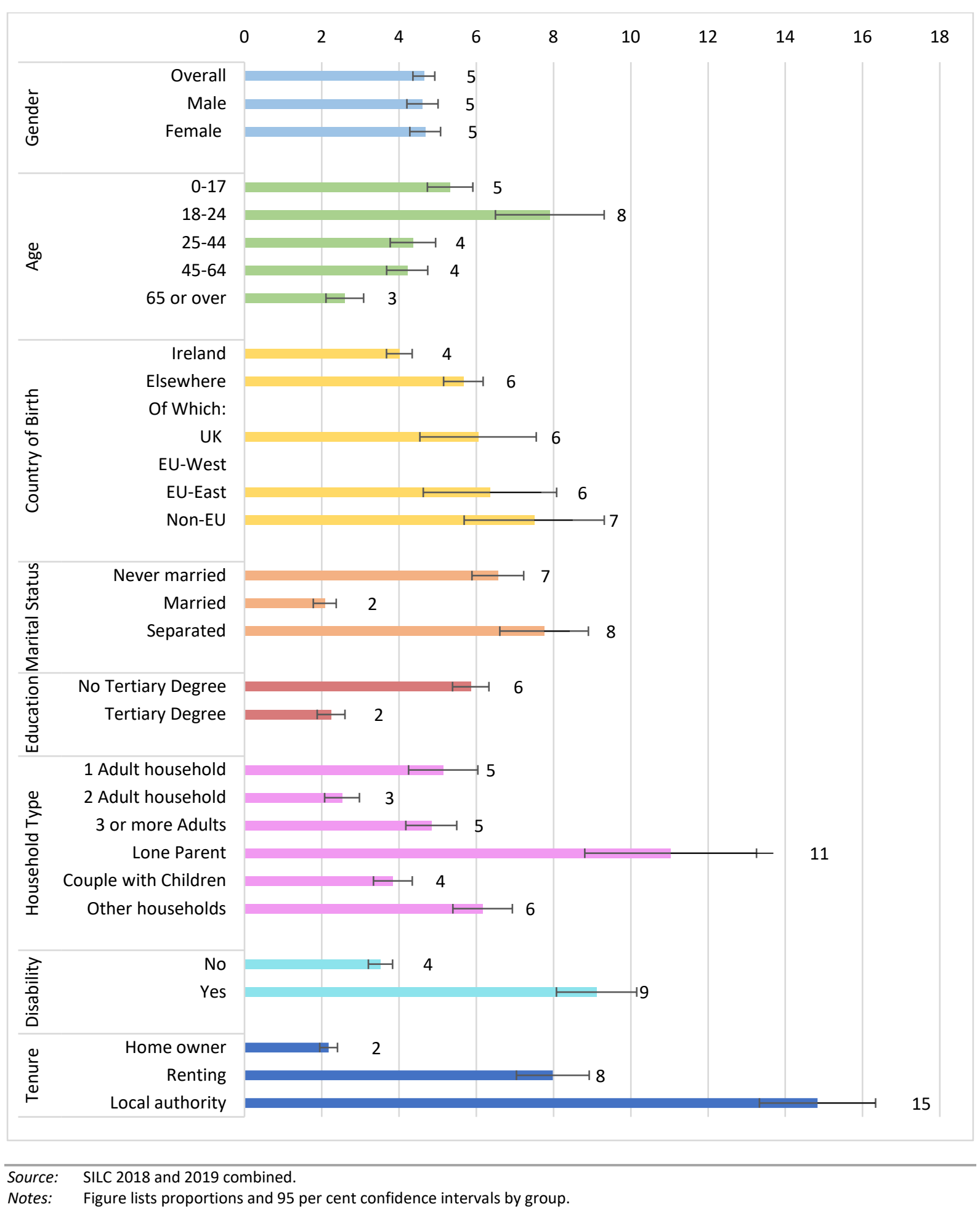


Regarding marital status we find that respondents who are separated ( 8 per cent) or have never been married ( 7 per cent) report significantly more problems keeping their home warm compared to married respondents ( 2 per cent). This pattern is similar to that found in 2006 by Scott et al. (2008).

We find a significant difference between those with and without a third-level degree, with those without (6 per cent) reporting more difficulty keeping their home warm compared to those with a third-level degree (2 per cent). This finding also emerges in Scott et al. (2008), who look at group differences in a similar outcome using logistic regression, controlling for a range of factors. They report that respondents without a formal education have higher odds of subjective fuel deprivation, when compared to respondents with a formal education.

Looking at household type we find that lone parents (11 per cent) have significantly more problems heating their home compared to all other household types. Two-adult households ( 3 per cent) and two-parent households ( 4 per cent) reported the least difficulty on this measure of housing quality.

Regarding disability, we find that those with disabilities (9 per cent) are significantly more likely to be deprived of the ability to keep their homes adequately warm compared to those without (4 per cent).

Finally, we note the tenure differences in this measure. Issues of heat and fuel poverty are especially uncommon for homeowners ( 2 per cent), when compared to those renting (9 per cent) and those who live in Local Authority housing (15 per cent). This result is also reflected in Scott et al. (2008) who report that renting households have higher odds of subjective fuel poverty when compared to homeowners, controlling for a range of measures including education and employment.

\subsection{SUMMARY}

Our results show several significant differences between groups in housing quality. We find that certain groups are more likely to have issues with the quality of their housing including non-EU migrants, lone parents, those with disabilities and those with lower educational qualifications. Housing quality is an especially important dimension; unlike measures like 
homeownership which are social processes that have legitimate or expected group differences, all people have the right to live in habitable conditions with heat, light, and adequate space.

Many of the differences found in this chapter likely reflect a difference in income between groups with those on lower incomes less able to afford structural repairs or larger housing. For example, previous research on migrants has found that Eastern European and non-EU nationals have significantly lower incomes compared to Irish nationals (McGinnity et al., 2020a). Research commissioned by the National Disability Authority (INDECON, 2011) highlights the additional costs associated with living with a disability. This additional financial burden faced by those with disabilities may explain the lower housing quality found among this group.

Despite Ireland having low rates of over-crowding compared to other countries (OECD, 2020), these rates vary significantly between groups living in Ireland. We find that migrants, specifically those from Eastern European and non-EU countries, and children are more likely to live in over-crowded conditions. The largest differences in over-crowding rates are between ethnic groups, with Irish Travellers, Black, and Asian minorities reporting overcrowded conditions more often than other groups. Little to no research has investigated housing quality differences between ethnic groups in Ireland, and future research should consider this issue further.

Issues with heating, housing quality and over-crowding point to potential shortfalls in the right to adequate housing in terms of habitability and access to services (including heating) as defined in ICESCR for some groups in Ireland, including Travellers, some migrant groups, and ethnic minorities. Lone parents, single person households and people with a disability are disadvantaged on two of the three indicators, though not on the over-crowding indicator because of the smaller family size. Those living in Local Authority accommodation are particularly exposed to housing quality problems. This is in part driven by the low incomes of LA tenants, however structural issues such as damp walls, leaky roofs, glazing, and central heating systems are the responsibility of the Local Authorities and therefore deficits in these aspects of social housing suggest that Local Authorities need to do more to 
address housing quality issues. The European Committee on Social Rights recently upheld a complaint by Local Authority tenants in Ireland finding that the government had:

failed to take sufficient and timely measures to ensure the right to housing of an adequate standard for not an insignificant number of families living in local authority housing. (ECSR, 2017 paragraph 121)

Housing quality problems were also relatively common in the private rented sector; given the increasing number of individuals residing in this sector this is a matter of policy concern.

\subsection{DATA GAPS}

Although SILC collects data on respondent's country of birth, the number of respondents in certain groups are too small to report on indicators; such is the case for Eastern and Western European migrants on the home heating indicator mentioned above. SILC does not contain data for respondent's religion, ethnicity, sexual orientation, or gender status beyond male or female. As a result, we cannot comment on differences between these groups. Future iterations of SILC should increase sample sizes to allow for adequate reporting on group differences between migrants and on indicators that are relatively uncommon but socially important; at present it is not possible to apply stricter definitions of housing adequacy problems (e.g. of over-crowding or experiencing two or more of housing quality issues), as there would be insufficient cases to disaggregate across groups. In addition, questions on respondent's sexual orientation, minority gender status, religion and ethnicity should also be added to the SILC questionnaire. 



\section{CHAPTER 8}

\section{Location, access to services and local environment}

This chapter considers aggregate and group-level indicators of neighbourhood quality. Under the ICESCR framework, this dimension covers the quality of the local environment including the social and physical infrastructure available to residents as well as safety, exposure to crime, pollution, availability of public and private services, and availability of green spaces.

Neighbourhood environment is not only important to mental health but also to physical health; living in a polluted area can have a detrimental effect on the health of its residents. Research shows that long-term exposure to certain pollutants significantly increases the risk of emphysema (Wang et al., 2019) and negatively affects mental health (Newbury et al., 2019). High levels of crime in a neighbourhood are also associated with poor mental health outcomes (Stockdale et al., 2007). Other aspects of neighbourhood environment are associated with greater mental well-being such as access to green spaces and recreational facilities (Wood et al., 2017) and access to public transport, grocery stores, schools, and community centres (O'Campo et al., 2009).

Location, access to services and environment are important to consider when evaluating whether the right to adequate housing has been met within the human rights perspective. The State has an obligation under Article 11(1) of ICESCR to ensure that individuals not only have access to affordable, habitable housing but also inhabitants should have:

sustainable access to natural and common resources, safe drinking water, energy for cooking, heating and lighting, sanitation and washing facilities, means of food storage, refuse disposal, site drainage and emergency services. $^{102}$ 
In addition, housing should be located in areas which allow for access to employment options as well as basic services such as healthcare and education and should not be close to pollutants which could negatively impact a person's health. ${ }^{103}$

Access to services is included under the right to an adequate standard of living under a number of international treaties for specific groups such as children, ${ }^{104}$ those with disabilities, ${ }^{105}$ families, ${ }^{106}$ older people, ${ }^{107}$ and those at risk of poverty or social exclusion. ${ }^{108}$ The State also has an obligation to prevent discrimination in access to services for those with disabilities, ${ }^{109}$ women, ${ }^{110}$ migrant workers and their families, ${ }^{111}$ and racial, national, or ethnic minorities. ${ }^{112}$

The Rebuilding Ireland Action plan for housing and homelessness (2016) recognises that the neighbourhood in which housing is located is central to enabling a decent standard of living. The plan states that housing which allows individuals to thrive 'maximises access to employment opportunities and to services such as education, public transport and health and amenities' (2016, p.24); however the plan does not specifically address how it will ensure that these services are easily available to all.

In addition to providing accessible services, the prevention of unnecessary pollution and improvement of air quality to protect the health of residents is central to the concept of the location dimension of housing quality. The government began consultation for a national clean air strategy in 2017 . The goal of the strategy is to set 'out a framework for how all government departments can work to reduce air pollution and promote cleaner air'. ${ }^{113} \mathrm{At}$ the time of writing this strategy had not yet been published.

ICESCR 11(1) General Comment No.4, para 8(f).

CRC Article 27 (1).

CRPD Article 28 (1).

ESC Article 16.

ESC Article 23(a).

ESC Article 30.

CRPD Article 9 (1)(a), CRPD Article 19.

CEDAW Article $14(2)(\mathrm{h})$.

Article 19 (4).

CERD Article 5 (e)(iii).

https://www.gov.ie/en/policy-information/26f183-environmental-policy/. 


\subsection{ANALYTICAL APPROACH}

We measure the quality of the local environment using both aggregate indicators which provide some important general context and indicators of neighbourhood quality at the individual level collected from household surveys. The latter set of indicators allows us to disaggregate the experience of different groups in society, to identify if some groups are particularly exposed to poor neighbourhoods.

Aggregate indicators presented in this chapter look at overall levels of access to basic services and facilities such as running water, sewerage facilities and internet access. These indicators use data from the 2016 Irish Census and capture the entire population's access to these services.

Individual-level indicators presented in this chapter use data from the European Quality of Life Survey (2016). Differences are presented across seven groups: gender, age, country of birth, marital status, educational level, household structure and disability. The first of these indicators examines respondent's difficulty accessing services in their area and draws on a question from EQLS which asks respondents 'Thinking of physical access, distance, opening hours and the like, how easy or difficult is your access to the following services?'. We draw on four key services in the analysis which include banking facilities, public transport facilities, recreational or green areas and grocery shops or supermarkets. We measure access to these services by the proportion of respondents who reported difficulty accessing two or more of these services. The second individual-level indicator presented looks at subjective sense of security in the area where an individual resides. This draws on a question from EQLS which asks respondents to what extent they agreed or disagreed with the statement 'I feel safe when I walk alone in this area after dark'. The analysis presented looks at the proportion of respondents across the aforementioned groups who agree with this statement. The EQLS has a much smaller sample size at national level than SILC, but this information is not collected in SILC or other national population surveys.

\subsection{AGGREGATE INDICATORS}

Figure 8.1 shows the proportion of private households with access to piped water, sewerage facilities and internet access (broadband access). Access to piped water and sewerage facilities does not appear to be an issue in the State with almost all of the private 
households captured in the 2016 Census reporting access to these. This number is slightly smaller for Traveller households with Census figures suggesting that 95 per cent of these households have access to piped water and sewerage facilities. ${ }^{114}$ However, almost 20 per cent of private households reported no internet access in the 2016 Census. Access to the internet has become increasingly important in recent years, especially with the emergence of the COVID-19 pandemic. Due to the lockdown restrictions, non-essential staff were required to work from home, and in various stages throughout the pandemic students were required to participate in schooling through online learning which required steady and reliable internet access in the household. Research from November 2020 by the Commission for Communications Regulation found that 76 per cent of respondents believed their broadband usage had increased since the beginning of the pandemic and just under threein-five of those employed in November were working from home to some degree (ComReg, 2020). Mohan et al. (2020) also report significant inequalities in access to broadband for secondary school students across Ireland, which directly impacted students' experience of remote education.

FIGURE 8.1 PROPORTION OF PRIVATE HOUSEHOLDS WITH ACCESS TO BASIC FACILITIES (CENSUS 2016)

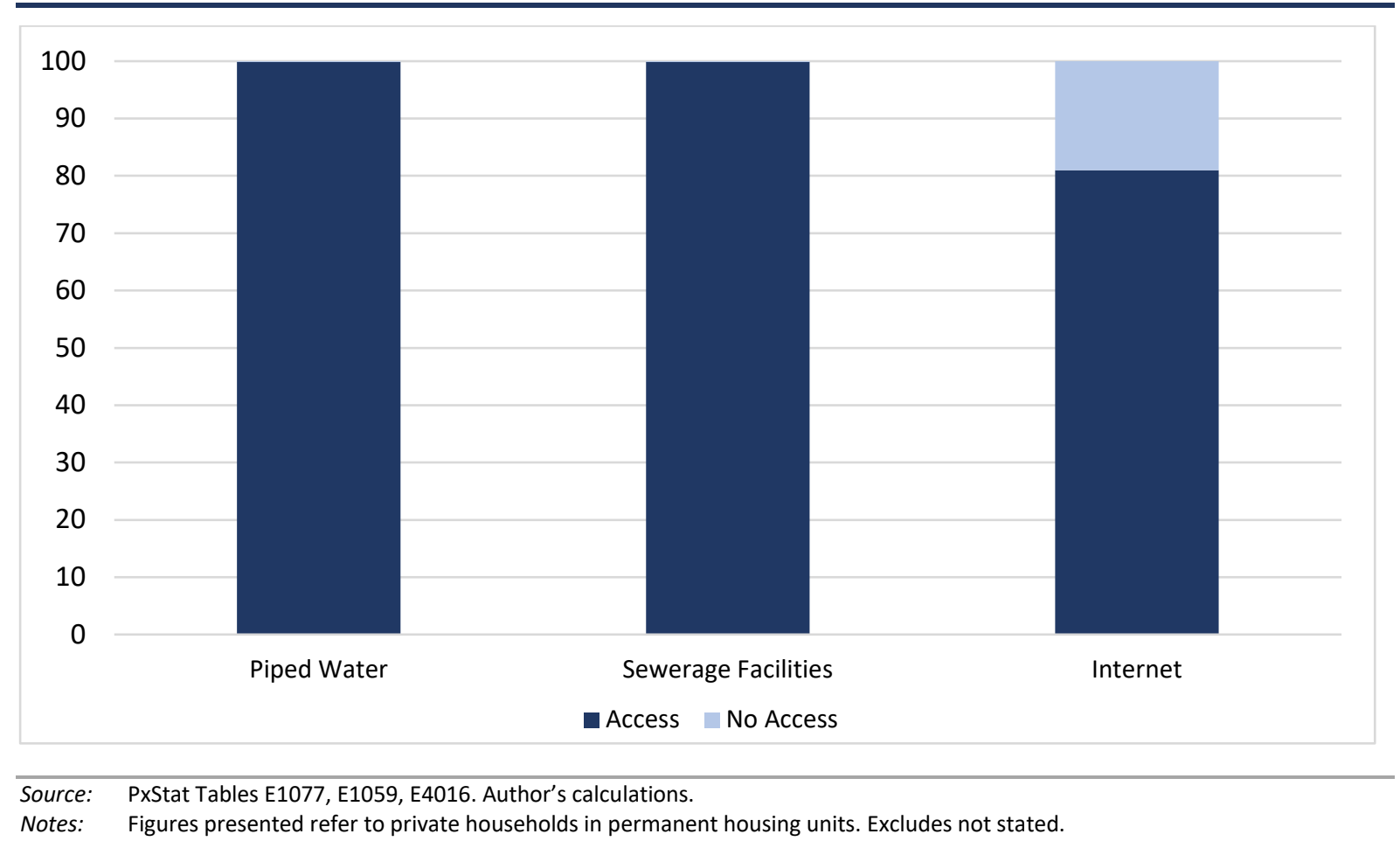


Although a lack of internet access may be related to low incomes, it is also related to the area in which a person lives with rural areas having less available internet services than cities. Figure 8.2 looks at the lack of access to internet by location. As expected, we find that those in rural areas are more likely to report no internet access with almost a quarter of those in rural areas reporting this issue compared to 16 per cent of individuals in urban areas. We also find that those in the Mid-East and Dublin are more likely to have access to the internet compared to those in the Midland, Mid-West, and those on the Border.

FIGURE 8.2 PROPORTION OF PRIVATE HOUSEHOLDS WITH NO ACCESS TO INTERNET BY LOCATION (CENSUS 2016)

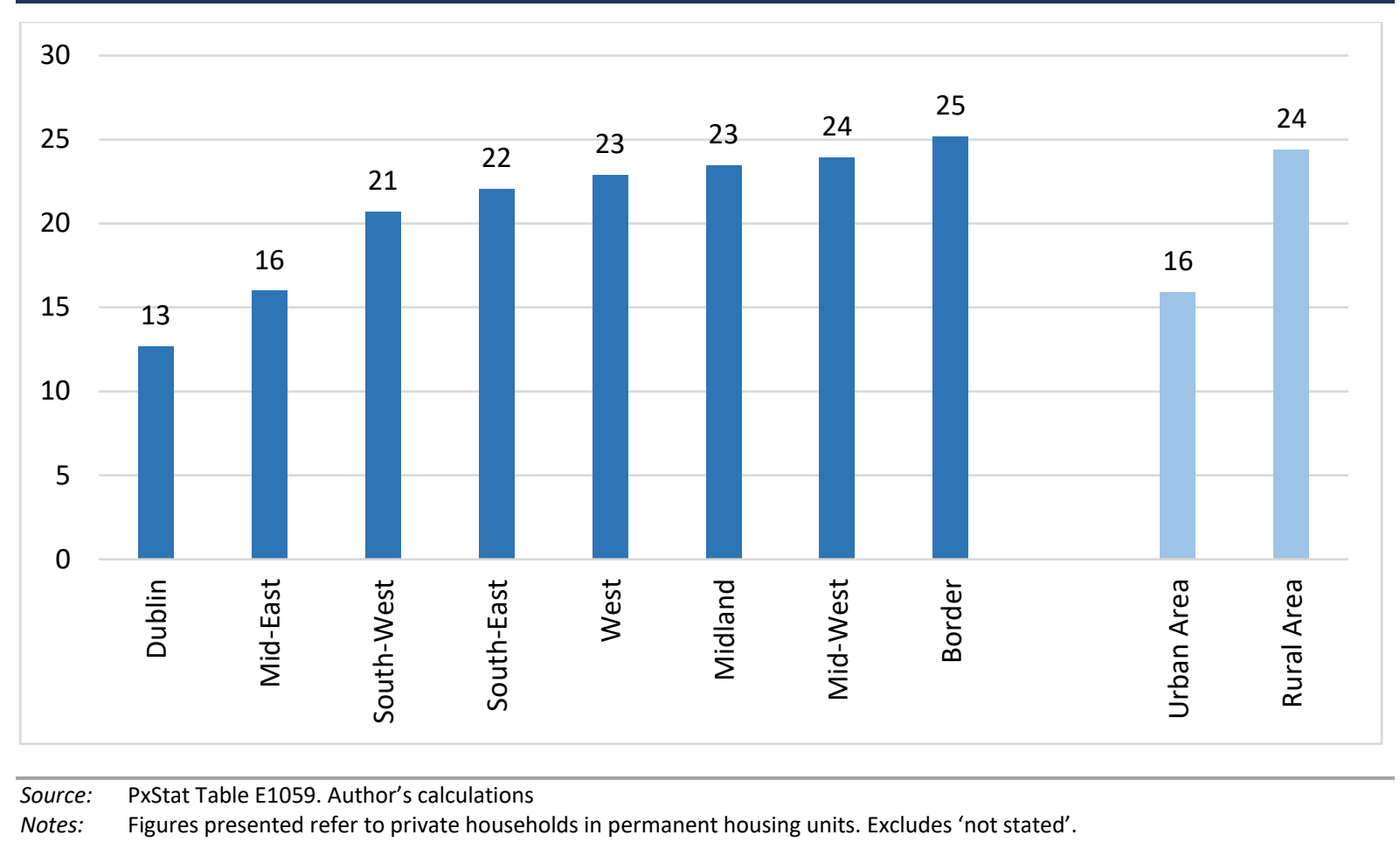

\subsection{INDIVIDUAL-LEVEL INDICATORS}

\subsubsection{Access to services}

Figure 8.3 shows the proportion of each group who had difficulty accessing two or more of the following services; banking, public transport facilities, recreational or green areas and grocery shops or supermarkets. Results are presented separately for urban and rural areas as the size of locality plays a significant role in access to services. Overall, we find that those in rural areas reported more difficulty accessing services compared to those in urban areas across almost all groups. This is reflected in the literature with previous research in an Irish context showing that basic services such as transport are concentrated in urban areas in the 
State (Nolan and Maître, 2008). It is important to note that the EQLS has a relatively small sample size for 2016 ( $n=1,011)$; as a result cell sizes for certain groups are small and likely affect statistical significance.

FIGURE 8.3 PROPORTION OF RESPONDENTS WHO HAD DIFFICULTY ACCESSING TWO OR MORE SERVICES (EQLS, 2016)

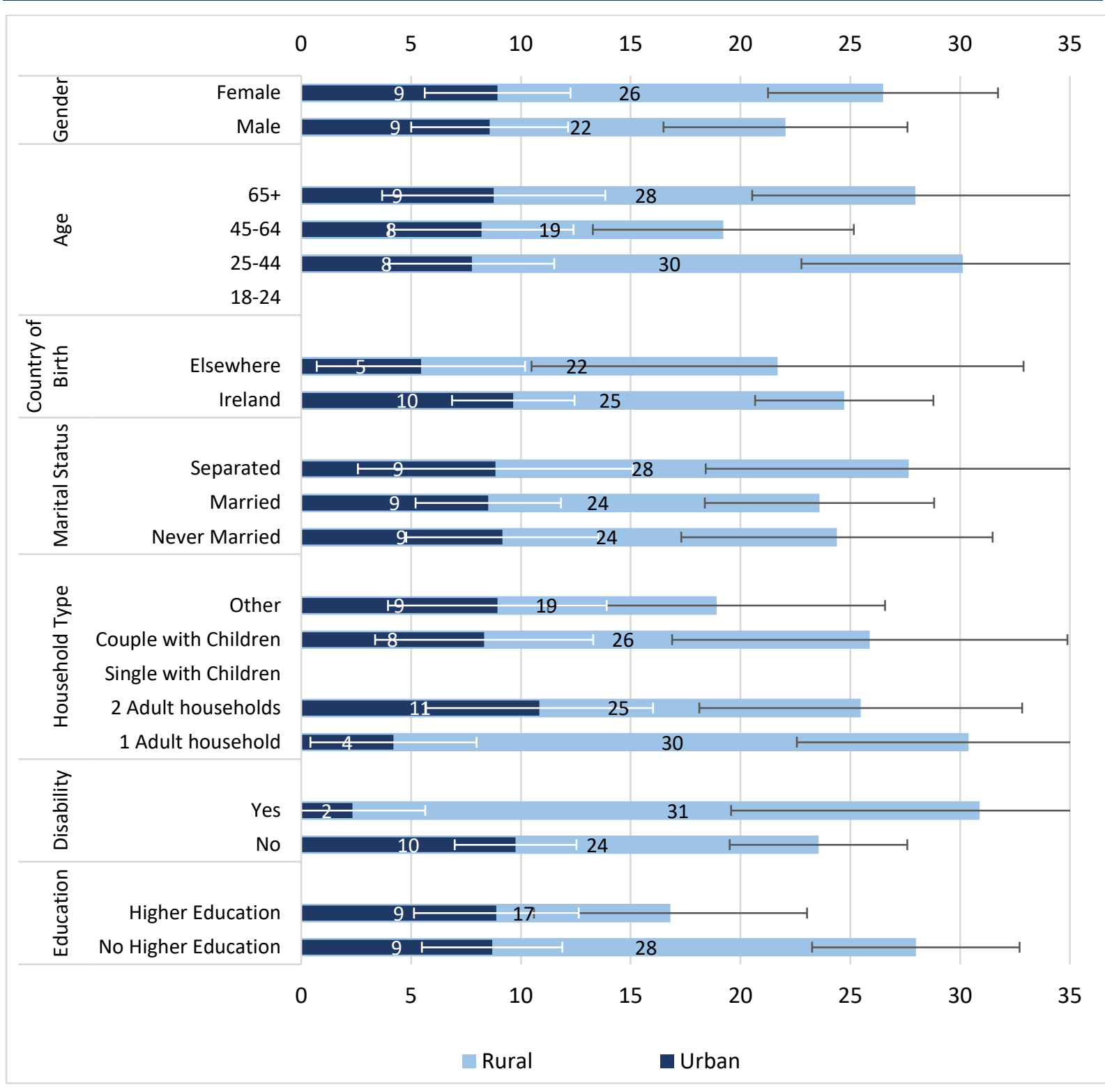

Source: EQLS 2016.

Notes: $\quad$ Figure lists proportions and 95 per cent confidence intervals by group.

Looking at differences between groups in accessing services in rural areas we find that respondents with no third-level education ( 28 per cent) are significantly more likely to report difficulty in accessing two or more services compared to those without (17 per cent). This may reflect income differences between these groups. A lack of accessible public transport in rural areas often necessities car ownership, which those on lower incomes may 
be unable to afford, in order to access services such as banking or supermarkets which may not be within walking distance.

There are a number of differences between groups that are large but not statistically significant. For example, differences between those aged 45 to 64 (19 per cent) and those aged 25 to 44 (30 per cent); or between those with a chronic illness or disability (31 per cent) and those without (24 per cent); between men (22 per cent) and women (26 per cent); those who were separated ( 28 per cent) and married or never married ( 24 per cent); and between those in 'other' households (19 per cent) and single households (30 per cent). Due to the small sample sizes of these groups, we cannot determine whether these differences are true reflections of differences between groups in the population.

Looking at difficulty accessing services for those in urban areas we find that respondents with no disabilities are significantly more likely to have difficulty accessing two or more services compared to those with chronic illnesses or disabilities ( 2 per cent).

Similarly, we find a number of large but insignificant differences between groups in difficulty accessing two or more services. For example, respondents born in Ireland (10 per cent) have more difficulty accessing services than those born abroad (5 per cent). Further, we find differences between those in single and two-adult households (11 per cent) who are more likely to report difficulty in accessing services than those in one-adult households (4 per cent).

Due to small sample sizes, we also analysed differential access to services in both rural and urban areas by calculating the mean number of services respondents had difficulty accessing. We find similar results using this measure for those in rural areas. The difference between those with and without disabilities is not significant for using the mean count measure, however we do find a significant difference between those born in Ireland and migrants. A statistical model of the number of services respondents had difficulty accessing 
revealed that controlling for size of locale, ${ }^{115}$ the only significant difference was between two-adult and one-adult households.

\subsubsection{Subjective sense of safety}

Figure 8.4 shows the proportion of respondents who feel safe walking alone in their area after dark. Overall, we find that over three-quarters of respondents felt safe walking alone in their area after dark. This differed largely by gender with men (91 per cent) significantly more likely to feel safe compared to women (64 per cent). The OECD (2020) reports similar findings for women in OECD countries. Previous research shows that women are more likely to feel vulnerable to crimes and worry about their personal safety than men (Harris and Miller, 2000; Riggs and Cook, 2014).

Looking at age we find that middle-aged respondents are more likely to feel safe walking in their area alone after dark compared to the youngest and oldest respondents. We find that respondents aged 45 to 64 are significantly more likely to feel safe than those over the age of 65 . Lower senses of safety among those aged over 65 may be related to their health with previous research showing that poor health is related to higher levels of feeling unsafe (Hanslmaier et al., 2018).

Respondents who have never been married (72 per cent) are significantly less likely to feel safe walking alone in their area after dark compared to those who are married (81 per cent). 
FIGURE 8.4 PROPORTION OF RESPONDENTS WHO FEEL SAFE WHEN THEY WALK ALONE IN THEIR AREA AFTER DARK (EQLS, 2016)

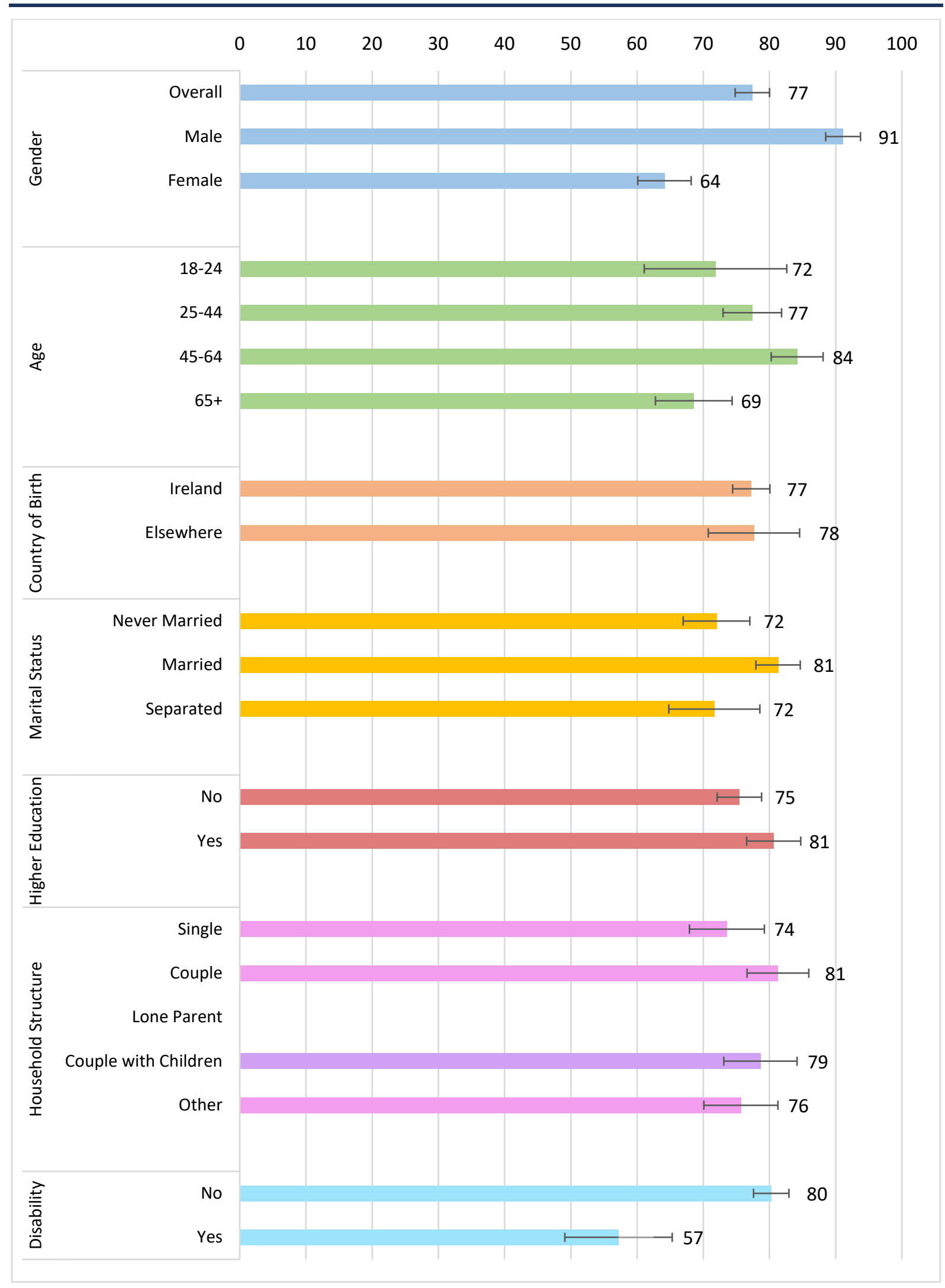

Source: EQLS 2016.

Notes: Figure lists proportions and 95 per cent confidence intervals by group. 
The largest difference in subjective sense of safety is found between those with and without disabilities. Respondents who have a chronic limiting illness or disability (57 per cent) are significantly less likely to agree that they feel safe walking alone in their area after dark compared to those without a disability or such illnesses (80 per cent). This perceived lack of safety may prevent those with disabilities from fully participating in the community. Qualitative interviews by the National Disability Authority (2010) found that a number of respondents would like to go out at night but did not because they felt unsafe to go outside at night-time.

No significant differences were found among groups on the basis of their educational level, household structure or their country of birth. Those who were married also had significantly higher odds of feeling safe than those who were never married.

\subsection{SUMMARY}

Overall, we find that access to basic facilities in Ireland such as sewerage facilities and piped water is extremely high with less than 1 per cent of individuals reporting a lack of access to such facilities in the 2016 Census. However, we do find evidence of differential access to internet in the household. Data from 2016 show large differences in access to internet based on location with those in rural areas less likely to have access. We find a similar urban/rural divide in access to services. The Rebuilding Ireland Action plan for housing and homelessness (2016) discusses rural renewal under the Town and Village Enhancement Scheme. The plan listed possible projects such as:

supporting greenways, cycleways, blueways and other environmental improvement initiatives that support economic activity in the area, environmental upgrading of public parks, civic areas, river walks, access facilities to amenities, public utilities such as street lighting, renovation of relevant derelict buildings, regeneration/re-use of vacant/disused sites, and other small-scale actions.

This plan was published in the same year as the EQLS data were collected. The seventh edition of EQLS is expected to be published in the summer of 2021; analysis of access to 
services using these data will reveal whether the Rebuilding Ireland action plan goal of rural renewal was successful in providing access to facilities and green areas.

The results on respondent's subjective sense of safety in their neighbourhood is concerning. We find that women and those with chronic limiting illnesses or disabilities are significantly less likely to feel safe walking alone in their area after dark. This may be because both groups feel vulnerable to attacks and unable to fight off any potential attacker. Feeling unsafe could prevent women and those with disabilities from participating in the community which would require them to be outside during the night and as such affect their right to an adequate standard of living.

\subsection{DATA GAPS}

There are a number of limitations to the analysis presented in this chapter. Firstly, the lack of statistically significant differences between certain groups may be the result of small sample sizes in the European Quality of Life Survey. These cross-national surveys tend to have a relatively small sample for each country (circa 1,000) and are designed as general population surveys. As result they generally do not obtain large samples of minority groups. Questions surrounding subjective feelings of safety in a neighbourhood and access to services are important indicators of adequate housing; however small sample sizes restrict their usefulness if we cannot determine the significance, if any, of differences between and among groups. In addition, because of sample sizes we were unable to distinguish between migrant groups, though we know from previous research that the experiences of migrants often differ widely across many different facets of life within the State (McGinnity et al., 2020b). We are also unable to analyse access to services and neighbourhood quality for certain equality groups as this information is not collected in the EQLS such as ethnicity, religion, sexual orientation and minority gender status. An ad hoc module on housing quality in the EU SILC is overdue. Such a module should cover important aspects of the quality of the local environment. Future iterations of SILC or surveys which include similar questions should increase the sample size of minority respondents and include questions on ethnicity, religion, sexual orientation and minority gender status to address these issues. 



\section{CHAPTER 9}

\section{Conclusion}

\subsection{MONITORING ADEQUATE HOUSING IN IRELAND}

Housing is a fundamental element of quality of life. Adequate housing is necessary for shelter, security, family life and as a basis for participation in society including employment. As Hohmann notes:

Safe and secure housing shields us from the elements and provides refuge from external physical threats. It gives us a material base from which to build a livelihood and take part in the life of the community and the State. But housing also provides a space in which our psychological needs can be met. (Hohmann, 2013, p.4)

The right to adequate housing is recognised in international human rights instruments including UNHRC, ICESCR, and the European Social Charter. ICESCR also spells out the dimensions of housing to be considered; access, affordability, security, cultural adequacy, habitability, and location/environment. In this report we set out to apply social science methods to operationalise and measure these dimensions of housing adequacy in Ireland in order to provide a baseline to monitor the right to adequate housing.

Following a review of relevant monitoring frameworks we consulted with over 30 individuals, representing a range of civil society groups, government departments/agencies and researchers, who were asked to assess and prioritise indicators of housing adequacy. Drawing on valuable insights gained from the consultation we propose a set of 12 indicators that are measured at the individual level and 13 aggregate level indicators to capture the current level of attainment of adequate housing in Ireland, and to provide a baseline for future monitoring. This baseline is measured pre-pandemic for all of the individual level indicators, though some of the aggregate indicators relate to 2020 and therefore capture the early stages of the COVID-19 crisis. Future monitoring can track the impact of pandemic on housing as relevant data become available. The individual-level indicators are disaggregated across a set of social groups, including those identified by equality legislation 
in Ireland and by social class (proxied by education level). This allows us to identify groups for whom the right to adequate housing is not fully realised.

The study finds that the dimensions of housing adequacy can be usefully applied in Ireland to identify a meaningful set of outcome indicators which capture inequalities in adequate housing and can track change over time in progress towards meeting the aims of adequate housing envisaged in international human rights instruments. We also identify limits in this approach, including significant data gaps, and note the considerable policy challenges to addressing important dimensions of housing adequacy.

\subsection{ADEQUATE HOUSING IN IRELAND AND FOR WHOM}

The most extreme form of inadequate housing is homelessness. In March 2021, 5,894 adults were recorded as homeless, including 913 families who had 2,166 dependants. This number of people accessing homeless services increased steadily between 2016 and 2019 before falling in 2020. Some of this fall may be attributed to emergency measures which were rapidly introduced in response to the COVID-19 pandemic (for example, rent freeze, and the moratorium on evictions). Importantly, we do not explicitly model the relationship between such restrictions and homeless figures.

The prospects for future levels of homelessness are very uncertain once the emergency protections are removed and when the impact of the severe restrictions of building activity on housing supply become apparent. These homeless figures also exclude those in 'hidden homeless' living situations - those staying with friends or family, 'sofa surfing', or those who are not engaging with homeless services. Additionally, there were 61,880 on the waiting list for social housing in 2020, ${ }^{116}$ indicating a very substantial number of households who are unable to meet their housing needs without government support, and high unmet demand for social housing. This number does not include those dependent on the housing assistance payment (HAP).

This figure is made up of people who qualify for social housing support. The figure excludes households currently living in Local Authority rented accommodation, voluntary/co-operative accommodation, accommodation provided under the Housing Assistance Payment (HAP) scheme, accommodation provided under the Rental Accommodation Scheme (RAS), accommodation provided under the Social Housing Capital Expenditure Programme (SHCEP) schemes or any household on a transfer list. 
Housing completions including social housing increased since 2015 following a period of exceptionally low housing supply. Despite the increase, the level of completions was still below predicted demand. The number of completions dropped again in 2020 due to the COVID-19 pandemic. Government capital spending on housing followed the same trend. The restrictions on construction work due to COVID-19 mean that there will be a significant shortfall in the number of housing units compared to that envisaged in the Rebuilding Ireland Action plan for housing and homelessness. This is likely to put increased pressures on house price affordability.

Results from the 2016 Census highlighted that a number of equality groups are overrepresented in the homeless population, including men, young adults, families with very young children, those who are single, separated or divorced, those from minority religions, people with a disability, non-Irish nationals, those of Black ethnicity and Travellers (Grotti et al., 2018). Previous research has also found that women are more likely to be in 'hidden homeless' situations. Here we find that young people and men are overrepresented among homeless services adults, while lone parents are overrepresented among homeless families. Lone parents and migrants are found to be overrepresented on the housing waiting lists.

There are also group differences in access to different housing tenures. There has traditionally been a high level of homeownership in the Irish housing system. While homeownership fell from a peak of 80 per cent in the 1990s (Grotti et al., 2018), by 2019 over two-thirds of people in Ireland - 70 per cent - lived in owner-occupied housing. The private rented sector was traditionally a residual sector in Ireland, associated with insecurity of tenure, and often quality and affordability issues (see below). The proportion of households living in Local Authority social housing halved between 1961 and 2011 but then stabilised between 2011 and 2016 (Grotti et al., 2018). The lower proportions of households in Local Authority housing may be due to a lack of new social housing completions. Migrants are significantly more likely to live in rental accommodation and significantly less likely to own their own home (except UK-born). Those born in Eastern Europe are overrepresented in rental accommodation and non-EU migrants are overrepresented in Local Authority housing. Migrants are also overrepresented in social housing waiting lists. Lone parents 
were also overrepresented in Local Authority housing and private rental and significantly less likely to own their own home compared to all other household groups.

The continuing problem of homelessness highlights a section of the community for whom the most basic measure of adequate housing as envisaged under international human rights agreements is not being met. Homelessness figures, however, do not include other individuals who are inadequately housed according to the other dimensions outlined in ICESCR.

The analyses reveal problems on the affordability dimension of housing in both aggregate and individual level indicators. Rental costs have increased in Dublin and the rest of the country since 2012, despite the introduction of Rent Pressure Zones in late 2016. ${ }^{117}$ Rents have increased beyond the pre-recession period by almost 40 per cent in Dublin and 20 per cent elsewhere. Rental costs have risen at a faster rate than mean earnings in Dublin and elsewhere. In 2020, we estimate that mean monthly rent in Ireland was 31 per cent of mean monthly earnings.

Issues of affordability are also evident at an individual level. We find that in $2018 / 2019$, 8 per cent of individuals lived in households paying more than 30 per cent of their household income on housing costs and 5 per cent were both paying more than that threshold and falling into the bottom 40 per cent of the income distribution. This figure rises to 15 per cent among renters. Additionally, we find that after housing costs are deducted from income, 15 per cent of individuals fall below the poverty line (less than 60 per cent of median household income) and 9 per cent were in arrears on their housing costs; i.e. 13 per cent of those in private and Local Authority tenancies and 5 per cent in the owner-occupied sector. All three measures therefore suggest a significant minority (between 5 and 15 per cent) of individuals are experiencing housing affordability problems in Ireland.

These figures suggest a gap in the achievement of the obligations set out in ICESCR that: 
Financial costs associated with housing should not threaten or compromise the attainment and satisfaction of other basic needs (for example, food, education, access to health care).

A number of groups are identified at higher risk of affordability problems on all three measures: lone parents, people with a disability, and non-EU migrants. Children are also significantly more likely to be living in households with affordability issues. Those living alone and those who are separated have a higher level of arrears and when we focus on those living in the private rented sector they emerge as being a group highly exposed to affordability problems.

The latest government figures show that over 91,600 were in receipt of government housing benefits (including HAP, RAS, and Rent Supplement). This represents a very substantial State investment in addressing affordability issues for those renting and highlights the extent of such issues in the housing market. Information on HAP recipients also provides an insight into those who would not be able to meet housing costs without government support. Groups overrepresented among HAP recipients includes non-Irish nationals (with the exception of EU-West nationals), those from minority ethnic groups, those aged 25-44 and women.

While some of the problems of affordability are due to rising prices that have significantly outpaced earnings, affordability is also a problem of persistently low income. This can be seen most clearly when we see that Local Authority tenants are highly likely to be poor after housing costs, even though rents in this sector are low. In this case, solutions lie in the levels of income supports and access to employment and educational opportunities rather than in housing alone. This underlines the importance of acknowledging housing as part of a broader concept of an adequate standard of living. Problems of attaining decent work, including adequate earnings, were highlighted in the companion study to this monitor (McGinnity et al., 2021). The interdependence of low income, inadequate housing and decent work underlines the indivisibility of socio-economic rights, which is a point emphasised in international treaties such as ICESCR.

The proportion of households in the private rented sector has increased from 10 per cent in the 2006 Census to 19 per cent in the 2016 Census. This decline in homeownership and lack 
of investment in social housing has resulted in an increased demand on the rental sector and means there has been a consequent shift in security, as in Ireland private tenancies lack the long-term certainty of other tenure types (see Norris, 2016; Norris and Byrne, 2018, for a discussion of the financial and housing policies behind this change).

Overall, those in the private rental sector had significantly shorter occupancy, a mean of four years, compared to a mean of seven years among Local Authority tenants and 21 years among those in the owner-occupied sector. There is some indication that within the private rental sector the length of tenancies has increased recently, with a growth in the number of tenancies lasting ten or more months. The total number of disputes between landlords and tenants reported to the RTB rose between 2017 and 2019, but the proportion tied to validity of notice and unlawful termination has fallen. Enhanced protections for tenants during COVID-19, including a rent freeze and moratorium on eviction, are in place until July 2021 , but evictions may spike when this protection is removed. For owner-occupiers, there has been a decrease in repossessions of principal dwellings, as the effect of the financial crash and the Great Recession receded.

We find that lone parents and migrants report shorter tenancies, which is heavily associated with housing tenure type. Within the private rented sector, there is no significant difference in duration of occupancy across groups. Statistics on tenure duration are limited in that they cannot tell us the role of choice - such as people wanting to move home because of moving to a new job - and constraint - people being forced to move because of affordability or notice from a landlord.

The perceived likelihood of having to move in the next six months due to affordability problems is a clearer indicator of disadvantage. Overall, 4 per cent of adults in Ireland fall into this category. However, because this is a relatively uncommon experience, the sample size in EQLS is too small to detect significant differences between groups.

The concept of cultural adequacy in the ICESCR and the human rights discourse has referred to the experience of indigenous populations. We take a broader approach here and include the experiences of the Traveller community and those living in Direct Provision who have been required to live in congregated settings that run contrary to mainstream cultural norms of adequate housing. 
Travellers are significantly overrepresented in homelessness and in poor-quality housing (see below). Here we find an increase in the number of Travellers in 'shared housing' since 2015 (typically informal arrangements and often referred to as hidden homeless) (Houses of the Oireachtas, 2018). There has also been an increase in the number housed by Local Authorities. There is a significant difference in the type of housing occupied by Travellers and their preferred form of housing. For example, fewer Travellers lived in Local Authority group housing and halting sites (17 per cent) than stated a preference for such accommodation (26 per cent) in a special survey by the Fundamental Rights Agency. A recurring issue in housing policy for Travellers in Ireland is unevenness across the Local Authorities in the extent to which they spend the national allocation of funds for Traveller accommodation. Only two-thirds of allocated funds were drawn down in 2019. It is of note however that all of the budget was used in $\mathbf{2 0 2 0}$ when the system shifted from allocation to one that allowed all councils to apply for funds and drawdown at any point of the year. It is important to note however that the drawdown of funds may have been used for the maintenance of existing accommodation rather than increasing the number of culturally appropriate housing stock.

The Direct Provision system of accommodation for international protection applicants has been found to be inadequate by international human rights bodies (UNCRC, 2016; CERD, 2019) and by numerous national bodies (IHREC, Ombudsman for Children; Government of Ireland, 2020). We note that in August 2020, there were 7,400 asylum seekers in Direct Provision and emergency accommodation in Ireland and the numbers living in Direct Provision have increased since 2016. However, there has been a significant decrease in the proportion of residents that have been living in Direct Provision for five years or more since 2015. There is now a government commitment to ending the Direct Provision system (Government of Ireland, 2021). Yet it remains to be seen what the system will be replaced by and whether it will meet the diverse needs of asylum seekers in Ireland. The continued monitoring of housing for asylum seekers is crucial.

Individual indicators of housing quality used were over-crowding and an index of housing deprivation. Over-crowding rates in Ireland are generally low relative to other European countries, but we find large differences in over-crowding between ethnicity and country of birth groups (Census 2016). Households headed by Eastern European (28 per cent) and non- 
EU migrants (27 per cent) are significantly more likely to live in over-crowded accommodation compared to those born in Ireland (4 per cent). Grotti et al. (2018) find that high rates of over-crowding among non-EU migrants persist after controlling for age, family status, household composition, disability, tenure, and income. Travellers (39 per cent), Black (41 per cent), Asian (35 per cent) or Other ethnicities (25 per cent) are also significantly overrepresented in over-crowding rates compared to White Irish and other White background. These reflect findings by EHRC (2018) for the UK, which found that ethnic minorities were more likely to live in over-crowded accommodation. High rates of overcrowding among Travellers were also found in previous Irish research (Watson et al., 2017a).

Lone parents and those with disabilities are found to experience structural issues with housing and are more likely to report being unable to keep their homes adequately warm. Migrants are also more likely to experience issues with the quality of their housing compared to those born in Ireland (differences here may reflect differences in tenure type).

These results suggest Ireland may not be meeting its obligations under the Housing Quality facet of the right to adequate housing which states that inhabitants should be protected from the cold, from structural issues, and have adequate space in their accommodation.

Almost all households in Ireland have access to basic facilities such as piped water or sewerage, however a clear rural-urban divide is evident in internet access. Internet has increasingly become a necessity for participation in society and this trend was accelerated by the COVID-19 pandemic which brought a massive increase in both homeworking and home-schooling. There is a growing body of evidence on the digital divide in Ireland which adversely affected learning of children and young from disadvantaged backgrounds during the lockdown (Mohan et al., 2020; Devitt et al., 2020). This may also apply to students in third-level education, however as Darmody et al. (2020) note there is a gap in research on students in higher education.

A substantial rural/urban divide is also evident in relation to access to services and amenities including public transport, recreational spaces and grocery shops. Among the rural population, it is those with lower resources, proxied by education level, who have the most difficulty accessing these services and amenities. The Rebuilding Ireland Action plan for 
housing and homelessness (2016) discusses rural renewal and includes access to facilities, amenities and public utilities as possible projects. The EQLS data used in this report were collected in the same year as the action plan; future analysis of the seventh edition of EQLS (expected to be published in 2021) may reveal if this was successful.

A subjective sense of safety in the locality was strongly emphasised as an aspect of adequate housing by the participants in the consultation process. Perceptions of safety differed strongly by gender. Women and those with disabilities were significantly less likely to feel safe when they walk alone in their area after dark. Feeling unsafe could prevent women and those with disabilities from fully participating in the community. Such safety issues need to be considered in the built environment (e.g. street lighting) as well as the provision of public services (transport and policing).

The consultation with stakeholders also highlighted that the location dimension of adequate housing as defined in ICESCR is too narrow. It misses out on the sense of community belonging in any given location, and indeed the importance of supporting sustainable communities, which is harder to achieve in the face of housing insecurity or without public amenities.

\subsection{IMPLICATIONS FOR DATA COLLECTION}

Broadly, we find a number of data gaps that are important to address in order to accurately measure access to adequate housing in Ireland overall, and for protected or vulnerable groups:

- Limited information on key groups in surveys and on detailed categories within groups (e.g. type of disability);

- Limited information on key groups in government and administrative data;

- A lack of data on housing preferences and subjective assessments of satisfaction with housing;

- A lack of suitable measures for housing security;

- Inadequate indicators of cultural adequacy;

- A lack of data on access to local services; 
- A lack of data on housing discrimination.

One of the biggest data limitations to monitoring housing outcomes from a human rights perspective is the lack of information on equality groups from key data sources including Survey of Income and Living Conditions (SILC) and administrative data such as the PASS homeless statistics. This restricts the ability to monitor outcomes by ethnicity, including Irish Traveller status, detailed nationality, sexual orientation, ${ }^{118}$ religion, or minority gender status. Additionally, as noted by McGinnity et al. (2020a), refugees are not identified in national surveys or general administrative data in Ireland, and there are no dedicated surveys of refugees. Data on those who live in residential settings are also uncommon, making it difficult to monitor progress on the policy of moving people with a disability out of congregated settings.

Therefore, there is an acute need for more disaggregated data including increased disaggregation within existing categories such as nationality and disability ${ }^{119}$ so that meaningful groups can be distinguished. The collection of information on key equality characteristics in the core national surveys of the population such as SILC, the Labour Force Survey and the General Household Survey is a priority. General principles for the collection of equality data are set out in the EU Guidelines on improving the collection and use of equality data which, among other recommendations, stress that the collection of equality data should be mainstreamed into EU and national surveys (European Commission, 2018).

Data collection funded by government or carried out by public bodies should aim to be disaggregated according to the requirements of national equality legislation and monitoring by international bodies. This is statutory responsibility of public bodies under the Public Sector Duty. Administrative data should also be made accessible to researchers and rights holders in an anonymised format as recommended by the European Commission National Security Board (NSB) (NSB, 2021). The collection of appropriately disaggregated data was also a recommendation of the recent Citizens Assembly on Gender Equality. ${ }^{120}$

The NSB (2021) recommends a study be conducted on the best practice to measure sexual orientation and gender identity in surveys or censuses.

The NSB (2021) recommends that Census 2022 definition of disability in all survey data as much as possible and disabled/non-disabled analyses of statistics be made available.

Recommendation 43 of the Assembly was to 'Ensure data gathering on key gender equality issues (including care), regular publication of such data and remedial action where necessary' (Citizens Assembly, 2021). 
The European Commission has also advised all Member States to create an equality data hub resource (NSB, 2021). In response to these guidelines and the request of the Equality Budgeting Committee the CSO have carried out an Equality Data Audit, which is intended to be updated regularly. ${ }^{121}$ This could provide a basis for an equality data hub.

The collection of a sufficient sample size to allow for disaggregation and research on intersectionality is also crucial. This is relevant when either the group in question represents a small proportion of the population or when the experience is a relatively uncommon occurrence (e.g. discrimination when looking for housing). Where sample sizes cannot be increased, more frequent fielding of ad hoc surveys or booster samples of minority groups should be considered. This means deliberately over-sampling minority groups, and reweighting data to ensure representativeness at the analysis stage. This has been suggested as a strategy for increasing representation of migrants in the SILC (Fahey et al., 2019).

However traditional survey methods that rely on household samples will not be adequate to include some groups for example Travellers, Roma and refugees; targeted data collection is likely to be necessary for these groups as well as the inclusion of the necessary identifiers in administrative data.

Harmonisation of definitions for individual characteristics across surveys and administrative data would also enhance the use of such data for legitimate research and policy purposes. The EU equality data group notes that:

Comparability is strongly affected when concepts, definitions or categories of study design vary across data sources, points in time or countries. Improving comparability implies that error due to sample or questionnaire design, mode of data collection, translation etc. is minimised. (European Commission, 2010 p.17)

Linking data from administrative sources to survey data presents an opportunity to expand the range and applicability of existing surveys and has been carried out successfully by the 
CSO using a range of datasets and administrative statistics, ${ }^{122}$ but crucially depends on the appropriate identifiers and characteristics being collected in administrative sources. IHREC notes that collection of information by public bodies to monitor non-discrimination and inequality of access to services and outcomes for minority groups is a legitimate public interest under GDPR.

Our analysis also highlights data gaps on topics identified as central for monitoring housing adequacy, namely satisfaction with housing, housing security, housing discrimination, perceived safety, and access to local services. While some relevant questions are fielded in European surveys there are insufficient cases for analyses. Discrimination is of key concern from an equality and human rights perspective but the most recently collected data which are contained in the CSO's General Household Survey 2019 do not have enough cases to allow for disaggregation. ${ }^{123}$ Repeated fielding of the relevant questions is needed to monitor housing discrimination and to provide a basis for evaluating the effectiveness of the amendment to the Equal Status Act prohibiting discrimination on the ground of receiving housing supports.

Given the importance of housing adequacy for standard of living and quality of life and Ireland's international commitments to progressing adequate housing, there is a strong argument for plugging these gaps with a new ad hoc module or national survey.

\subsection{STRENGTHS AND WEAKNESSES OF A MONITORING APPROACH}

Overall, the dimensions of housing adequacy identified in the ICESCR framework were found to have a broad legitimacy among housing stakeholders in Ireland and cover the same key dimensions of housing included in poverty and quality of life frameworks. Indeed, the ICESCR dimensions are generally more comprehensive than other frameworks and include https://www.cso.ie/en/aboutus/Igdp/csodatapolicies/csodataprotocol/archiveofcompleteddatamatchingactivi ties/. 
concepts of perceived safety and cultural adequacy that are not usually addressed in other frameworks.

This exercise has shown that it is possible to identify a set of meaningful outcome indicators of the dimensions of housing adequacy that, with efforts to address the data gaps outlined above, could be used to track progress (or lack of progress) towards housing adequacy in Ireland. Setting individual-level outcomes within the context of broader aggregate outcomes provides a means of looking at broader trends in household adequacy. There is also an opportunity to compare many of the outcome indicators used to those in other EU countries, this is true for all those based on SILC data and for those on the European Quality of Life Survey. The monitor can also identify groups experiencing deficits in adequate housing across multiple dimensions. One of the limitations of a monitor is that the processes behind the observed differences in outcomes cannot be explored, including the respective role of preferences and constraints, however the results can point to areas for further in-depth research.

\subsection{POLICY ISSUES}

Issues of supply shortages and affordability continue to challenge the achievement of adequate housing in Ireland. There is evidence that limits to lending that the Central Bank introduced on foot of the property collapse during the recession have acted as a brake on rising house prices (McQuinn et al., 2020), yet rents have been rising steeply and increasing numbers of areas have been defined as Rent Pressure Zones. Between 5 and 15 per cent of people are still facing affordability issues. The pause in construction due to the pandemic has added a further set-back to achieving housing supply targets to address the large number of people on housing waiting lists and those renting who wish to transition to owner-occupancy.

The growth in the private rented sector and the policy shift to housing those with housing needs, including those experiencing homelessness and other vulnerable groups, in private rental accommodation supported by $\mathrm{HAP}^{124}$ has raised additional issues around the security 
and quality of housing. A number of reviews have highlighted the problem in outsourcing the housing search to groups who have limited bargaining power and who are vulnerable to discrimination, and the lack of long-term security involved (Hearne and Murphy, 2018; IHREC, 2017; Government of Ireland, 2020). There is a lack of information to assess how well the additional legal protection against discrimination in the housing domain has worked (see Chapter 1), and a systematic evaluation of the impacts of housing supports is warranted.

The shift in provision toward private rental housing also places an increased onus on the State to address quality issues through regulation and enforcement. A recent review of the National Oversight Audit Committee revealed a range of weaknesses in the regulation of standards in the private rented sector. It reported that inspection activity by Local Authorities of the houses was low - amounting to less than 2 per cent of registered tenancies in seven Local Authorities, and when dwellings were inspected, a high level of non-compliance was found (55 per cent). The report also noted that there was limited recourse to the available enforcement mechanisms, and 'follow-up inspections did not appear to achieve a high degree of compliance in many authorities'. NOAC (2016) concluded that 'the inspection process as currently administered by Local Authorities is not having a sufficient impact on the standard of rental accommodation'.

Issues with heating, housing quality, and over-crowding point to potential shortfalls in the right to adequate housing in terms of habitability and access to services (including heating) as defined in ICESCR for some groups in Ireland, including Travellers, some migrant groups, and ethnic minorities. Lone parents, single person households and people with a disability are disadvantaged on two of the three indicators, though not on the over-crowding indicator because of the smaller family size. Those living in Local Authority accommodation are particularly exposed to housing quality problems. This is in part driven by the low incomes of LA tenants, however structural issues such as damp walls, leaky roofs, glazing and central heating systems are the responsibility of the Local Authorities and therefore deficits in these aspects of social housing suggest that Local Authorities need to do more to address housing quality issues.

There is considerable scope to expand housing commitments in the national strategies for equality groups. Individuals with disabilities are currently the only equality group with a 
specific housing strategy published by the government (National Housing Strategy for People with a Disability 2011-2016, extended to 2020). Housing is largely unaddressed by the national equality strategies with the exception of the National Traveller and Roma Inclusion Strategy 2017-2021. This strategy focused on making accommodation accessible, culturally adequate and affordable, however our findings show that Travellers are vulnerable to homelessness and have high over-crowding rates in accommodation. Future iterations of the strategy, which is due to expire this year, should attempt to track progress on the goals set out within the strategy and address issues of over-crowding and homelessness.

Other equality strategies such as the Migrant Integration Strategy 2017-2020, National Strategy for Women and Girls 2017-2020125 and the National Youth Strategy 2015-2020 do not cover the adequate housing dimensions discussed in this report apart from the accessibility of services. Given the disadvantage that some groups, particularly some groups of migrants, lone parents and young people, experience across a number of adequate housing indicators, these gaps should be addressed in the new strategies. In addition, future iterations of national equality strategies should include measurable indicators to allow for evaluation on their implementation. 



\section{REFERENCES}

Ahmed, A.M. and M. Hammarstedt (2008). 'Discrimination in the rental housing market: A field experiment on the Internet', Journal of Urban Economics, 64(2), 362-372.

Amore K., M. Baker and P. Howden-Chapman (2011). 'The ETHOS definition and classification of homelessness: an analysis', Eur J Home. 5(2).

Andersson, L., N. Jakobsson and A. Kotsadam (2012). 'A Field Experiment of Discrimination in the Norwegian Housing Market: Gender, Class, and Ethnicity', Land Economics, Vol. 88(2), pp. 233-240.

Arnold, S. (2012). State Sanctioned Child Poverty and Exclusion - The case of children in state accommodation for asylum seeker, Irish Refugee Council.

Arnold, S., E. Quinn, E. Gusciute and L. Kinlen (2019). 'Cultivating problems for the future: Integration supports for resettled and spontaneous refugees in Ireland', Migration Studies. https://doi.org/10.1093/migration/mnz016.

Auspurg, K., T. Hinz and L. Schmid (2017). 'Contexts and conditions of ethnic discrimination: Evidence from a field experiment in a German housing market', Journal of Housing Economics, 35, 26-36.

Baker, E., K. Mason and R. Bentley (2015). 'Measuring housing affordability: A longitudinal approach', Urban policy and research, 33(3), 275-290.

Baldini, M. and M. Federici (2011). 'Ethnic discrimination in the Italian rental housing market', Journal of Housing Economics, Vol. 20, pp. 1-14.

Bergin, A. and A. García-Rodríguez (2020). Regional demographics and structural housing demand at a county Level. ESRI, Economic and Social Research Institute.

Berthoud, R. (2008). 'Disability employment penalties in Britain', Work, employment, and society, 22(1), 129-148. 
Bosch, M., M.A. Carnero and L. Farré (2010). 'Information and discrimination in the rental housing market: Evidence from a field experiment', Regional Science and Urban Economics, Vol. 40 (1), pp. 11-19.

Bottero, W. (2005). 'Interaction distance and the social meaning of occupations', The Sociological Review, 53(2_suppl), pp. 56-72.

Burchardt, T. (2017). 'Equality and human rights monitoring in Britain: theory and practice', Presentation 23 March 2017. Economic and Social Research Institute, Dublin.

Burchardt, T. and P. Vizard (2011). 'Operationalizing the Capability Approach as a Basis for Equality and Human Rights Monitoring in Twenty-first-century Britain', Journal of Human Development and Capabilities, Vol. 12, No.1, pp. 91-119.

Byrne, D. and M. Treanor (2020). Income, Poverty and Deprivation among Children: $A$ Statistical Baseline Analysis. Department of Children and Youth Affairs.

Byrne, M. and R. McArdle (2020). 'Secure occupancy, power, and the landlord-tenant relation: a qualitative exploration of the Irish private rental sector', Housing Studies, 1-19.

Chevallier, C., S. Murphy and C. Buggy (2019). Understanding the Lived Experiences of Gender Minority Students in Irish Third-Level Education.

Citizen's Assembly (2021). Report of the Citizen's Assembly on Gender Equality. The Citizen's Assembly.

Citizens Information (2021b). Renting and COVID-19: Evictions when COVID-19 restrictions limit movement to $5 \mathrm{~km}$.

Committee on the Elimination of Racial Discrimination (2019). Concluding observations on the combined fifth to ninth reports of Ireland, December 2019.

ComReg (2020). Study on the Impact of COVID-19 on Home Broadband and Mobile Service Usage. ComReg. 
Conefrey T. and D. Staunton (2019). 'Population Change and Housing Demand in Ireland', Central Bank of Ireland Economic Letter No. 14.

Corrigan, E. and D. Watson (2018). 'Social housing in the Irish housing market' (No. 594). ESRI Working Paper.

Corrigan, E., P. Cotter and G. Hussey (2019a). 'The Housing Aspirations and Preferences of Renters', IGEES Research Paper.

Corrigan, E., D. Foley, K. McQuinn, C. O'Toole and R. Slaymaker (2019b). 'Exploring affordability in the Irish housing market', The Economic and Social Review, 50(1), pp. 119-157.

Coulson, N.E. (2002). 'Regional and State Variation in Homeownership Rates; or if California's Home Prices were as Low as Pennsylvania's would its Ownership Rate be as High?', Journal of Real Estate Finance and Economics, Vol. 24(3), pp. 261-273.

CSO (2019). Survey on Income and Living Conditions (SILC).

Daly, A., S. Craig and E. O'Sullivan (2018). 'The institutional circuit: Single homelessness in Ireland', Eur. J. Homelessness, 12, 79-94.

Daly, M. (2019). ESPN Thematic Report on National strategies to fight homelessness and housing exclusion - Ireland, European Social Policy Network. Brussels: European Commission Darmody, M., E. Smyth and H. Russell (2020). Implications of the COVID-19 Pandemic for Policy in Relation to Children and Young People: A Research Review. Dublin: ESRI/DCYA.

Department of Employment Affairs and Social Protection (2019). Social Inclusion Monitor 2017. Dublin: Department of Employment Affairs and Social Protection.

Department of Housing, Local Government and Heritage (2020). Rebuilding Ireland Home Loan Scheme. 
Department of Housing, Local Government and Heritage (2020b). Statement from Minister O’Brien on co-living.

Department of Housing, Planning and Local Government (2018). Sustainable Urban Housing: Design Standards for New Apartments. Guidelines for Planning Authorities. Dublin: Department of Housing, Planning and Local Government.

Department of Housing, Planning and Local Government (2019). Traveller Accommodation, Expert Review. Independent Expert Review Group on behalf of the Minister of Housing, Planning and Local Government. (https://rebuildingireland.ie/news/minister-englishpublishes-the-report-of-the-expert-review-group-on-Traveller-accommodation/).

Department of Housing, Planning and Local Government (2020a). Co-Living/Shared Accommodation Report. Dublin: Department of Housing, Planning and Local Government.

Department of Justice and Equality (2019). Direct Provision: Overview of Current Accommodation Expenditure. Department of Justice and Equality.

http://www.justice.ie/en/JELR/Spending_Review.pdf/Files/Spending_Review.pdf [Accessed 13 July 2020].

Department of the Environment, Climate and Communications (2020). Home Energy Grants.

Department of the Taoiseach (2021). Government agrees to begin work on a Well-Being Framework for Ireland. Available at: https://www.gov.ie/en/press-release/9dce3government-agrees-to-begin-work-on-a-well-being-framework-for-ireland/ [Accessed 31 May 2021].

Desmond, M. and C. Gershenson (2016). 'Housing and Employment Insecurity among the Working Poor', Social Problems, 63 (1), pp. 46-67.

Devitt, A., A. Bray, J. Banks and E. Ni Chorcora (2020). 'Teaching and Learning During School Closures: Lessons Learned', Irish Second-Level Teacher Perspectives, Dublin, Trinity College Dublin, July 2020. 
Drydakis, N. (2011). 'Ethnic discrimination in the Greek housing market', Journal of Population Economics, Vol. 24(4), pp. 1235-1255.

Duffy, D., D. Foley, N. Mc Inerney and K. McQuinn (2016). 'Demographic Change, Long-Run Housing Demand and the Related Challenges for the Irish Banking Sector', in Ireland's Economic Outlook: Perspectives and Policy Challenges. Economic and Social Research Institute (ESRI).

ECSR (2017). International Federation for Human Rights (FIDH) v. Ireland. European Committee of Social Rights.

EIGE (2020). Gender Equality Index 2020 Digitalisation and the future of work. Luxembourg: Publications Office of the European Union.

Equality and Human Rights Commission (2017). Measurement Framework for Equality and Human Rights. London: EHRC.

Equality and Human Rights Commission (2018). Is Britain Fairer? The State of equality and human rights 2018.

Erikson, R. and J.H. Goldthorpe (2002). 'Intergenerational inequality: A sociological perspective', Journal of Economic Perspectives, 16(3), pp. 31-44.

Eurofound (2017). European Quality of Life Survey 2016: Quality of life, quality of public services, and quality of society. Publications Office of the European Union, Luxembourg.

European Commission (2018). Guidelines on improving the collection and use of equality data.

European Commission against Racism and Intolerance (2019). ECRI Report on Ireland (fifth monitoring cycle). Strasbourg: ECRI Secretariat.

Eurostat (2020). Quality of Life Statistics Methodology. Eurostat https://ec.europa.eu/eurostat/web/quality-of-life/methodology. 
Ewens, M., B. Tomlin and L.C. Wang (2014). 'Statistical discrimination or Prejudice? A Large Sample Field Experiment', Review of Economics and Statistics, Vol. 96(1), pp. 119-134.

Fahey, T., B. Nolan and B. Maître (2004). Housing, poverty, and wealth in Ireland (No. 34). Combat Poverty Agency.

Fahey, É., H. Russell and R. Grotti (2019). Diverse neighbourhoods: An analysis of the residential distribution of immigrants in Ireland. Economic and Social Research Institute.

Farha, L. (2019). Guidelines for the Implementation of the Right to Adequate Housing: Report of the Special Rapporteur on adequate housing as a component of the right to an adequate standard of living, and on the right to non-discrimination in this context. United Nations.

Fisk, W.J., Q. Lei-Gomez and M.J. Mendell (2007). 'Meta-analyses of the associations of respiratory health effects with dampness and mold in homes', Indoor air, 17(4), 284-296.

Focus Ireland (2019). 'Family Homelessness in Dublin: Causes, Housing Histories, and Finding a Home', Insights into Family Homelessness. Focus Ireland.

FRA (2020). Roma And Travellers In Six Countries: Roma and Travellers Survey. Luxembourg: Publications Office of the European Union.

Friedman, S. and D. Laurison (2020). The class ceiling: Why it pays to be privileged.

Gabriel, M., K. Jacobs, K. Arthurson, T. Burke and J. Yates (2005). Conceptualising and measuring the housing affordability problem: National Research Venture 3: Housing Affordability for Lower Income Australians: research paper 1.

Gaffney, E. and D. Greaney (2020). COVID-19 payment breaks on residential mortgages. Central Bank of Ireland.

Gambi, L. and S. Sheridan (2020). 'Family Homelessness in Ireland: The Importance of Research Design in Evidence-Based Policy-Making', European Journal of Homelessness Vol. 14(1). 
Government of Ireland (2020). Report of The Advisory Group on the Provision of Support Including Accommodation to Persons in the International Protection Process 'The Day Report'. Government of Ireland.

Government of Ireland (2021). A White Paper to End Direct Provision and to Establish a New International Protection Support Service. Department of Children, Equality, Disability, Integration and Youth.

Groarke, S. and P. Brazil (2020). National statuses granted for protection reasons in Ireland, European Migration Network, ESRI Research Series No. 96, Dublin: Economic and Social Research Institute. https://doi.org/10.26504/rs96.

Grotti, R., B. Maître, D. Watson and C.T. Whelan (2017). Technical paper on poverty Transitions in Ireland. Social inclusion Technical Paper No. 8.

Grotti, R., H. Russell, E. Fahey and B. Maître (2018). Discrimination and Inequality in Housing in Ireland. Dublin: ESRI/IHREC.

Gusciute, E., P. Mühlau and R. Layte (2020). 'Discrimination in the rental housing market: a field experiment in Ireland', Journal of Ethnic and Migration Studies.

DOI: 10.1080/1369183X.2020.1813017.

HansImaier, M., A. Peter and B. Kaiser (2018). 'Vulnerability and fear of crime among elderly citizens: what roles do neighborhood and health play?', J Hous and the Built Environ 33, pp. 575-590. https://doi.org/10.1007/s10901-018-9626-1.

Hanson, A. and Z. Hawley (2011). 'Do landlords discriminate in the rental housing market? Evidence from an internet field experiment in US cities', Journal of Urban Economics, Vol. 70, pp. 99-114.

Harris, M. and K. Miller (2000). 'Gender and perceptions of danger', Sex Roles, 43, pp. 843-863.

Hearne, R. and J. Walsh (forthcoming). Scoping Study on the 'Housing Assistance Ground' under the Equal Status Acts 2000-2018. Dublin: IHREC. 
Hearne, R. and M. Murphy (2018). 'An absence of rights: Homeless families and social housing marketisation in Ireland', Administration, 66(2).

Hearne, R. and P. Kenna (2014). 'Using the human rights-based approach to tackle housing deprivation in an Irish urban housing estate', Journal of Human Rights Practice, 6(1), 1-25.

Heylen, K. (2020). 'Targeted affordable housing subsidies in Flanders: evaluating equity using equivalence scales', International Journal of Housing Policy, 20(4), pp. 513-533.

Hilber, C.A.L. (2007). 'The Determinants of Homeownership across Europe: Panel Data Evidence', paper presented to the 54th Annual North American Meeting of the Regional Science Association International. Savannah, November 9, 2007.

Hohmann, J. (2013). The right to housing: Law, concepts, possibilities. Bloomsbury Publishing.

Houses of the Oireachtas (2018). Traveller Accommodation: The challenges of implementation. Houses of the Oireachtas.

IHREC (2015). Your Equal Status Rights Explained. Dublin: IHREC.

IHREC (2017). Observations On The Equality (Miscellaneous Provisions) Bill 2017. Dublin: IHREC.

IHREC (2019). 'Ireland and the Convention on the Elimination of Racial Discrimination: Submission to the United Nations Committee on the Elimination of Racial Discrimination on Ireland's Combined 5th to 9th Report'. Dublin: IHREC.

IHREC (2020). IHREC submission to the Irish Government's Direct Provision White Paper. IHREC.

IHREC (2021a). Comments on Ireland's 18th National Report on the implementation of the European Social Charter. Dublin: IHREC. 
IHREC (2021b). Submission to the United Nations Human Rights Committee on the List of Issues for the Fifth Periodic Examination of Ireland. Dublin: IHREC.

INDECON (2011). INDECON Report on the cost of disability. NDA.

Irish Travellers Movement (2021). Statistics - Irish Travellers Movement. Available at: https://itmtrav.ie/strategic-priorities/accommodation/statistics/ [Accessed 28 June 2021].

Joseph Rowntree Foundation, T. Maclnnes, A. Tinson, C. Hughes, T. Barry-Born and H. Aldridge (2015). Monitoring poverty and social exclusion 2015.

Kenna, P. (2005). Housing rights and human rights. Feantsa.

Kenna, P. (2011). Housing law, rights, and policy. Clarus Press.

Kilkenny, P. (2019). Trends Analysis: Housing Assistance Payment (2014-2019) Dublin: Department of Public Expenditure and Reform.

Kim (2010). 'Neighborhood disadvantage and mental health: the role of neighborhood disorder and social relationships', Soc. Sci. Res., 39,pp. 260-271,

Landt, J. and R. Bray (1997). Alternative approaches to measuring rental housing affordability in Australia. Canberra: NATSEM, University of Canberra.

Maître, B. and E. Fahey (2018). 'Social Inclusion and Integration' in McGinnity, F., E. Fahey, E. Quinn, S. Arnold, B. Maître and P. O'Connell (Eds.). Monitoring Report on Integration 2018. ESRI Report, November 2018.

Maître, B. and H. Russell (2017). 'Social Inclusion and Integration' in Barrett, A., F. McGinnity and E. Quinn (Eds.). Monitoring report on integration (Vol. 132). Dublin, Ireland: ESRI.

Maître, B., I. Privalko and D. Watson (2020). Social Transfers and Deprivation in Ireland: A study of cash and non-cash payments tied to housing, childcare, and primary health care services. Dublin: ESRI/ DSP. 
Mayock, P. and S. Sheridan (2012). Women's Homeless 'Journeys': Key Findings from a Biographical Study of Homeless Women in Ireland. Dublin, School of Social Work and Social Policy and Children's Research Centre, Trinity College Dublin.

McGinnity, F., R. Grotti, S. Groarke and S. Coughlan (2018). Ethnicity and Nationality in the Irish Labour Market. Dublin: ESRI/Irish Human Rights and Equality Commission.

McGinnity, F., S. Enright, E. Quinn, B. Maître, I. Privalko, M. Darmody and M. Polakowski (2020a). Monitoring Report on Integration 2020. Dublin: The Economic and Social Research Institute and Department of Justice.

McGinnity, F., I. Privalko, E. Fahey, D. O’Brien and S. Enright (2020b). Origin and Integration: a study of migrants in the 2016 Irish Census. Dublin: ESRI/Department of Justice and Equality.

McGinnity, F., H. Russell, I. Privalko and S. Enright (2021). Monitoring Decent Work in Ireland. Dublin: ESRI.

McGlinchey, E., P. McCallion, E. Burke, R. Carroll and M. McCarron (2013). 'Exploring the Issue of Employment for Adults with an Intellectual Disability in Ireland', Journal of Applied Research in Intellectual Disabilities, 26(4), pp.335-343.

McMahon Report (2015). Final Report, Working Group to Report to Government on Improvements to the Protection Process, including Direct Provision and Supports to Asylum Seekers.

McQuinn, K. (2021). House prices and mortgage credit: Empirical evidence for Ireland - An update. Dublin: ESRI.

McQuinn, K., C. O’Toole, P. Economides and T. Monteiro (2017). Quarterly Economic Commentary, Winter 2017. ESRI Forecasting Series.

McQuinn, K., C. O'Toole, M. Allen-Coghlan and C. Coffey (2020). Quarterly Economic Commentary, Spring 2020. Macroeconomic Forecasting, Dublin: The Economic and Social Research Institute. 
McQuinn, K., C. O'Toole, I. Kostarakos, C. Coffey and W. Disch (2021). Quarterly Economic Commentary, Summer 2021. ESRI Forecasting Series.

Mohan, G., S. McCoy, S. Lyons, E. Carroll, G. Mihut and C. Mac Domhnaill (2020). Learning for all? Second-level education in Ireland during COVID-19. Dublin: ESRI.

National Oversight and Audit Commission NOAC (2016). Rented Houses Inspections: A Review of Local Authority Performance of Private Rented Houses Regulations Functions, NOAC Report No. 10.

NDA (2010). Independent and Community Living - the views of people with disabilities families and frontline staff: Focus Group Consultation Report. National Disability Authority.

Nepal, B., R. Tanton and A. Harding (2010). 'Measuring housing stress: how much do definitions matter?', Urban Policy and Research, 28(2), pp.211-224.

NESC (2020). Housing Policy: Actions to Deliver Change. Dublin: NESC.

Newbury, J.B., L. Arseneault, S. Beevers, S., et al. (2019). 'Association of Air Pollution Exposure With Psychotic Experiences During Adolescence', JAMA Psychiatry. 76(6), pp.614-623. doi:10.1001/jamapsychiatry.2019.0056.

Ní Raghallaigh, M., M. Foreman and M. Feeley (2016). Transitioning from Direct Provision to Life in the Community: The Experiences of Those Who Have Been Granted Refugee Status, Subsidiary Protection or 'Leave to Remain' in Ireland. Dublin: University College Dublin.

Nolan, B. and B. Maître (2008). A Social Portrait of Communities in Ireland. Dublin: Office for Social Inclusion/ ESRI.

Norris, M. (2016). 'Varieties of Home Ownership: Ireland's Transition from a Socialised to a Marketised Policy Regime', Housing Studies 31:1, pp. 81-101.

Norris, M. and M. Byrne (2018). 'Housing market (in)stability and social rented housing: comparing Austria and Ireland during the global financial crisis', Journal of Housing, and the Built Environment (2018) 33:227-245. 
NSB (2021). Quality Information for All - Numbers Matter. Government of Ireland.

O'Campo, P., C. Salmon and J. Burke (2009). 'Neighbourhoods and mental well-being: What are the pathways?', Health \& Place, 15(1), pp. 56-68.

OECD (2011). Measuring well-being and progress. Organisation for Economic Co-operation and Development (OECD).

OECD (2013). OECD framework for statistics on the distribution of household income, consumption, and wealth. OECD Publishing.

OECD (2015). Settling In: Indicators of Immigrant Integration. Chapter 9: Immigrants and housing.

OECD (2020). How's Life? 2020: Measuring Well-being, OECD Publishing: Paris. https://doi.org/10.1787/9870c393-en.

Ombudsman for Children's Office (2020). Direct Division: Children's Views and Experiences of Living in Direct Provision. Dublin: OCO.

Orr, J., S. Scarlett, O. Donoghue and C. McGarrigle (2016). Housing conditions of Ireland's older population. Implications for physical and mental health', TCD. TILDA working paper, https://tilda.tcd.ie/publications/reports/pdf/Report_HousingConditions.pdf.

Pavee Point (2017). Towards an Ethnic Equality Question in Census 2021, Submission to the Central Statistics Office (CSO). Dublin: Pavee Point.

Privalko, I., B. Maître, D. Watson and R. Grotti (2019). 'Access to childcare and home care services across Europe: an analysis of the Survey on Income and Living Conditions (SILC), 2016', Economic and Social Research Institute (ESRI) Research Series.

Quigley, J.M. and S. Raphael (2004). 'Is housing unaffordable? Why isn't it more affordable?', Journal of Economic Perspectives, 18(1), 191-214.

Rebuilding Ireland (2016). Action plan for housing and homelessness. 
Reichelt, M. and M. Abraham (2017). 'Occupational and regional mobility as substitutes: A new approach to understanding job changes and wage inequality', Social Forces, 95(4), $1399-1426$.

Rich, J. (2014). 'What Do Field Experiments of Discrimination in Markets Tell Us? A MetaAnalysis of Studies Conducted Since 2000', IZA Discussion Paper No. 8584.

Riggs, S. and C. Cook (2014). 'The shadow of physical harm? Examining the unique and gendered relationship between fear of murder versus fear of sexual assault on fear of violent crime', Journal of Interpersonal Violence, 30, pp.2383-2409.

Roantree, B., B. Maître, A. McTague and I. Privalko (2021). Poverty, income inequality and living standards in Ireland. Economic and Social Research Institute (ESRI) Research Series.

RTB (2020). Residential Tenancies Board Rent Index 2020 https://www.rtb.ie/images/uploads/Comms\%20and\%20Research/RTB_Rent_Index_2020_Q 3_\%28WEB\%29_Final.pdf.

Russell, H., B. Maître and N. Donnelly (2011). Financial exclusion and over-indebtedness in Irish households. Department of Community, Equality and Gaeltacht Affairs and Economic and Social Research Institute.

Saunders, P., M. Wong and B. Bradbury (2016). 'Poverty in Australia since the financial crisis: the role of housing costs, income growth and unemployment', Journal of Poverty and Social Justice, 24(2), pp.97-112.

Savage, M. (2015). Social class in the 21st century. Penguin UK.

Scott, S., S. Lyons, C. Keane, D. McCarthy and R.S. Tol (2008). Fuel poverty in Ireland: Extent, affected groups and policy issues (No. 262). ESRI Working paper.

SEAI (2021). Better Energy Home Statistics. Available at: https://www.seai.ie/data-andinsights/seai-statistics/better-energy-home-statistics/ [Accessed 29 June 2021]. 
Sen, A. (1993). 'Capability and Well-Being', in Nussbaum, M. and A. Sen, (Eds.), The Quality of Life. Oxford: Clarendon Press.

Sen, A. (2004). 'Capabilities, lists, and public reason: continuing the conversation', Feminist economics, 10(3), 77-80.

Sheridan, A. (2020). Annual Report on Migration and Asylum 2019: Ireland, European Migration Network. Dublin: ESRI.

Shortt, N. and J. Rugkåsa (2007). " The walls were so damp and cold" fuel poverty and ill health in Northern Ireland: results from a housing intervention', Health \& place, 13(1), 99-110.

Stockdale, S., K. Wells, L. Tang, T. Belin, L. Zhang and C. Sherbourne (2007). 'The importance of social context: Neighborhood stressors, stress-buffering mechanisms, and alcohol, drug, and mental health disorders', Social Science \& Medicine, 65(9), pp.1867-1881.

The Housing Agency (2021). Summary of Social Housing Assessments 2020. Dublin: The Housing Agency.

The National Traveller Data Steering Group and the Community Foundation for Ireland (2017). Traveller Community National Survey. The National Traveller Data Steering Group and the Community Foundation for Ireland.

Turner, M., C. Herbig, D. Kaye, J. Fenderson and D. Levy (2005). Discrimination against persons with disabilities: Barriers at every step. Washington DC: The Urban Institute Press.

Turner, M.A. and S.L. Ross (2003a). Discrimination in Metropolitan Housing Markets. Phase 3 - Native Americans. Urban Institute, Washington DC.

Turner, M.A. and S.L. Ross (2003b). Discrimination in Metropolitan Housing Markets. Phase 2 - Asians and Pacific Islanders. Urban Institute, Washington DC.

UN Committee on the Rights of the Child (2016). Concluding observations on the combined third and fourth periodic reports of Ireland. 
UN Habitat (2009). Fact Sheet No. 21 The Right to Adequate Housing.

UN Habitat (2017). Building Capacities to Improve Access for All to Adequate, Safe and Affordable Housing.

UN Housing Rights Programme (2003). Working Paper 1: Monitoring housing rights. Developing a set of indicators to monitor the full and progressive realisation of the human right to adequate housing.

UNCRC (2016). Concluding observations on the combined third and fourth periodic reports of Ireland.

Wang M., C.P. Aaron, J. Madrigano et al. (2019). 'Association Between Long-term Exposure to Ambient Air Pollution and Change in Quantitatively Assessed Emphysema and Lung Function', JAMA. 322(6), pp. 546-556.doi:10.1001/jama.2019.10255.

Watson, D., B. Maître and C.T. Whelan (2012). Understanding childhood deprivation in Ireland. Dublin: Department of Social Protection.

Watson, D., J. Banks and S. Lyons (2015). Educational and employment experiences of people with a disability in Ireland: An Analysis of the National Disability Survey. Economic and Social Research Institute (ESRI) Research Series.

Watson, D., B. Maître, C.T Whelan and H. Russell (2016). Social risk and social class patterns in poverty and quality of life in Ireland. Dublin: DSP/ESRI.

Watson, D., O. Kenny and F. McGinnity (2017). A social portrait of Travellers in Ireland. Research series No, 56.

Watson, D., C.T. Whelan, B. Maître and J. Williams (2017a). 'Non-Monetary Indicators and Multiple Dimensions: The ESRI Approach to Poverty Measurement', The Economic and Social Review, 48(4), pp. 369-392. 
Watson, D., B. Maître, C.T. Whelan and H. Russell (2017b). 'Poverty Economic Stress and Quality of Life - Lessons from the Irish Case', International Review of Economics, 64(2), pp. $125-143$.

Whelan, C.T., H. Russell and B. Maître (2016). 'Economic stress and the great recession in Ireland: polarization, individualization or 'Middle class squeeze'?', Social Indicators Research, 126(2), 503-526.

Whelan, C.T., D. Watson and B. Maître (2019). 'From Income Poverty to Multidimensional Quality of Life', The Economic and Social Review, 50(4), pp. 683-705

Whitehead, C. and K.J. Scanlon (2007). Social housing in Europe. London School of Economics and Political Science.

Wood, G. and R. Ong (2011). 'Factors shaping the dynamics of housing affordability in Australia 2001-06', Housing Studies, 26(7-8), pp. 1105-1127.

Wood, L., P. Hooper, S. Foster and F. Bull (2017). 'Public green spaces and positive mental health - investigating the relationship between access, quantity and types of parks and mental well-being', Health \& Place, 48, pp.63-71.

World Health Organization (2018). WHO Housing and Health Guidelines. Geneva: WHO. 


\section{APPENDIX 1}

\section{Adequate housing international instruments}

\section{TABLE A1.1 DIMENSIONS OF ADEQUATE HOUSING INTERNATIONAL REPORTING TABLE}

\begin{tabular}{|c|c|c|c|}
\hline $\begin{array}{l}\text { Dimensions } \\
\text { of Adequate } \\
\text { Housing }\end{array}$ & $\begin{array}{l}\text { European Social Charter/Collective } \\
\text { Complaints }\end{array}$ & ICESCR & $\begin{array}{l}\text { Intersectional UN } \\
\text { treaties (CEDAW, } \\
\text { CERD, CRC, CRPD, } \\
\text { and ICCPR) }\end{array}$ \\
\hline $\begin{array}{l}\text { Access to } \\
\text { Housing }\end{array}$ & $\begin{array}{l}\text { Article } 15 \text { (3) - The right of persons with } \\
\text { disabilities to independence, social } \\
\text { integration, and participation in the life of } \\
\text { the community } \\
\text { Article } 16 \text { - The right of the family to social, } \\
\text { legal, and economic protection } \\
\text { Article } 19 \text { (4) - The right of migrant workers } \\
\text { and their families to protection and } \\
\text { assistance } \\
\text { Article } 23 \text { (a) - The right of elderly persons } \\
\text { to social protection } \\
\text { Article } 30 \text { - The right to protection against } \\
\text { poverty and social exclusion } \\
\text { Article } 31 \text { (1) - The right to housing. } \\
\text { No. 100/2013 European Roma Rights Centre } \\
\text { (ERRC) v. Ireland (Violation of Article 16) } \\
\text { No. 110/2014 International Federation for } \\
\text { Human Rights (FIDH) v. Ireland (Violation of } \\
\text { Article 16) }\end{array}$ & $\begin{array}{l}\text { Article } 11 \text { (1) } \\
\text { General Comment } \\
\text { No. } 4 \text { - The right to } \\
\text { adequate housing, } \\
\text { para.8(e) - } \\
\text { Accessibility }\end{array}$ & $\begin{array}{l}\text { CERD Article } 5(\mathrm{~d})(\mathrm{v}) \\
\text { and (e)(iii) } \\
\text { CRC Article } 27 \text { (3) } \\
\text { CRPD Article } 19- \\
\text { Living independently } \\
\text { and being included } \\
\text { in the community. } \\
\text { CRPD Article } 28 \\
\text { (2)(d) - Adequate } \\
\text { standard of living } \\
\text { and social protection }\end{array}$ \\
\hline $\begin{array}{l}\text { Affordability } \\
\text { of housing }\end{array}$ & $\begin{array}{l}\text { Article } 16 \text { - The right of the family to social, } \\
\text { legal, and economic protection } \\
\text { Article } 19(4) \text { - The right of migrant workers } \\
\text { and their families to protection and } \\
\text { assistance } \\
\text { Article } 30 \text { - The right to protection against } \\
\text { poverty and social exclusion } \\
\text { Article } 31(3) \text { - The right to housing }\end{array}$ & $\begin{array}{l}\text { Article } 11 \text { (1) } \\
\text { General Comment } \\
\text { No. } 4 \text { - The right to } \\
\text { adequate housing, } \\
\text { para. } 8 \text { (c) - } \\
\text { Affordability }\end{array}$ & $\begin{array}{l}\text { CEDAW Article } 13 \\
\text { (b) } \\
\text { CERD Article } 5 \text { (d)(v) } \\
\text { and (e)(iii) } \\
\text { CRC Article } 27 \text { (3) } \\
\text { CRPD Article } 19- \\
\text { Living independently } \\
\text { and being included } \\
\text { in the community. } \\
\text { CRPD Article } 28 \text { (1) - } \\
\text { Adequate standard } \\
\text { of living and social } \\
\text { protection }\end{array}$ \\
\hline
\end{tabular}


TABLE A1.1 CONTD

\begin{tabular}{|c|c|c|c|}
\hline $\begin{array}{l}\text { Dimensions } \\
\text { of Adequate } \\
\text { Housing }\end{array}$ & $\begin{array}{l}\text { European Social Charter/Collective } \\
\text { Complaints }\end{array}$ & ICESCR & $\begin{array}{l}\text { Intersectional UN } \\
\text { treaties (CEDAW, } \\
\text { CERD, CRC, CRPD, } \\
\text { and ICCPR) }\end{array}$ \\
\hline Security & $\begin{array}{l}\text { Article } 16 \text { - The right of the family to social, } \\
\text { legal, and economic protection } \\
\text { Article } 19 \text { (4) - The right of migrant workers } \\
\text { and their families to protection and } \\
\text { assistance } \\
\text { Article } 30 \text { - The right to protection against } \\
\text { poverty and social exclusion } \\
\text { Article } 31 \text { - The right to housing. } \\
\text { No. 100/2013 European Roma Rights Centre } \\
\text { (ERRC) v. Ireland (Violation of Article 16) } \\
\text { No. 110/2014 International Federation for } \\
\text { Human Rights (FIDH) v. Ireland (Violation of } \\
\text { Article 16) }\end{array}$ & $\begin{array}{l}\text { Article } 11 \text { (1) } \\
\text { General Comment } \\
\text { No. } 4 \text { - The right to } \\
\text { adequate housing, } \\
\text { para.8(a) - Legal } \\
\text { security of tenure } \\
\text { General Comment } \\
\text { No. } 7 \text { - Forced } \\
\text { evictions }\end{array}$ & $\begin{array}{l}\text { CERD Article } 5 \text { (e)(iii) } \\
\text { CRC Article } 16 \\
\text { CRC Article } 27 \text { (1) } \\
\text { ICCPR Article } 17 \\
\text { CRPD Article } 28 \text { (1) - } \\
\text { Adequate standard } \\
\text { of living and social } \\
\text { protection }\end{array}$ \\
\hline $\begin{array}{l}\text { Cultural } \\
\text { Adequacy }\end{array}$ & $\begin{array}{l}\text { Article } 16 \text { - The right of the family to social, } \\
\text { legal, and economic protection } \\
\text { Article } 31 \text { - The right to housing. } \\
\text { No. } 100 / 2013 \text { European Roma Rights Centre } \\
\text { (ERRC) v. Ireland (Violation of Article 16) }\end{array}$ & $\begin{array}{l}\text { Article } 11 \text { (1) } \\
\text { General Comment } \\
\text { No. } 4 \text { - The right to } \\
\text { adequate housing, } \\
\text { para. } 8(\mathrm{~g}) \text { - Cultural } \\
\text { adequacy }\end{array}$ & $\begin{array}{l}\text { CERD Article } 5 \text { (e)(iii) } \\
\text { CRC Article } 27 \text { (1) } \\
\text { CRPD Article } 28 \text { (1)- } \\
\text { Adequate standard } \\
\text { of living and social } \\
\text { protection }\end{array}$ \\
\hline $\begin{array}{l}\text { Housing } \\
\text { Quality }\end{array}$ & $\begin{array}{l}\text { Article } 16 \text { - The right of the family to social, } \\
\text { legal, and economic protection } \\
\text { Article } 19 \text { (4) - The right of migrant workers } \\
\text { and their families to protection and } \\
\text { assistance } \\
\text { Article } 23 \text { (a) - The right of elderly persons } \\
\text { to social protection } \\
\text { Article } 30 \text { - The right to protection against } \\
\text { poverty and social exclusion } \\
\text { Article } 31 \text { - The right to housing. } \\
\text { No. 100/2013 European Roma Rights Centre } \\
\text { (ERRC) v. Ireland (Violation of Article 16) } \\
\text { No. 110/2014 International Federation for } \\
\text { Human Rights (FIDH) v. Ireland (Violation of } \\
\text { Article 16) }\end{array}$ & $\begin{array}{l}\text { Article } 11 \text { (1) } \\
\text { General Comment } \\
\text { No. } 4 \text { - The right to } \\
\text { adequate housing, } \\
\text { para.8(b) - } \\
\text { Availability of } \\
\text { services, materials, } \\
\text { facilities and } \\
\text { infrastructure and } \\
\text { para.8(d) - } \\
\text { Habitability }\end{array}$ & $\begin{array}{l}\text { CEDAW Article } 14 \\
\text { (2)(h) } \\
\text { CERD Article } 5 \text { (e)(iii) } \\
\text { CRC Article } 27 \text { (1) } \\
\text { CRPD Article } 9 \text { (1)(a) } \\
\text { - Accessibility } \\
\text { CRPD Article } 19 \text { - } \\
\text { Living independently } \\
\text { and being included } \\
\text { in the community. } \\
\text { CRPD Article } 28 \text { (1) - } \\
\text { Adequate standard } \\
\text { of living and social } \\
\text { protection }\end{array}$ \\
\hline
\end{tabular}


TABLE A1.1 CONTD

\begin{tabular}{|c|c|c|c|}
\hline $\begin{array}{l}\text { Dimensions } \\
\text { of Adequate } \\
\text { Housing }\end{array}$ & $\begin{array}{l}\text { European Social Charter/Collective } \\
\text { Complaints }\end{array}$ & ICESCR & $\begin{array}{l}\text { Intersectional UN } \\
\text { treaties (CEDAW, } \\
\text { CERD, CRC, CRPD, } \\
\text { and ICCPR) }\end{array}$ \\
\hline $\begin{array}{l}\text { Location, } \\
\text { access to } \\
\text { services and } \\
\text { local } \\
\text { environment }\end{array}$ & $\begin{array}{l}\text { Article } 16 \text { - The right of the family to social, } \\
\text { legal, and economic protection } \\
\text { Article } 19 \text { (4) - The right of migrant workers } \\
\text { and their families to protection and } \\
\text { assistance } \\
\text { Article } 23(\mathrm{a}) \text { - The right of elderly persons } \\
\text { to social protection } \\
\text { Article } 30 \text { - The right to protection against } \\
\text { poverty and social exclusion } \\
\text { Article } 31 \text { - The right to housing }\end{array}$ & $\begin{array}{l}\text { Article } 11 \text { (1) } \\
\text { General Comment } \\
\text { No. } 4 \text { - The right to } \\
\text { adequate housing, } \\
\text { para. } 8(\mathrm{~b}) \text { - } \\
\text { Availability of } \\
\text { services, materials, } \\
\text { facilities and } \\
\text { infrastructure and } \\
\text { para.8(f) - Location }\end{array}$ & $\begin{array}{l}\text { CEDAW Article } 14 \\
\text { (2)(h) } \\
\text { CERD Article } 5 \text { (e)(iii) } \\
\text { CRC Article } 27 \text { (1) } \\
\text { CRPD Article } 9 \text { (1)(a) } \\
\text { - Accessibility } \\
\text { CRPD Article } 19- \\
\text { Living independently } \\
\text { and being included } \\
\text { in the community. } \\
\text { CRPD Article } 28 \text { (1)- } \\
\text { Adequate standard } \\
\text { of living and social } \\
\text { protection }\end{array}$ \\
\hline
\end{tabular}





\section{APPENDIX 2}

\section{Consultation event}

The consultation on the right to adequate housing was held at the ESRI on 3 March 2020. A total of 37 individuals/organisations were invited to attend. Participants were selected to cover a range of key informants including NGOs, academics/researchers, legal experts and policymakers. The invitees were selected to cover the following at-risk groups; the homeless, people with a disability, Travellers and Roma, migrants, refugees, young people/students, Local Authority/social housing tenants, private rental tenants, women/lone parents, those in care, older people, rural dwellers, and those living in poverty.

Thirty individual participants attended on the day. During the consultation, the participants were split into six groups and given three tasks to complete within their groups. A notetaker was assigned to each table and each group selected one of the participants as their facilitator.

\section{ENGAGEMENT EVENT TASK ONE}

For Task One of the consultation, participants were provided with a brief overview of the seven domains included under the right to adequate housing in the International Covenant on Economic, Social and Cultural Rights (ICESCR) framework (namely security of tenure, affordability, habitability, availability of services and facilities, accessibility, location and cultural adequacy; see Chapter 1). The first task asked respondents to discuss what the right to adequate housing meant to them or to the groups that they represent, and whether the ICESCR domains cover the relevant dimensions of adequate housing. A hard copy of the seven ICESCR principles on decent housing was provided on each table as well as a list of the protected groups in Irish equality legislation. 


\section{ENGAGEMENT EVENT TASK TWO}

The second task required respondents in their groups to choose their top ten outcome indicators of decent housing from a list of 27 potential indicators across six domains. ${ }^{126}$ The final column in Table A2.1 indicates how frequently different indicators appeared in each group's 'top 10', to give a sense of their popularity.

\section{TABLE A2.1 TASK TWO WITH RESULTS FROM CONSULTATION}

\begin{tabular}{|c|c|c|c|c|c|}
\hline Theme & Indicator & $\begin{array}{l}\mathbf{N} \\
\text { groups } \\
\text { covered }\end{array}$ & $\begin{array}{c}\text { Data } \\
\text { (Latest) }\end{array}$ & Frequency & $\begin{array}{l}\text { Ranking? } \\
\mathrm{N} \text { times } \\
\text { in top } 10\end{array}$ \\
\hline \multirow{4}{*}{$\begin{array}{l}\text { Access to } \\
\text { housing }\end{array}$} & $\begin{array}{l}\text { Homelessness rate (per } 1,000 \text { or } \\
\text { per } 100,000 \text { ) }\end{array}$ & 13 & $\begin{array}{l}\text { Census } \\
(2016)\end{array}$ & 5 years, & 5 \\
\hline & $\begin{array}{l}\text { Tenure types (\% Public rental, } \\
\text { private rental, homeownership) }\end{array}$ & 9 & $\begin{array}{l}\text { Census } \\
(2016) / \\
\text { SILC (2018) }\end{array}$ & $\begin{array}{l}5 \text { years/ } \\
\text { annual }\end{array}$ & 4 \\
\hline & $\begin{array}{l}\text { Subjective experience of } \\
\text { discrimination in accessing } \\
\text { housing }\end{array}$ & 13 & $\begin{array}{l}\text { QNHS } \\
\text { Equality } \\
\text { (2019) }\end{array}$ & 4-6 years & 3 \\
\hline & $\begin{array}{l}\text { Number on social housing } \\
\text { waiting list/Length of time on } \\
\text { social housing waiting list }\end{array}$ & 5 & $\begin{array}{l}\text { Housing } \\
\text { Agency }\end{array}$ & Annual & 3 \\
\hline \multirow{5}{*}{ Affordability } & $\begin{array}{l}\text { Households who spend more } \\
\text { than } 30 \text { or } 40 \text { per cent of } \\
\text { disposable income on housing } \\
\text { costs (\%) [and in the bottom } 40 \% \\
\text { of income distribution] }\end{array}$ & 9 & SILC (2018) & Annual & 3 \\
\hline & $\begin{array}{l}\text { Households who are below the } \\
\text { poverty line ( } 60 \% \text { of median } \\
\text { income) when housing costs are } \\
\text { deducted from income (\%). }\end{array}$ & 9 & SILC (2018) & Annual & 4 \\
\hline & $\begin{array}{l}\text { Households who say housing } \\
\text { costs are a 'heavy burden' (\%) }\end{array}$ & 9 & SILC (2018) & Annual & 0 \\
\hline & $\begin{array}{l}\text { Households who had arrears over } \\
\text { the last } 12 \text { months for rent or } \\
\text { mortgage payments (\%) }\end{array}$ & 9 & $\begin{array}{l}\text { SILC (2018)/ } \\
\text { EQLS (2016) }\end{array}$ & $\begin{array}{l}\text { Annual/ } \\
4 / 5 \text { years }\end{array}$ & 2 \\
\hline & $\begin{array}{l}\text { Households who had arrears over } \\
\text { the last } 12 \text { months for utilities } \\
\text { such as electricity or heating (\%) }\end{array}$ & 9 & $\begin{array}{l}\text { SILC (2018)/ } \\
\text { EQLS (2016) }\end{array}$ & $\begin{array}{l}\text { Annual/ } \\
4 / 5 \text { years }\end{array}$ & 0 \\
\hline
\end{tabular}

Contd. 
TABLE A2.1 CONTD.

\begin{tabular}{|c|c|c|c|c|c|}
\hline Theme & Indicator & $\begin{array}{l}\text { N } \\
\text { groups } \\
\text { covered }\end{array}$ & $\begin{array}{c}\text { Data } \\
\text { (Latest) }\end{array}$ & Frequency & $\begin{array}{l}\text { Ranking? } \\
\mathbf{N} \text { times } \\
\text { in top } 10\end{array}$ \\
\hline \multirow{2}{*}{$\begin{array}{l}\text { Sufficiency } \\
\text { and cultural } \\
\text { adequacy }\end{array}$} & $\begin{array}{l}\text { Over-crowding (multiple } \\
\text { definitions) }\end{array}$ & 9 & $\begin{array}{l}\text { SILC (2018)/ } \\
\text { EQLS (2016) }\end{array}$ & $\begin{array}{l}\text { Annual/ } \\
4 / 5 \text { years }\end{array}$ & 5 \\
\hline & $\begin{array}{l}\text { Subjective satisfaction with } \\
\text { 'your accommodation'. }\end{array}$ & 8 & EQLS (2016) & $4 / 5$ years & 0 \\
\hline \multirow{3}{*}{$\begin{array}{l}\text { Security of } \\
\text { tenure }\end{array}$} & $\begin{array}{l}\text { Length of time (in years) in } \\
\text { current dwelling }\end{array}$ & 9 & SILC (2018) & Annual & 3 \\
\hline & $\begin{array}{l}\text { 'Over the last } 12 \text { months have } \\
\text { you moved to a cheaper home, } \\
\text { taken other people into your } \\
\text { home or moved into someone } \\
\text { else's home to save on housing } \\
\text { costs?' }\end{array}$ & 8 & EQLS (2016) & $4 / 5$ years & 1 \\
\hline & $\begin{array}{l}\text { Subjective sense of security; } \\
\text { 'How likely or unlikely do you } \\
\text { think it is that you will need to } \\
\text { leave your accommodation } \\
\text { within the next } 6 \text { months } \\
\text { because you can no longer } \\
\text { afford it?' }\end{array}$ & 8 & EQLS (2016) & $4 / 5$ years & 1 \\
\hline \multirow{7}{*}{$\begin{array}{l}\text { Quality, } \\
\text { habitability, } \\
\text { and } \\
\text { facilities* }\end{array}$} & $\begin{array}{l}\text { Households with leaking roofs, } \\
\text { damp walls, floors, or } \\
\text { foundations. Rot in window- } \\
\text { frames or floors }(\%)\end{array}$ & 9 & SILC (2018) & Annual & 1 \\
\hline & $\begin{array}{l}\text { Households dwelling: too dark, } \\
\text { not enough light (\%) }\end{array}$ & 9 & SILC (2018) & Annual & 0 \\
\hline & $\begin{array}{l}\text { Households without flushing } \\
\text { indoor toilets and personal } \\
\text { baths or showers (\%) }\end{array}$ & 9 & SILC (2018) & Annual & 0 \\
\hline & $\begin{array}{l}\text { Households lacking central } \\
\text { heating, double glazing (\%) }\end{array}$ & 9 & SILC (2018) & Annual & 0 \\
\hline & $\begin{array}{l}\text { Households who cannot keep } \\
\text { home adequately warm (\%) }\end{array}$ & 9 & SILC (2018) & Annual & 2 \\
\hline & $\begin{array}{l}\text { Households who cannot } \\
\text { replace worn-out furniture (\%) }\end{array}$ & 9 & SILC (2018) & Annual & 0 \\
\hline & $\begin{array}{l}\text { Households who had to go } \\
\text { without heating during last } 12 \\
\text { months due to lack of money } \\
\text { (\%) }\end{array}$ & 9 & SILC (2018) & Annual & 1 \\
\hline
\end{tabular}

Contd. 
TABLE A2.1 CONTD.

\begin{tabular}{|c|c|c|c|c|c|}
\hline Theme & Indicator & $\begin{array}{c}\text { N } \\
\text { groups } \\
\text { covered }\end{array}$ & $\begin{array}{c}\text { Data } \\
\text { (Latest) }\end{array}$ & Frequency & $\begin{array}{l}\text { Ranking? } \\
\mathbf{N} \text { times } \\
\text { in top } 10\end{array}$ \\
\hline \multirow{3}{*}{$\begin{array}{l}\text { Accessibility to } \\
\text { services/ } \\
\text { Location/ } \\
\text { Neighbourhood } \\
\text { environment* }\end{array}$} & $\begin{array}{l}\text { Self-reported issues with noise } \\
\text { from neighbours or from the } \\
\text { street (traffic, business, and } \\
\text { factories) }\end{array}$ & 9 & $\begin{array}{l}\text { SILC } \\
(2018) / \\
\text { EQLS } \\
(2016)\end{array}$ & $\begin{array}{l}\text { Annual/ } \\
4 / 5 \text { years }\end{array}$ & 0 \\
\hline & $\begin{array}{l}\text { Self-reported issues with air } \\
\text { quality, litter on the street, and } \\
\text { heavy traffic in immediate } \\
\text { neighbourhood }\end{array}$ & 8 & $\begin{array}{l}\text { EQLS } \\
(2016)\end{array}$ & $4 / 5$ years & 0 \\
\hline & Self-reported issues with crime & 9 & $\begin{array}{l}\text { SILC } \\
(2018)\end{array}$ & Annual & 0 \\
\hline \multirow{3}{*}{$\begin{array}{l}\text { *These may be } \\
\text { included } \\
\text { together as an } \\
\text { index, or } \\
\text { separately as } \\
\text { discrete } \\
\text { measures. }\end{array}$} & $\begin{array}{l}\text { Access to basic services (banking; } \\
\text { transport; cinema and culture, } \\
\text { theatre; recreational areas; } \\
\text { groceries; recycling services) }\end{array}$ & 8 & $\begin{array}{l}\text { EQLS } \\
(2016)\end{array}$ & $4 / 5$ years & 5 \\
\hline & $\begin{array}{l}\text { How safe do you - or would you - } \\
\text { feel walking alone in this area } \\
\text { (respondent's local area or } \\
\text { neighbourhood) after dark? }\end{array}$ & 9 & $\begin{array}{l}\text { ESS } \\
(2018)\end{array}$ & 2 years & 4 \\
\hline & $\begin{array}{l}\text { Have you or a member of your } \\
\text { household been the victim of a } \\
\text { burglary or assault (respondent's } \\
\text { local area or neighbourhood) in } \\
\text { the last } 5 \text { years? }\end{array}$ & 9 & $\begin{array}{l}\text { ESS } \\
(2018)\end{array}$ & 2 years & 2 \\
\hline
\end{tabular}

Source: Authors' analysis.

Group measures across datasets (Subject to adequate sample size for the group):

- EU-SILC: Gender, age, disability, type of disability, nationality, country of birth, family status, marital status, education, and housing tenure;

- Equality Modules 2004, 2010, 2014: Gender, age, disability, type of disability, nationality, country of birth, ethnicity, family status, marital status, religion, Traveller community (not available 2004, 2010), education and housing tenure;

- Equality Module 2019: Gender, minority gender, age, disability, type of disability, nationality, country of birth, ethnicity, family status, marital status, religion, sexual orientation, Traveller community, education, and housing tenure;

- Census of the Population: Gender, age, disability, type of disability, nationality, country of birth, ethnicity, family status, marital status, religion, Traveller community, education, and housing tenure. 
- European Quality of Life Survey: Gender, age, disability, country of birth, marital status, family status, education, and housing tenure

- European Social Survey: Gender, age, disability, religion, marital status, household composition, education, country of birth, and education

- Housing Agency Statistics: Age, family status, nationality, Traveller community, disability.

\section{ENGAGEMENT EVENT TASK THREE}

For the final task, groups were asked to choose their top five context indicators (national indicators) for decent housing. Groups were also given the option to add indicators they believed were important and missing from the existing lists. Members of the research team were on hand to answer any questions of clarification. 
TABLE A2.2 TASK THREE RESULTS

\begin{tabular}{|c|c|c|}
\hline Indicator & Data Source & $\begin{array}{l}\text { Ranking? } \\
\text { Top } 5\end{array}$ \\
\hline Average cost of house & $\begin{array}{l}\text { Property price register, Daft House price } \\
\text { report }\end{array}$ & 2 \\
\hline Average rental costs & Residential Tenancies Board/ESRI & 4 \\
\hline Cases against tenants or landlords & Residential Tenancies Board & 1 \\
\hline New dwelling completions & CSO, Ireland & 2 \\
\hline $\begin{array}{l}\text { Number of households in mortgage } \\
\text { arrears }\end{array}$ & Central Bank of Ireland & 0 \\
\hline $\begin{array}{l}\text { Total spending on rent allowance and } \\
\text { Rent Supplement }\end{array}$ & $\begin{array}{l}\text { Statistical Information on Social Welfare } \\
\text { Services Annual Reports }\end{array}$ & 1 \\
\hline $\begin{array}{l}\text { Number of HAP tenancies set up or } \\
\text { agreed }\end{array}$ & $\begin{array}{l}\text { Trend Analysis: Housing Assistance } \\
\text { Payment (2014-2019) }\end{array}$ & 1 \\
\hline Number of exits from HAP & $\begin{array}{l}\text { Trend Analysis: Housing Assistance } \\
\text { Payment (2014-2019) }\end{array}$ & 0 \\
\hline HAP tenancies by family type & $\begin{array}{l}\text { Trend Analysis: Housing Assistance } \\
\text { Payment (2014-2019) }\end{array}$ & 0 \\
\hline Sale of Local Authority houses & $\begin{array}{l}\text { Sale of Local Authority Dwellings Annual } \\
\text { Report }\end{array}$ & 0 \\
\hline Social housing units delivered/provided & Social Housing Delivery Output reports & 4 \\
\hline Social housing construction projects & $\begin{array}{l}\text { Social Housing Construction Projects, } \\
\text { Status Reports }\end{array}$ & 1 \\
\hline $\begin{array}{l}\text { Total number of households qualified } \\
\text { for social housing support }\end{array}$ & $\begin{array}{l}\text { Summary of Social Housing Assessment } \\
2019\end{array}$ & 0 \\
\hline Length of time on housing waiting list & $\begin{array}{l}\text { Summary of Social Housing Assessment } \\
2019\end{array}$ & 1 \\
\hline $\begin{array}{l}\text { Traveller families in all categories of } \\
\text { accommodation }\end{array}$ & $\begin{array}{l}\text { Department of Housing, Local } \\
\text { Government and Heritage Official } \\
\text { Statistics }\end{array}$ & 3 \\
\hline $\begin{array}{l}\text { Drawdown on funds for Traveller } \\
\text { accommodation by Local Authority }\end{array}$ & $\begin{array}{l}\text { IHREC special reports and Parliamentary } \\
\text { Questions }\end{array}$ & 2 \\
\hline $\begin{array}{l}\text { Length of stay in emergency } \\
\text { accommodation }\end{array}$ & $\begin{array}{l}\text { Homelessness Quarterly Performance } \\
\text { Reports }\end{array}$ & 3 \\
\hline Numbers in emergency accommodation & $\begin{array}{l}\text { Homelessness Quarterly Performance } \\
\text { Reports }\end{array}$ & 5 \\
\hline $\begin{array}{l}\text { Housing adaptation grants (older } \\
\text { people, people with a disability, mobility } \\
\text { aid) }\end{array}$ & $\begin{array}{l}\text { Department of Housing, Local } \\
\text { Government and Heritage }\end{array}$ & 0 \\
\hline Better Energy Home Scheme & $\begin{array}{l}\text { Department of Housing, Local } \\
\text { Government and Heritage }\end{array}$ & 0 \\
\hline Urban regeneration funding allocations & $\begin{array}{l}\text { Department of Housing, Local } \\
\text { Government and Heritage }\end{array}$ & 0 \\
\hline Rural regeneration funding allocations & $\begin{array}{l}\text { Department of Housing, Local } \\
\text { Government and Heritage }\end{array}$ & 0 \\
\hline Numbers in Direct Provision & Department of Justice & 1 \\
\hline Mortgage drawdowns & $\begin{array}{l}\text { Banking and Payments Federation of } \\
\text { Ireland }\end{array}$ & 1 \\
\hline
\end{tabular}


TABLE A2.3 LIST OF CONSULTATION ORGANISATIONS

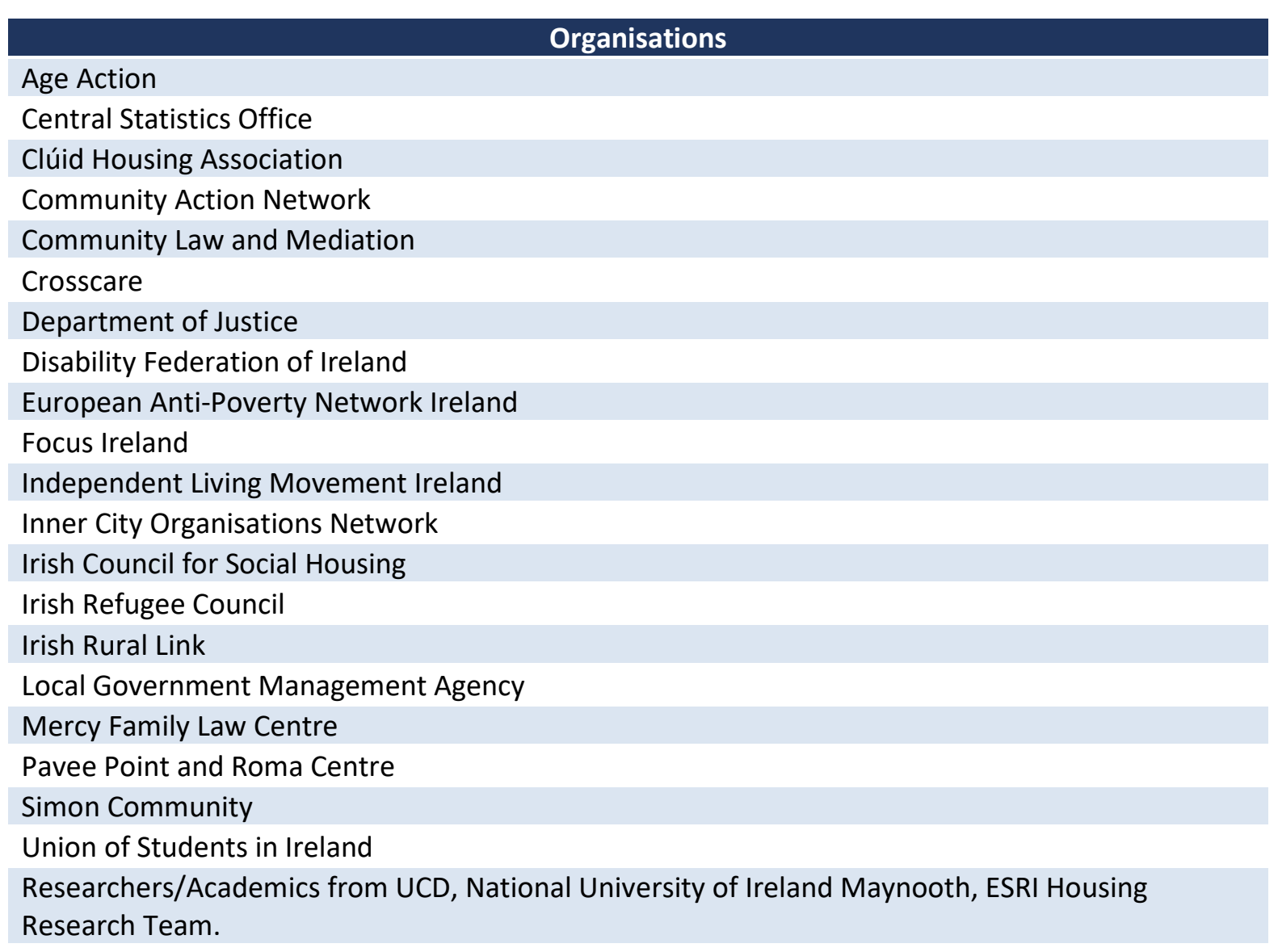





\section{APPENDIX 3}

\section{UN housing rights indicators}

\section{TABLE A3.1 HOUSING RIGHTS INDICATORS DEVELOPED BY UN HOUSING RIGHTS PROGRAMME}

\begin{tabular}{|c|c|}
\hline Element & Proposed Indicators \\
\hline $\begin{array}{l}\text { Housing Adequacy* } \\
\text { Availability of services, } \\
\text { facilities etc. } \\
\text { Affordability } \\
\text { Habitability } \\
\text { Accessibility }\end{array}$ & $\begin{array}{l}\text { 1. } \mathrm{N}: 1,000 \mathrm{HH} \text { with potable water } \\
\text { 2. } \mathrm{N}: 1,000 \mathrm{HH} \text { with sanitation facilities } \\
\text { 3. Median } \mathrm{HH} \text { Cost/Median } \mathrm{HH} \text { Income } \\
\text { 4. } \mathrm{N}: 1,000 \mathrm{HH} \text { with }>2 \text { persons per room } \\
\text { 5. } \mathrm{N}: 1,000 \mathrm{HH} \text { living in temp/dilapidated structures } \\
\text { 6. Legislation ensuring handicap (sic) accessibility to multi-unit } \\
\text { residential buildings }\end{array}$ \\
\hline $\begin{array}{l}\text { Security of tenure/scale and } \\
\text { scope of forced eviction }\end{array}$ & $\begin{array}{l}\text { 7. } \mathrm{N}: 1,000 \text { displaced persons } \\
\text { 8. } \mathrm{N}: 1,000 \mathrm{HH} \text { forcibly evicted over the past } 12 \text { months } \\
\text { 9. } \mathrm{N}: 1,000 \mathrm{HH} \text { with legally enforceable contractual protections } \\
\text { 10. } \mathrm{N}: 1,000 \mathrm{HH} \text { in informal settlements }\end{array}$ \\
\hline $\begin{array}{l}\text { Scale and scope of } \\
\text { homelessness }\end{array}$ & $\begin{array}{l}\text { 11. } \mathrm{N}: 1,000 \text { homeless persons ( } \mathrm{N} \text { of homeless over the last } 12 \\
\text { months) }\end{array}$ \\
\hline $\begin{array}{l}\text { Rights to non-discrimination } \\
\text { and equality }\end{array}$ & $\begin{array}{l}\text { 12. Presence of national legislation forbidding discrimination in } \\
\text { housing } \\
\text { 13. Presence of legislation ensuring the equal right to housing of } \\
\text { men and women }\end{array}$ \\
\hline National legal protection & $\begin{array}{l}\text { 14. Presence of national legislation recognising the right to } \\
\text { housing } \\
\text { 15. Presence of governmental offices/institutions responsible for } \\
\text { housing rights }\end{array}$ \\
\hline $\begin{array}{l}\text { Acceptance of international } \\
\text { standards }\end{array}$ & $\begin{array}{l}\text { 16. Ratification of international convention on economic social } \\
\text { and cultural rights } \\
\text { 17. Regular report to the Committee on Economic, Social and } \\
\text { Cultural rights }\end{array}$ \\
\hline
\end{tabular}




Coimisiún na hÉireann um Chearta

an Duine agus Comhionannas

Irish Human Rights and Equality Commission

The Irish Human Rights and Equality Commission

16 - 22 Sráid na Faiche, Baile Átha Cliath, D07 CR20 16-22 Green Street,

Dublin, D07 CR20
Íosghlao/Lo-Call 1890245245 Guthán/Phone + 353 (0) 18583000 Ríomhphost/Email info@ihrec.ie Idirlion/Web www.ihrec.ie a_ihrec 